\title{
Avian Use of Norris Hill Wind Resource Area, Montana
}

A. Harmata, K. Podruzny, J. Zelenak

Fish and Wildlife Program

Biology Department

Montana State University

Bozeman, Montana

NREL Technical Monitor: Karin Sinclair

DISTRIBUTION OF THS DCCUMENT IS UNLAMTES

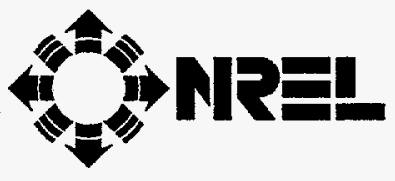

National Renewable Energy Laboratory 1617 Cole Boulevard Golden, Colorado 80401-3393

A national laboratory of the U.S. Department of Energy Managed by Midwest Research Institute for the U.S. Department of Energy under contract No. DE-AC36-83CH10093

Work performed under Subcontract No. XAN-5-15126-01 July 1998 


\section{NOTICE}

This report was prepared as an account of work sponsored by an agency of the United States government. Neither the United States govemment nor any agency thereof, nor any of their employees, makes any warranty, express or implied, or assumes any legal liability or responsibility for the accuracy, completeness, or usefulness of any information, apparatus, product, or process disclosed, or represents that its use would not infringe privately owned rights. Reference herein to any specific commercial product, process, or service by trade name, trademark, manufacturer, or otherwise does not necessarily constitute or imply its endorsement, recommendation, or favoring by the United States govemment or any agency thereof. The views and opinions of authors expressed herein do not necessarily state or reflect those of the United States government or any agency thereof.

Available to DOE and DOE contractors from:

Office of Scientitic and Technical Information (OSTI)

P.O. Box 62

Oak Ridge, TN 37831

Prices available by calling (423) $576-8401$

Available to the public from:

National Technical Information Service (NTIS)

U.S. Department of Commerce

5285 Port Royal Road

Springfield, VA 22161

(703) $487-4650$ 


\section{DISCLAIMER}

Portions of this document may be illegible electronic image products. Images are produced from the best available original document. 


\section{Foreword}

In the United States, as proposed wind power development sites are evaluated for their viability, one issue that is often considered is the potential impact on resident, migratory, and breeding birds. In order to assess whether birds might be impacted at the proposed Norris Hill Wind Resource Area (NHWRA) of southwestern Montana, preconstruction avian surveys were conducted between August 1995 and August 1996. The researchers learned early on that much of the avian activity was occurring during the night. Marine surveillance radars were therefore used to enhance the collection of data.

This report describes the Before-After Control-Impact (BACI) study design used, with the data presented herein documenting the Before-Impact and Before-Control component for avian use and mortality in and near the proposed wind resource area. Results of the BACI analysis are provided, as well as comparisons of visual and radar detectability. Development has not yet occurred at the site. Should it occur, comparable post-impact data could be collected to complete the study.

The use of marine surveillance radars resulted in the improved detectability of avian movements in and near the NHWRA. The report includes data on use of the NHWRA and vicinity by migratory birds, breeding and local raptors, and breeding and local nonraptorial birds. An assessment of avian mortality is also included. The use of radar lead to the detection of 12 times as many birds as had been detected during previous diurnal visual observations. In addition, radar permitted sampling at night, which was a time of more intense migration.

The research reported in this document was conducted by the authors under a subcontract with the National Wind Technology Center of the National Renewable Energy Laboratory, with funding from the Wind Energy Program at the U. S. Department of Energy.

\footnotetext{
$\frac{\text { Kari C. Puclaie }}{\text { Karin C. Sinclair }}$

Avian Projects Manager

National Wind Technology Center

National Renewable Energy Laboratory

1617 Cole Boulevard

Golden, Colorado 80401

E-Mail Address: karin_sinclair@nrel.gov

Phone: $303-384-69 \overline{46}$

Fax: $303-384-6901$
} 


\section{Preface}

This document presents results of a study of avian use and mortality in and near a proposed wind resource area in southwestern Montana. Data collected in autumn 1995 through summer 1996 represented preconstruction condition; it was compiled, analyzed, and presented in a format such that comparison with postconstruction data would be possible. The primary emphasis of the study was recording avian migration in and near the wind resource area using state-of-the-art marine surveillance radar. Avian use and mortality were investigated during the breeding season by employing traditional avian sampling methods, radiotelemetry, radar, and direct visual observation.

Implementation of this study involved the active participation and cooperation of many people and agencies. Titles and responsibilities of personnel involved in the study are listed below. Personnel involved in radar monitoring and mortality surveys during autumn/winter 1995 were:

Shelley Kremer - Field Team Leader, Radar Specialist, Mortality Surveys, Radio-tracker, Data Entry.

John Goodell -Logistics Specialist, Mechanic, Radar Operator, Mortality Surveys, Observer, Radio-tracker, Data Entry.

Dana Shurtleff, M.S. - Radar Operator, Observer, Data Entry.

Aaron Hicks - Radar Operator, Observer, Data Entry.

George Montopoli, Ph.D. (Department of Mathematics, Univ. of Wyoming) - Climbing Consultant, Nestling Bald Eagle Banding and Radio-tagging (1996 also).

Amanda Dumin, M.S. - Radar Operator, Observer, Radio-tracker, Data Entry (8-20 to 9-15).

Personnel involved in seasonal avian use studies during 1996 were:

James R. Zelenak, M.S. - Field Team Leader, Radar Specialist, Mortality Surveys, Raptor Surveys, Raptor Capture, Eagle Banding, Observer, Radio-tracker, Data Entry, Data Analysis, Author.

Kevin Podruzny, M.S. - Radar and Data Analysis Specialist, Mortality Surveys, Observer, Radio-tracker, Data Entry, Author.

Rosemary Jaffe - Radar Specialist, Mortality Surveys, Raptor Capture, Eagle Banding, Observer, Radiotracker, Data Entry.

Neil Shook - Radar Specialist, Mortality Surveys, Raptor Capture, Radio-tracker, Data Entry.

Elizabeth Madden, M.S. - Point Count Specialist.

Mark Vekasy, M.S. - Eagle Capture Specialist, Radio-tracker.

Greg Dohney - Raptor Capture Specialist.

Randy Loewen - Owner and pilot of the radio-controlled model aircraft.

Significant logistical and financial support were facilitated by the following personnel and their agencies:

Jim Roscoe, Bureau of Land Management, Butte District, Dillon Resource Area; significant funding.

Mark Petroni, M.S., District Ranger and Ron Weissman, Forest Service, Madison District, Ennis, MT; housing, vehicles, maps, significant logistical support.

Dennis Flath, M.S., Nongame Coordinator, Montana Department of Fish, Wildlife \& Parks, Nongame Program; vehicles, snow machine.

Tom Ring and Van Jamison, Montana Department of Environmental Quality; maps, Digital Elevation Model, funding assistance, insight.

Jay J. Rotella, Ph.D., and Daniel Gustafson, Ph.D., Biology Department, Montana State University; statistical and computer support. 
Primary funding for this study was provided by the U.S. Department of Energy, and the National Renewable Energy Laboratory's (NREL) National Wind Technology Center. Holly Davis and Karin Sinclair, NREL, served as technical monitors; Mike Morrison, Ph.D., avian consultant for NREL provided direction, support, and statistical expertise in developing the study plan and preparing the final report. 


\section{Table of Content}

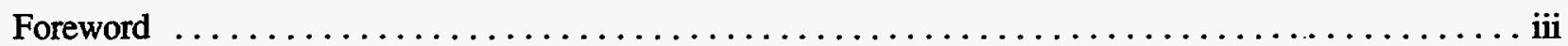

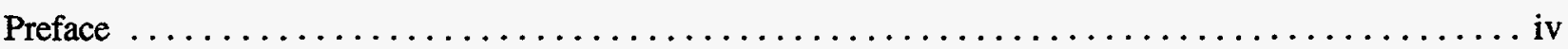

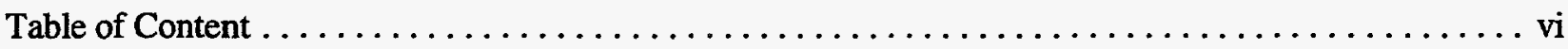

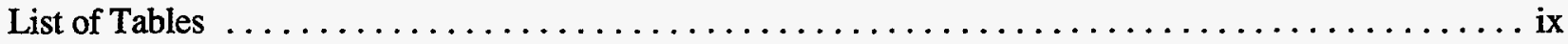

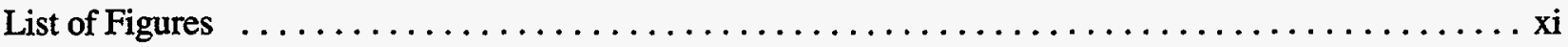

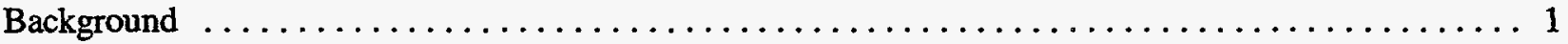

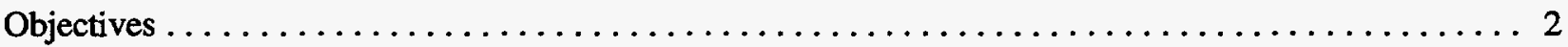

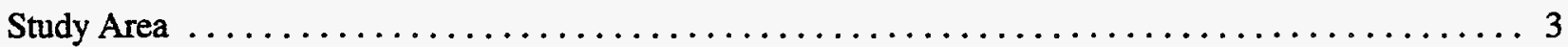

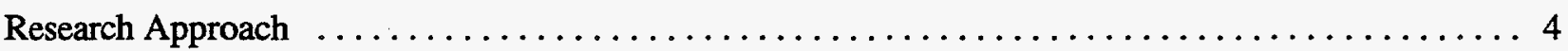

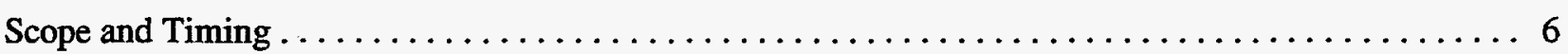

Methods $\ldots \ldots \ldots \ldots \ldots \ldots \ldots \ldots \ldots \ldots \ldots \ldots \ldots \ldots \ldots \ldots \ldots \ldots \ldots \ldots \ldots$

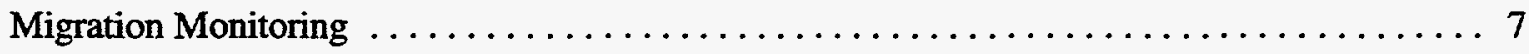

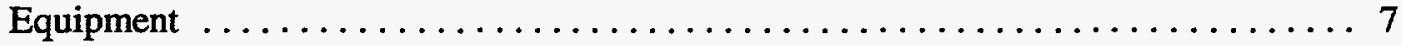

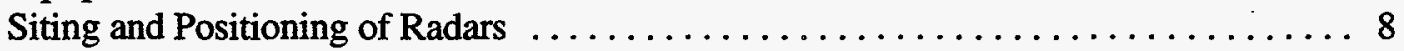

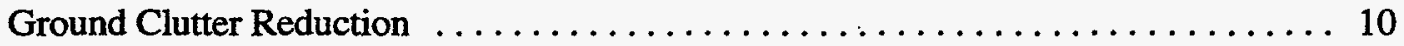

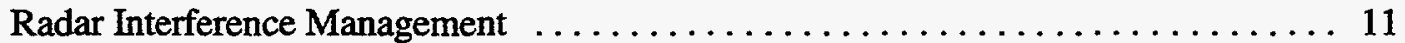

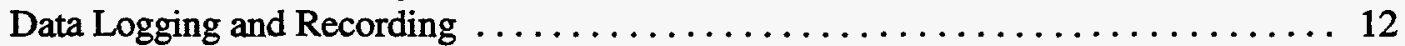

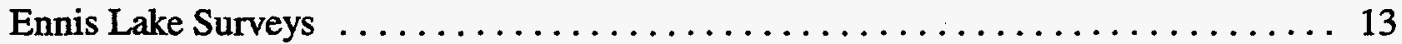

Use of NHWRA and Vicinity by Breeding and Local Nonraptorial Birds $\ldots \ldots \ldots \ldots \ldots 13$

Use of NHWRA by Breeding and Local Raptors $\ldots \ldots \ldots \ldots \ldots \ldots \ldots \ldots \ldots \ldots \ldots \ldots \ldots$

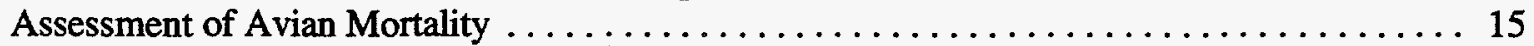

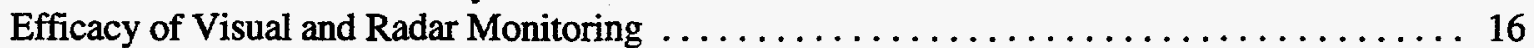

Observations ........................................ 16

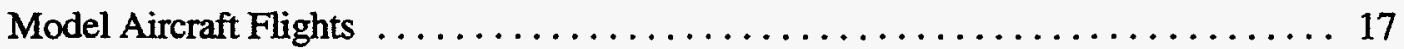

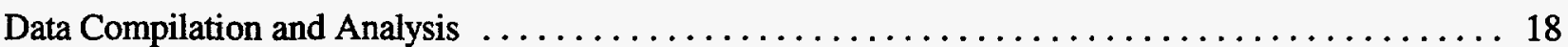

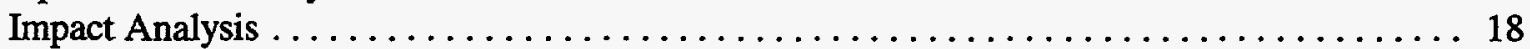

Use of NHWRA and Reference Areas by Migratory Birds $\ldots \ldots \ldots \ldots \ldots \ldots \ldots$

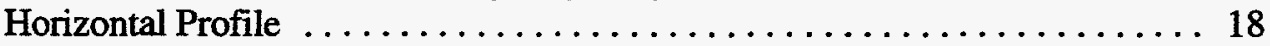

Altitudinal Profile ............................ 19

Spatio-temporal Profile of Use of NHWRA and Vicinity $\ldots \ldots \ldots \ldots \ldots \ldots \ldots \ldots \ldots$

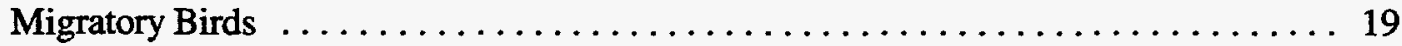

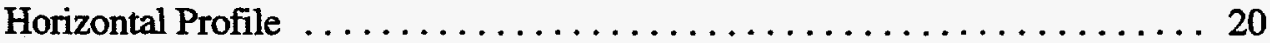

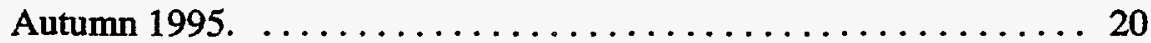

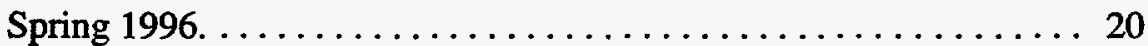

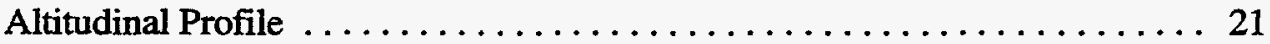

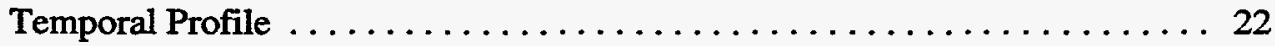

Estimated Magnitude and Altitude of Avian Migration in and near NHWRA . 22 
Estimated Minimum Sampling Effort for Future Radar Monitoring . . . . 23

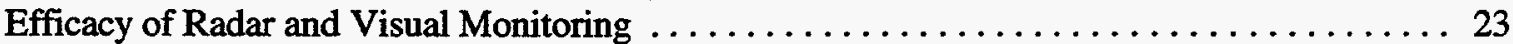

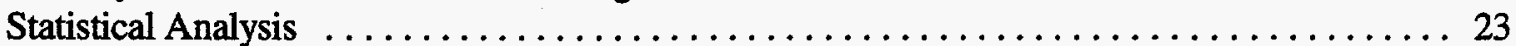

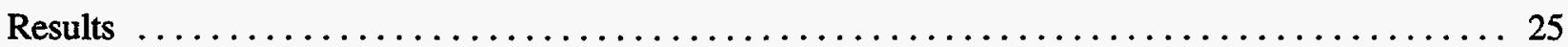

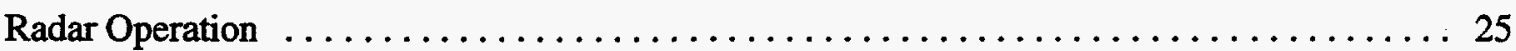

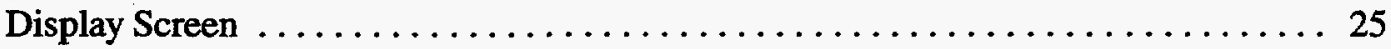

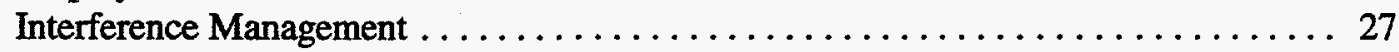

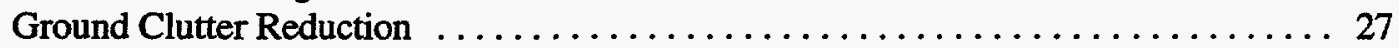

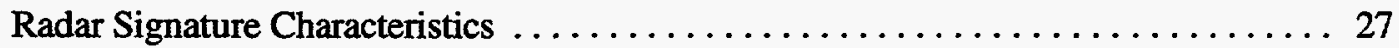

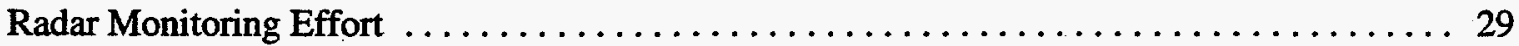

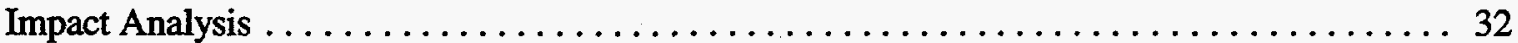

Use of Impact and Reference Areas by Migratory Birds $\ldots \ldots \ldots \ldots \ldots \ldots \ldots \ldots$

Horizontal Profile of Use . . . . . . . . . . . . . . . . . . 32

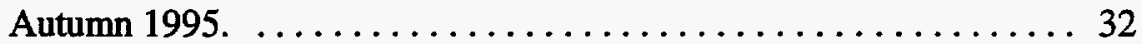

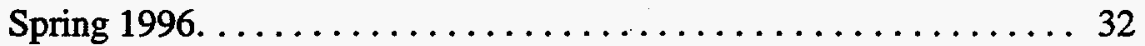

Altitudinal Profile of Use . . . . . . . . . . . . . . . . . . . . 32

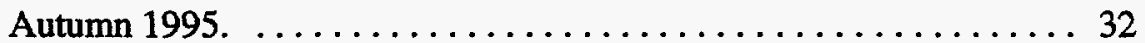

Spring 1996. ................................ 33

Use of Impact and Reference Areas by Breeding and Local Nonraptorial Birds . . . . 34

Use of Impact and Reference Areas by Breeding and Local Raptors . . . . . . . . . 34

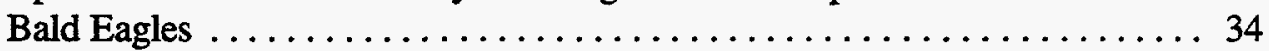

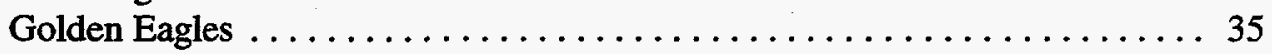

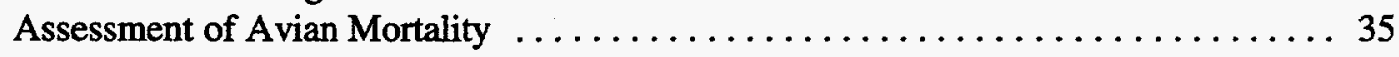

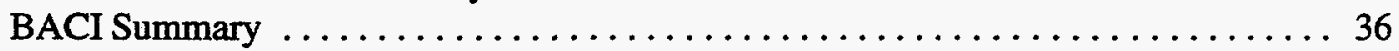

Spatio-temporal Profile of Avian Use of NHWRA and Vicinity $\ldots \ldots \ldots \ldots \ldots \ldots \ldots \ldots$

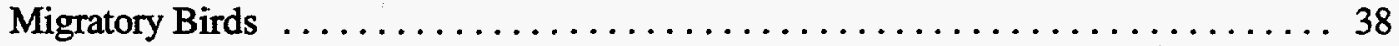

Horizontal Profile ............................ 38

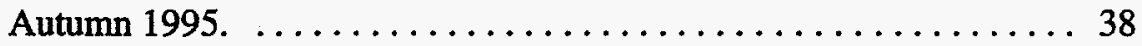

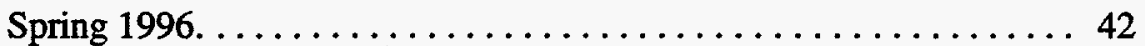

Altitudinal Profile ......................... 47

Temporal Profile of Migration $\ldots \ldots \ldots \ldots \ldots \ldots \ldots \ldots \ldots \ldots 48$

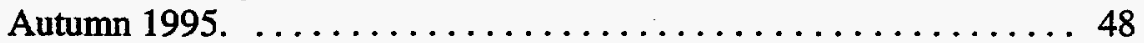

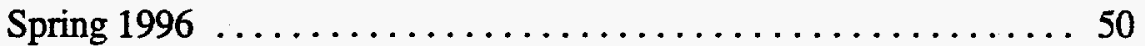

Effect of Weather on Passage Rate ................. 53

Estimated Magnitude and Altitude of Avian Migration in and near NHWRA . 54

Ennis Lake Counts ............................. 55

Estimated Minimum Sampling Effort for Future Radar Monitoring . . . . . 57

Breeding and Local Nonraptorial Birds $\ldots \ldots \ldots \ldots \ldots \ldots \ldots \ldots \ldots \ldots \ldots$

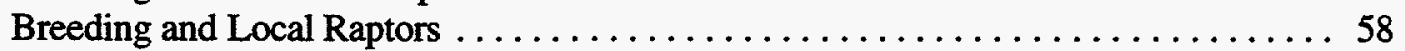

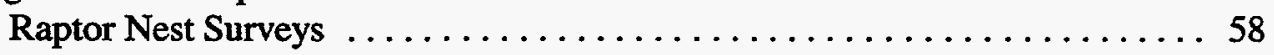

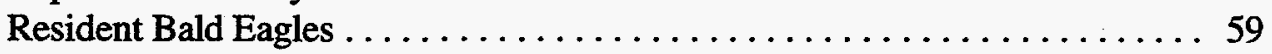

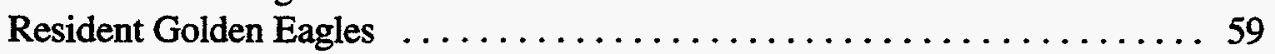

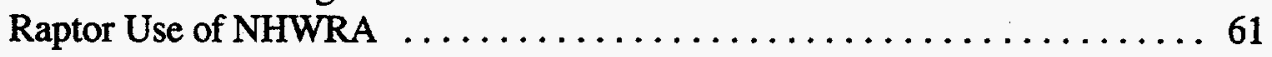

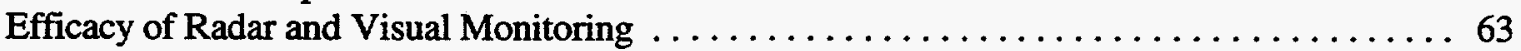

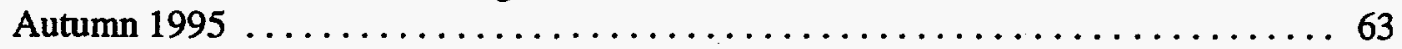

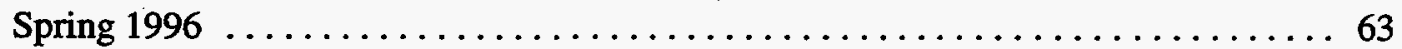

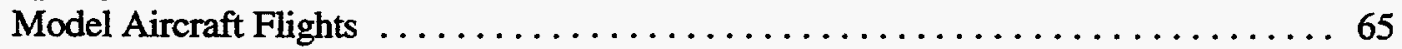

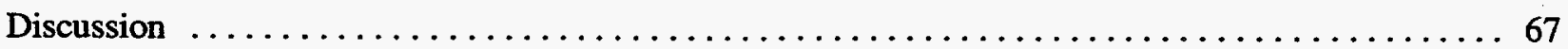

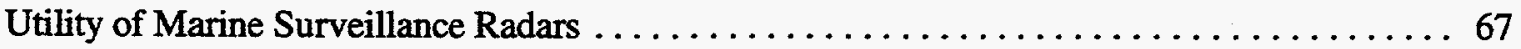




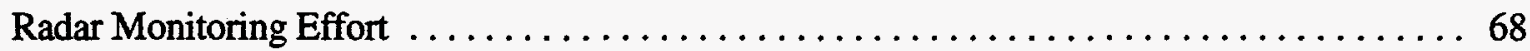

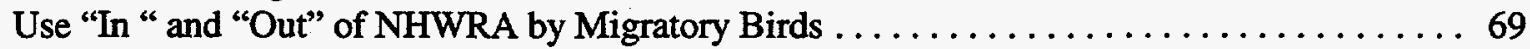

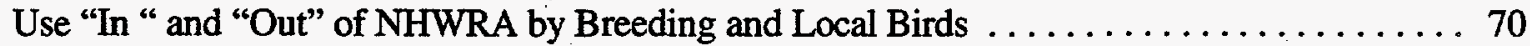

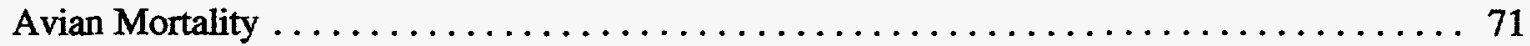

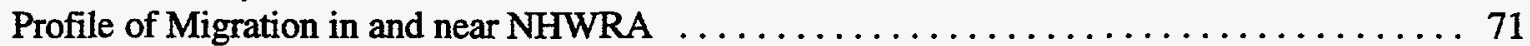

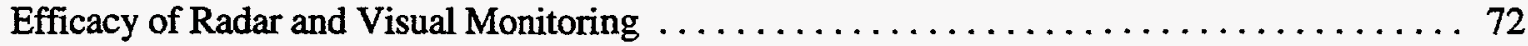

Recommendations for Future Radar Study of Avian Migration $\ldots \ldots \ldots \ldots \ldots \ldots \ldots \ldots \ldots \ldots$

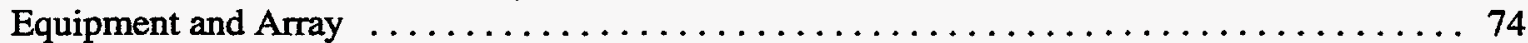

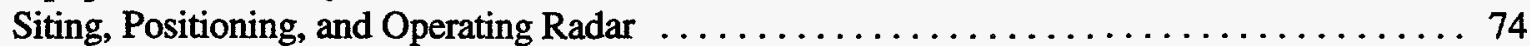

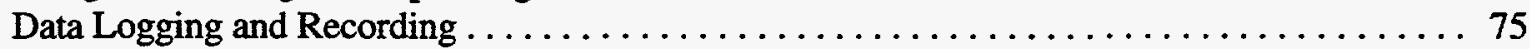

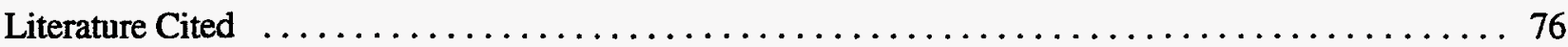

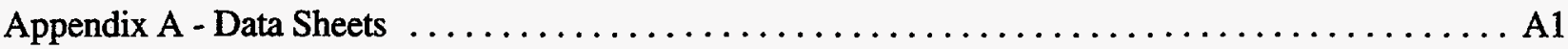

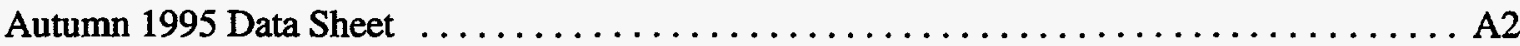

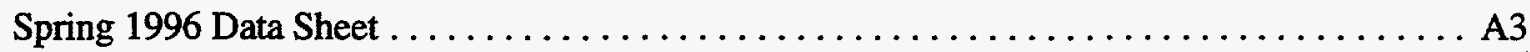

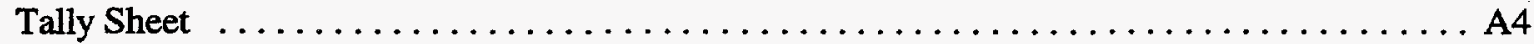

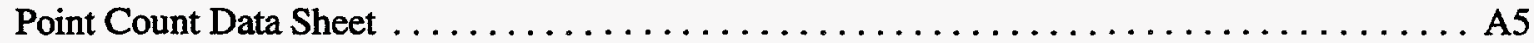

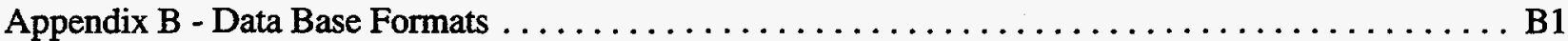

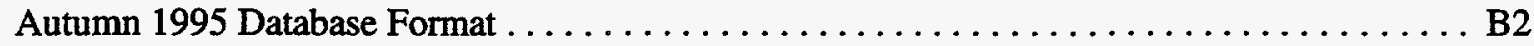

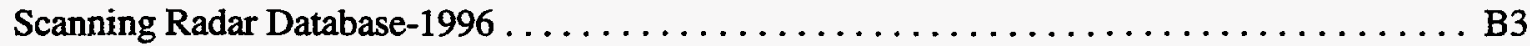

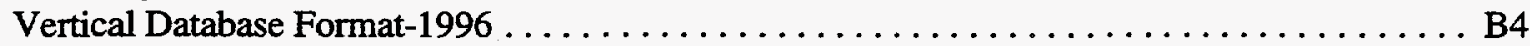

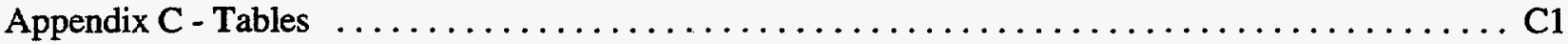

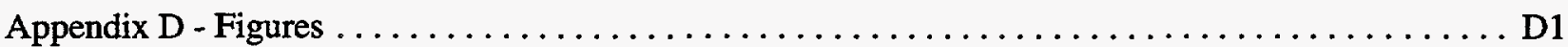

Appendix E - Alpha Codes for North American Bird Species and Vegetative Groups Associated with Cover Types $\ldots \ldots \ldots \ldots \ldots \ldots \ldots \ldots \ldots$ E1 


\section{List of Tables}

Table 1. Maximum Detection Range of Scanning and Vertical Radars by Range Setting. . . . . . 26

Table 2. Surveillance Area Size and Events Detected Seasonally "In" and "Out" of

NHWRA by Scanning and Vertical Radar Arrays. . . . . . . . . . . . . . . . 32

Table 3. Altitude (meters) Above Radar and Ground Level of Events Detected Seasonally

"In and "Out" of NHWRA by Vertical Radar. ....................... 34

Table 4. Avian Abundance and Diversity in BACI Areas Detected During Point

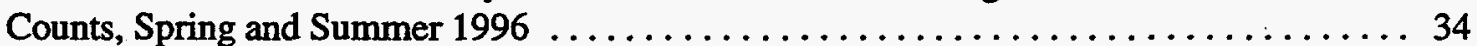

Table 5. Location of Adult Bald Eagles Nesting in Bear Trap Canyon Relative to

NHWRA During Visual Monitoring, Summer 1996. . . . . . . . . . . . . 35

Table 6. Locations of Radio-tagged Adult Male Golden Eagles Nesting at Sites Closest

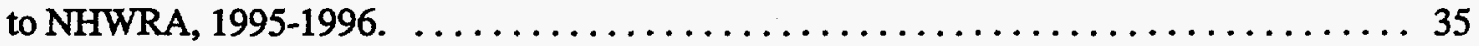

Table 7. Avian Mortality Detected on Transects "In" and "Out" of NHWRA ........... 36

Table 8. Proportion of Avian Mortalities Discovered in and near NHWRA, 1995 and

1996, Assigned to Cause. . . . . . . . . . . . . . . . . . . . . . . . 36

Table 9. Summary of BACI Analysis of Parameters of Avian Use and Mortality in and out of NHWRA by Migratory Birds, Autumn 1995-Spring 1996. . . . . . . . . . . . 37

Table 10. Summary of BACI Analysis of Avian Use Parameters for Local and Breeding

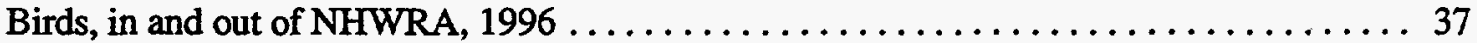

Table 11. Adjusted and Expected Number of Events in each Range Ring, Calculated from Those Detected by Scanning Radar, NHWRA, Autumn 1995 . . . . . . . . . . . 39

Table 12. Adjusted and Expected Number of Events "In" and "Out" of NHWRA, Calculated from Detections by Scanning and Vertical Radars, Autumn 1995. . . . . . . . 39

Table 13. Adjusted and Expected Number of Events in NHWRA and Reference Areas (S12-S18) Calculated from Events Detected by Scanning Radar, Spring 1996. . . . . . . 43

Table 14. Adjusted and Expected Number of Events "In" and "Out" of NHWRA Calculated from Events Detected by Scanning and Vertical Radars, Spring 1996 . . . . . . 44

Table 15. Barometric Trends Associated with Mean Passage Rates of Events Detected by Scanning and Vertical Radars, NHWRA, Autumn 1995 and Spring $1996 . . \ldots \ldots \ldots .53$

Table 16. Estimated Magnitude and Altitude of Seasonal Avian Migrations Through NHWRA and Vicinity. Estimate Derived from Adjusted Number of Events Detected by Scanning and Vertical Radars, 1995 and 1996. Low Altitude

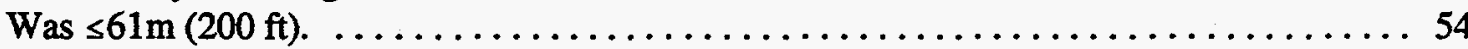

Table 17. Waterfowl, Shorebirds, and Raptors Counted on Ennis Lake between 21 Oct.-16 Dec. (Autumn) 1995 and 9 Mar.-10 June (Spring) 1996. . . . . . . . . . . . 55

Table 18. Abundance of 10 Most Common Avian Species, Including Flyovers, Detected During Point Counts, NHWRA, $1996 \ldots \ldots \ldots \ldots \ldots \ldots \ldots \ldots \ldots \ldots \ldots$

Table 19. Number of Species of Birds (Excluding Flyovers) and Abundance within $150 \mathrm{~m}$ (492 ft), Observed During Point Counts and Associated Vegetative

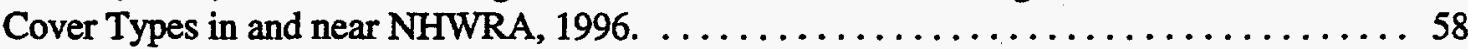

Table 20. Raptor Breeding Areas Located During Aerial Surveys within $25 \mathrm{~km}$ (16 mi)

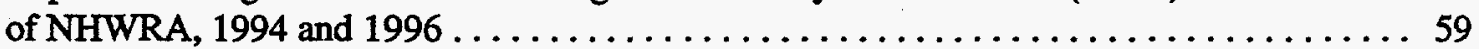

Table 21. Use of NHWRA by Radio-tagged Adult Male Golden Eagles Relative to Home Ranges, 1995-1996. . . . . . . . . . . . . . . . . . . . . . . 61

Table 22. Raptor Use of NHWRA During 79.32 Hours of Observation in 30 Periods, 2 July-16 August 1996.

Table 23. Raptor Use of NHWRA Between 2 July-16 August 1996, as Determined by Radar and Visual Monitoring. 
Table 24. Visually Estimated Altitudes of Raptors in NHWRA by Time of Day, 2 July-16 August 1996.

Table 25. Detection Rates of Scanning Radar and Visual Monitoring During Paired Observations, Autumn 1995

Table 26. Detection Rates of Scanning Radar and Visual Monitoring During Paired Observations, Spring 1996

Table 27. Success of Visual Target Acquisition Attempts by Scanning and Vertical Radar Operators During Solo and Paired Radar Observation Sessions ${ }^{1}$, Spring 1996.

Table 28. Success of Target Acquisition Attempts by Coincident Monitoring Method on or Near NHWRA During Raptor Observation Sessions, Summer 1996 (Scanning Radar Only)

Table 29. Visually Estimated Altitudes of Raptors Detected or Undetected by Scanning Radar in NHWRA, Summer 1996.

Table 30. Detection Success of All Model Airplane Flights within $2 \mathrm{~km}(11 / 4 \mathrm{mi})$ of Scanning Radar, NHWRA, Summer 1996.

Table 31. Transects Completed for Assessment of Preimpact Avian Mortality in and near NHWRA, August 1995 - August 1996.

Table 32. Raptors, Swans, and Pelicans Visually Detected During Radar Monitoring, NHWRA, Autumn 1995.

Table 33. Raptors, Swans, and Pelicans Visually Detected During Radar Monitoring, NHWRA, Spring 1996.

Table 34. Other Species and Respective Altitude Ranges Detected in NHWRA, Summer 1996. 


\section{List of Figures}

Figure 1. Location of Norris Hill Wind Resource Area (NHWRA), Madison

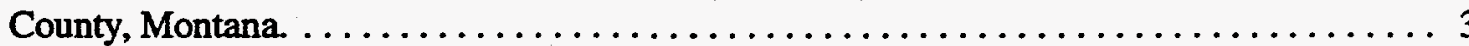

Figure 2. Radar monitoring station, Norris Hill Wind Resource Area, Madison County,

Montana. View is toward south. Scanning radar antenna is on trailer roof.

Figure 3. Positioning of radar antenna for detection of flight altitude of birds, Norris

Hill Wind Resource Area, Madison County, Montana. View is to north

Figure 4. Relative location and surveillance range of scanning and vertical radars, autumn 1995. Circle is $1.5 \mathrm{~nm}(2.8 \mathrm{~km})$ surveillance diameter of scanning radar. Hour glass is horizontal surveillance area of vertical radar extending $2.8 \mathrm{~km}(1.7 \mathrm{mi})$ east and west of radar location. . . . . . . . . . . . . . . . . . . . 9

Figure 5. Relative location and surveillance area of scanning and vertical radars, NHWRA, spring 1996. Circle is $3 \mathrm{~nm}(5.6 \mathrm{~km})$ surveillance diameter of scanning radar. Hour glass is horizontal surveillance area of vertical radar. Asymmetry of vertical radar surveillance area, extending $3.2 \mathrm{~km}(2 \mathrm{mi})$ west and $2.3 \mathrm{~km}(1.4 \mathrm{mi})$ east was due to origin offset feature on the radar screen. . . . . 10

Figure 6. Scanning and vertical radar pedestal mount for interference management. ......... 11

Figure 7. Point count locations spring/summer 1996 and mortality survey routes in 1995 , in and near NHWRA. . . . . . . . . . . . . . . . . . . 14

Figure 8. Routes for avian mortality surveys in and near NHWRA, spring/summer 1996. . . . . . 16

Figure 9. Display screen of scanning radar during autumn 1995 monitoring. Large, irregular light areas are clutter (higher topographic relief). Surveillance range was $1.5 \mathrm{~nm}(2.8 \mathrm{~km})$. Top is due north, right is east. Distance between concentric rings is $0.25 \mathrm{~nm}$ (463 m)

Figure 10. Display screen of vertical radar during autumn 1995 monitoring. Light horizontal area at bottom is ground level. Top is straight up, right is west. Distance between concentric rings is $0.25 \mathrm{~nm}(463 \mathrm{~m})$. Signature in center,

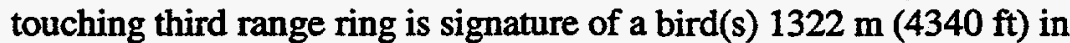
altitude above radar. Detection range above radar was $5.1 \mathrm{~km}(16,732 \mathrm{ft}) \mathrm{AGL} . \ldots \ldots 26$

Figure 11. Signature of 2 flocks of waterfowl (dots in line) flying southwest, between 1.8 and $2.8 \mathrm{~km}$ (1.1-1.7 mi) west-northwest of NHWRA, autumn 1995. Brighter

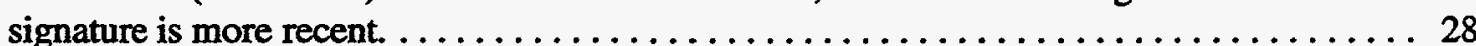

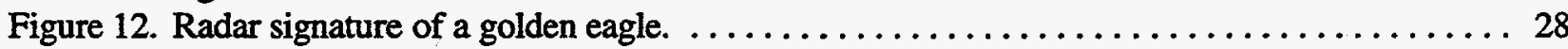

Figure 13. Radar signature of a flock of passerines (cloudy area, near center) . . . . . . . . 28

Figure 14. Scanning radar screen during intense migratory activity, spring $1996 . \ldots \ldots \ldots \ldots 28$

Figure 15. Signature of aircraft on vertical radar. Altitude was $\sim 1.8 \mathrm{~km}(5906 \mathrm{ft})$ AGL. . . . . . . 29

Figure 16. Hourly monitoring effort with scanning radar, NHWRA during autumn $1995 \ldots \ldots \ldots \ldots 30$

Figure 17. Hourly monitoring effort with vertical radar, NHWRA during autumn $1995 . \ldots \ldots \ldots 30$

Figure 18. Distribution of monitoring effort per hour with scanning radar, NHWRA

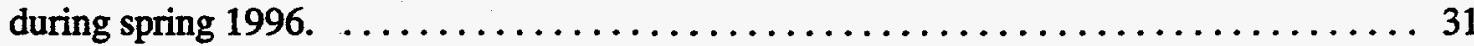

Figure 19. Hourly monitoring effort with vertical radar, NHWRA during spring $1996 \ldots \ldots \ldots \ldots . .31$

Figure 20. Altitude distribution of events detected In and Out of NHWRA, spring 1996.

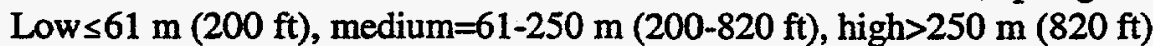

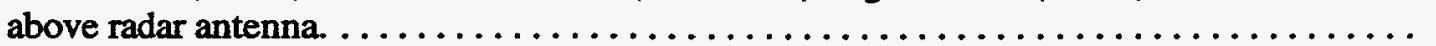

Figure 21. Altitude distribution of events detected In and Out of NHWRA, autumn 1995. Low $\leq 61 \mathrm{~m}(200 \mathrm{ft})$, medium=61-250 m (200-820 ft), high>250 m (820 ft) above radar antenna. . . . . . . . . . . . . . . . . . . . . . . . . . . . .

Figure 22. Total number of events detected within each of six range rings surrounding scanning radar, NHWRA, autumn 1995. 
Figure 23. Probability of detection of targets at increasing distance from scanning radar,

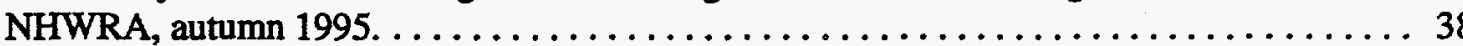

Figure 24. Adjusted number of events/hectare/hour within each of five proximate range rings surrounding scanning radar, NHWRA, autumn $1995 \ldots \ldots \ldots \ldots \ldots \ldots \ldots \ldots$

Figure 25. Total number of events detected by vertical radar within each of six distance categories east and west of radar combined, NHWRA, autumn 1995.

Figure 26. Probability of detection of targets at increasing distance from vertical radar, NHWRA, autumn 1995. . . . . . . . . . . . . . . . . . . . . . . . 41

Figure 27. Adjusted number of events within each horizontal distance category (east and

Figure 28. Adjusted number of events $/ \mathrm{m} / \mathrm{hr}$ within each of six horizontal distance categories (east and west combined) from vertical radar relative to ground level, NHWRA, autumn 1995.

Figure 29. Number of events detected in NHWRA and each Reference area (S12-S18) by scanning radar at range setting $3 \mathrm{~nm}(5.6 \mathrm{~km})$, spring 1996.

Figure 30. Probability of detection of targets at increasing distance east (R) and west

(L) of scanning radar, NHWRA, spring 1996.

Figure 31. Adjusted number of events (from events detected by scanning radar) per hectare/hour within each reference area (S12-S18) and NHWRA, spring 1996.

Figure 32. Distribution of events detected by vertical radar within 100-m (328-ft) horizontal distance categories, NHWRA, spring 1996.

Figure 33. Detection probability of targets at increasing distance east (R) and west (L) of vertical radar, NHWRA, spring 1996.

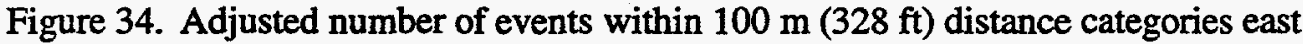
and west of vertical radar, NHWRA, spring 1996. Horizontal line is expected

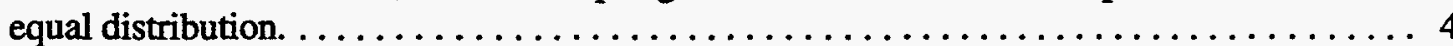

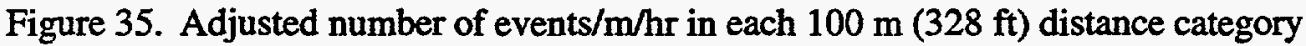
relative to ground level east and west of vertical radar, NHWRA, spring 1996.

Figure 36. Median elevation (above sea level) of events detected by vertical radar within each range ring relative to ground level, NHWRA, autumn 1995. Number of events both east and west of radar were combined.

Figure 37. Elevational distribution (above sea level) of all events detected by vertical radar, NHWRA, spring 1996.

Figure 38. Median elevation (above sea level) of events within each $100 \mathrm{~m}$ horizontal distance category, east and west of vertical radar, NHWRA, spring 1996.

Figure 39. Daily passage rate of events detected by scanning radar between 20 August

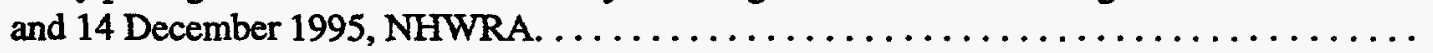

Figure 40. Weekly passage rate of events detected by scanning radar between 20 August and 14 December 1995, NHWRA. ................................

Figure 41. Hourly passage rate of events detected by scanning radar between 20 August

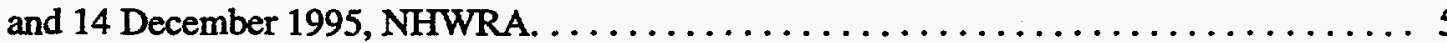

Figure 42. Daily passage rate of events detected by scanning radar between 20 February

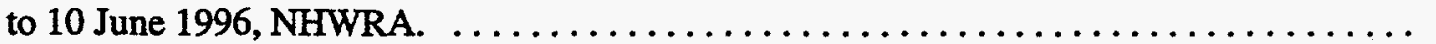

Figure 43 . Weekly passage rate of events detected by scanning radar between 20 February and 10 June 1996, NHWRA. . . . . . . . . . . . . . . . . . . . . . .

Figure 44 . Hourly passage rate of events detected by scanning radar between 20 February

Figure 45. Daily passage rate of events detected by vertical radar between 20 February

Figure 45 . Daily passage rate of events detected by vertical radar between 20 February to 10 June 1996, NHWRA.

Figure 46 . Weekly passage rate of events detected by vertical radar between 20 February

and 10 June 1996, NHWRA. 
Figure 47 . Hourly passage rate of events detected by vertical radar between 20 February and 10 June 1996, NHWRA.

Figure 48. Relationship of numbers of waterfowl counted on Ennis Lake with mean passage rate of events detected by scanning radar located in NHWRA, autumn 1995.

Figure 49. Relationship of numbers of waterfowl counted on Ennis Lake with mean passage rate of events detected by scanning radar located in NHWRA, spring 1996.

Figure 50. Median and percentile ranges of $10^{4}$ bootstrapped samples of 233 mean passage rates sampled at decreasing percentages. Passage rates were determined during of $172.7 \mathrm{hrs}$ of vertical radar monitoring, NHWRA, spring 1996.

Figure 51. Raptor breeding areas located during aerial and ground surveys, $1996 \ldots \ldots \ldots \ldots \ldots$

Figure 52. Delectability of radio-controlled model aircraft at three radar ranges when flown

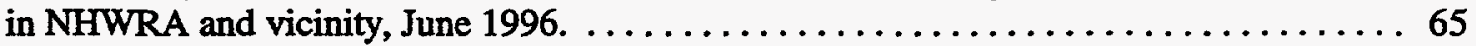

Figure 53. Canada geese counted on Ennis Lake, autumn 1995 ................... D2

Figure 54. Snow geese counted on Ennis Lake, autumn $1995 \ldots \ldots \ldots \ldots \ldots \ldots \ldots \ldots \ldots \ldots \ldots \ldots \ldots \ldots \ldots \ldots$

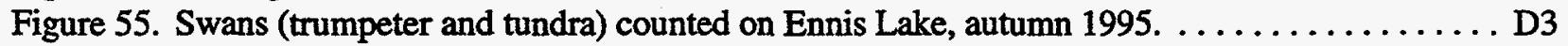

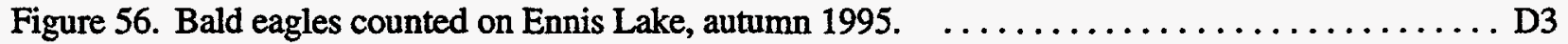

Figure 57. American white pelicans counted on Ennis Lake, spring 1996. . . . . . . . . . . D4

Figure 58. Swans (trumpeter and tundra) counted on Ennis Lake, spring 1996. . . . . . . . . . D4

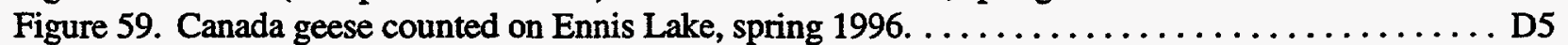

Figure 60. Bald eagles counted on Ennis Lake, spring 1996. . . . . . . . . . . . . . . . . . D5

Figure 61. Other water-associated birds (e.g., grebes, loons, gulls, cranes, coots, herons, shorebirds) counted on Ennis Lake, spring 1996. 


\section{Background}

Proposed wind power development in the Norris Hill Wind Resource Area (NHWRA) of southwestern Montana includes installation of wind turbines up to $30 \mathrm{~m}$ (98 ft) in height, with blade diameters of $28 \mathrm{~m}$ (92 $\mathrm{ft}$ ), dispersed in varying densities over 121 hectares (300 acres). Because similar structures and siting in California induced potentially significant avian mortality (Orloff and Flannery 1992), there is concern that development of wind resources may pose significant hazards to migrant, breeding, post-fledging, and wintering birds at NHWRA as well. Proposed development of NHWRA stimulated investigation of avian use of the area.

Studies of avian use of NHWRA began in March 1994. Initial study was of a "reconnaissance nature" (Gauthreaux 1995) and consisted of five somewhat independent phases; two emphasized seasonal migrations whereas others focused on size and distribution of local raptor and neotropical landbird breeding populations as well as winter use by raptors. Searches for dead birds were also conducted to evaluate predevelopment mortality within NHWRA and vicinity (Harmata 1995).

Seasonal migrations were monitored visually in 1994. Observers recorded many birds passing through or near NHWRA, but only during daylight hours. Observations sampled less than $25 \%$ of the diem because many birds, especially waterfowls and passerines, migrate at night (Bellrose 1978). Additionally, numbers of birds associated with Ennis Lake, a migratory stopover site $4.8 \mathrm{~km} \mathrm{(3} \mathrm{mi)} \mathrm{due} \mathrm{south} \mathrm{of} \mathrm{NHWRA,} \mathrm{did} \mathrm{not} \mathrm{correlate}$ with those observed passing over NHWRA. Migrants either arrived and departed undetected via pathways other than over NHWRA, moved at night, or both. Visual monitoring alone clearly was not representative of avian use of NHWRA during migration.

Radar (RAdio Detection And Ranging) has been employed for monitoring avian movements since the 1940s (Bellrose 1964). More recently, marine surveillance radars have become more affordable and used more frequently to investigate avian migration (Eastwood 1967; Kerlinger and Gauthreaux 1984; Gauthreaux 1985a,b; Cooper et al. 1991).

Because biases inherent to visual observations prevented adequate description of avian use of NHWRA, stateof-the-art marine surveillance radars were employed to investigate characteristics of avian use in and around NHWRA before development of wind resources. Although emphasis was on seasonal migration periods, study also included the breeding season and focused on priority avian groups and species.

Data generated during this study are intended to represent avian use and mortality in NHWRA and vicinity before development of wind resources. These results may be compared to postdevelopment avian use and mortality data for analysis of impact, should NHWRA be developed. In addition, attempts were made to describe the spatial and temporal profile of avian use of NHWRA and vicinity. Also included in the study were efforts to design, develop, modify, or complement standardized research protocols for determining avian use of wind resource areas, as were efforts to evaluate radar technology and determine minimum sampling effort for future radar studies. 


\section{Objectives}

The primary objective of the study was to establish preconstruction avian use and mortality in NHWRA and vicinity for comparison with postconstruction use and mortality. This objective was pursued in the context of testing the following hypotheses:

1. $H_{o}=$ Preconstruction avian use in NHWRA and vicinity will not differ from postconstruction use. $H_{A}=$ Wind resource development will positively or negatively impact avian use in NHWRA.

2. $H_{o}=$ Preconstruction avian mortality in NHWRA and vicinity will not differ from postconstruction mortality.

$H_{\mathrm{A}}=$ Wind resource development will increase or decrease avian mortality in NHWRA.

Secondary objectives were:

1. Determination of methods and standards to develop, modify, or complement new or existing research protocols for avian studies during the preconstruction phase of wind resource area development

2. Employment and modification of radar products, methods, and technology plus data acquisition and logging options to define avian use of a wind resource area

3. Evaluation and verification of visual and radar surveillance techniques for describing avian use of selected areas

4. Determination of a minimum sample of independent radar observations necessary to quantify migrational movement of birds over NHWRA. 


\section{Study Area}

NHWRA is located in Madison County, Montana, approximately $16 \mathrm{~km}(10 \mathrm{mi})$ north of Ennis. NHWRA was chosen by industry based on availability of electrical transmission capability and meteorological characteristics. Initial 300 megawatt development is planned on four hectares (10 acres) of private land within a $1.3 \mathrm{~km}^{2}(1 / 2$ $\mathrm{mi}^{2}$ ) area located in the south $1 / 2$ of the east $1 / 2$ section 12, T4S-R1W (see Fig. 1). Planned Phase I development includes $34,300 \mathrm{~kW}$ turbines, $28 \mathrm{~m}(92 \mathrm{ft})$ blade diameter, in four or five rows extending east-southeast to west-northwest. Each row will contain six to 10 turbines, depending on development option. Dominant wind direction is $196^{\circ}$. Sustained wind velocities in excess of $96 \mathrm{kph}(60 \mathrm{mph})$ are common. Mean elevation of NHWRA is $\approx 1830 \mathrm{~m}(6000 \mathrm{ft})$.

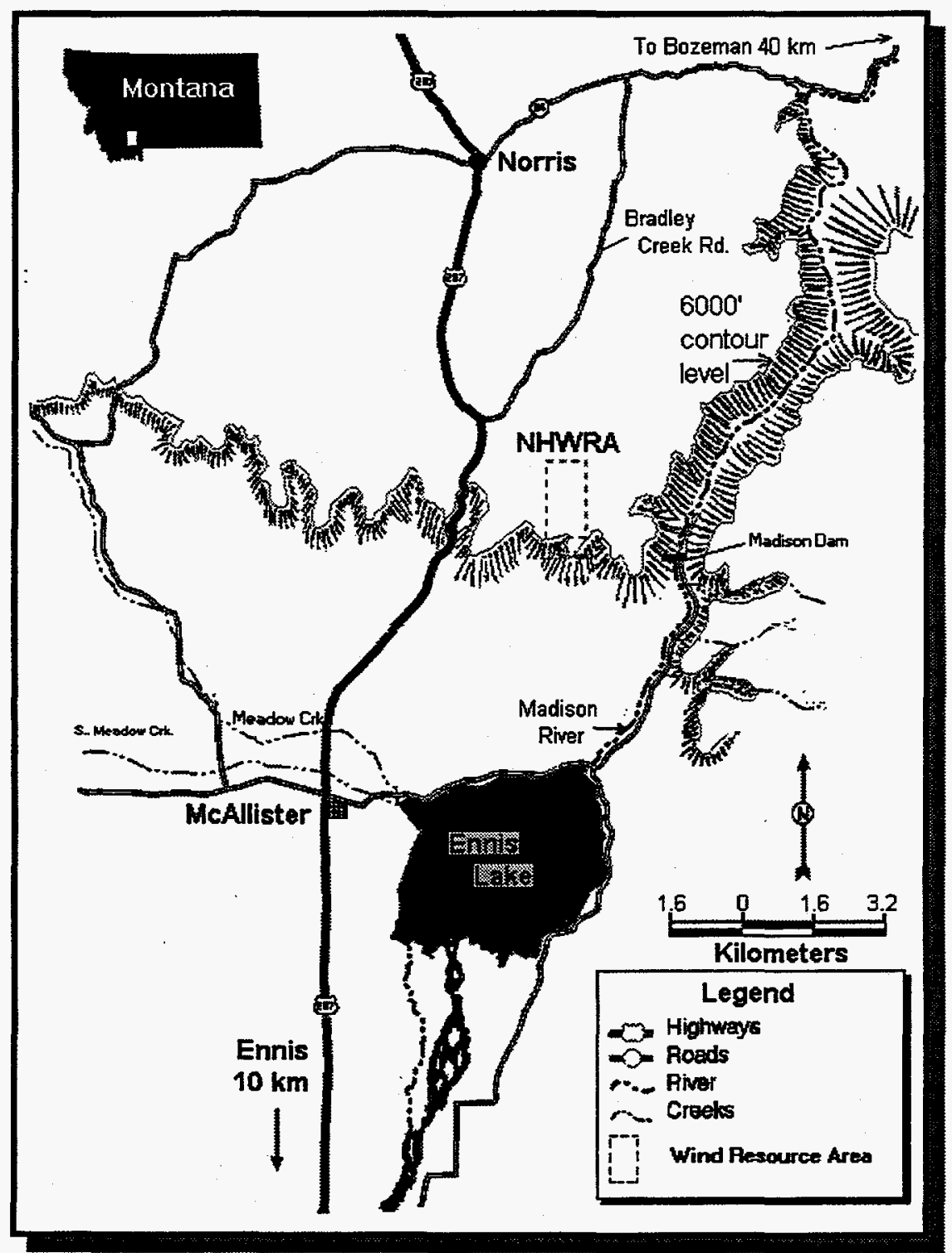

Figure 1. Location of Norris Hill Wind Resource Area (NHWRA), Madison County, Montana. 


\section{Research Approach}

The study included three major approaches for pursuit of stated objectives: 1) determination of seasonal avian use and mortality in the context of evaluating impact of future wind resource development of NHWRA (Impact analysis approach), 2) description of a seasonal spatio-temporal profile of avian use of NHWRA and vicinity (Descriptive approach), and 3) evaluation of the efficacy of radar and visual monitoring techniques for recording avian movements (Efficacy approach). Impact and Descriptive analyses were performed on the same avian-use data sets and, although the Efficacy approach involved use of most avian data sets derived from radar, the latter approach also involved a substudy designed to evaluate the ability of radar and visual monitoring to detect avian presence and movements.

Within this framework, avian use and mortality were investigated for three groups of birds present on or near NHWRA: 1) migratory birds, 2) breeding and local nonraptorial birds, and 3) breeding and local raptors. Avian use by migratory birds was defined as number of events ${ }^{1}$ detected per unit of time and/or area by monitoring of marine surveillance radars. Use of NHWRA by breeding and local nonraptorial birds was defined by diversity and abundance of birds present and determined by traditional bird-sampling techniques. Use by local and breeding raptors was determined by radar, radio-tracking, and direct observation of individuals, and was expressed as the proportion of total time monitored in NHWRA or number of locations in or out of NHWRA.

Impact analysis required compilation of data in a preconstruction format so that if wind resources at NHWRA were developed, comparison with postconstruction data would be possible. For this purpose, a Before-AfterControl-Impact (BACI) research design (Green 1979) was employed. Avian use and mortality results of this study are intended to serve as "Before-Impact" and "Before-Control" data. Impact and control areas were defined as either "In" or "Out" of NHWRA and avian use and mortality parameters quantified in absolute numbers for each. Analyses involved only comparisons between "Before" categories. Mortality was represented by the numbers of dead birds (or evidence thereof) discovered on pedestrian transects during each of the three seasons and was analyzed under the Impact analysis approach.

The Descriptive approach was included primarily to illustrate how birds used NHWRA and vicinity spatially and over time. Absolute numbers of events detected by radar during seasonal migration periods were adjusted by detection probabilities at respective distances, a task not required for BACI analysis. Adjusted numbers produced a more representative estimate of overall numbers and a more accurate view of a spatial profile of migration in and near NHWRA than analysis of raw numbers (i.e., Impact approach). Events detected per unit of time (rates) were used to describe the temporal profile of migration and were determined hourly, daily, and weekly for NHWRA and vicinity. Spatial use by breeding and local nonraptorial birds were determined by comparing abundance and diversity estimates in a variety of cover types. Patterns of spatial and temporal use by breeding and local raptors were determined by aerial surveys for breeding sites, radar and visual monitoring, and radiotelemetry locations. Raptor use was expressed as time inside the boundaries of NHWRA relative to total monitoring time, by species.

Efficacy analysis employed coincident radar and visual monitoring. Results of migration activity data collected when radar and visual observers were in communication were compared with those collected when observers did not communicate, so that detection rates and success for both could be evaluated. Efficacy monitoring

\footnotetext{
${ }^{1}$ An individual target (also known as a signature or "echo") detected on the radar screen was considered an event. An event may have consisted of a single bird or many birds of several species, grouped tightly enough to present one signature per antenna rotation on the display screen. Bird signatures were easily distinguished from aircraft signatures.
} 
occurred during all seasons. In addition, a radio-controlled model aircraft was flown at known locations and altitudes to test the ability of the radar and radar technicians to detect targets of unknown location and altitude. 


\section{Scope and Timing}

Avian use of NHWRA was investigated during three seasons: autumnal migration, vernal migration, and the breeding season. Use of NHWRA during annual migration was monitored between 21 August and 15 December 1995 in autumn and between 20 February and 10 June 1996 in spring. Use of NHWRA and vicinity by local breeding birds was investigated between 15 March and 7 July 1995 and 1996 . Movements of breeding and locally produced raptors were investigated from $\approx 1$ December 1995 for eagles (Aquila or Haliaeetus spp.) and $\approx 15$ April for hawks (Buteo spp.) and falcons (Falco spp.) to dispersal of most young ( $\approx 30$ August 1995 and 1996). Searches for dead birds were conducted throughout the study. 


\section{Methods}

\section{Migration Monitoring}

\section{Equipment}

Two identical X-band, 10-kw Raytheon ${ }^{\mathrm{TM}}$ 1210XX Marine Surveillance Radars were used for monitoring seasonal bird migrations. Frequency of radars was $9410 \pm 10 \mathrm{MHz}$. Surveillance range was $25 \mathrm{~m}$ (27 yd) minimum and 72 nautical miles $(\mathrm{nm})(133 \mathrm{~km}: 83 \mathrm{mi})$ maximum, depending on range setting. Display units (screens) were green cathode-ray tubes, $32 \mathrm{~cm}(\mathrm{~W}) \times 47 \mathrm{~cm}$ (D) X $39 \mathrm{~cm}(\mathrm{H})(12.6 \times 15.7 \times 15.4 \mathrm{in})$, weighing $\sim 17 \mathrm{~kg}(37.5 \mathrm{lbs}$.). Antenna units were $45 \mathrm{~cm}(\mathrm{H})$ X $29 \mathrm{~cm}(\mathrm{~W})$ X $50 \mathrm{~cm}$ (D) with a 191-cm (75.2in) swing circle, rotating at $24 \mathrm{mpm}$. Emanated beam width was $1.2^{\circ}$ horizontal and $25^{\circ}$ vertical. A power input requirement of the systems was 10.2 43.2 Volts Direct Currents (VDC).

One radar system, a scanning array with antenna rotation of $360^{\circ}$ in a horizontal plane, provided display of targets relative to distance and compass direction from the antenna. Pedestal and antenna of the scanning array were initially mounted atop a 6.4-m (21-ft) recreational trailer (Fig. 2). The pedestal was positioned so that the front was facing due north and the display screen showed north at top. An electronic heading sensor interface provided true north bearing on the scanning display screen.

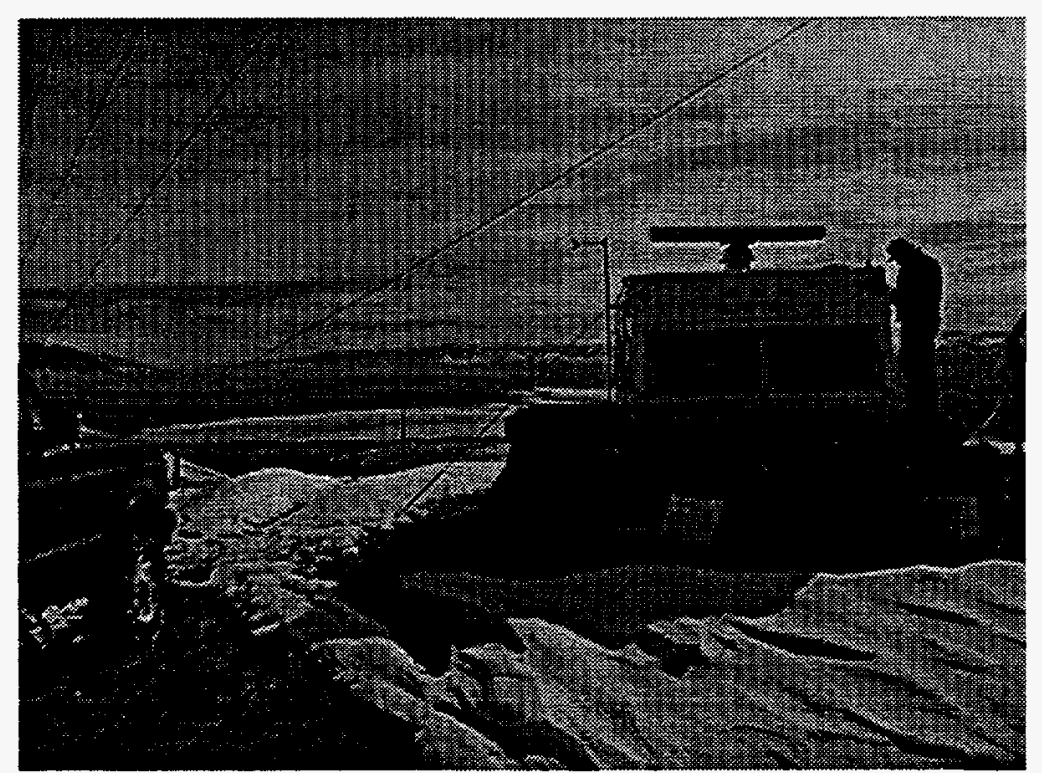

Figure 2. Radar monitoring station, Norris Hill Wind

Resource Area, Madison County, Montana. View is toward south. Scanning radar antenna is on trailer roof.

A second Marine Surveillance Radar was used to determine the height of birds flying through NHWRA and vicinity. Previous attempts using marine radar to determine altitude included replacing the rotating antennae with a nonrotating parabolic dish (e.g., Cooper et al. 1991). This configuration provided altitudes of birds flying only directly over the radar site, unless the parabolic dish was mounted on a swivel. Swivel mounts permitted aiming the dish for altitude determination; however, targets must be known and acquired. In a simple but profound conceptual change, Harold Romberg of Marine Radio Service, Wilmington, CA 90744 (310-835-6640), recommended modifying the plane of rotation of a standard antenna from horizontal to vertical. The plane of antenna rotation for the vertical array was therefore perpendicular to ground level. This configuration created a vertical "curtain" of radar waves extending east-west across the NHWRA and beyond. 
A bird penetrating the curtain created a radar signature that permitted measurement of distance above the radar antenna for distances up to $3.2 \mathrm{~km}(2 \mathrm{mi})$ from the radar station.

The vertical array pedestal and antenna were mounted on a 2.2-m (7-ft) long, 10.2- X 5.1-cm (4- X 2-in.), $5-\mathrm{mm}(3 / 8$-in) thick steel channel buried $61 \mathrm{~cm}(2 \mathrm{ft})$ in the ground, perpendicular to the Earth's surface and

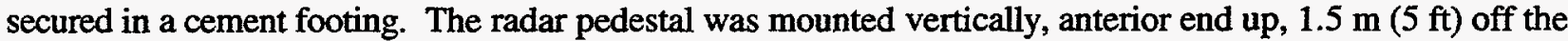
ground (see Fig. 3). Antenna rotation was in an east-west plane, resulting in a vertical curtain of emanated radar waves perpendicular to a north-south compass line.

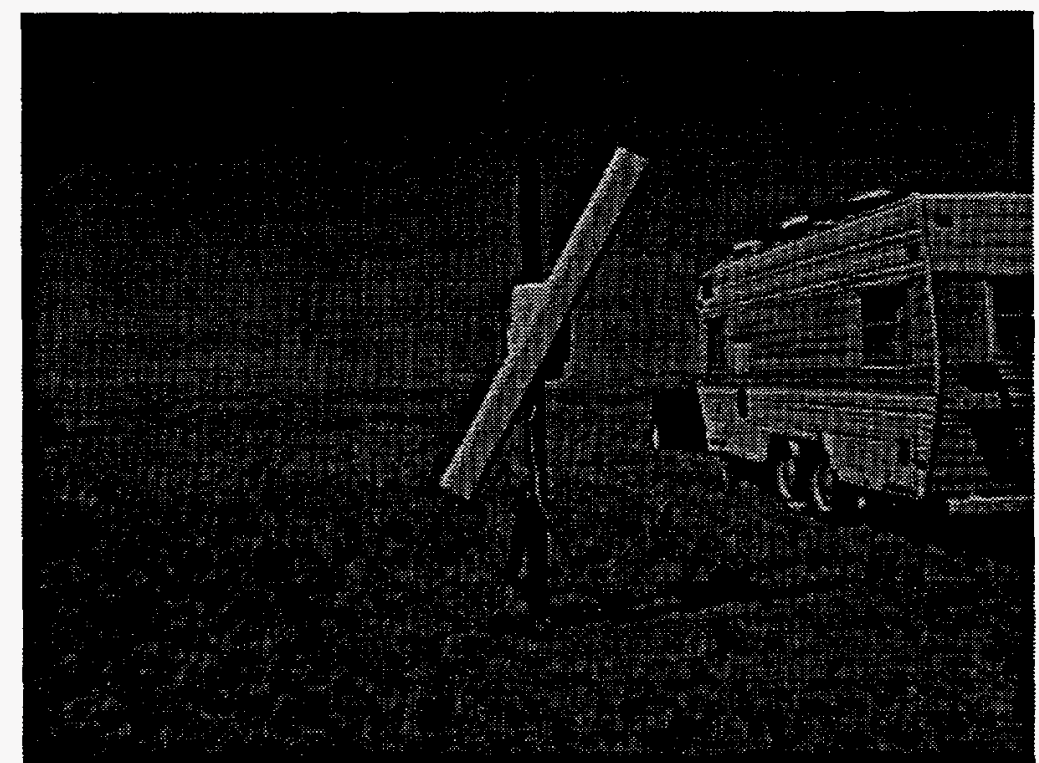

Figure 3. Positioning of radar antenna for detection of flight altitude of birds, Norris Hill Wind Resource Area, Madison County, Montana. View is to north.

Display screens were mounted on a large table in the dining section of the trailer. An electronic heading sensor was placed on a shelf above the display but not fastened to the substrate. This permitted adjustment when the trailer moved in high winds. Power for both arrays was supplied by a 10-28 VDC, $10-\mathrm{kW}$ portable military gas generator. A second 10-kW portable military gas generator and two 12-volt deep-cycle Recreational Vehicle batteries, wired in parallel, were used as backup power.

\section{Siting and Positioning of Radars}

Autumn migrants approached NHWRA from the north. Therefore, the radar site during autumn migration was situated atop the highest grassy knoll (elevation $=1890 \mathrm{~m}[6200 \mathrm{ft}]$ ) within the northern portion of NHWRA, northeast $1 / 4$, section 12, T4S, R1W (see Fig. 4). The radar location permitted unobstructed scanning of the entire Wind Resource Area and a vast area to the north, east, and west. Vernal migrants approached from the south. Therefore, the radar site during vernal migration was situated atop the highest grassy knoll (elevation= $1914 \mathrm{~m}$ [6280 ft]) within the southern portion of NHWRA, southeast 1/4, section 12, T4S, R1W (see Fig. 5). This location provided maximum unobstructed scanning of NHWRA and vicinity in all directions and included the northern part of Ennis Lake, a migratory stopover site for waterfowl, shorebirds, and bald eagles. Both sites were easily accessible by vehicle, except in deep snow and mud. 


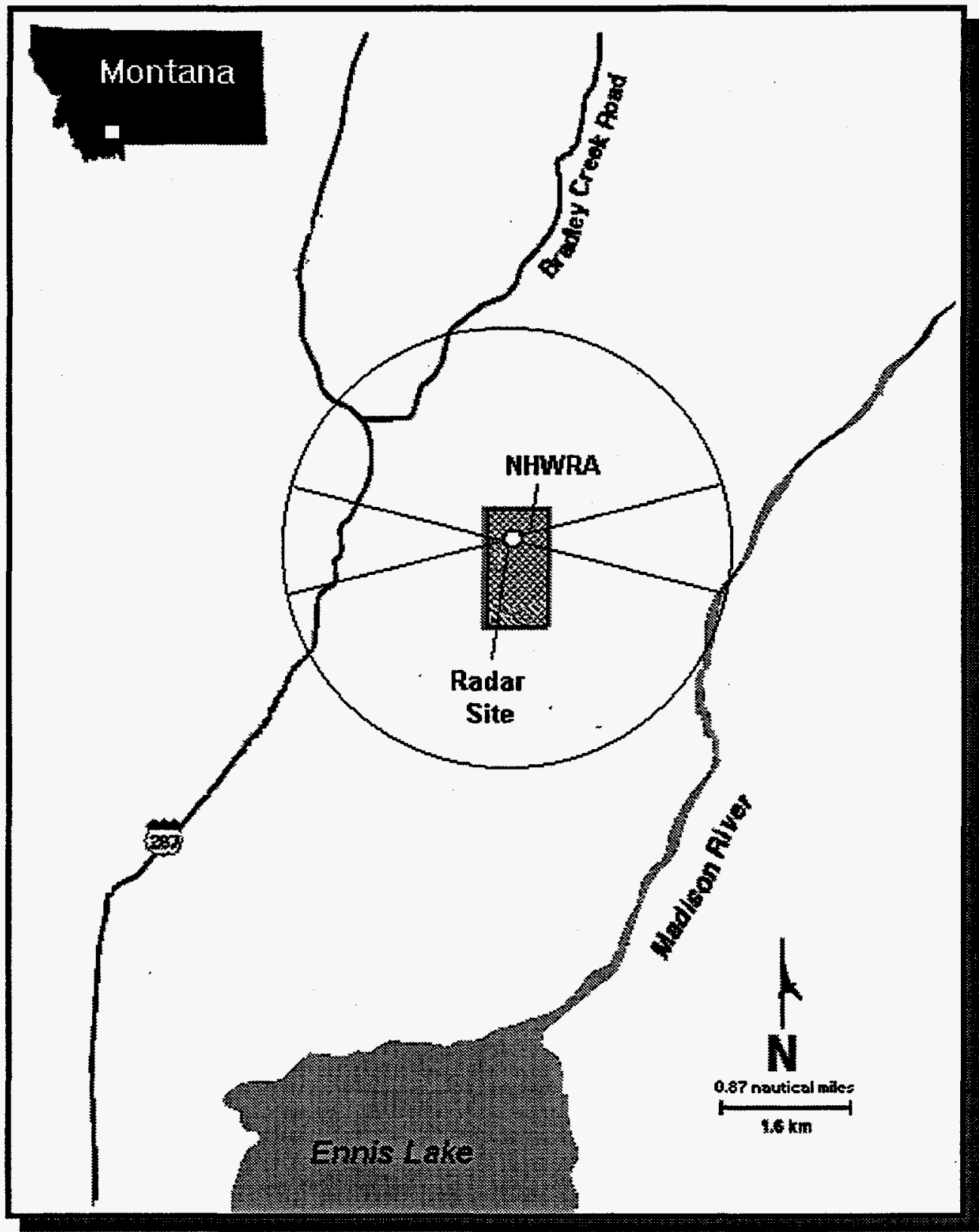

Figure 4. Relative location and surveillance range of scanning and vertical radars, autumn 1995. Circle is $1.5 \mathrm{~nm}(2.8 \mathrm{~km})$ surveillance diameter of scanning radar. Hour glass is horizontal surveillance area of vertical radar extending $2.8 \mathrm{~km}(1.7 \mathrm{mi})$ east and west of radar location. 


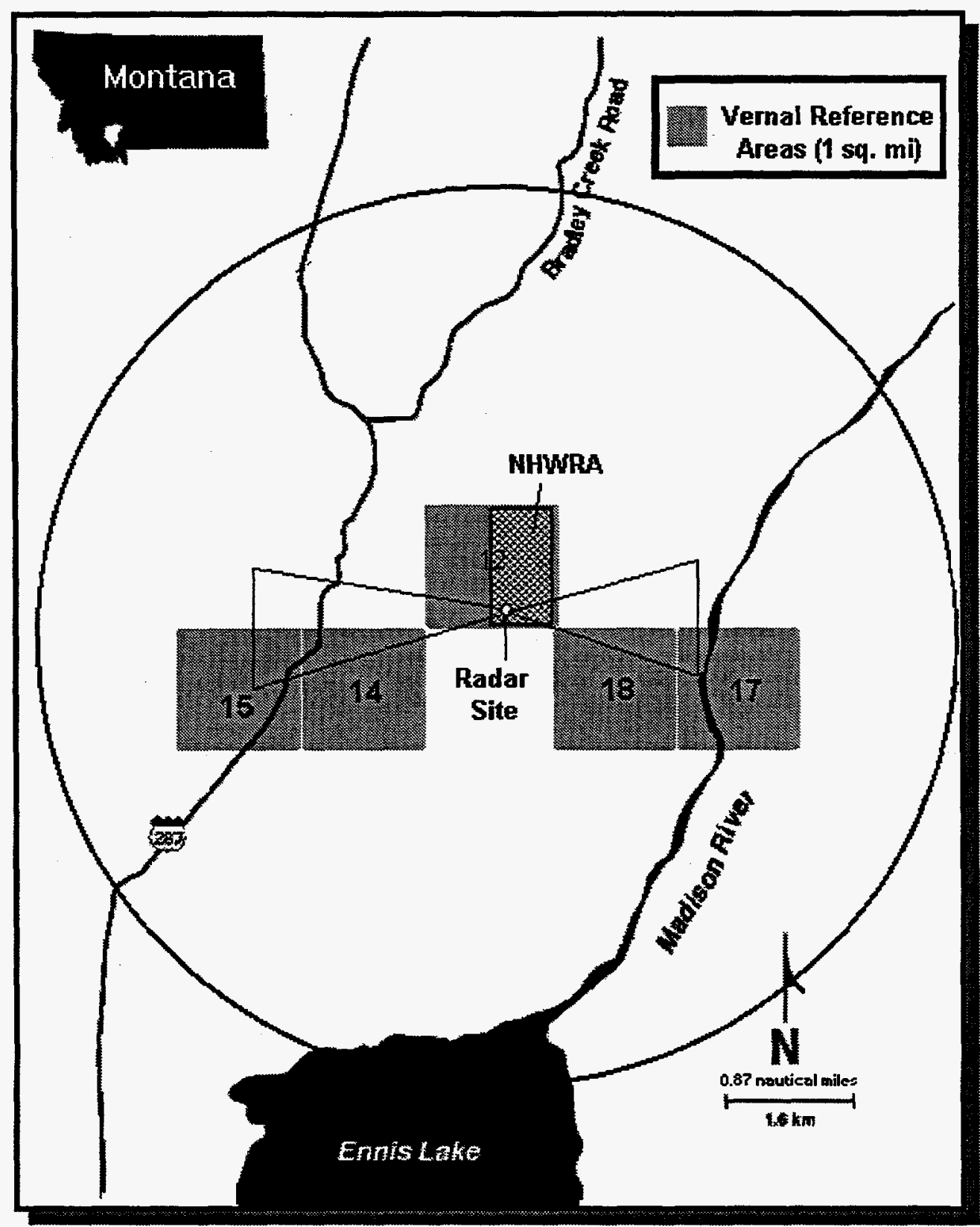

Figure 5. Relative location and surveillance area of scanning and vertical radars, NHWRA, spring 1996. Circle is $3 \mathrm{~nm}(5.6 \mathrm{~km})$ surveillance diameter of scanning radar. Hour glass is horizontal surveillance area of vertical radar. Asymmetry of vertical radar surveillance area, extending $3.2 \mathrm{~km}(2 \mathrm{mi})$ west and $2.3 \mathrm{~km}(1.4 \mathrm{mi})$ east was due to origin offset feature on the radar screen.

\section{Ground Clutter Reduction}

Topography produced identifiable radar signatures "ground clutter" on the scanning radar display screen. During autumn 1995, ground clutter obliterated a large portion of the radar screen. In an attempt to minimize clutter during spring 1996 monitoring, a ground clutter reduction screen recommended by Cooper et al. (1991) was fabricated and installed on the scanning radar. 


\section{Radar Interference Management}

Despite activation of the interference rejection (IR) mode in both radars, simultaneous operation of both radars soon revealed interference between arrays. Interference was manifested in pinwheel-like spirals, beginning on the periphery of the display screen and progressing toward the center or small dashes appearing randomly throughout the screen. Uncompensated for, these interference signatures would eventually obliterate the display. In an attempt to eliminate interference and on the recommendation of technicians at Raytheon, an alternate mounting scheme was developed and implemented for both pedestals. They were mounted on a 4.6$\mathrm{m}$ (15-ft) post of $10.2-\mathrm{cm} \times 5.1 \mathrm{~cm}$ (4-in. x 2-in.), 5-mm (3/8-in.) thick steel channel mounted vertically on a cement footing supported with guy wires. This placed the vertical antenna and pedestal above the scanning pedestal and antenna (see Fig. 6). The scanning antenna was shielded from radio frequency (RF) energy from the vertical antenna by a barrier of radar-absorbent material.

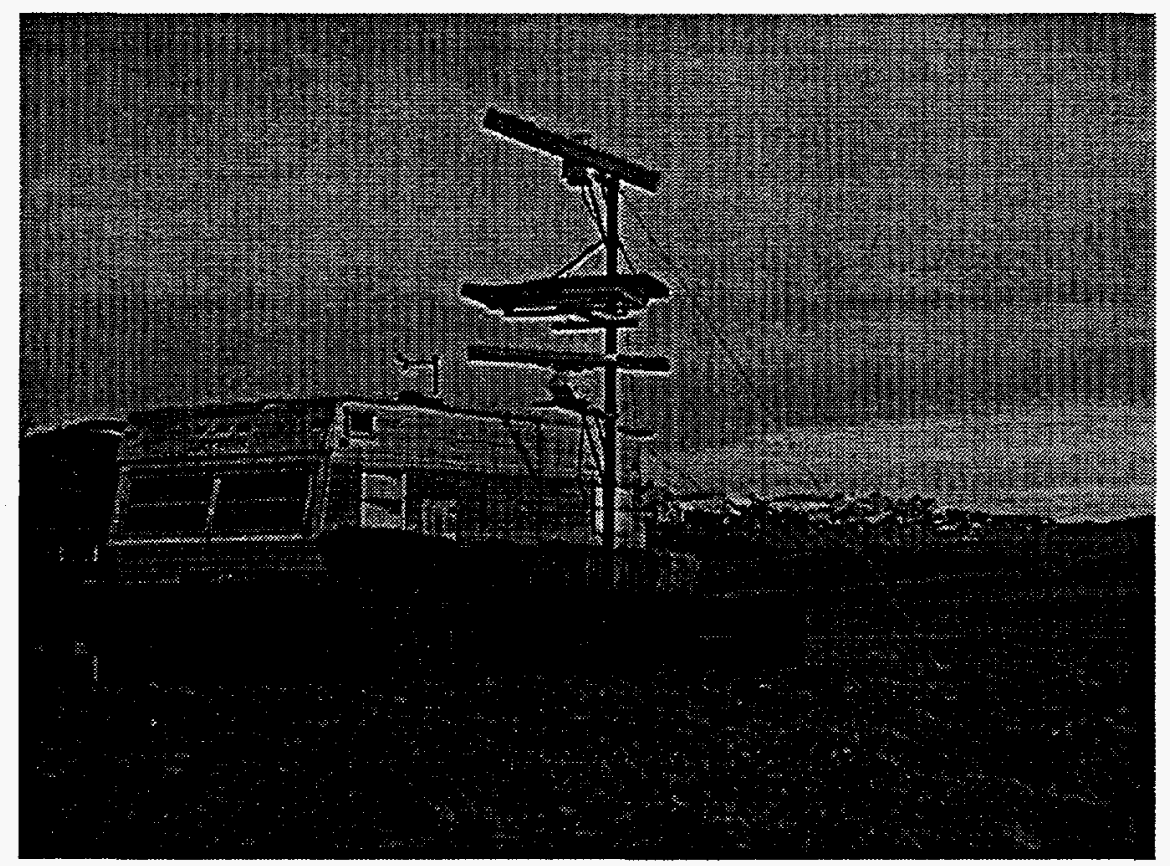

Figure 6. Scanning and vertical radar pedestal mount for interference management. 


\section{Data Logging and Recording}

During autumn 1995, range was set at $1.5 \mathrm{~nm}(2.8 \mathrm{~km})$ on both scanning and vertical radars. During spring 1996 , only scanning radar data collected at range setting $3 \mathrm{~nm}(5.6 \mathrm{~km})$ was analyzed. Range setting was again $1.5 \mathrm{~nm}(2.8 \mathrm{~km})$ for vertical radar. Radars were operated during daylight and darkness. Number and time of monitoring periods per day varied to accommodate logistics, accidents, weather, and exhausted technicians while attempting to provide as close to an even distribution of effort over all hour periods in one week as possible.

An individual target (or "echo") detected on the radar screen was considered an event. An event may have consisted of a single bird or many birds of several species, grouped tightly enough to present one signature per antenna rotation on the display screen. In autumn 1995, data associated with each event were recorded on a data sheet (Appendix A2). A copy of a 71/2 minute U.S. Geological Survey (USGS) topographical map of NHWRA and vicinity accompanied the data sheet on which the radar site and range rings were displayed. Davis Weatherlink $\Pi^{\mathrm{TM}}$ hardware and software displayed and logged on-site wind velocity, direction, and barometric pressure associated with event records. Event paths relative to clutter were plotted on the map using unique (to that sheet) combinations of colors and patterns, with each event and pattern indexed on the front of the data sheet. Ground level was clearly identifiable on the vertical radar and Variable Range Marker (VRM) capability on the screen provided accurate distance (i.e., altitude) measurement above the radar. Each event and associated data were afforded a record line on the data sheet. In an attempt to identify migrants to group (e.g., diving vs. dabbling ducks) speeds of radar events were initially determined by the elapsed time over a measured distance on the screen. Subsequently, when operators became more familiar with the system (spring 1996), the AQUIRE mode of the radar, which automatically tracked events and calculated speeds, was used. Additionally, an accessory Heading Sensor provided bearings of migratory movements relative to true north in spring.

By mid-season (October 1995) it was obvious the data sheet was inadequate, but too much time and activity had passed to revise the sheet and still maintain consistency and utility of data already accrued. The data sheet was completely revised prior to spring 1996 monitoring (Appendix A3). This data sheet was appropriate for use during nonpeak periods, but as the magnitude of migratory movement increased beyond all expectations, the data sheet became too cumbersome to accurately capture the magnitude of events during peak movement periods. A "Tally Sheet" was devised for use during busy ( $230 \mathrm{events} / \mathrm{min}$ ) periods (Appendix A4). The tally sheet eliminated many of the variables that previously were recorded for every target detected by radar (e.g., distance, altitude, direction of a flight path). Instead, tally sheets focused effort on counting total number of events and where they occurred.

NHWRA was defined as the Impact area. However, true "Control" areas could not be randomly selected because independent areas that exhibited similar meteorology, elevation, topography, and vegetation as NHWRA did not exist within radar range. Constraints imposed by influence of local topography on scanning area (i.e., hills shielding certain areas) further limited options for designating control areas. Accordingly, areas adjacent to NHWRA that were well within effective range of scanning radar were identified and termed "Reference" rather than "Control" areas. Screen overlays were constructed that displayed Impact and Reference areas in spring 1996 (n.b., Fig. 5). The overlays facilitated rapid data recording on tally sheets and insured consistency of data collection with BACI design.

Monitoring of the scanning array was emphasized during busy periods, and a range setting of $3 \mathrm{~nm}$ was used most often. All events detected in NHWRA and each Reference area were recorded for a 3-min interval and entered on the tally sheet. The radar screen was cleared and $1 \mathrm{~min}$ passed before beginning the next 3-min count interval. This ensured that targets previously displayed had moved completely out of tally areas, thereby avoiding double-counting events. During periods of intense migration activity during spring 1996, all flight paths still could not be recorded on tally sheets. At these times, observers recorded estimates of percentage 
of overall migration activity they believed they were able to accurately record from the scanning radar screen. These data-capture percentages, normally estimated for $15-\mathrm{min}$ to 1 -hr periods, were then used to adjust numbers of events recorded to more accurately reflect the magnitudes of migration during peak activity periods. For example, if an observer estimated $70 \%$ data capture for a given interval, the number of events recorded during that interval were divided by 0.70 .

Information on data sheets for each season was entered into the database utility of STATISTICA ${ }^{\mathrm{n}}$ (StatSoft 1995). The autumn 1995 database contained 44 fields (Appendix B2); each event and associated data were included in one record. Spring 1996 data was entered into two databases: one for scanning radar data (see Appendix B3) and one for vertical radar data (see Appendix B4).

\section{Ennis Lake Surveys}

Ennis Lake, $4.8 \mathrm{~km}$ ( $3 \mathrm{mi}$ ) south of NHWRA, is a 202-hectare (500-acre) impoundment of the Madison River that is a migratory stopover for waterfowl, eagles, shorebirds, and other water-associated species. All waterfowls, shorebirds, and raptors on or within $100 \mathrm{~m}$ (328ft) of Ennis Lake were periodically counted during the autumn 1995 and spring 1996 migration seasons, as well as during part of the 1996 breeding season.

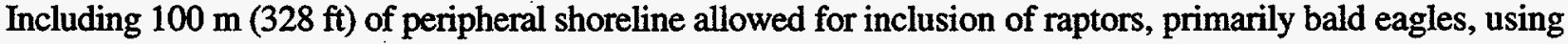
the lake but perched in trees or on power poles along the lake shore. Lake counts were used to add perspective to, and allow comparison with, the profile of avian movement results as determined by radar. Observers used 7.5-15X binoculars and a 20-60X window-mounted spotting scope to count and identify species, when possible, all birds in the vicinity of the lake visible from two roads paralleling the east and north shores of the lake (see Fig. 1) and from pullouts at the four comers of the lake. Attempts were made to conduct surveys at least biweekly.

\section{Use of NHWRA and Vicinity by Breeding and Local Nonraptorial Birds}

Resident breeding and local birds were surveyed by point counts (Ralph et al. 1993). Nest searches for waterfowl were not conducted. Point counts were conducted between 30 May and 7 July 1996, on days with calm winds (rare) and usually between 0500 and $1000 \mathrm{hrs}$. Counts were made at 49 sites. Sites were $\geq 250$ $\mathrm{m}(820 \mathrm{ft})$ apart to maintain independence among sites. Six sites were within NHWRA and 43 outside of NHWRA distributed over 8 routes (see Fig. 7). Each site was surveyed three times for a total of 147 counts with an average of 10 counts made per day. An observer counted birds visually or by song at distances up to

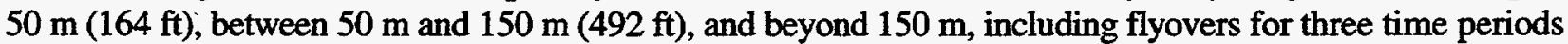
each: $3 \mathrm{~min}, 5 \mathrm{~min}$, and $10 \mathrm{~min}$ (see data sheet Appendix A5). Three time regimes ensured comparability with other studies; most use 3- or 5-min count periods, but some use $10 \mathrm{~min}$.

Vegetation was analyzed within $150 \mathrm{~m}$ (492 ft) of each point count location in summer 1994 to determine summer vegetative associations of neotropical migrant land birds. Dominant species (Appendix E), geographical attributes (e.g., elevation, and slope), percent cover of soil, rock and vegetation, and height was recorded at each site. 


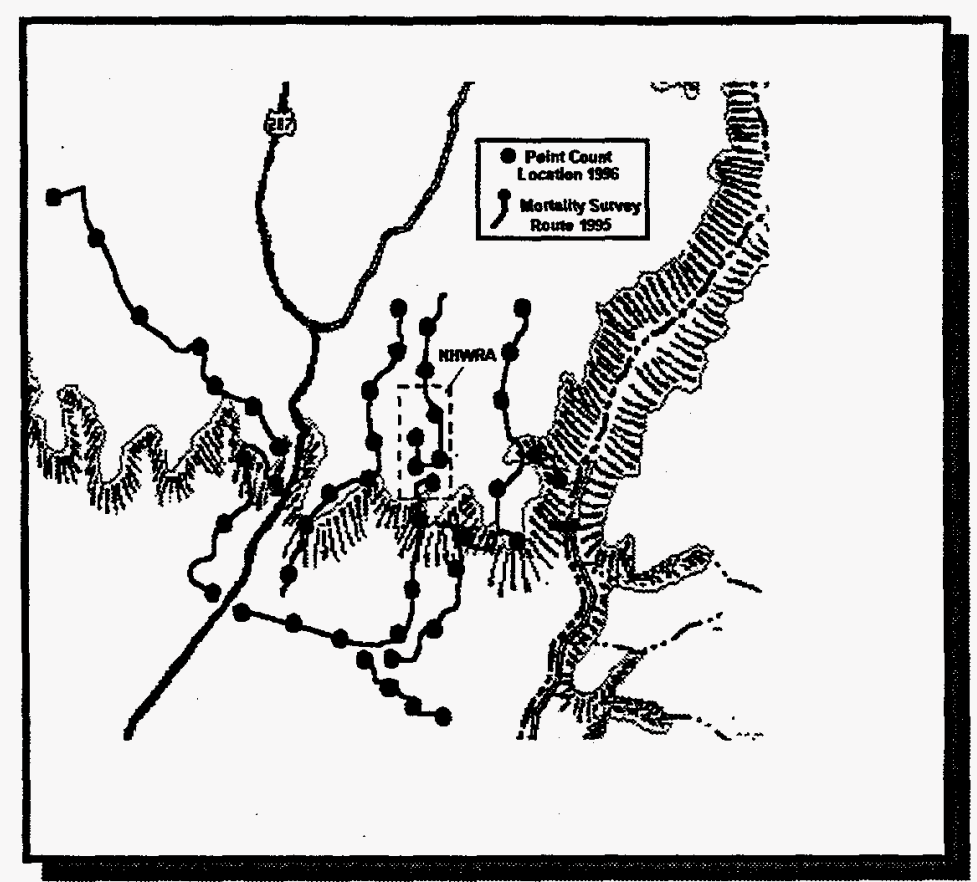

Figure 7. Point count locations spring/summer 1996 and mortality survey routes in 1995, in and near NHWRA.

\section{Use of NHWRA by Breeding and Local Raptors}

Total wind power development may extend up to $9.6 \mathrm{~km}(8 \mathrm{mi})$ west-northwest of NHWRA when complete and some raptors may forage up to $25 \mathrm{~km}(16-\mathrm{mi})$ from their nest site (Tyus and Lockhart 1979; Harmata and Oakleaf 1992). Therefore, a circular area within a $25-\mathrm{km}$ (16-mi) radius from the center of NHWRA was surveyed for raptor breeding areas. Nest searches in heavily forested areas were precluded by labor and time constraints. Aerial and ground surveys were employed for locating raptor nest sites and eyries (Fuller and Mosher 1987). Likely raptor nesting sites were searched from the air in a Piper Super Cub and noted for further inspection on the ground. Raptor breeding areas were identified primarily by the presence of at least one adult near (within $800 \mathrm{~m} \mathrm{[1/2} \mathrm{mi])} \mathrm{a} \mathrm{stick} \mathrm{nest} \mathrm{or} \mathrm{eyrie,} \mathrm{either} \mathrm{during} \mathrm{surveys,} \mathrm{serendipitous} \mathrm{observations,}$ or from historical data. Raptor sites detected during aerial and ground surveys were plotted onto 1:62,500 USGS topographic maps. Number of breeding sites, distance and direction from the NHWRA boundary to the nearest site was recorded for each species. Searches were conducted only to determine location of breeding areas and species that occupied or built nests and not to determine nesting phenology or productivity.

Capture of adults of each pair of golden eagles (A. chrysaetos) associated with breeding areas within $10 \mathrm{~km}$ (6 mi) of the NHWRA were accomplished using padded leg-hold traps (Harmata 1985) and a radio-controlled bow net (Jackman et al. 1994).

Captured adult golden eagles were fitted with 3-g (1.2-oz.) radio transmitters, $148 \mathrm{MHz}$ frequency band, ninemonths estimated life. Transmitters were attached to the center two tail feathers by Vetafil $^{\mathrm{TM}}$, a veterinary suture material. Long-lived ( $>1$ yr) backpack transmitters were fitted to nestling bald eagles. Eaglets were lowered from the nest at six weeks of age, banded with USFWS bands and blue over silver colorbands, measured, and then two adjacent secondary feathers were notched for visual identification. The eaglets were then radio-tagged and returned to the nest. Backpack transmitter straps were secured with cotton sutures, thus ensuring release of the package within three years.

Radio-tagged eagles were monitored by a single tracker at a stationary site within NHWRA. The tracker monitored frequencies of radio-tagged eagles sequentially. Once detected, the radio-tagged eagle was verified 
as to only "In" or "Out" of NHWRA. The monitoring scheme was variable and flexible, but designed to provide as much coverage of each diurnal hour period as funding and manpower allowed. The primary objective of monitoring was not to record extensive movements, but rather to determine, at minimum, if radiotagged eagles visited NHWRA during monitoring.

Bald eagles associated with a breeding area within $3 \mathrm{~km}(1.9 \mathrm{mi})$ of NHWRA were observed to determine their use of NHWRA. Two observers were located at observation points $3 \mathrm{~km}$ (1.9 mi) apart on the west Madison River Canyon rim (n.b., Fig. 1). One observer was in view of the nest site at all times while the other had a clear view of the entire NHWRA. Both communicated via voice radio, each alerting the other to the location or absence of bald eagles.

Use of NHWRA by other resident and local raptors (e.g., falcons, harriers [Circus spp.], buteos) was determined by a combination of visual and radar monitoring. Raptor use monitoring occurred between 1 July and 15 August 1996; the schedule was designed to sample each diurnal hour as evenly as possible. Three visual observers were stationed at strategic points along the NHWRA boundary to watch for raptors entering the NHWRA. A radar technician monitored the radar screen simultaneously to scan for targets. All communicated via voice radio and alerted each other to targets. Visual observers used 7.5-15X binoculars and continually scanned the NHWRA and periphery for the presence of raptors and other birds. The radar operator monitored the NHWRA and surrounding area using the scanning radar array, which was usually set at 1.5-nm $(2.8-\mathrm{km})$ range (vertical was not functioning and/or returned for repairs). Birds or targets were recorded according to method of initial detection (i.e., visually or by radar) and whether subsequently confirmed by the other monitoring technique. Targets that were visually confirmed were identified as to species. Number of minutes in NHWRA (bird-use minutes) and a visual estimate of average height (in $\mathrm{m}$ ) above ground level (AGL) were recorded for all raptors (turkey vultures [Cathartes aura]) and ravens [Corvus corax]) were considered raptors in this study) that entered the NHWRA. Observations were conducted during four time categories: 1) morning (0600-0959), 2) midday (1000-1359), 3) afternoon (1400-1759), and 4) evening (18002100). Evaluation of the effect of observer presence on raptor use could only be determined subjectively.

\section{Assessment of Avian Mortality}

Ground line transects were covered by pedestrians or bicyclists, who searched for dead or dying birds or indication that birds had been injured or killed (e.g., feather piles, bones or fragments, and blood trails) within the NHWRA and vicinity. Nine transects consistent with point count routes covered in 1995 were used (see Fig. 8). Transects were designated as either "In" or "Out" of the NHWRA. Transect routes were modified in 1996 to include more linear distance "In" and less "Out" of the NHWRA. One transect followed a power line corridor that transverses the northeast $1 / 4$ of the NHWRA and vicinity for $1.5 \mathrm{~km}(0.93 \mathrm{mi})$ in both years (see Fig. 8). Transects were covered between 30 May 1995 and 1 August 1996, except during periods of inaccessibility due to snow ( $\approx$ mid-December-mid-March). Otherwise, selection of time of day and day of week for mortality surveys was random, driven by logistical and scheduling considerations. Number of replicates for each transect varied from none to six in 1995. All transects were replicated seven times in 1996. No effort was made to evaluate removal or habitat biases during mortality surveys, but relative abundance of mammalian scavengers was noted along transects. Cause of death was assigned to all carcasses or evidence of mortality found and proportional mortality determined (e.g., unknown, predation, starvation, or blunt trauma). Necropsies were not performed. Cause of death was determined by gross inspection of carcasses by field personnel. 


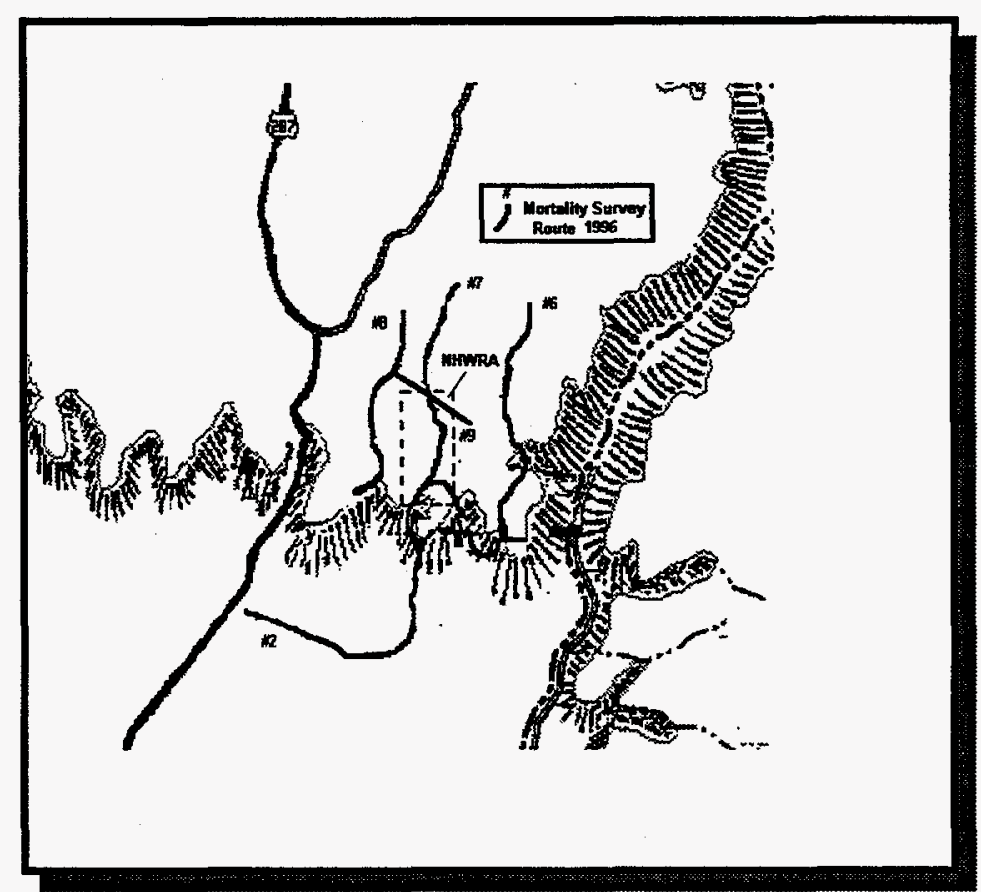

Figure 8. Routes for avian mortality surveys in and near NHWRA, spring/summer 1996.

\section{Efficacy of Visual and Radar Monitoring}

\section{Observations}

Four types of observation schemes were employed during migration periods (autumn, spring). Solo Radar and Paired Radar monitoring were designed to strictly gather data. Solo Radar monitoring involved one observer monitoring both radar screens and was completed most often in autumn 1995. Paired Radar monitoring involved two observers, each monitoring a radar screen. This scheme was employed to maximize data recording during periods of intense activity, usually at night, and was completed most often in spring 1996.

Paired Verified and Paired Silent monitoring schemes were designed to test the efficacy of monitoring techniques (visual or scanning radar) while also gathering data. Verification schemes were used only during daylight hours. Use of night scopes in verification monitoring was rejected after one attempt: small depth and field of view and cumbersome focusing of night scopes made acquisition of moving targets virtually impossible.

Paired Verified monitoring involved two observers simultaneously and independently scanning, one by scanning radar and one visually. The visual observer directed scanning in the direction of oncoming migratory birds, i.e., to the north in autumn and south in spring, searching at least $180^{\circ}$ while the radar obligatorily searched $360^{\circ}$. Each observer alerted the other to targets detected, communicating by two-way voice radios. Paired Silent monitoring involved simultaneous scanning by radar and visual observers, who did not communicate. Paired Silent observers searched directions and degrees as Paired Verified observers were monitoring, but were oriented so neither could see the other and thus be alerted to presence of a target. The visual observer during both Paired Verified and Paired Silent observations was usually inside a vehicle (due to high winds and inclement weather) $100 \mathrm{~m}$ (328 ft) north of the radar trailer north-center, northwest $1 / 4$, Sect. 
12 in autumn and center, southeast $1 / 4$, Sect. 12 in spring (see Fig. 1). Data derived from summer Raptor Use Observations (above) were also included in analysis of efficacy of monitoring techniques.

Vertical radar data were not included in efficacy analysis because vertical radar was not used independent of scanning radar when paired observations were conducted. Visual observers always scanned $360^{\circ}$ while the vertical radar was restricted to a $24^{\circ}$ maximum surveillance area, $180^{\circ}$ above the antenna. Area searched was not comparable.

\section{Model Aircraft Flights}

A radio-controlled model airplane was flown from points around and in the NHWRA up to $6 \mathrm{~km}(33 / 4 \mathrm{mi})$ distant from the radar to test detectability by radar at various heights and distance. Use of the model aircraft also assisted in identifying signature characteristics of targets on screen. A 91-cm (36-in.) long x 15-cm (6in.) deep "Piper Cub-type" remote-controlled model airplane with a 1.4-m (55-in.) wingspan was used to measure the ability of scanning radar to detect a "hawk-sized" target at different altitudes and distances from the radar antenna. Potential sites and cardinal directions of flights were determined based on a distance category from radar (500 m [1640 ft]) intervals, beginning $500 \mathrm{~m}$ [1640 ft] from the radar site), the absence of ground clutter on the radar screen, and access. A stratified random sample of sites and flight directions was then drawn from the pool of 50 potential sites.

The airplane was flown three times over a 400-600 m (1312-1969 ft) level flight path in each cardinal direction at each selected site (12 flights at each site). Each flight in one direction began at a different height AGL. Height categories were low (0-15 m [0-49 ft]), medium (15-60 m [50-(197 ft]), and high (>60 m [197 $\mathrm{ft}$ ) AGL at the starting point. Heights at flight starting points were estimated using a graduated staff (similar to a forester's cruising rod), and practice flights showed that the pilot could keep the plane in level flight (if he could see it), usually very close to the middle of each starting height category. Although the plane flew straight and level, height AGL over the duration of the flight varied considerably. Height at the end of the flight path was determined from a topographic map, and height AGL at both the start and end point of each flight were used as flight locations in radar efficacy analysis.

A single radar operator, using the three scanning arrays, was alerted at the start of each flight but did not know flight location, direction, or altitude. Up to three flights were flown at each altitude for a given location and flight direction. The radar operator was instructed as to which range setting $(0.75,1.5$, or $3 \mathrm{~nm})$ to use during detection attempts because some flight locations were too distant to be visible to the radar at lower range settings. For each flight the radar operator recorded range setting and, if the plane was detected by radar, drew the flight path on a map of the study area. 


\section{Data Compilation and Analysis}

Data collection methods, type, and amount varied throughout the study. Most differences were in collection methods for radar monitoring of avian migration between autumn 1995 and spring 1996, as illustrated by differences in data sheets (Appendices A2 and A3). As a result, considerable effort was expended in data management, compilation, and analysis to promote compatibility of seasonal data sets. Methods of compilation and analysis evolved throughout the study. Where methods of data compilation were not obvious or straightforward, involved subtleties inflicted by data peculiarities, or were complicated, specifics are noted below. Otherwise, data were compiled to promote comparisons by simple statistical tests. Tests used for specific data sets are presented in Results.

\section{Impact Analysis}

Impact analysis followed the BACI design (Green 1979). Units of avian use (e.g., number of events and minutes) were identified as having occurred "In" or "Out" of the NHWRA, where "In" and "Out" categories represented "Before-Impact" and "Before-Reference." Reference areas differed between migration seasons and are defined below. Data were collected and analyzed in a manner intended to allow comparison with "After-Impact" and "After-Reference" data that may be collected, should NHWRA be developed and followup avian-use studies completed. BACI data were presented with the assumption that "After" data will be collected by identical methods in the same areas as "Before" data.

Four major aspects of avian use of "Impact" and "Reference" areas were investigated: 1) use by migratory birds, 2) use by breeding and local nonraptorial birds, 3) use by breeding and local raptors, and 4) assessment of avian mortality. Use by migratory birds was investigated by comparing events detected with marine surveillance radars in "Impact" and "Reference" areas. Use by breeding and local nonraptorial birds was compared in terms of species abundance and diversity as determined by standard point count methodology. Use by breeding and local raptors in "Impact" and "Reference" areas was assessed by comparing numbers of observations gathered by radiotelemetry and visual observations. Avian mortality was explored by comparing the number of dead birds detected in "Impact" and "Reference". areas. For all comparisons, differences existed if $P \leq 0.05$ and were considered statistically significant, unless otherwise stated. $P$ values 20.05 indicated no difference between or among samples. Samples were either "different" or not, to avoid continual use of the terms significant(ly).

\section{Use of NHWRA and Reference Areas by Migratory Birds}

Use of NHWRA and Reference Areas by migratory birds was determined by number of events detected "In" and "Out" by both scanning and vertical radars. Both scanning and vertical radar data were analyzed independently to describe horizontal profiles, i.e., distribution of migration relative to horizontal distance from radars. Only vertical radar data were analyzed to describe altitudinal profiles of use.

\section{Horizontal Profile}

In autumn 1995, the number of events detected within the entire $360^{\circ}$ surveillance areas around the scanning radar was included in analysis. The autumn Reference area ("Out") was the entire surveillance area excluding NHWRA. Vertical radar data used in analysis included events that passed through the linear curtain of radar that extended east, west, and above the antenna (see Figs. 4 and 5), and were collected at a range setting of 1.5 nm.

In spring 1996, total numbers of events detected "In" and "Out" of NHWRA by scanning radar were determined by combining data from both standard data sheets and tally sheets (see Data Logging and 
Recording, pg. 10). Only events detected in NHWRA or Reference areas were included in analysis because only data for those areas were recorded on tally sheets. Vertical data from 1996 were analyzed, as were those from 1995.

\section{Altitudinal Profile}

Altitudes of events recorded relative to height of a vertical radar antenna in both autumn 1995 and spring 1996 were placed into three categories: Low (0-61 m [0-200 ft]), Medium (62-250 m [203-820 ft]), and High ( $>250 \mathrm{~m}$ [820 $\mathrm{ft}]$ ). The Low category was selected based on the consideration that proposed wind turbine configurations may reach $45 \mathrm{~m}(148 \mathrm{ft})$ in height and because birds may easily deviate $15 \mathrm{~m}(49 \mathrm{ft})$ or more in altitude while flying over NHWRA. In both years, the vertical radar covered the entire width of the NHWRA as well as the majority of the migration corridor between the Madison River Canyon to the east and Highway 287 to the west of NHWRA. Resulting distributions of altitudes (Low, Medium, High) were reported "In" and "Out" of the NHWRA.

Because radar detectability decreased by unknown probability with increasing distance and height of targets, and because ground level dropped off in all directions from radar location, event altitudes "In" and "Out" of the NHWRA were analyzed within two maximum distances from radar: 0-805 m (1/2 mi) and 0-2800 $\mathrm{m}(1.7$ $\mathrm{mi})$. The $0-805 \mathrm{~m}(0-1 / 2 \mathrm{mi})$ category included equal surveillance area "In" and "Out" because the radar was located on the western boundary of the NHWRA. Mean altitudes relative to radar were calculated for targets "In" and "Out" of NHWRA both years. Altitude of events detected by vertical radar in autumn 1995 and spring 1996 relative to the radar antenna was converted to elevation in m AGL. To illustrate event altitudes

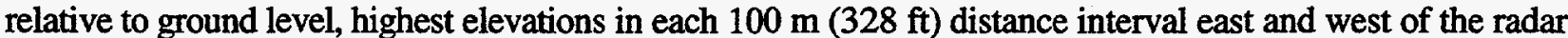
was determined from contour lines on $7 \frac{1}{2}$ ' topographical maps of the study area. Highest elevation was considered ground level in each distance interval. However, because direction (east or west) and distance from radar (other than a range ring of occurrence) were not recorded during autumn 1995 monitoring, precise relationship to ground level could not be displayed for events detected in autumn.

\section{Spatio-temporal Profile of Use of NHWRA and Vicinity}

\section{Migratory Birds}

Spatial and temporal use patterns of NHWRA and vicinity by migratory birds were defined by distance, altitude, and passage rate of events detected by radar. The intent of analysis was to describe patterns of movement directionally (horizontally) and altitudinally (vertically) from the radar. Scanning and vertical radar data were analyzed independently to describe a horizontal profile, i.e., distribution of migratory events relative to horizontal distance from radars, and to compare surveillance techniques. Vertical radar data were analyzed to describe altitudinal profiles of migratory events. Scanning radar provided data for temporal description of use in autumn 1995, while both scanning and vertical radar data were used for temporal analysis in spring 1996.

BACI analysis and previous study (Harmata 1995) indicated raw numbers of events detected by radar did not accurately reflect spatial distribution of migratory events. The farther from the radar, the less likely events were to be detected. Also, it was clear that smaller targets (e.g., passerines) were not being detected as far away from the radar as larger targets, such as American white pelicans (Pelicanus Erythrorhynchos), swans (Olor spp.), eagles, or flocks of birds. To more accurately depict spatial relationships, the number of events detected at increasing distances needed to be inflated to account for a decline in detection capability of radar at increasing distances. No other radar ornithology study reviewed presented methods of data analysis addressing the concept of detectability of different-sized birds at increasing distances and the effect on interpretation of results. Commercially available radar analysis software included methods to evaluate 
detectability of different-sized targets at different ranges. However, upon inspection of the manual associated with the program, it became clear that much of the material was beyond the scope of this study. Detectability analysis provided only "probability of maximum detectable distance" of targets of different cross-sectional area. This probability was very different from overall probability of detection of different-sized targets at different ranges. Also, capacity of birds to reflect radar waves probably was more a function of the configuration rather than mass (i.e., a B-117 bomber probably has less reflective capacity than a pelican and a falcon less than a raven). Therefore, to obtain an index of detectability and more accurately represent use of the area by migratory birds at distances $>500 \mathrm{~m}$ from the radar, detectability methods of standard avian sampling techniques were employed. Point transect or line transect analyses (Burnham et al. 1980) were used to construct detection probability curves from raw numbers of events detected (DOS program DISTANCE, Laake et al. 1993).

\section{Horizontal Profile}

Autumn 1995. Point transect analysis from the DISTANCE program was applied to scanning radar data. Accordingly, scanning radar was considered a stationary observer. However, because only the range ring in which an event occurred was recorded in autumn 1995, and not distance and direction from radar, location of each event was the range ring in which it occurred at its closest point of approach to the radar. Therefore, each event was assigned to one of 6 range rings representing distance categories from radar: $1=0-402 \mathrm{~m}(0-1319$ ft), $2=403-805 \mathrm{~m}(1322 \mathrm{ft}-1 / 2 \mathrm{mi}), 3=806-1207 \mathrm{~m} \mathrm{(1/2-3/4} \mathrm{mi),} 4=1208-1609 \mathrm{~m}(3 / 4-1 \mathrm{mi}), 5=1610-2414 \mathrm{~m}$ $\left(1-1 \frac{1}{2} \mathrm{mi}\right)$, and $6=2415-3219 \mathrm{~m}\left(1 \frac{1}{2}-2 \mathrm{mi}\right)$. Distance categories did not match range rings displayed on the radar screen and those in range ring six were excluded from analysis because it was not entirely visible on screen. Numbers of events in each range ring were imported into the DISTANCE program to generate detection-probability curves. DISTANCE selected the best fit model using Akaike's Information Criterion (AIC, Buckland et al. 1993) as well as detectability cut off points.

Line transect methodology was applied to vertical radar data because only targets that passed to the east or west of the radar antenna could be detected by the vertical "curtain" of radar. In this case, the radar antenna was treated as an observer moving along a north-south transect, recording distances to events detected to the east or west. Each event was assigned to one of six horizontal distance categories corresponding to range rings used for scanning radar analysis, above. Number of events in each distance category was recorded and imported into DISTANCE, which generated a detection-probability curve.

Number of events detected by either radar array in each range ring or distance category was adjusted for detectability by dividing actual number of events by probability of detection in each respective range ring or distance category. Expected number of events per range ring was calculated by multiplying the total adjusted number of events by the area (ha) of each range ring (range ring 6 was excluded because its entire area was not visible on the radar screen) for scanning data and linear width (in $\mathrm{m}$ ) of the range ring for vertical data.

Number of events detected by each array was corrected relative to surveillance area to compare within- and between-season differences in migration intensity and account for surveillance area size differences. Adjusted number of events was presented as events/hectare $/ \mathrm{hr}$ monitored for scanning radar data and events $/ \mathrm{m} / \mathrm{hr}$ monitored for vertical radar data.

Spring 1996. Events detected by scanning radar that were recorded on standard data sheets were corrected for data capture percentage (see Data Logging and Recording, pg. 10) and combined with data recorded on tally sheets. This was accomplished by assigning events detected on tally and standard data sheets into one of three distance categories based on where they occurred: $1=0-805 \mathrm{~m}(1 / 2 \mathrm{mi}), 2=806-2414 \mathrm{~m}(1 / 2-11 / 2 \mathrm{mi})$, and $3=2415-3219 \mathrm{~m}(11 / 2-2 \mathrm{mi})$. Categories were consistent with distance to the nearest boundary of the NHWRA and one of five Reference areas from radar (see Fig. 5). 
Number of events detected by scanning radar in each distance category was adjusted by detection probability as determined by the DISTANCE program. However, line transect methodology rather than point transect methodology (Autumn 1995 analysis) was employed because flight paths at their closest to the radar could only have been to east or west of the radar antenna and still be detected within the NHWRA or Reference units. In this case, the radar antenna was treated as an observer moving along a north-south transect recording distances to events detected in the NHWRA or Reference areas to the east or west. Numbers of events were adjusted for detectability by dividing the observed number of events by the probability of detection for NHWRA or Reference units. Expected numbers of events were calculated by multiplying the sum of adjusted events by the relative areas (ha) of the NHWRA or corresponding Reference units for comparability with 1995 data.

Horizontal profile analysis with vertical radar in spring 1996 improved considerably over other analyses because of quality and resolution of data capture. Distances (m) from the radar antenna to targets were measured directly from the radar screen using the VRM utility and with enough precision to allow assignment to $100 \mathrm{~m}$ ( $328 \mathrm{ft}$ ) distance categories up to $3.2 \mathrm{~km}$ ( $2 \mathrm{mi}$ ) from the radar. Further, direction east or west of the radar was also recorded.

Number of events detected in each $100-\mathrm{m}$ (328-ft) category was compiled. However, because some targets in a portion of the first $100-\mathrm{m}$ category to both east and west was not detectable, these categories were excluded from analysis. Corrected data were imported into DISTANCE to generate a detection-probability curve (events detected only visually or by scanning radar were not included). Line transect methodology was used because only targets that passed to the east or west of the radar antenna could be detected by the vertical

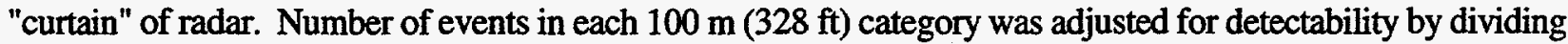
the actual number of events detected by probability of detection for a given category. Expected number of events per 100-m (328-ft) category was expressed as mean number of events per category. Numbers of events per 100-m (328-ft) categories were presented as adjusted numbers of events $/ \mathrm{m} / \mathrm{h}$ monitored to compare withinand between-season differences in migration intensity.

To compare migration intensities across the study area, $100-\mathrm{m}$ (328-ft) distance categories were grouped into larger intervals: $1=100-499 \mathrm{~m}(328-1637 \mathrm{ft}), 2=500-999 \mathrm{~m}(1640-3278 \mathrm{ft}), 3=1000-1499 \mathrm{~m}(328-14918$

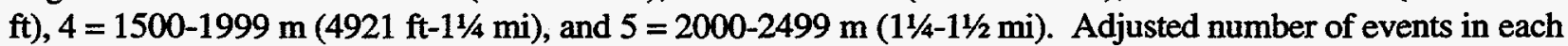
larger distance category was the sum of adjusted events in 100-m (328-ft) categories. Expected numbers of events per category were calculated by multiplying the sum of adjusted events by the relative distance (m) of the corresponding coarse category.

To illustrate within- and between-season differences in migration intensity for scanning radar data, numbers of events in NHWRA and Reference units were expressed as adjusted numbers of events/ha/h monitored.

\section{Altitudinal Profile}

Altitudes of events detected by vertical radar were calculated relative to radar and to ground level as for Impact Analysis (see Altitude Profile, pg. 17). Events detected by vertical radar in autumn 1995 were assigned to one of six horizontal distance categories corresponding to range rings: $1=0-402 \mathrm{~m}(0-1319 \mathrm{ft}), 2=403-805 \mathrm{~m}$ $(1322 \mathrm{ft}-1 / 2 \mathrm{mi}), 3=806-1207 \mathrm{~m}(1 / 2-3 / 4 \mathrm{mi}), 4=1208-1609 \mathrm{~m}(3 / 4-1 \mathrm{mi}), 5=1610-2414 \mathrm{~m}(1-11 / 2 \mathrm{mi})$, and $6=$ 2415-3219 $\mathrm{m}\left(1 \frac{1}{2}-2 \mathrm{mi}\right)$. Median and quartile elevations of events that occurred within each range ring distance category, east and west of radar, were calculated and plotted at $100-\mathrm{m}(328-\mathrm{ft})$ intervals relative to ground-level elevation.

Increased resolution of data collection in spring 1996 permitted altitudes relative to the radar to be plotted more precisely relative to ground level. Ground-level and median and quartile elevations of events that occurred 
within $100 \mathrm{~m}(328 \mathrm{ft})$ distance categories were calculated and plotted relative to ground-level elevations, both east and west of the radar site.

\section{Temporal Profile}

Temporal use of the NHWRA by birds during migratory periods (February-May and August-December) was defined as number of events detected per hour per unit area of sampling and expressed as passage rate. However, radar monitoring sessions during both seasons were seldom initiated or terminated on the hour, nor were they equal in duration, nor did they span complete hours. Nevertheless, an hourly passage rate could be assigned to a sampling period of any duration within an hour period (e.g., 2300-2400 hrs), regardless of length. Passage rate for each sampling block was therefore unique to a particular date and hour period. The assumption was that the rate held over the entire hour period regardless of how small the sampling time was. For example, if 32 events were detected during a monitoring bout from 2300 to 2359 on 1 April, passage rate was 32.5 events/hr for hour period 2300 on that date. If 32 events were detected during a monitoring bout from 2317 to 2348 on 2 April, passage rate was 61.9 events $/ \mathrm{hr}$ for that date. Passage rates were calculated by date, week, and hour period to determine trends in passage rates over time. Daily passage rates were total events detected for that day divided by total hours of monitoring during that day. Weekly rates were calculated as the mean of all sample block passage rates that occurred during a given week. Hourly rates were calculated as the mean of all sample block passage rates that occurred during a given hour period of the day.

Vertical radar was inoperable for approximately two weeks during the peak of autumn 1995 migration, so only scanning radar data were used for analysis of a temporal profile of autumn migration. Passage rates were calculated independently for both scanning and vertical radar data in the spring of 1996 by combining events recorded both on tally and standard data sheets. On tally sheets, however, observers' only recorded events that occurred in the NHWRA or Reference units, but events recorded on standard data sheets included all events visible on the entire radar screen. Thus, to incorporate tally sheet data, the numbers of events detected in NHWRA and Reference units were adjusted by the proportion of events recorded during standard data collection that occurred neither in NHWRA nor a Reference unit (approximately 20\%). This adjustment included only events with flight paths that moved in directions of between $>315^{\circ}$ and $\angle 45^{\circ}$ (essentially north) recorded on standard data sheets. Passage rates for hour blocks collected via tally sheets were calculated in the same manner as those for standard data sheets.

Effect of local meteorological conditions on migratory bird movements was analyzed by comparing barometric trends with passage rates. A barometric trend, a discrete measurement displayed on the weather monitor, was categorized as increasing, decreasing, or steady. Mean passage rates were calculated for each barometric trend condition.

\section{Estimated Magnitude and Altitude of Avian Migration in and near NHWRA}

Magnitude of avian migration within radar range and "In" NHWRA was crudely calculated by multiplying adjusted number of events detected by radar (scanning or vertical) by total number of hours available for migration in the season (autumn or spring) by average number of birds per event detected during the season. The mean number of birds per event (mean flock size) was calculated from radar observations that were visually verified and for which the number of birds was determined during Paired Verified observations (pg. 15). The product was divided by the number of hours monitored during the respective season by the respective radar (scanning or vertical) to produce an estimate of total number of birds passing through radar range and NHWRA. The formula was $\left[\mathrm{A}_{\mathrm{rsa}} \mathrm{S}_{\mathrm{s}} \mathrm{F}_{\mathrm{s}}\right] / \mathrm{h}_{\mathrm{rs}}$ where $\mathrm{A}=$ total adjusted number of events detected by scanning or vertical radar (r) during autumn or spring (s) within radar range or "In" NHWRA (a), S = total number of hours in autumn or spring (s), $\mathrm{F}=$ mean flock size in autumn or spring (s), and $\mathrm{h}=$ hours monitored by respective radar ( $r$ ) during season $s$ (autumn or spring). Number of birds passing low through NHWRA was estimated by multiplying total estimated birds "In" by the percentage of total events detected low "In" NHWRA during 
monitoring during the respective season with the respective radar array. Temporal Profile results were not used to estimate magnitude of migration because they included only raw numbers of events. Numbers of events adjusted for detectability was more representative of migration magnitude.

\section{Estimated Minimum Sampling Effort for Future Radar Monitoring}

An estimate of the minimum sample of radar monitoring hours needed for future study was derived by "bootstrapping" analysis of spring 1996 vertical radar monitoring results. These data were used because vertical radar was most consistently used through the season (no downtime) and data capture was most complete. Further, if future studies employed only one radar, it should be a vertical array because it has the capability to capture spatial, altitudinal, and temporal data alike. Scanning arrays can capture only spatial and temporal data.

The objective was to determine the minimum sampling effort (hours monitored) that would limit variability around the overall mean number of events/hr to no more than $20 \%$. A FORTRAN program was written that sampled 233 passage rate estimates (see Temporal Profile, above) $10^{4}$ times, with replacement. A mean passage rate was calculated for each of the $10^{4}$ samples. A median, 2.5 , and 97.5 percentile $(\sim 95 \% \mathrm{CI})$ were calculated from the $10^{4}$ mean passage rates. The process was repeated, simulating decreased effort by including fewer samples from the 233 original rates, e.g., $90 \%$ effort $=210$ samples, $80 \%$ effort $=186$ samples, $70 \%$ effort $=163$ samples. Minimum sampling effort was estimated at effort where percentiles were $\leq 20 \%$ of the observed mean passage rate.

\section{Efficacy of Radar and Visual Monitoring}

The efficacy of Radar and Visual Monitoring was tested under three monitoring regimes: Paired Silent and Paired Verified monitoring during migration periods; Solo Radar and Paired Radar monitoring, spring 1996; and during study of breeding and local raptor use of NHWRA during summer 1996. Capability of visual and radar monitoring techniques to detect avian targets in and near the NHWRA was evaluated by compiling mean number of events/hr detected visually and by scanning radar. Only scanning radar was used because both visual observer and scanning radar searched more similar areas and scanning radar was used most often during paired observations. However, vertical radar also was used in analysis of proportion of targets detected first by each method and subsequently verified by the other. Vertical radar was included in that analysis because area searched was not relevant; each observer alerted the other to the presence and relative location of a target.

Limitations of radar to detect targets at low altitudes were evaluated by analyzing data collected during study of breeding and local raptor use of NHWRA in 1996. Visually estimated altitudes of raptors were compared with altitudes of respective targets detected and not detected by scanning radar.

\section{Statistical Analysis}

Simple means tests (t-test, Mann-Whitney) were used when appropriate. Chi-square ( $\left(X^{2}\right)$ goodness-of-fit tests and tests for independence were used to evaluate differences in expected values from raw (observed) data, " $\mathrm{In}$ " and "Out" of NHWRA, when appropriate. Prior to employment of parametric tests, homogeneity of variance and normality were tested. If variability and normality assumption were not met, nonparametric tests were used. All statistical tests were conducted within appropriate utilities of STATISTICA ${ }^{\mathrm{TM}}$ and SOLO ${ }^{\mathrm{TM}}$ (Hintze 1989). As in Impact Analysis, $P$ values of $\leq 0.05$ were considered statistically significant for most statistical comparisons, unless otherwise stated, and indicated by the terms "difference" or "different" to avoid continual use of significant(ly). Because statistical significance does not always equate to biological significance, Pvalues $\leq 0.10$ were occasionally chosen to minimize the likelihood of Type II errors. Type II errors could have a more detrimental effect on the avian resource when impacts are evaluated and management strategies 
developed. Multiple comparison tests (LSD) were employed for further analysis when some $P$ values were $\leq 0.10$ to reveal differences among groups. If $X^{2}$ or parametric tests indicated significant differences, Bonferroni simultaneous confidence intervals (Holm 1979) were constructed to identify specific differences among categories. "Before-Impact" and "Before-Control/-Reference" data also were compiled in incomplete BACI tables to permit comparison with "After-Impact" and "After-Control/Reference" data, should NHWRA be developed and follow-up avian-use studies completed. 


\section{Results}

\section{Radar Operation}

\section{Display Screen}

The scanning radar screen displayed a series of concentric rings (distance between rings was dependent on range setting) and irregular areas of topographic relief, or ground clutter (see Fig. 9). Targets were not visible in ground clutter but could often be tracked entering and/or exiting. The vertical radar screen displayed a large band of clutter representative of ground level east and west (see Fig. 10). Surveillance ranges for both radars and proportion of scanning radar screen obliterated by clutter varied with range setting and season (see Table 1). In 1995, maximum detection range east and west for both radars was $2.8 \mathrm{~km}(1.7 \mathrm{mi})$ and ground clutter contributed to $31 \%$ of the scanning radar screen. In 1996, depending on range setting, maximum detection range east and west for both radars was $230 \mathrm{~m}(755 \mathrm{ft})$ to $11.1 \mathrm{~km}(6.9 \mathrm{mi})$ and ground clutter contributed from $14 \%-55 \%$ of the scanning radar screen.

Clutter display on the scanning radar screen was not representative of topographical relief. Initial perception bias dictated that clutter boundaries "should" have been coincident with topographical contour lines. They were not. Clutter boundaries proximate to the radar were often tops of ridges or high points and distal boundaries indicative of shadow, regardless of topography. Once this was perceived, more accurate plotting of avian flight paths was facilitated.

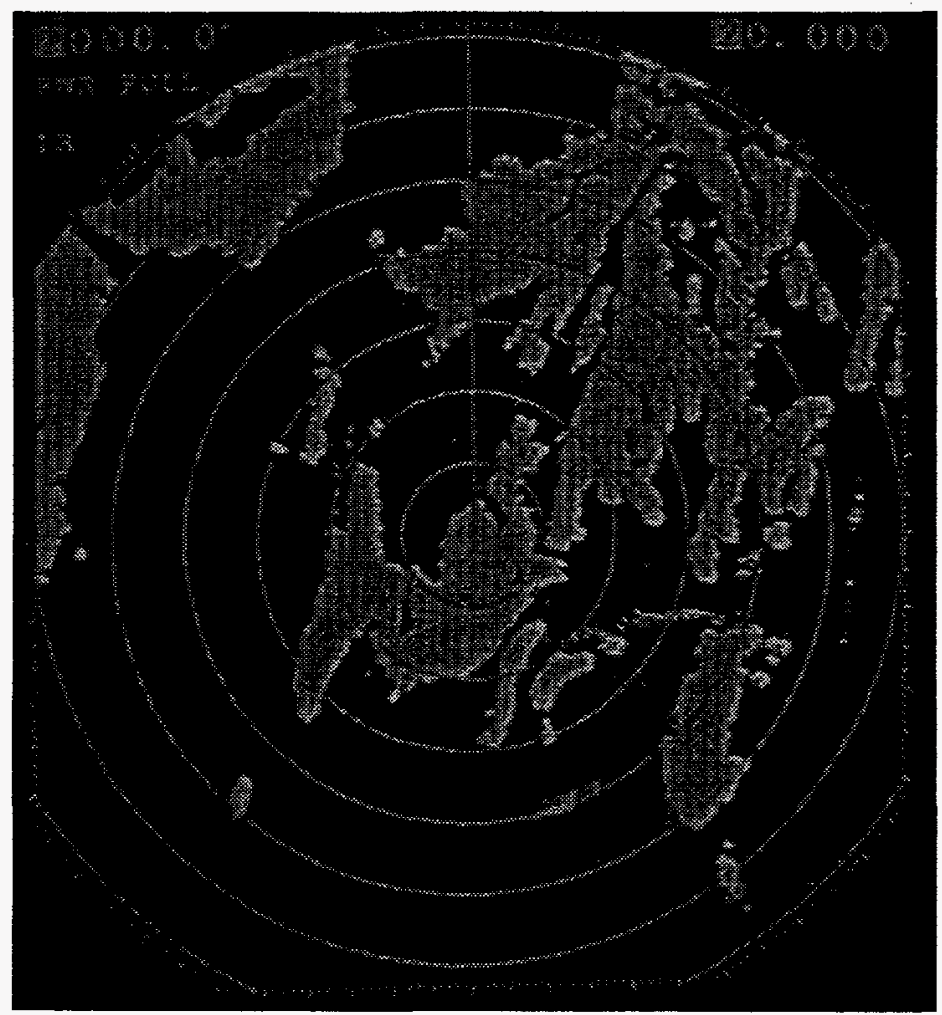

Figure 9. Display screen of scanning radar during autumn 1995 monitoring. Large, irregular light areas are clutter (higher topographic relief). Surveillance range was $1.5 \mathrm{~nm}(2.8 \mathrm{~km})$. Top is due north, right is east. Distance between concentric rings is $0.25 \mathrm{~nm}$

(463 m). 


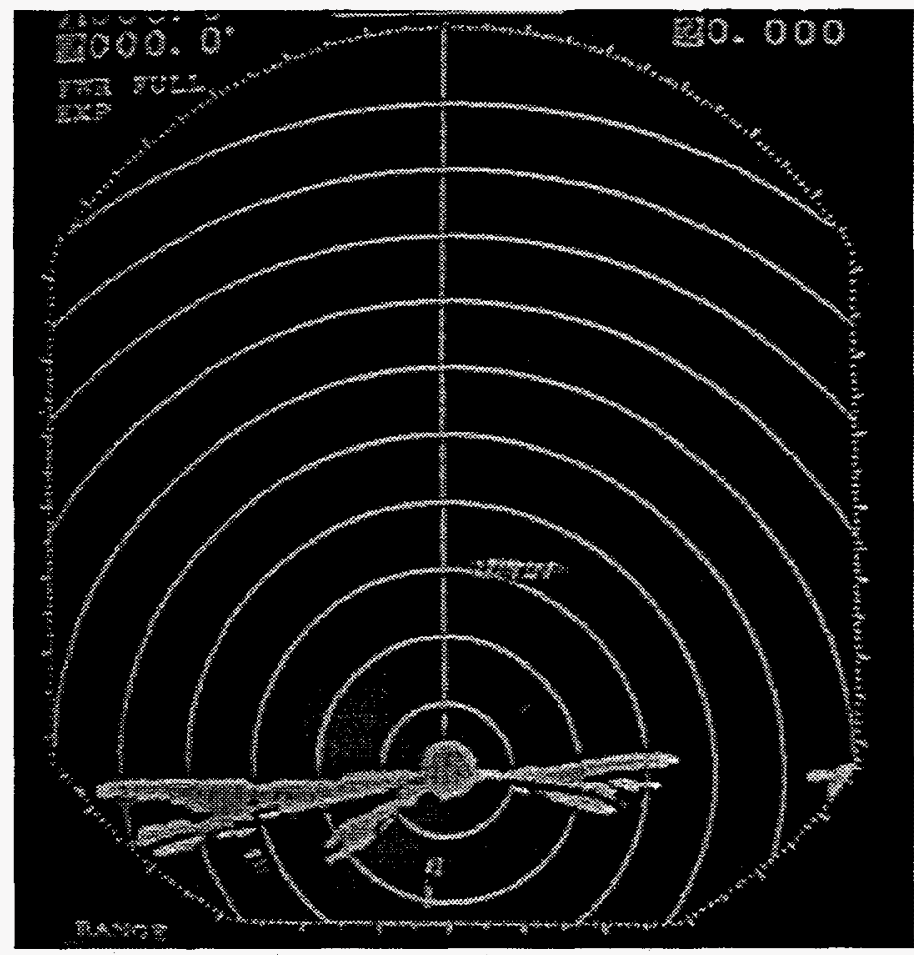

Figure 10. Display screen of vertical radar during autumn 1995 monitoring. Light horizontal area at bottom is ground level. Top is straight up, right is west. Distance between concentric rings is $0.25 \mathrm{~nm}$ $(463 \mathrm{~m})$. Signature in center, touching third range ring is signature of a bird(s) $1322 \mathrm{~m}$ (4340 ft) in altitude above radar. Detection range above radar was $5.1 \mathrm{~km}(16,732 \mathrm{ft})$ AGL.

Table 1. Maximum Detection Range of Scanning and Vertical Radars by Range Setting.

\begin{tabular}{|c|c|c|c|c|c|}
\hline \multirow{2}{*}{$\begin{array}{c}\text { Year/ } \\
\text { Range Setting } \\
\text { (Nautical } \\
\text { Miles) }\end{array}$} & \multicolumn{2}{|c|}{ Scanning Detection Range (m) } & \multirow{2}{*}{$\begin{array}{l}\text { Scanning Clutter } \\
\text { (\% of Screen) }\end{array}$} & \multicolumn{2}{|c|}{$\begin{array}{c}\text { Vertical Detection Range } \\
\text { (m) }\end{array}$} \\
\hline & East and West & South & & East and West & Overhead \\
\hline 19951.5 & 2,784 & 2,916 & $30.6 \mathrm{C}^{1}$ & 2,784 & 4,470 \\
\hline 19960.125 & 232 & 243 & $55 \mathrm{E}^{2}$ & 232 & 395 \\
\hline 0.25 & 464 & 489 & $45 \mathrm{E}$ & 464 & 790 \\
\hline 0.5 & 928 & 972 & $35 \mathrm{E}$ & 928 & 1,580 \\
\hline 0.75 & 1,392 & 1,458 & $22 \mathrm{C}$ & 1,392 & 2,370 \\
\hline 1.5 & 2,784 & 2,916 & $14.1 \mathrm{C}$ & 2,784 & 4,740 \\
\hline 3.0 & 5,568 & 5,832 & $35 \mathrm{C}$ & 5,568 & 9,480 \\
\hline 6.0 & 11,136 & 11,664 & $40 \mathrm{E}$ & 11,136 & 18,960 \\
\hline
\end{tabular}

${ }^{\mathrm{i}} \mathrm{C}=$ Area calculated by electronic planimeter.

${ }^{2} \mathrm{E}=$ Area estimated. 


\section{Interference Management}

Repositioning radar arrays from the trailer roof and 1.5-m (5-ft) post (see Fig. 8) to the 4.6-m (15-ft) guyed stand (see Fig. 4) did nothing to eliminate or even reduce frequency or amount of interference between radars. Interference was managed by manipulating screen display characteristics. Interference episode frequency was reduced when transmitted wave-pulse lengths were set differently for the same range settings on both radars and when radars were operated at difference surveillance ranges. Pulse lengths were set prior to each observation bout. Pulse lengths for vertical radar remained at default levels but were changed on the scanning radar display. Changing pulse lengths on the scanning radar also increased radar power output and accented the sizes of smaller targets. When interference signatures began, quickly changing surveillance range up then down usually eliminated interference. Occasionally, both displays needed simultaneous interference management. A disadvantage of changing ranges was that signature wakes were erased; if the wakes were not recorded prior to change or, unless targets persisted after interference clearing, some data could be lost.

\section{Ground Clutter Reduction}

Installation of the ground clutter reduction shield on scanning radar reduced ground clutter displayed on screen by an estimated $10 \%-20 \%$. Clutter reduction was most evident at ranges of $>1.5 \mathrm{~nm}(2.8 \mathrm{~km})$ where percent of screen composed of clutter was less (see Table 1). However, after analysis of scanning radar and model aircraft detection data post-monitoring, it was apparent that the shield reduced detection capability of the radar by limiting target acquisition to near-horizontal line of sight.

Detectability of targets at distances $>1.5 \mathrm{~nm}(2.8 \mathrm{~km})$ to the south of NHWRA was impeded by the ground clutter reduction shield because topographic relief declined from $\sim 1920 \mathrm{~m}(\sim 6300 \mathrm{ft})$ at the radar site to $\sim 1500 \mathrm{~m}(\sim 4900 \mathrm{ft})$ at the level of Ennis Lake. Although ground clutter was reduced around the periphery of Ennis Lake on the radar screen, targets at Ennis Lake range and elevation were virtually undetectable. Birds on or leaving Ennis Lake probably were not detected until they had ascended to a horizontal line-of-sight altitude from radar (at least $500 \mathrm{~m}$ [1600 ft] above Ennis Lake). Hindsight indicated that the ground clutter reduction shield was a hindrance rather than a benefit during spring 1996 monitoring, especially for detecting birds on, near, or flying low over Ennis Lake.

\section{Radar Signature Characteristics}

Identification of radar targets to species or group failed at night. Perpetual wind prevented identification by auditory cues and targets never flew past the seldom-visible moon. Night-vision devices had too narrow of a field of view and depth of field to acquire fast-moving targets. Although species could not be determined visually or from radar signature characteristics, confirmed identifications secured during Paired Verified observations indicated signatures on scanning radar screen could be subjectively assigned to one of several groups. Waterfowl signatures were especially distinctive (see Fig. 11). Signature behavior and speed also helped identification. Large, solitary, slow-moving, signatures (during daylight) were often golden eagles or buteo hawks (see Fig. 12). Large signatures moving slowly in a corkscrew or undulating pattern were often white pelicans. Moving "clouds" were small passerines, particularly barn swallows (Hirundo rustica) (see Fig. 13). Clark's nutcrackers (Nucifraga columbiana) produced distinct round signatures, in pairs or loosely associated groups, moving in straight lines. Sandhill cranes (Grus canadensis) produced very distinct slow, crescent-shaped signatures that were often very high (>1400 m [4600 ft] AGL). Signatures of ducks (see Fig. 11) moving over $50 \mathrm{kph}(31 \mathrm{mph})$ were probably diving ducks (e.g., Bucephala and Mergus spp.). Duck flocks flying less than $50 \mathrm{kph}(31 \mathrm{mph})$ were probably dabbling ducks (e.g., Anas spp.). Flight speeds recorded for other species or groups were: Canada geese (Branta candensis) - $70 \mathrm{kph}$ (44 mph); swans 55-83 $\mathrm{kph}$ (40-52 mph); pelicans_-59 kph (37 mph); great blue herons (Ardea herodias)—-76 kph (47 mph); and 
golden eagles and buteo hawks- $52 \mathrm{kph}(32 \mathrm{mph})$. During periods of intense migration, the screen was nearly obliterated with wakes of birds (see Fig. 14).

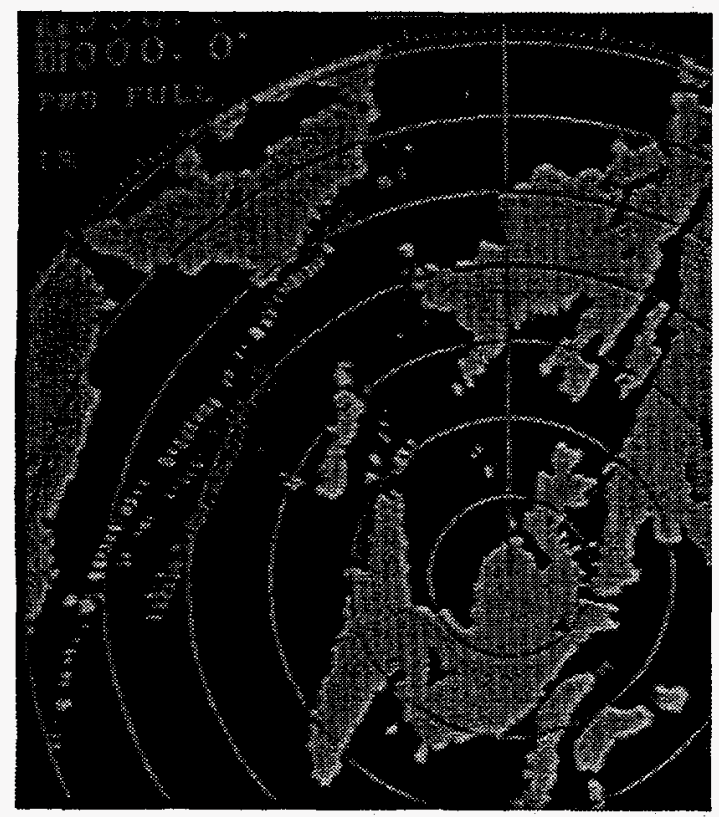

Figure 11. Signature of 2 flocks of waterfowl (dots in line) flying southwest, between 1.8 and $2.8 \mathrm{~km}$ (1.1-1.7 mi) westnorthwest of NHWRA, autumn 1995.

Brighter signature is more recent.

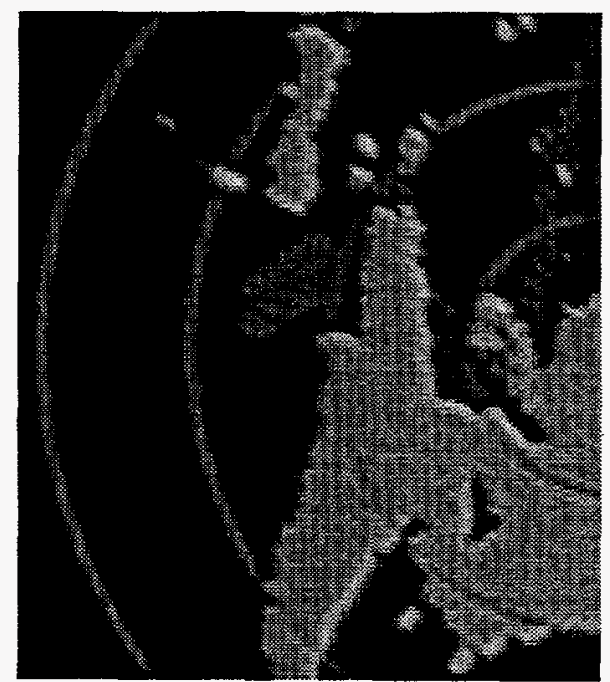

Figure 13. Radar signature of a flock of passerines (cloudy area, near center).

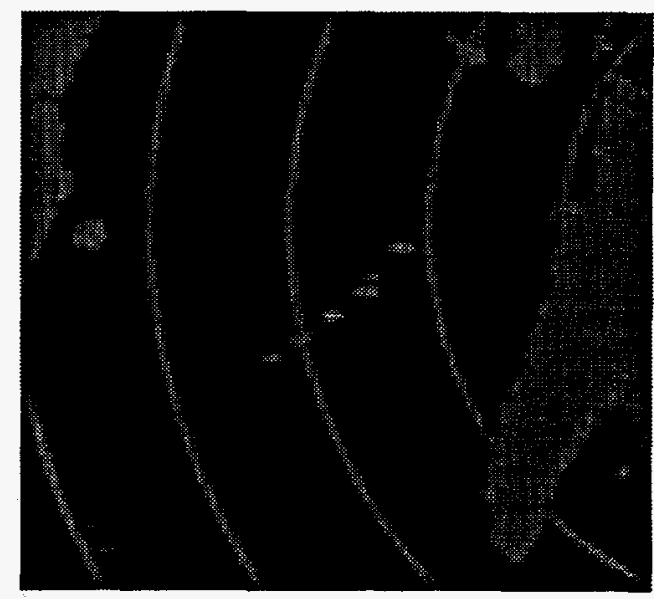

Figure 12. Radar signature of a golden eagle.

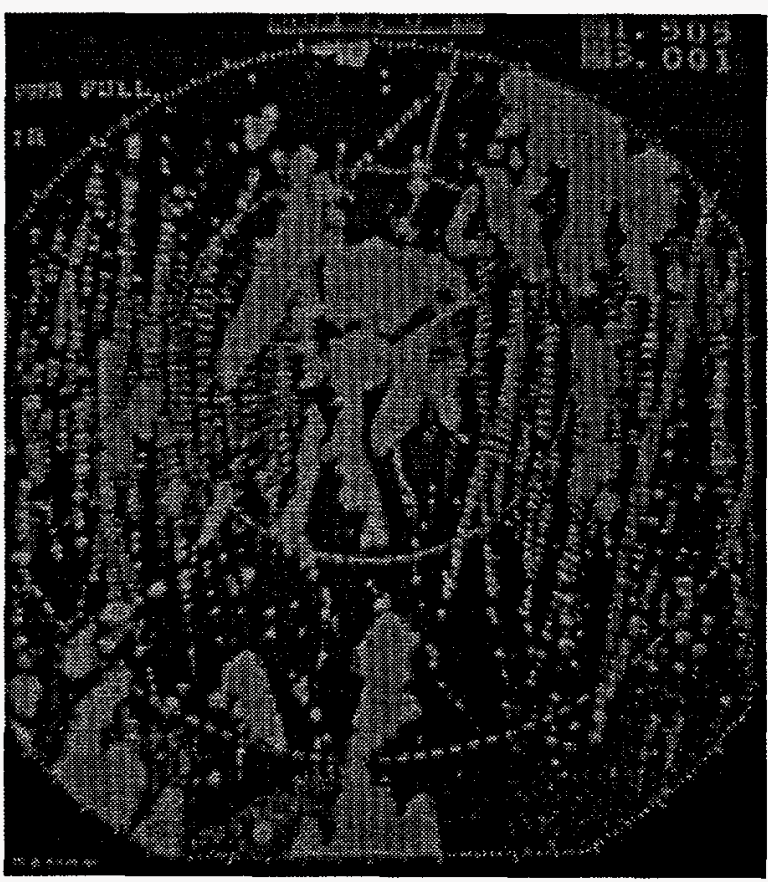

Figure 14. Scanning radar screen during intense migratory activity, spring 1996. 
In late spring 1996, many targets, similar to those produced by small passerines, began appearing, mostly on the scanning radar screen during daylight and usually only within $1 \mathrm{~km}(0.6 \mathrm{mi})$. Travel was obligate to wind direction and speed. Many were within $180 \mathrm{~m}(591 \mathrm{ft})$ of the radar but visual observers could not locate any birds (small passerines were often visible up to $800 \mathrm{~m} \mathrm{[1/2} \mathrm{mi]).} \mathrm{It} \mathrm{soon} \mathrm{became} \mathrm{evident} \mathrm{that} \mathrm{they} \mathrm{were} \mathrm{swarms}$ of insects, probably Russian wheat aphids (Diuraphis noxia [Mordvilko]), (Blodgett, 1997a), which were undetectable to the naked or aided eye due to their small size ( $<2 \mathrm{~mm}[0.08 \mathrm{in}])$, even in swarms. All events were recorded because insects were often interspersed with small birds (i.e., appearance of insects coincided with peak of passerine migration) and usually could not be distinguished because wind direction was primarily from the south, the same direction as migration. Also, wind speeds often matched or exceeded typical passerine flight speeds. Insect signatures did not appear to be detected by the vertical radar array. Signatures on vertical radar could not be distinguished among species or groups. Signatures of aircraft however, were quite evident (see Fig. 15).

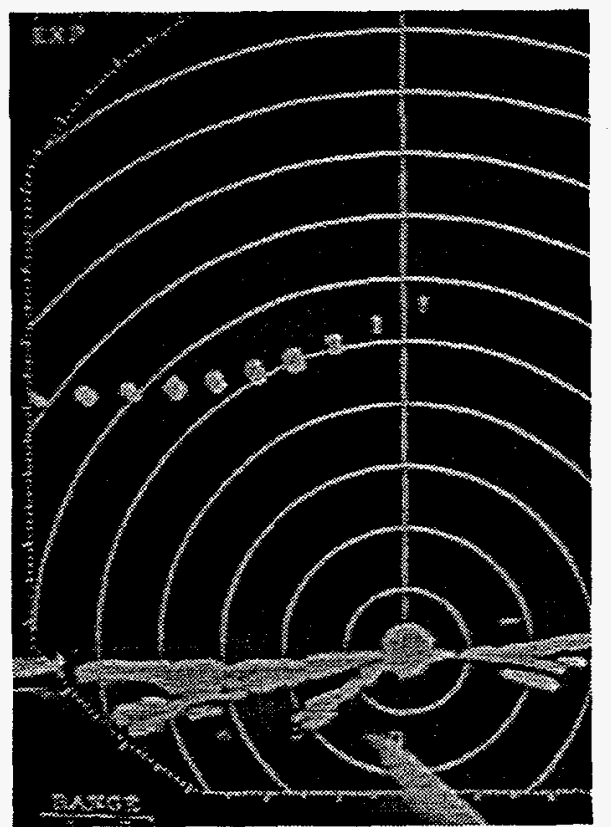

Figure 15. Signature of aircraft on

vertical radar. Altitude was

$\sim 1.8 \mathrm{~km}(5906 \mathrm{ft}) \mathrm{AGL}$.

\section{Radar Monitoring Effort}

Between 24 August and 14 December 1995, scanning radar was monitored for 658.5 hrs over 103 days at range setting $1.5 \mathrm{~nm}(2.8 \mathrm{~km})$ (see Fig. 16). During the same period, $599.1 \mathrm{hrs}$ were monitored with vertical radar over 93 days (see Fig. 17). The disparity between scanning and vertical radar monitoring efforts was a result of a burned-out motor in the vertical pedestal. The unit was returned to the manufacturer for repair on 18 October and returned on 29 October. Effort during early morning hours (0200-0800) was clearly lacking. 


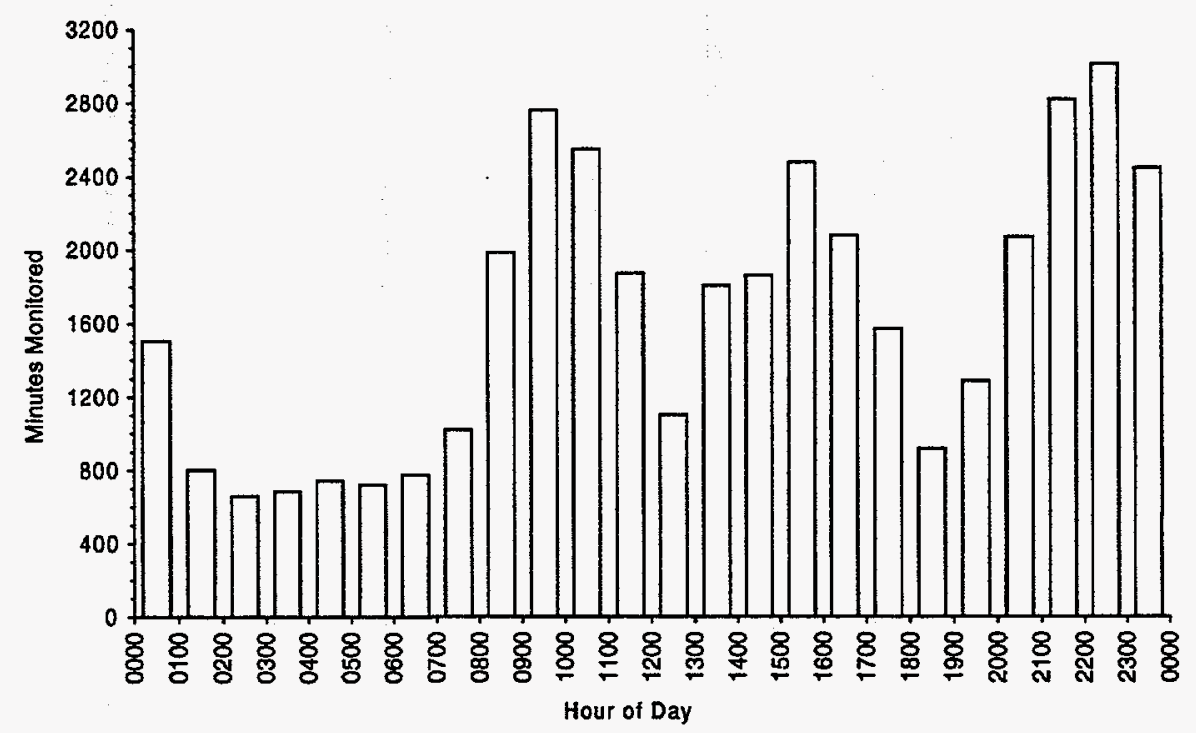

Figure 16. Hourly monitoring effort with scanning radar, NHWRA during autumn 1995.

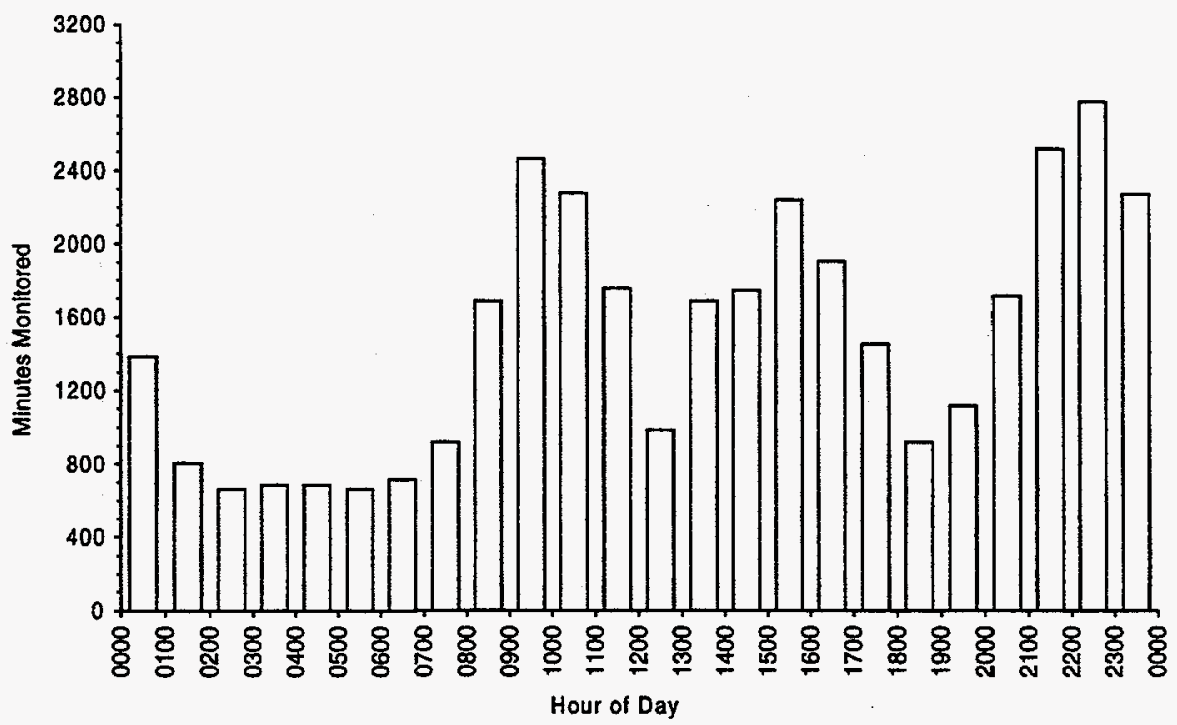

Figure 17. Hourly monitoring effort with vertical radar, NHWRA during autumn 1995.

Monitoring time was more comparable between arrays in spring 1996, and distribution among hourly periods was also more equal. Between 20 February and 10 June, scanning radar was monitored for 184.4 hrs over 63 days on range setting $3 \mathrm{~nm}(5.6 \mathrm{~km}$ ) (see Fig. 18) and vertical radar monitored for $172.7 \mathrm{hrs}$ over 59 days on range setting $1.5 \mathrm{~nm}(2.8 \mathrm{~km})$ (see Fig. 19). The discrepancy in hours between scanning and vertical array was due to moisture in the vertical radar antenna between 2 and 6 May. Once dried, the system came back on-line. Data compilation and analysis consumed over one man-year. Most effort was directed at data entry, "cleaning," and verification. 


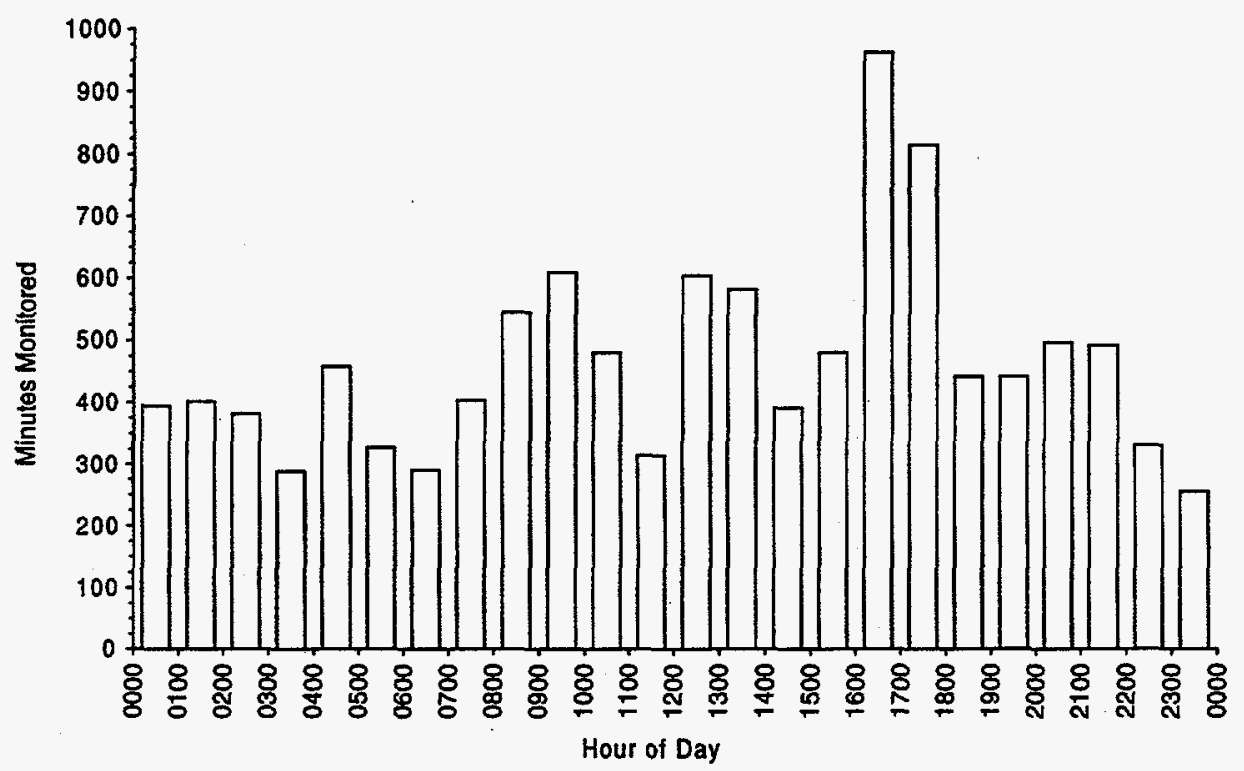

Figure 18. Distribution of monitoring effort per hour with scanning radar, NHWRA during spring 1996.

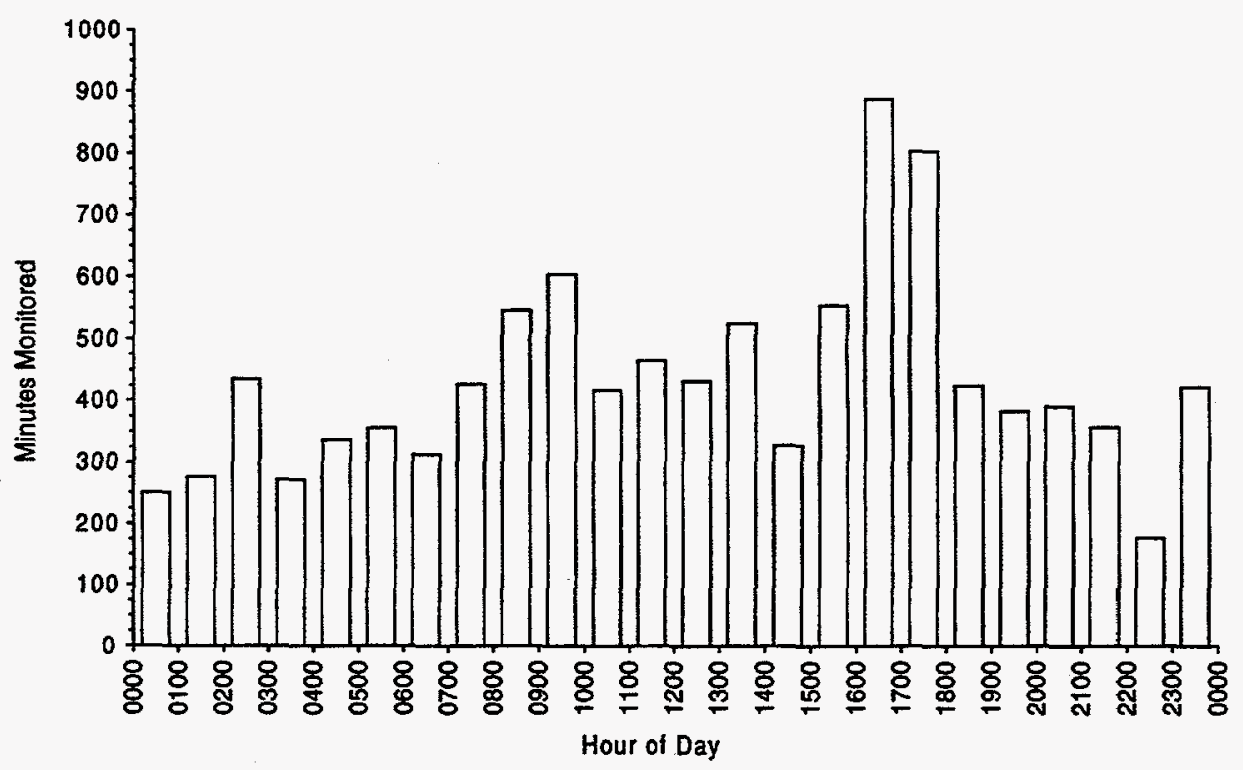

Figure 19. Hourly monitoring effort with vertical radar, NHWRA during spring 1996. 


\section{Impact Analysis}

\section{Use of Impact and Reference Areas by Migratory Birds}

\section{Horizontal Profile of Use}

Autumn 1995. A total of 26,282 events was recorded within $2.4 \mathrm{~km}\left(1 \frac{1}{2} \mathrm{mi}\right)$ of scanning radar during autumn 1995. Thirty-five percent were detected "In" the NHWRA and $65 \%$ were detected "Out" (see Table 2). Vertical radar detected 4,228 events: 34\% "In" the NHWRA and 66\% "Out" (see Table 2). There was no difference between arrays in proportion of events detected "In" and "Out" $\left(X^{2}=1.96,2 \mathrm{df}, \mathrm{P}=0.1615\right)$.

Table 2. Surveillance Area Size and Events Detected Seasonally "In" and "Out" of NHWRA by Scanning and Vertical Radar Arrays.

\begin{tabular}{|c|c|c|c|c|c|c|c|c|}
\hline \multirow{3}{*}{ Area } & \multicolumn{4}{|c|}{ Autumn 1995} & \multicolumn{4}{|c|}{ Spring 1996} \\
\hline & \multicolumn{2}{|c|}{ Scanning } & \multicolumn{2}{|c|}{ Vertical } & \multicolumn{2}{|c|}{ Scanning } & \multicolumn{2}{|c|}{ Vertical } \\
\hline & $\begin{array}{c}\text { Size } \\
\mathbf{k m}^{2}\left(\mathbf{m i}^{2}\right)\end{array}$ & No. & $\begin{array}{c}\text { Size } \\
\mathbf{k m}(\mathbf{m i})\end{array}$ & No. & $\begin{array}{c}\text { Size } \\
\mathbf{k m}^{2}\left(\mathbf{m i}^{2}\right)\end{array}$ & No. & $\begin{array}{c}\text { Size } \\
\mathbf{k m}(\mathbf{m i})\end{array}$ & No. \\
\hline In NHWRA & $1.3(1 / 2)$ & 9,252 & $.805(1 / 2)$ & 1,441 & $1.3(1 / 2)$ & 2,578 & $.805(1 / 2)$ & 1,509 \\
\hline Out NHWRA & $17(6.6)$ & 17,030 & $5.6(3.5)$ & 2,787 & $11.6(4.5)^{1}$ & 17,452 & $7.24(4.5)^{1}$ & 4,366 \\
\hline
\end{tabular}

${ }^{1}$ Includes only Reference areas, not entire $3 \mathrm{~nm}(5.6 \mathrm{~km})$ radius surveillance circle.

Spring 1996. The proportion of events detected "In" and "Out" of NHWRA by each radar array was different during spring $1996\left(X^{2}=560.41,2 \mathrm{df}, \mathrm{P}<0.0001\right)$. Of 20,030 events detected in NHWRA and Reference areas by scanning radar, $13 \%$ were "In" NHWRA and $87 \%$ were "Out" (see Table 2). Vertical radar detected $26 \%$ of 5,875 events "In" NHWRA and 74\% "Out" (see Table 2).

Area size surveyed changed between seasons for scanning radar so testing for seasonal differences in proportions "In" and "Out"was only meaningful for vertical data, which showed proportionally more events detected "In" NHWRA in autumn than spring $\left(X^{2}=83.45,2 \mathrm{df}, P<0.0001\right)$ (see Table 2$)$. Both radar arrays consistently detected more events "In" NHWRA than expected and less "Out," relative to surveillance area in both seasons $\left(X^{2}=183,1 \mathrm{df}, \mathrm{P}<0.0001\right)$.

\section{Altitudinal Profile of Use}

Autumn 1995. Altitudes of 3,247 events detected within $805 \mathrm{~m}(1 / 2 \mathrm{mi})$ of the radar showed distributional differences among High, Medium, and Low altitude categories "In" and "Out" of NHWRA $\left(X^{2}=21.545,2\right.$ df, $P<0.0001$ ) (see Fig. 20). "In," fewest events were Low (27\%) <High (33\%) <Medium (40\%); "Out," fewest were High (26\%) LLow (27\%) <Medium (47\%) (see Fig. 20). Altitudes of 5,324 events within approximately $2.8 \mathrm{~km}$ ( $1.7 \mathrm{mi})$ east and west of the radar in autumn 1995 was also distributed differently "In" and "Out" of the NHWRA ( $\left.X^{2}=152.3,2 \mathrm{df}, \mathrm{P}<0.0001\right)$ (see Fig. 20). A greater proportion (35\%) were low, the same medium (47\%), and fewer (18\%) High. 


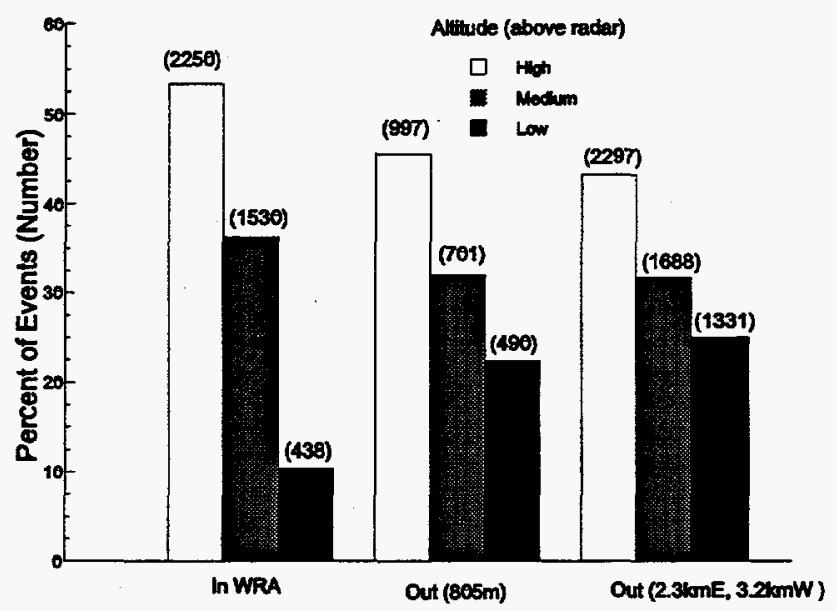

Figure 20. Altitude distribution of events detected In and Out of NHWRA, spring 1996. Low $\leq 1 \mathrm{~m}$ (200 ft), medium=61$250 \mathrm{~m}$ (200-820 ft), high>250 $\mathrm{m}$ (820 ft) above radar antenna.

Spring 1996. Altitudes of 4,574 events detected within $805 \mathrm{~m} \mathrm{(1/2} \mathrm{mi)} \mathrm{of} \mathrm{the} \mathrm{radar} \mathrm{showed} \mathrm{distributional}$ differences among altitude categories "In" and "Out" of NHWRA $\left(X^{2}=168.07,2 \mathrm{df}, \mathrm{P}<0.0001\right)$ (see Fig. 21). "In," fewest events were Low (6\%) <Medium (30\%) <High (64\%); "Out," fewest were Low (19\%) $<$ Medium (31\%) <High (50\%) (see Fig. 21). Altitudes of 7,512 events within approximately $2.3 \mathrm{~km}(1.4 \mathrm{mi})$ east and $3.2 \mathrm{~km}(2 \mathrm{mi})$ west of the radar were also distributed differently "In" and "Out" of the NHWRA $\left(X^{2}\right.$ $=337.05,2 \mathrm{df}, \mathrm{P}<0.0001$ ) (see Fig. 21). A greater proportion (23\%) were Low, the same Medium (32\%), and fewer (45\%) High (see Fig. 21). A higher proportion of events detected "Out" of NHWRA were low at greater surveillance range ( $P=0.0002)$.

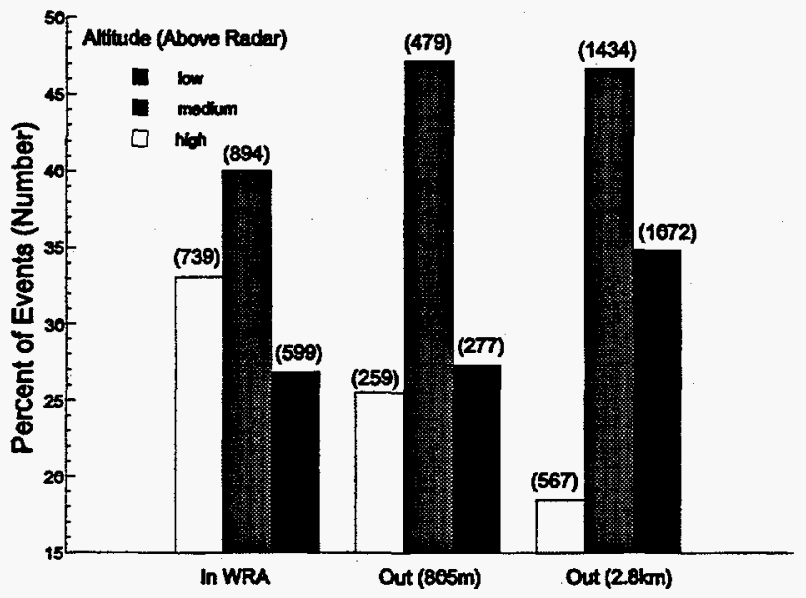

Figure 21. Altitude distribution of events detected In and

Out of NHWRA, autumn 1995. Low $\leq 61 \mathrm{~m}$ (200 ft), medium $=61-250 \mathrm{~m}(200-820 \mathrm{ft})$, high $>250 \mathrm{~m}(820 \mathrm{ft})$ above radar antenna. 
Mean altitude of events detected above radar level "In" NHWRA was higher than those detected "Out" $(t=$ 12.65, 3,976-df, $\mathrm{P}<0.0001)$ in autumn 1995 and spring 1996 ( $\mathrm{t}=11.37,6,366$-df, $\mathrm{P}<0.0001)$ (see Table 3). However, altitudes relative to radar were not representative of distribution of events relative to topography because ground level was higher "In" NHWRA than "Out." Mean altitude of targets above ground level was not different "In" and "Out" of NHWRA in spring 1996 ( $t=0.5674,3,084-d f, P=0.5764)$ (see Table 3).

Table 3. Altitude (meters) Above Radar and Ground Level of Events Detected Seasonally "In and "Out" of NHWRA by Vertical Radar.

\begin{tabular}{|c|c|c|c|c|c|c|c|}
\hline \multirow{2}{*}{ Area } & \multirow{2}{*}{$\begin{array}{c}\text { Altitude } \\
\text { Relative } \\
\text { to: }\end{array}$} & \multicolumn{3}{|c|}{ Autumn 1995} & \multicolumn{3}{|c|}{ Spring 1996} \\
\hline & & n & $\bar{x}$ & SD & $\mathbf{n}$ & $\bar{x}$ & SD \\
\hline In NHWRA & Radar & 2,251 & 260.8 & 281.6 & 2,805 & 458.7 & 393.3 \\
\hline Out NHWRA & Radar & 3,073 & 171.7 & 210.1 & 4,707 & 347.0 & 434.8 \\
\hline In NHWRA & Ground & .1 & - & - & 1,509 & 397.7 & 364.9 \\
\hline Out NHWRA & Ground & - & - & - & 4,364 & 404.1 & 433.1 \\
\hline
\end{tabular}

${ }^{1}$ Direction and distance of events to radar not recorded so relationship to ground level cannot be determined.

\section{Use of Impact and Reference Areas by Breeding and Local Nonraptorial Birds}

Cumulative species richness and ecological diversity (Shannon 1948 see Refs.) "Out" of NHWRA were higher than "In" NHWRA (likely due to larger sampled area) (see Table 4). However, relative abundance (mean number of detections per point) did not differ "In" and "Out" of NHWRA $(t=-1.49,47 \mathrm{df}, \mathrm{P}=0.14)$.

Table 4. Avian Abundance and Diversity in BACI Areas Detected During Point Counts, Spring and Summer 1996.

\begin{tabular}{cccccccc}
\hline \multirow{2}{*}{$\begin{array}{c}\text { BACI } \\
\text { Area }\end{array}$} & \multicolumn{3}{c}{ Number } & & & \multicolumn{2}{c}{ Species } \\
\cline { 2 - 4 } \cline { 6 - 7 } & $\begin{array}{c}\text { Detection } \\
\mathbf{S}\end{array}$ & Points & Visits & $\begin{array}{c}\mathbf{t} \\
\mathbf{t}\end{array}$ & Richness & Diversity $^{\mathbf{1}}$ \\
\hline NHWRA & 120 & 6 & 18 & $20.0(3.8)$ & 4 & 1.81 \\
Out & 1,041 & 43 & 129 & $24.2(6.8)$ & 43 & 4.05 \\
\hline
\end{tabular}

'Shannon Index.

\section{Use of Impact and Reference Areas by Breeding and Local Raptors}

\section{Bald Eagles}

Two fledgling bald eagles from the Bear Trap Canyon nest (n.b. Fig. 24) were radio-tracked for 94 hrs over 21 days between fledging on 19 July and leaving southwestern Montana on 19 August 1995 . Neither radio-tagged eagle was detected within $1 \mathrm{~km}(0.6 \mathrm{mi})$ of the NHWRA. 
Resident adult bald eagles breeding at the same site were visually monitored for $76 \mathrm{hrs}$ in 1996, during which neither adult was known to have entered the NHWRA. Both adult eagles were known to be "Out" of NHWRA $95 \%$ of all time monitored, but birds were unaccounted for 5\% of monitoring time (locations relative to the NHWRA unknown [see Table 5]). Eagles were known not to be in or over the NHWRA $100 \%$ of the time during paired visual observations, but only $53 \%$ of the time during solo visual observations. Eagles were not visible and locations were unknown during solo observations $47 \%$ of the time.

Table 5. Location of Adult Bald Eagles Nesting in Bear Trap Canyon Relative to NHWRA During Visual Monitoring, Summer 1996.

\begin{tabular}{|c|c|c|c|c|}
\hline \multirow{2}{*}{$\begin{array}{c}\text { Observation } \\
\text { Type }\end{array}$} & \multirow{2}{*}{$\begin{array}{c}\text { Total } \\
\text { Monitoring } \\
\text { Time (min) }\end{array}$} & \multicolumn{3}{|c|}{ Location (min) } \\
\hline & & $\begin{array}{c}\text { Known, } \\
\text { Not In NHWRA }\end{array}$ & $\begin{array}{l}\text { Unknown, } \\
\text { Not In NHWRA }\end{array}$ & Unknown \\
\hline Solo $^{1}$ & 518 & 275 & - & 243 \\
\hline Paired $^{2}$ & 4,042 & 782 & 3,260 & - \\
\hline Both & 4,560 & 1,057 & 3,260 & 243 \\
\hline
\end{tabular}

${ }^{1}$ Single observer with nest site and NHWRA in view.

${ }^{2}$ Two observers $2.4 \mathrm{~km}\left(1 \frac{1}{2} \mathrm{mi}\right)$ apart, one as solo, second with primary foraging area on Madison River and the NHWRA in view (both communicate).

\section{Golden Eagles}

Two adult male golden eagles' are residents at nest sites in Bear Trap Canyon within $6.4 \mathrm{~km}$ (4 mi) of NHWRA (see Fig. 24), were radio-tagged and subsequently located within NHWRA between 6 December 1995 and 9 September 1996. Three percent of all locations of radio-tagged golden eagles occurred "In" NHWRA (see Table 6). Number of locations "In" represented $2.1 \%$ and $8 \%$ of total telemetry detections of the "Power House" male and "Bear Trap" male, respectively.

Table 6. Locations of Radio-tagged Adult Male Golden Eagles Nesting at Sites Closest to NHWRA, 1995-1996.

\begin{tabular}{cccccc}
\hline $\begin{array}{c}\text { Nest Site } \\
\text { (Trans. Freq.) }\end{array}$ & $\begin{array}{c}\text { Date } \\
\text { Radio-tagged }\end{array}$ & $\begin{array}{c}\text { Inclusive Tracking } \\
\text { Dates }\end{array}$ & $\begin{array}{c}\text { No. Days } \\
\text { Located }\end{array}$ & \multicolumn{2}{c}{ No. Locations } \\
\cline { 5 - 6 } & & & & In NHWRA & $\begin{array}{c}\text { Out of } \\
\text { NHWRA }\end{array}$ \\
\hline $\begin{array}{c}\text { Power House } \\
(148.740)\end{array}$ & $05-15-96$ & 15 May-9 Sept. 1996 & 59 & $3^{1}$ & 140 \\
$\begin{array}{c}\text { Bear Trap } \\
(148.769)\end{array}$ & $12-06-95$ & 6 Dec. 1995-5 June & 22 & $2^{3}$ & 25 \\
Both & & $1996^{2}$ & 81 & 5 & 165 \\
\hline
\end{tabular}

${ }^{1}$ Two flights above $200 \mathrm{~m}(656 \mathrm{ft})$ AGL, one perch on fence post on southern boundary of NHWRA.

${ }^{2}$ Found dead recently, cause unknown.

${ }^{3}$ Altitude above $200 \mathrm{~m}(656 \mathrm{ft})$ AGL.

\section{Assessment of Avian Mortality}

Avian mortality transects were surveyed between 23 August 1995 and 9 August 1996. No transects were covered between 1 December and 1 April due to inaccessibility from snow cover. A total of $289.8 \mathrm{~km}$ (180 
mi) of transects was surveyed, $14.7 \%$ of survey routes were "In" and $85.3 \%$ was "Out" of the NHWRA (see Appendix Table 31). Four dead birds were found ( 1 "In" and 3 "Out," [see Table 7]). Case study assessment of mortalities indicated raptors as the primary vector of death (see Table 8).

Table 7. Avian Mortality Detected on Transects "In" and "Out" of NHWRA.

\begin{tabular}{rrrccc}
\hline Year & Area & \multicolumn{1}{c}{$\begin{array}{c}\text { km (mi) } \\
\text { Surveyed }\end{array}$} & $\begin{array}{c}\text { Dead } \\
\text { Birds } \\
\text { Observed }\end{array}$ & $\begin{array}{c}\text { Dead Birds/km } \\
\text { (mi) }\end{array}$ \\
\hline 1995 & In & $17.54(10.9)$ & 0 & 0 \\
& Out & $131.37(81.64)$ & 1 & $0.008(0.012)$ \\
1996 & In & $25.1(15.6)$ & 1 & $0.040(0.064)$ \\
& Out & $115.82(71.98)$ & 2 & $0.017(0.028)$ \\
Both & In & $42.64(26.6)$ & 1 & $0.023(0.038)$ \\
& Out & $247.19(153.63)$ & 3 & $0.012(0.019)$ \\
\hline
\end{tabular}

Nine mortality transects were surveyed one to nine times each in 1995 , totaling $148.9 \mathrm{~km}(92.5 \mathrm{mi})$ covered (see Appendix Table 31). Only one dead bird was found ( 0.0067 dead birds/km). Transects surveyed "In" NHWRA produced no dead birds. Transects walked "Out" of NHWRA produced one dead bird (see Table 7), a gray partridge (Perdix perdix) that was apparently killed by a raptor.

Five transects were surveyed eight times in 1996 , totaling $140.9 \mathrm{~km}(87.6 \mathrm{mi})$ covered (see Appendix Table 31). Three dead birds were found $(0.0213$ dead birds $/ \mathrm{km})$. Transects surveyed "In" NHWRA produced one dead bird, an unidentified grassland sparrow that was apparently killed by a raptor. Transects surveyed "Out" of NHWRA produced two dead magpies (Pica pica), one apparently killed by a raptor. Cause of death for the other magpie was unknown.

Table 8. Proportion of Avian Mortalities Discovered in and near NHWRA, 1995 and 1996, Assigned to Cause.

\begin{tabular}{lcc}
\hline Mortality Agent & Number & Proportion of Total \\
\hline Raptor & 3 & 0.6 \\
Vehicle $^{1}$ & 1 & 0.2 \\
Unknown & 1 & 0.2 \\
\hline
\end{tabular}

${ }^{\mathrm{N}}$ Not detected during survey.

Although the overall number of dead birds found per $\mathrm{km}$ of transect "In" NHWRA was almost twice that of "Out" (see Table 8), the total number of birds found was very small $\left(\sum=4\right)$. Thus, meaningful comparisons could not be made regarding dead bird numbers or dead birds found per km of transect "In" versus "Out." However, BACI analysis can be performed when "After" data are collected.

\section{BACI Summary}

Impact analysis results are summarized in Tables 9 and 10. These "Before-Impact," "Before-Reference" results may be used for comparison with "After-Impact" and "After-Reference" results obtained after 
construction of wind turbines, should NHWRA ever be developed, and if data are collected in the same areas with identical methodology. Sample sizes and standard deviations (where applicable) are not summarized in the following table but can be found in specific BACI results above.

Table 9. Summary of BACI Analysis of Parameters of Avian Use and Mortality in and out of NHWRA by Migratory Birds, Autumn 1995-Spring 1996.

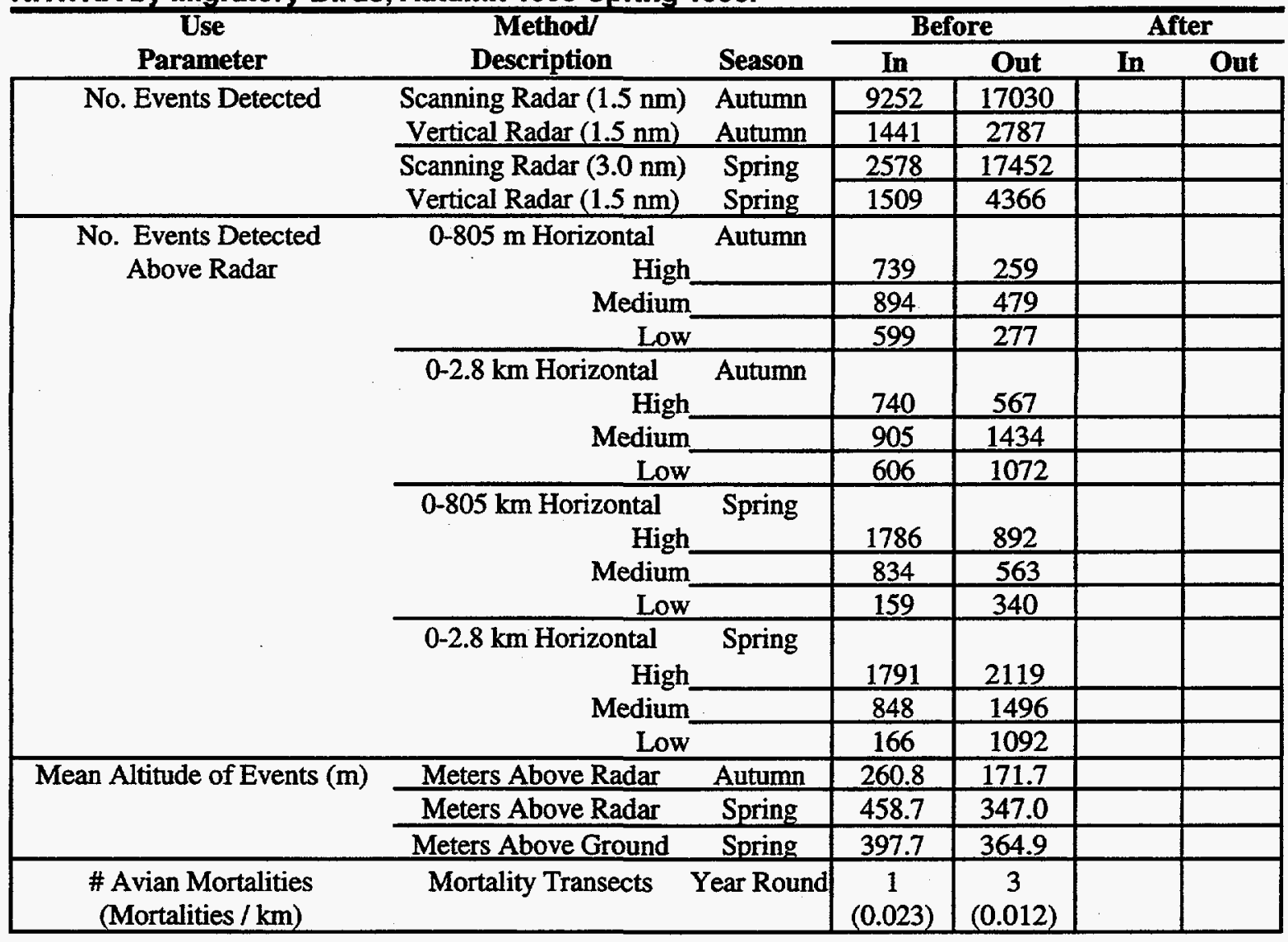

Table 10. Summary of BACI Analysis of Avian Use Parameters for Local and Breeding Birds, in and out of NHWRA, 1996.

\begin{tabular}{|c|c|c|c|c|c|c|}
\hline \multirow[b]{2}{*}{ Parameter } & \multirow{2}{*}{$\begin{array}{l}\text { Method/ } \\
\text { Description }\end{array}$} & \multirow[b]{2}{*}{ Season } & \multicolumn{2}{|c|}{ Before } & \multicolumn{2}{|c|}{ After } \\
\hline & & & In & Out & In & Out \\
\hline No. Detections & Point Counts & Summer & 120 & 1041 & & \\
\hline $\begin{array}{c}\text { Mean No. } \\
\text { Detections/Point }\end{array}$ & Point Counts & Summer & 20.0 & 24.2 & & \\
\hline Species Richness & Point Counts & Summer & 4 & 43 & & \\
\hline Species Diversity & Point Counts & Summer & 1.81 & 4.05 & & \\
\hline $\begin{array}{l}\text { Hours Observed } \\
\text { via Radio-telemetry }\end{array}$ & Fledgling Bald Eagles & Summer & 0 & 94 & & \\
\hline $\begin{array}{c}\text { Minutes Observed } \\
\text { Visually }\end{array}$ & Adult Bald Eagles & Summer & $\begin{array}{c}0 \\
\text { (234 unknown) }\end{array}$ & 4317 & & \\
\hline No. Radio locations & Adult Golden Eagles & $\begin{array}{l}\text { Winter- } \\
\text { Summer }\end{array}$ & 5 & 160 & & \\
\hline
\end{tabular}




\section{Spatio-temporal Profile of Avian Use of NHWRA and Vicinity}

\section{Migratory Birds}

\section{Horizontal Profile}

Autumn 1995. Scanning radar detected 26,282 events within six range rings during autumn 1995 (see Fig. 22). Range ring six was eliminated from analysis because the entire ring was not visible on screen (n.b., see Fig. 9). The DISTANCE program generated a detection-probability curve from the distribution of events detected in the five proximate rings (see Fig. 23). The direction of events from radar was not recorded in autumn 1995 so comparisons could not be made regarding numbers of events to east or west of radar; comparisons could only be made among various distances from radar. Numbers of events in each ring after adjustment by detection probability were different from expected among range rings $\left(X^{2}=11452.9, \mathrm{P}<\right.$ 0.0001). Fewer events than expected were calculated at more proximate distances and more than expected farther away (see Table 11).

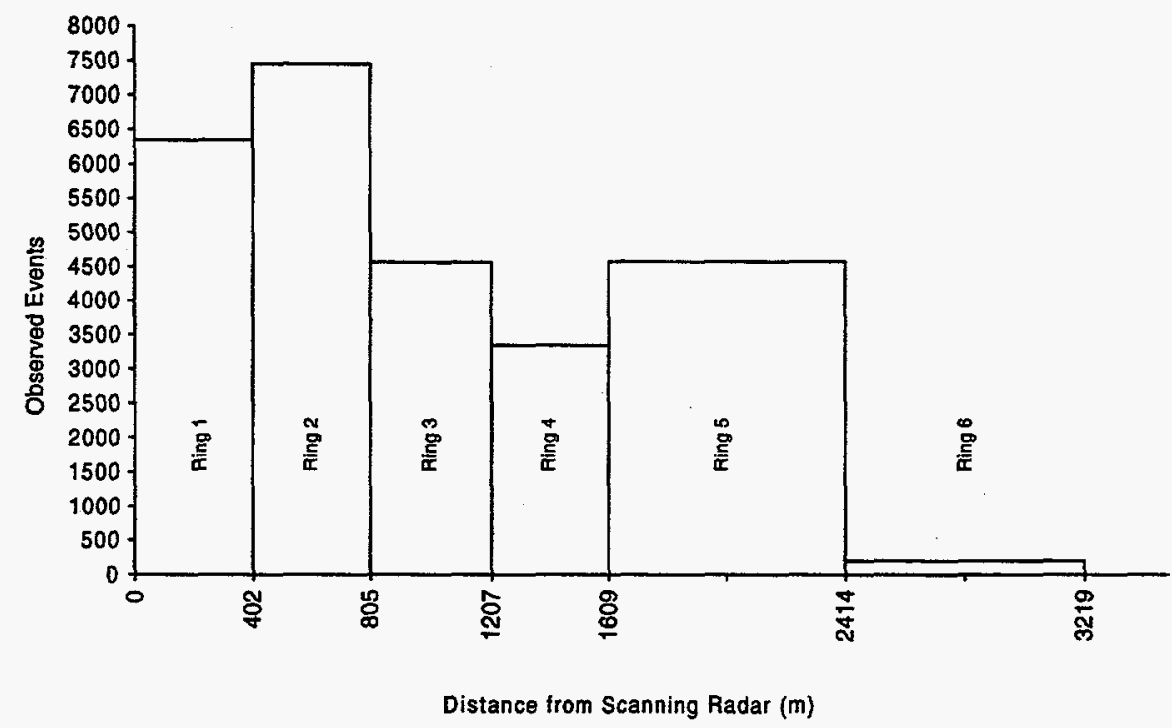

Figure 22. Total number of events detected within each of six range rings surrounding scanning radar, NHWRA, autumn 1995.

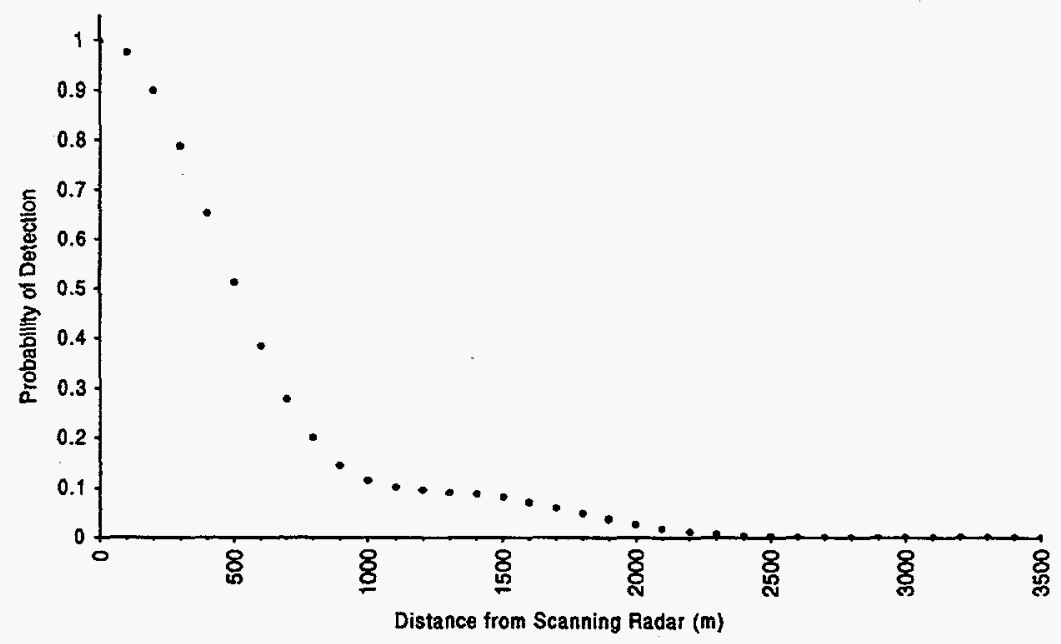

Figure 23. Probability of detection of targets at increasing distance from scanning radar, NHWRA, autumn 1995. 
Table 11. Adjusted and Expected Number of Events in each Range Ring, Calculated from Those Detected by Scanning Radar, NHWRA, Autumn 1995.

\begin{tabular}{ccccc}
\hline Range Ring & $\begin{array}{c}\text { No. Events } \\
\text { Detected }\end{array}$ & $\begin{array}{c}\text { Adjusted No. } \\
\text { of Events }\end{array}$ & Expected $^{1}$ & $\begin{array}{c}\text { Difference }^{2} \text { from } \\
\text { Expected }^{2}\end{array}$ \\
\hline 1 & 6,343 & 7,063 & $8,219.74$ & Less \\
2 & 7,451 & 19,494 & $24,659.24$ & Less \\
3 & 4,564 & 39,948 & $41,098.75$ & Less \\
4 & 3,347 & 38,909 & $57,538.25$ & Less \\
5 & 4,577 & 190,497 & $164,395.02$ & More \\
\hline Total & 26,282 & 295,911 & 295,911 & \\
\hline
\end{tabular}

Calculated by area of range ring relative to total area scanned.

${ }^{2}$ Bonferroni Test, $\mathrm{P}<0.05$.

Adjusted number of events "In" and "Out" of NHWRA was different from expected $\left(X^{2}=1176.8, P<0.0001\right)$. There were fewer than expected results "In" and more than expected "Out" (see Table 12). Number of adjusted events/ha/hr was 0.22 for five range rings (see Fig. 24).

Vertical radar detected 4,228 events within six linear-distance categories in autumn 1995 (see Fig. 25). Distance categories were not equal to width of respective range ring (n.b., Fig. 9). The DISTANCE program generated a detection-probability curve from the distribution of events detected by distance category (see Fig. 26). The detection-probability curve did not mirror the curve generated from the scanning radar because the DISTANCE program chose a model that best fit the existing vertical radar data (see Fig. 23). Number of events in each ring was adjusted by detection probability per distance category (see Fig. 27). Adjusted number of events calculated by range ring was different from expected among rings $\left(X^{2}=62.03, P<0.0001\right)$. Fewer events than expected occurred in range rings 1 and 4 and more than expected in 5 and 6 (see Table 11).

Table 12. Adjusted and Expected Number of Events "In" and "Out" of NHWRA, Calculated from Detections by Scanning and Vertical Radars, Autumn 1995.

\begin{tabular}{rlcccc}
\hline $\begin{array}{c}\text { Radar } \\
\text { Array }\end{array}$ & Area & \multicolumn{2}{c}{ Number of Events } & & Difference $^{2}$ \\
\cline { 3 - 4 } & & Detected & Adjusted & Expected & from Expected $^{1}$ \\
\hline Scanning & In & 9,252 & 16,147 & $20,931.4$ & Less \\
& Out & 17,030 & 279,764 & $274,979.6$ & More \\
\multirow{2}{*}{ Vertical } & In & 1,441 & 1,490 & 1,198 & More \\
& Out & 2,787 & 8,094 & 8,386 & Less \\
\hline
\end{tabular}

${ }^{1}$ Calculated from Adjusted, $P<0.05$.

${ }^{2}$ Bonferroni Test, $\mathrm{P}<0.05$. 


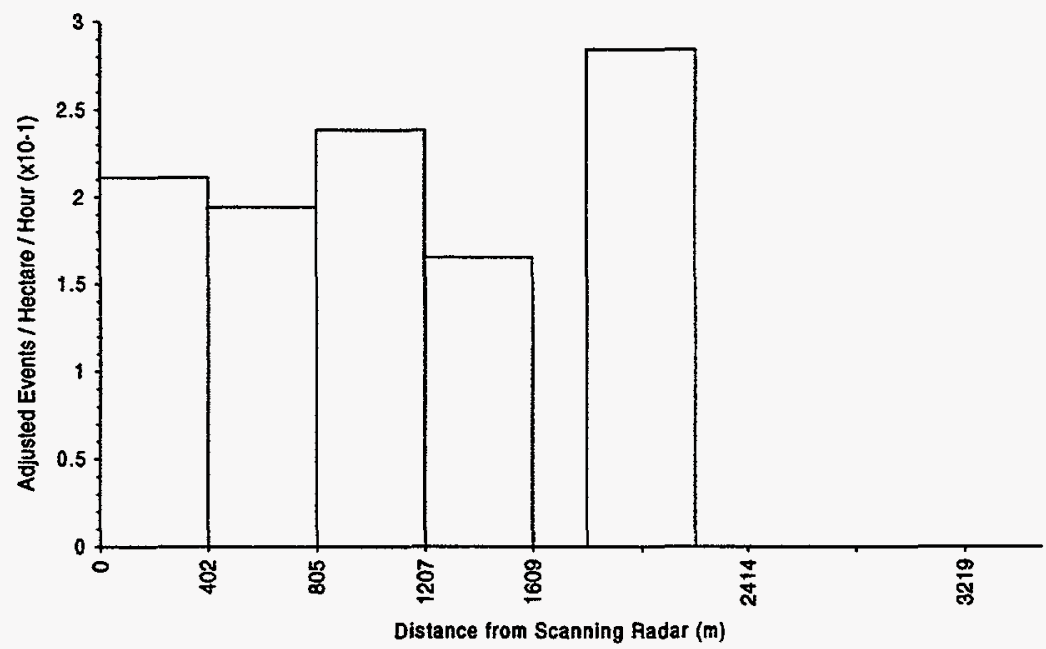

Figure 24. Adjusted number of events/hectare/hour within each of five proximate range rings surrounding scanning radar, NHWRA, autumn 1995.

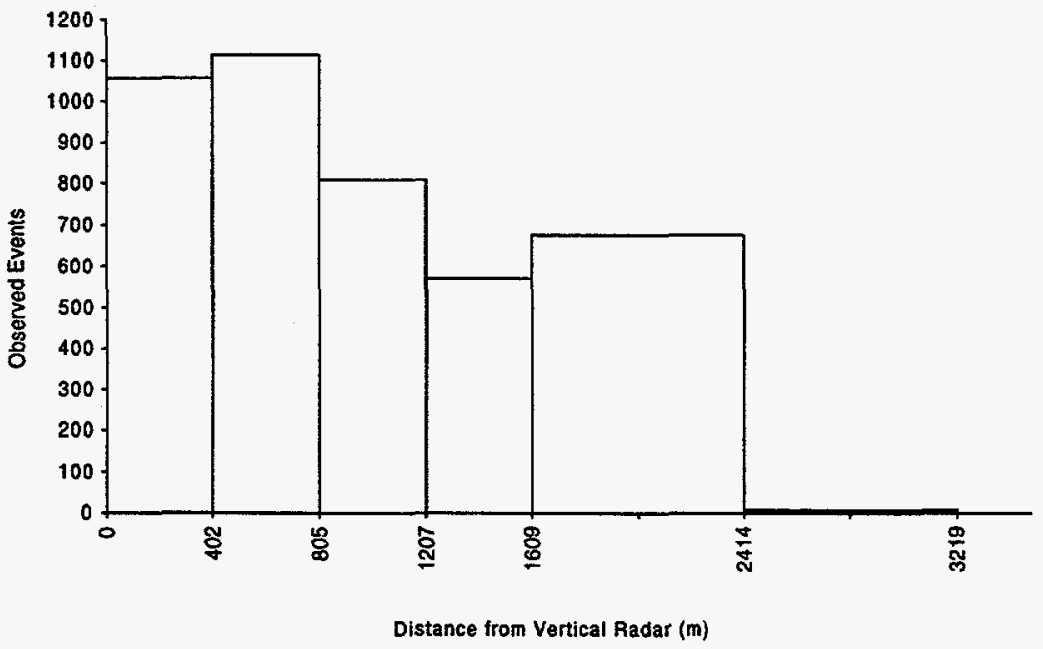

Figure 25. Total number of events detected by vertical radar within each of six distance categories east and west of radar combined, NHWRA, autumn 1995. 


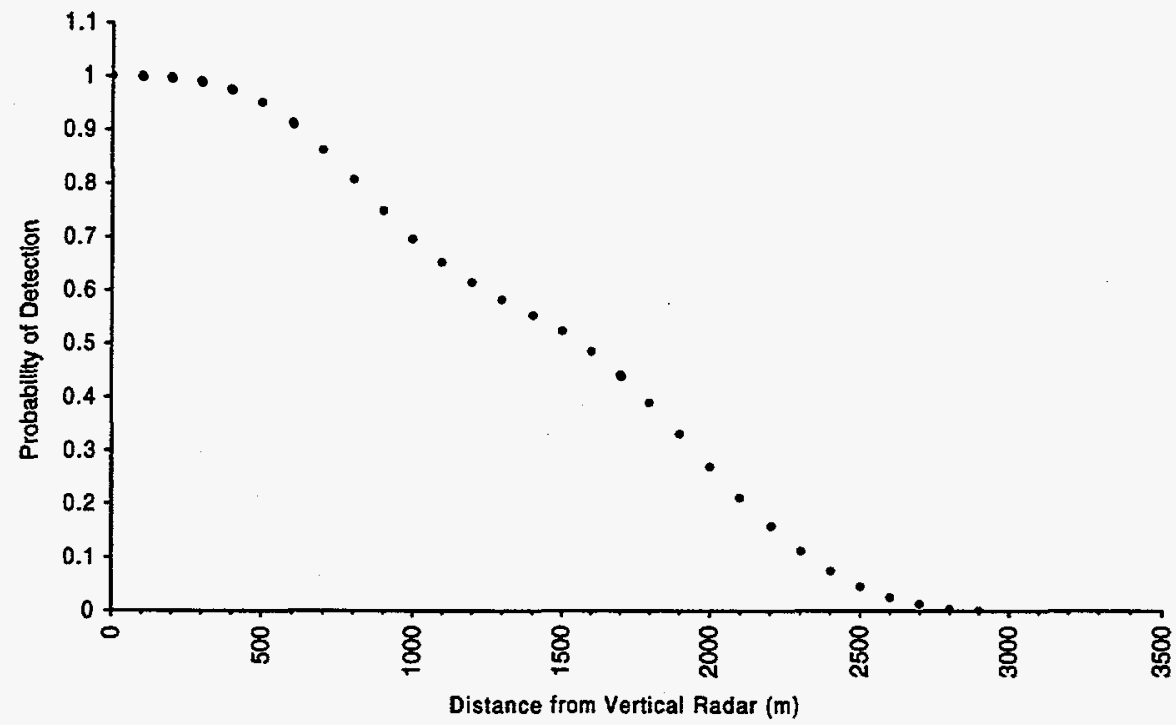

Figure 26. Probability of detection of targets at increasing distance from vertical radar, NHWRA, autumn 1995.

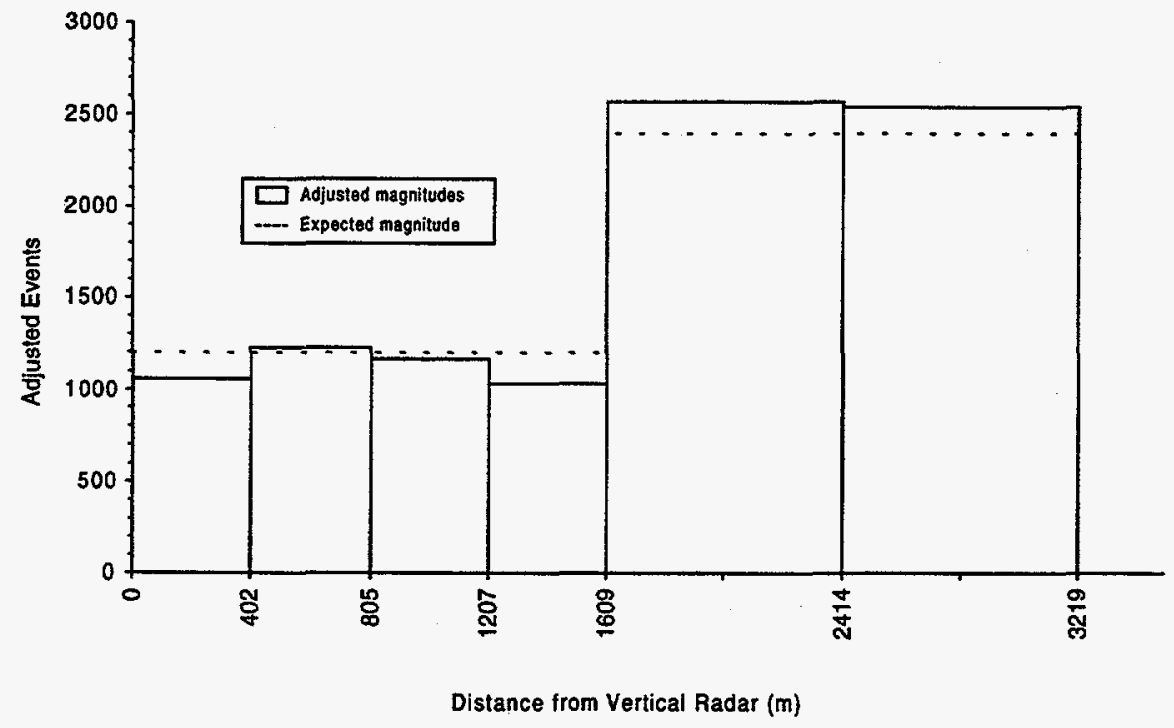

Figure 27. Adjusted number of events within each horizontal distance category (east and west combined) from vertical radar, NHWRA, autumn 1995. 
Adjusted number of events calculated "In" and "Out" of NHWRA were also different from expected for vertical monitoring $\left(X^{2}=81.34, \mathrm{P}<0.0001\right)$. More events than expected resulted "In" and fewer than expected "Out" (see Table 12). The number of adjusted events $/ \mathrm{m} / \mathrm{hr}$ was 0.0025 . No relationship of adjusted number of events with topography was evident (see Fig. 28), probably due to large width of distance categories used in analysis and because direction from radar to event was not recorded in 1995.

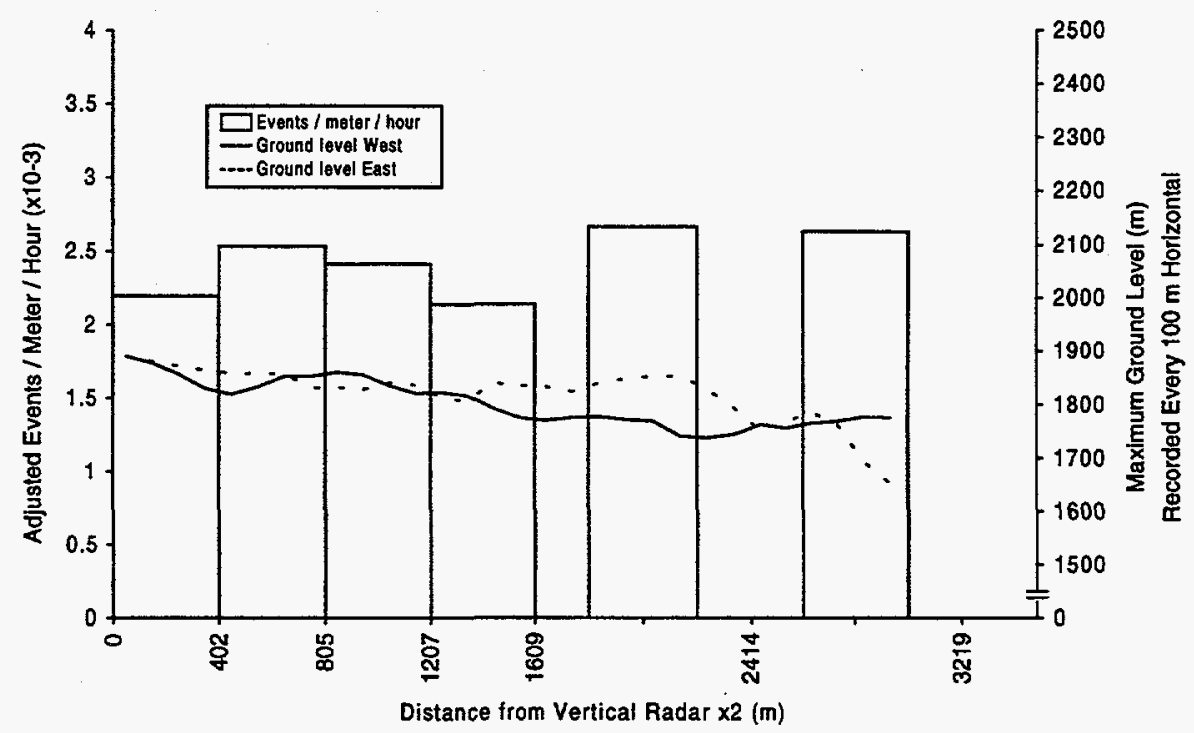

Figure 28. Adjusted number of events/m/hr within each of six horizontal distance categories (east and west combined) from vertical radar relative to ground level, NHWRA, autumn 1995.

Spring 1996. Scanning radar data revealed 20,030 events within NHWRA and five Reference areas during spring 1996 (see Fig. 29). The DISTANCE program generated a detection-probability curve based on distribution of events detected (see Fig. 30) and number of events was adjusted for each area (see Table 13). Adjusted number of events in NHWRA and Reference areas were different from expected $\left(X^{2}=335.2, \mathrm{P}<\right.$ 0.0001). More events than expected occurred in two of three Reference areas west of NHWRA and fewer than expected in eastern Reference areas and NHWRA (see Table 13).

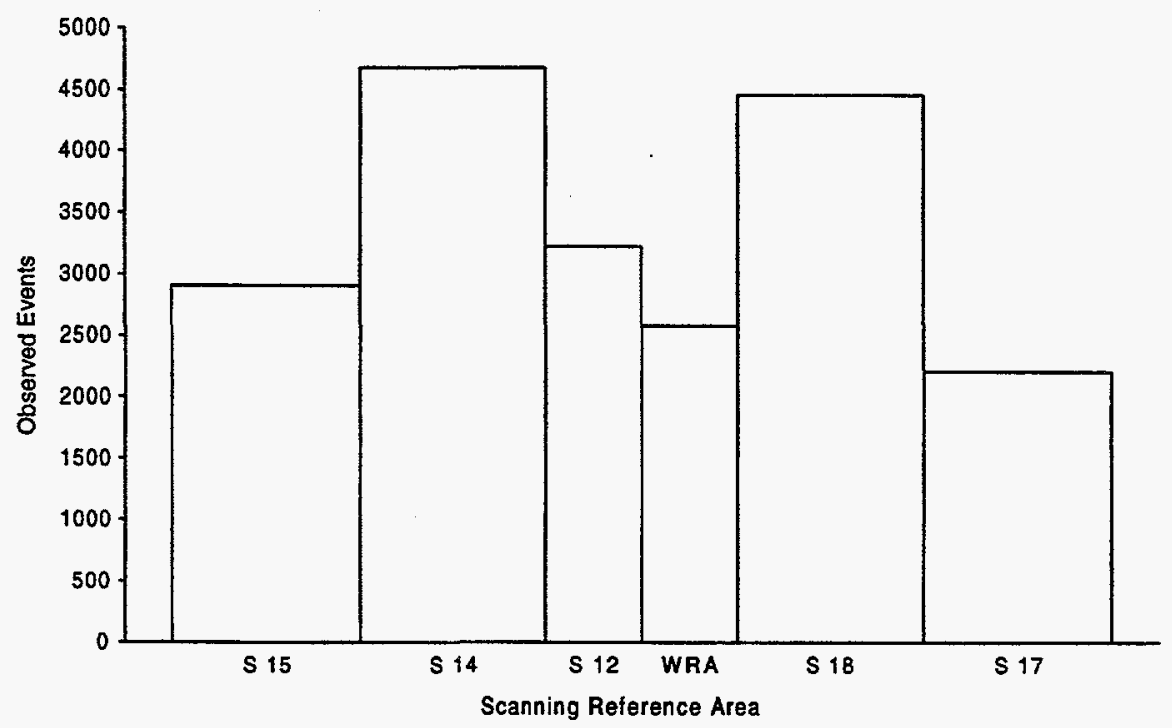

Figure 29. Number of events detected in NHWRA and each Reference area (S12-S18) by scanning radar at range setting $3 \mathrm{~nm}(5.6 \mathrm{~km})$, spring 1996. 


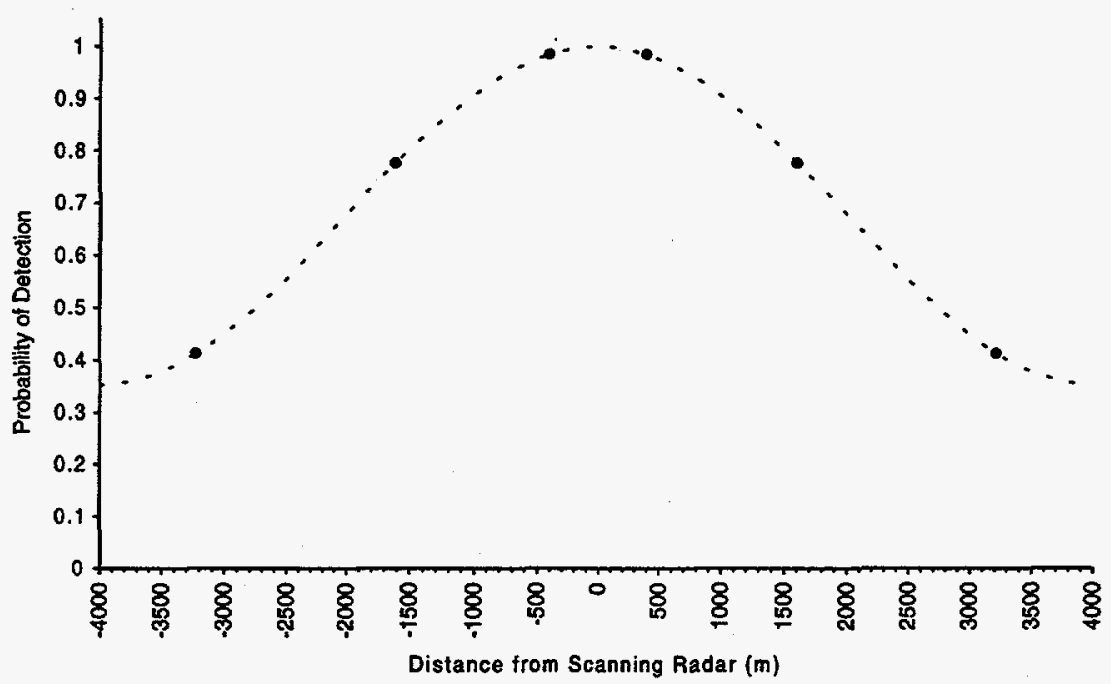

Figure 30. Probability of detection of targets at increasing distance east (R) and west (L) of scanning radar, NHWRA, spring 1996.

Table 13. Adjusted and Expected Number of Events in NHWRA and Reference Areas (S12-S18) Calculated from Events Detected by Scanning Radar, Spring 1996.

\begin{tabular}{|c|c|c|c|c|c|}
\hline \multirow{2}{*}{ Area ${ }^{1}$} & \multirow{2}{*}{$\begin{array}{l}\text { Direction } \\
\text { from Radar }\end{array}$} & \multicolumn{3}{|c|}{ No. Events } & \multirow{2}{*}{$\begin{array}{c}\text { Difference }^{3} \\
\text { from } \\
\text { Expected }\end{array}$} \\
\hline & & Detected & Adjusted & Expęcted & \\
\hline S15 & SW & 2,905 & 7,015 & $5,995.8$ & More \\
\hline S14 & SW & 4,671 & 6,018 & $5,995.8$ & None \\
\hline S12 & W & 3,222 & 3,274 & $2,997.9$ & More \\
\hline NHWRA & & 2,578 & 2,620 & $2,997.9$ & Less \\
\hline S18 & $\mathrm{SE}$ & 4,454 & 5,739 & $5,995.8$ & Less \\
\hline S17 & SE & 2,200 & 5,313 & $5,995.8$ & Less \\
\hline
\end{tabular}

${ }^{1}$ Reference sections were $2.59 \mathrm{~km}^{2}\left(1 \mathrm{mi}^{2}\right)$ except for sect. 12 . West $1 / 2$ sect. 12 was Reference, east $1 / 2$ was impact (see Fig. 5).

${ }^{2}$ Calculated by size of area relative to total searched.

${ }^{3}$ Bonferroni Test, $\mathrm{P}<0.05$. 
Number of events "In" and "Out" of NHWRA were different from expected $\left(X^{2}=52.93, P<0.0001\right)$. Fewer than expected occurred "In" and more than expected "Out" (see Table 14). Average adjusted events /ha/hr was 0.17 for NHWRA and the five Reference areas (see Fig. 31).

\begin{tabular}{|c|c|c|c|c|c|}
\hline \multirow{2}{*}{$\begin{array}{l}\text { Radar } \\
\text { Array }\end{array}$} & \multirow{2}{*}{ Area } & \multicolumn{2}{|c|}{ Number of Events } & \multirow{2}{*}{ Expected $^{1}$} & \multirow{2}{*}{$\begin{array}{l}\text { Difference } \\
\text { from Expected }\end{array}$} \\
\hline & & Detected & Adjusted & & \\
\hline \multirow[t]{2}{*}{ Scanning } & In & 2,578 & 2,620 & $2,997.9$ & Less \\
\hline & Out & 17,452 & 27,359 & $26,981.1$ & More \\
\hline \multirow[t]{2}{*}{ Vertical } & In & 1,509 & 1,605 & $1,563.6$ & None \\
\hline & Out & 4,366 & 10,807 & $10,848.4$ & None \\
\hline
\end{tabular}

${ }^{1}$ Calculated from Adjusted.

${ }^{2}$ Bonferroni Test, $\mathrm{P}<0.05$.

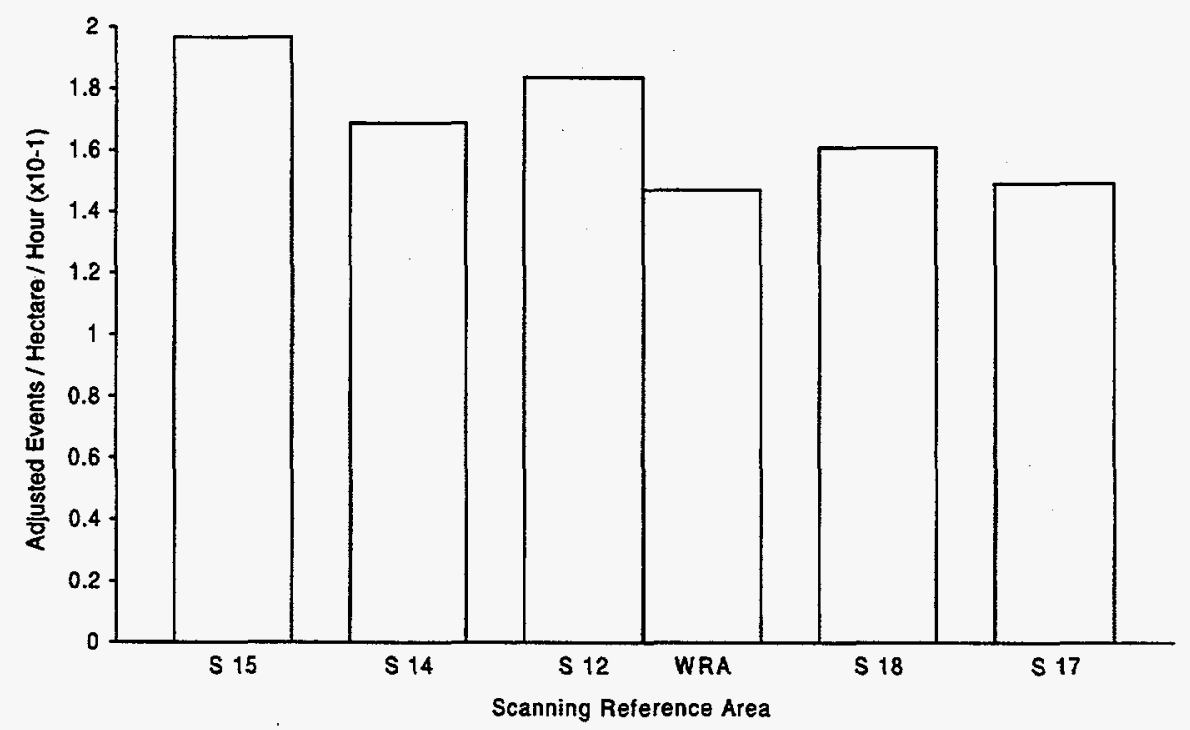

Figure 31. Adjusted number of events (from events detected by scanning radar) per hectare/hour within each reference area (S12-S18) and NHWRA, spring 1996. 
Vertical radar detected 5,875 events distributed among 100-m (328-ft) distance categories within $2.4 \mathrm{~km}(1.5$ mi) of radar location in spring 1996 (see Fig. 32). The DISTANCE program generated a detection-probability curve (see Fig. 33) and number of events adjusted in each distance category (see Fig. 34). Average adjusted events $/ \mathrm{m} / \mathrm{hr}$ was 0.0167 , calculated from 12,412 adjusted events. More events occurred over swales and valleys and less over peaks within $2,000 \mathrm{~m}$ (1.2 mi) of radar location. The largest number of events was over the pass to the west and lowest number over Bear Trap Canyon to the east of the radar location (see Fig. 35).

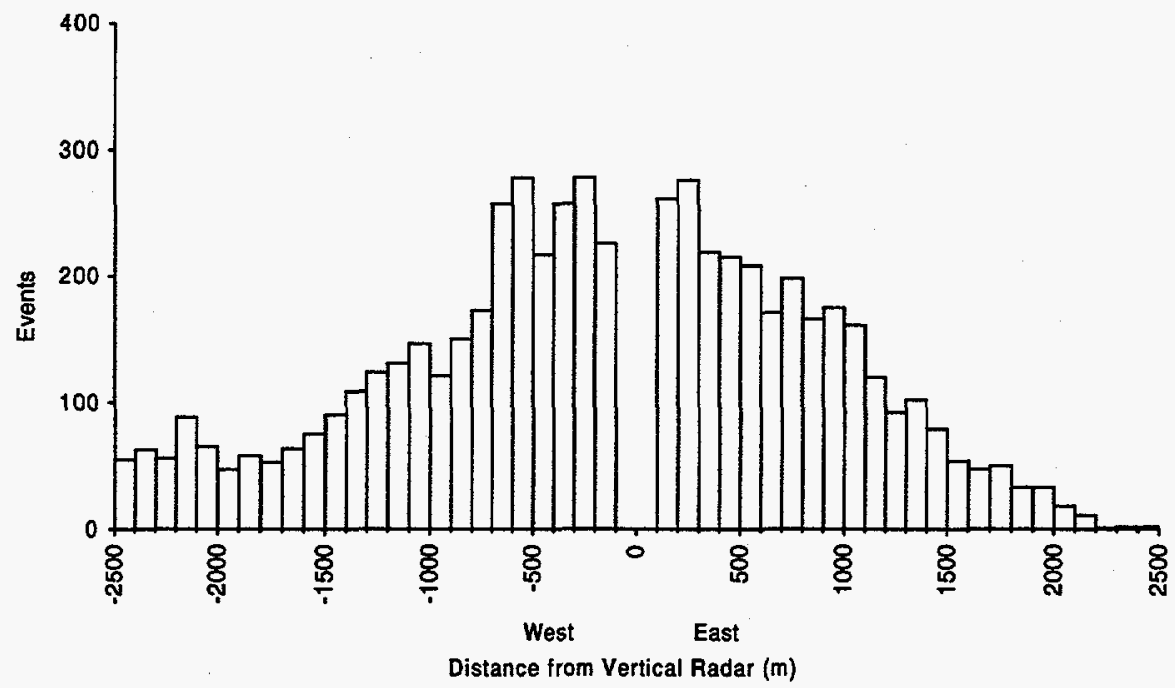

Figure 32. Distribution of events detected by vertical radar within 100-m (328-ft) horizontal distance categories, NHWRA, spring 1996.

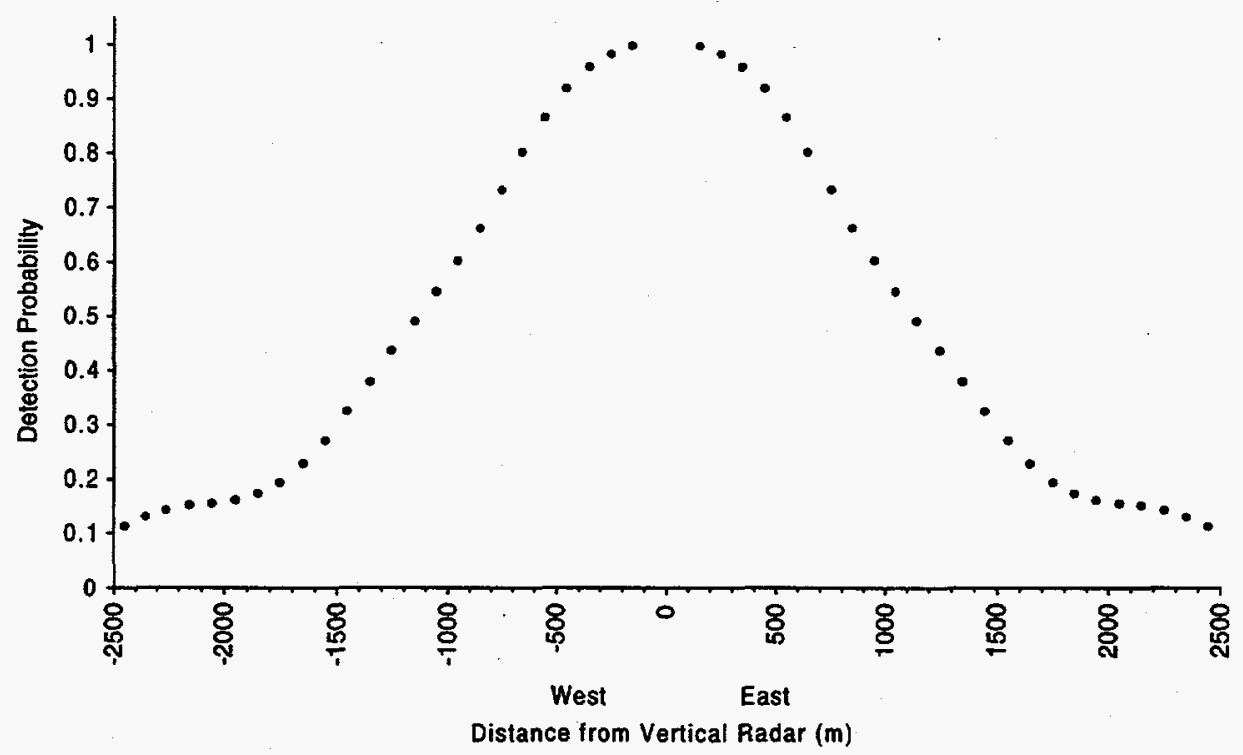

Figure 33. Detection probability of targets at increasing distance east (R) and west (L) of vertical radar, NHWRA, spring 1996. 


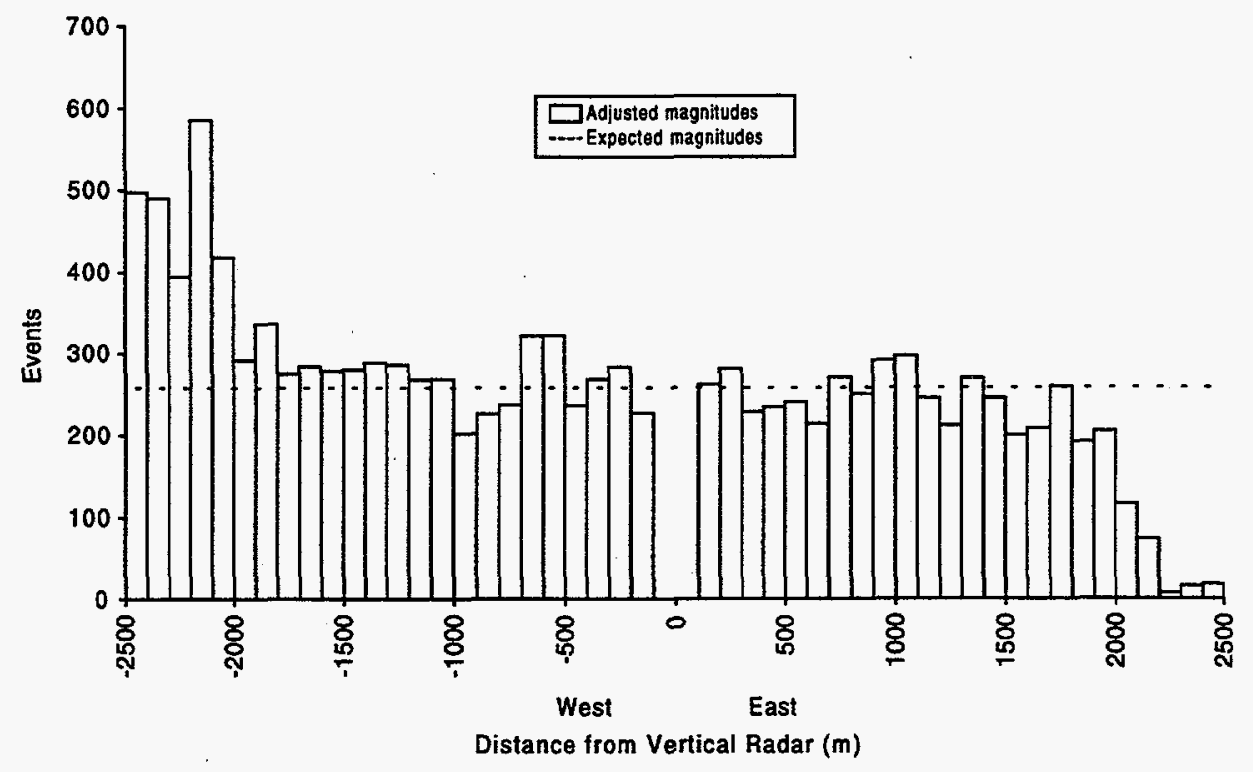

Figure 34. Adjusted number of events within $100 \mathrm{~m}$ (328 ft) distance categories east and west of vertical radar, NHWRA, spring 1996. Horizontal line is expected equal distribution.

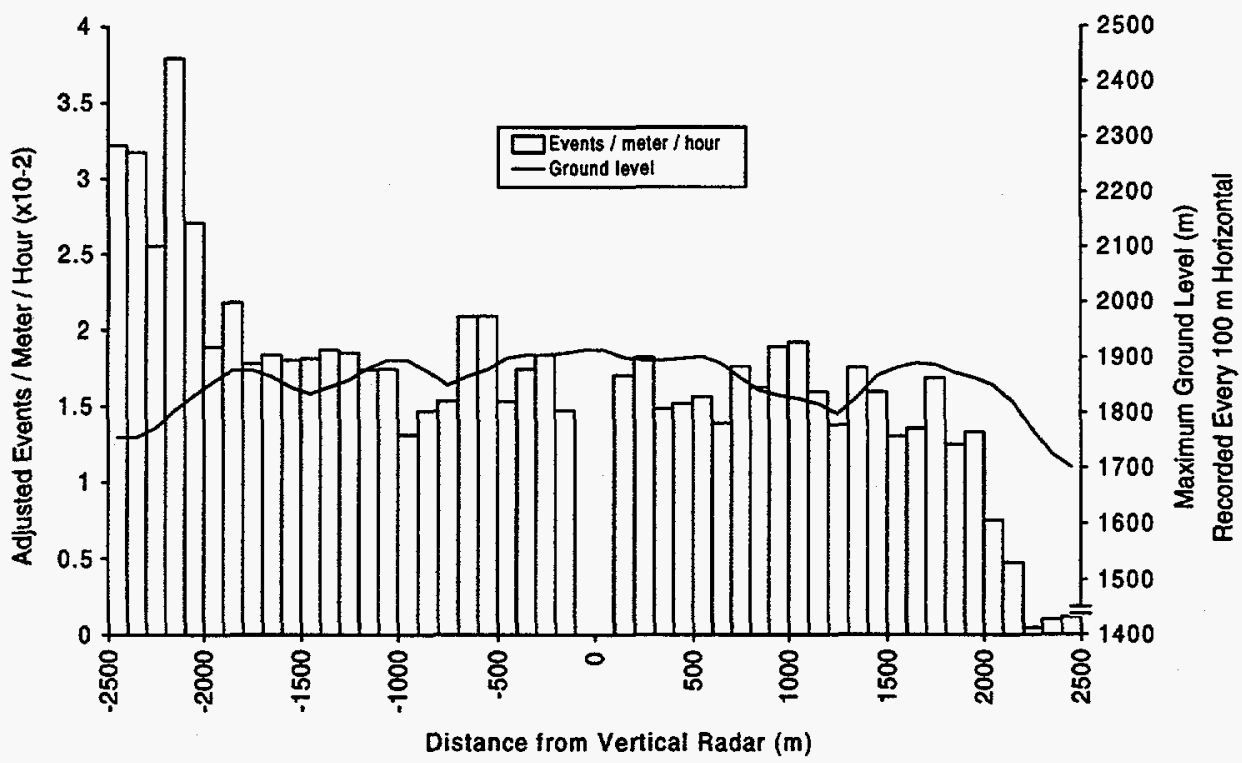

Figure 35. Adjusted number of events/m/hr in each $100 \mathrm{~m}$ (328 ft) distance category relative to ground level east and west of vertical radar, NHWRA, spring 1996.

Adjusted numbers of events were pooled into $500 \mathrm{~m}(1640 \mathrm{ft})$ distance categories east and west for more meaningful analysis and to minimize Type I error; differences would have resulted just by virtue of a large number of events and distance categories. Resultant adjusted numbers of events per category were still different from expected $\left(X^{2}=1,871.00, P<0.0001\right)$. Fewer events than expected occurred beyond $1.5 \mathrm{~km}$ $(4922 \mathrm{ft}$ ) to the east of radar but more than expected occurred beyond $1 \mathrm{~km}(0.6 \mathrm{mi})$ to the west (Bonferroni Test, $P<0.05$ ). Adjusted numbers of events "In" and "Out" of NHWRA were not different from expected $\left(X^{2}=1.26, P=0.26\right)$ (see Table 14$)$. 


\section{Altitudinal Profile}

Mean altitude of all events detected by vertical radar in autumn 1995 was $209.3 \mathrm{~m}(687 \mathrm{ft}$ ) above radar ( $\mathrm{n}=$ $5,324, \mathrm{SD}=246)$. Range of altitudes detected was 0-2,000 m (6562 ft). Median altitude above radar was

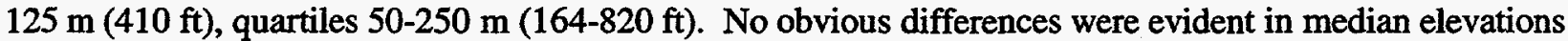
(above sea level) among six distance categories based on visual inspection of quartile distributions (quartile ranges overlapped) (see Fig. 36). Median elevation of events within distance categories showed no apparent relationship to topography, probably because of large and varying width of range rings, and because direction to targets was not recorded in autumn 1995 (see Fig. 36).

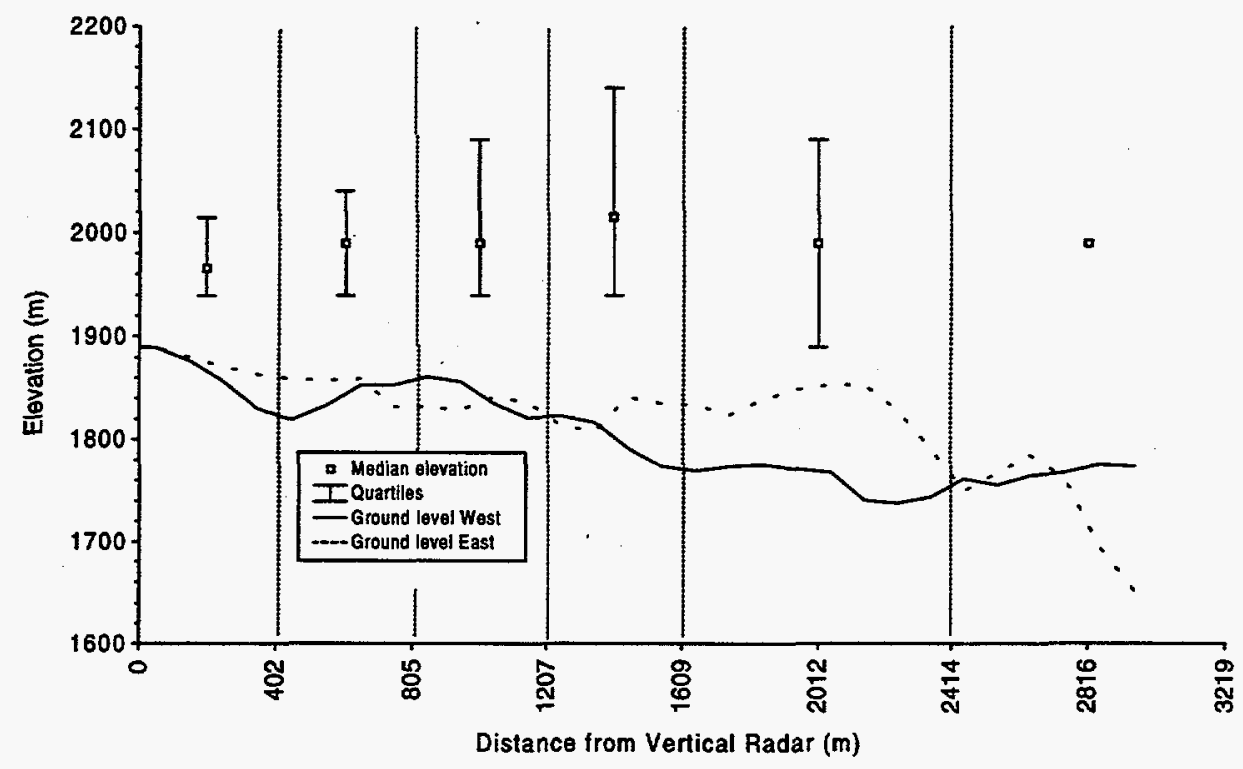

Figure 36. Median elevation (above sea level) of events detected by vertical radar within each range ring relative to ground level, NHWRA, autumn 1995. Number of events both east and west of radar were combined.

Mean altitude of events-detected by vertical radar in spring 1996 was $388.2 \mathrm{~m}(1,274 \mathrm{ft})$ above radar $(\mathrm{n}=$ 7,521, $\mathrm{SD}=423.1)$ and $404.5 \mathrm{~m}(1,327 \mathrm{ft})$ AGL ( $=5,873, \mathrm{SD}=416.6)$. Range of altitudes was 0-4,554.2 m (14,942 ft). However, it was clear vertical radar detected only events at an elevation of the radar or above (see Fig. 37). Median altitude above radar and AGL was $265 \mathrm{~m}(869 \mathrm{ft})$, quartiles 107-554 $\mathrm{m}(351-1,818 \mathrm{ft})$ and $274.8 \mathrm{~m}$ (902 ft), quartiles $138-539 \mathrm{~m}(453-1,770 \mathrm{ft})$, respectively. A positive correlation $\left(\mathrm{r}^{2}=0.43, \mathrm{P}<\right.$ 0.0001 ) was found between median flight elevation and ground level (excluding three medians derived by less than three samples), indicating birds tended to fly at a fairly uniform height above the ground (see Fig. 38). 


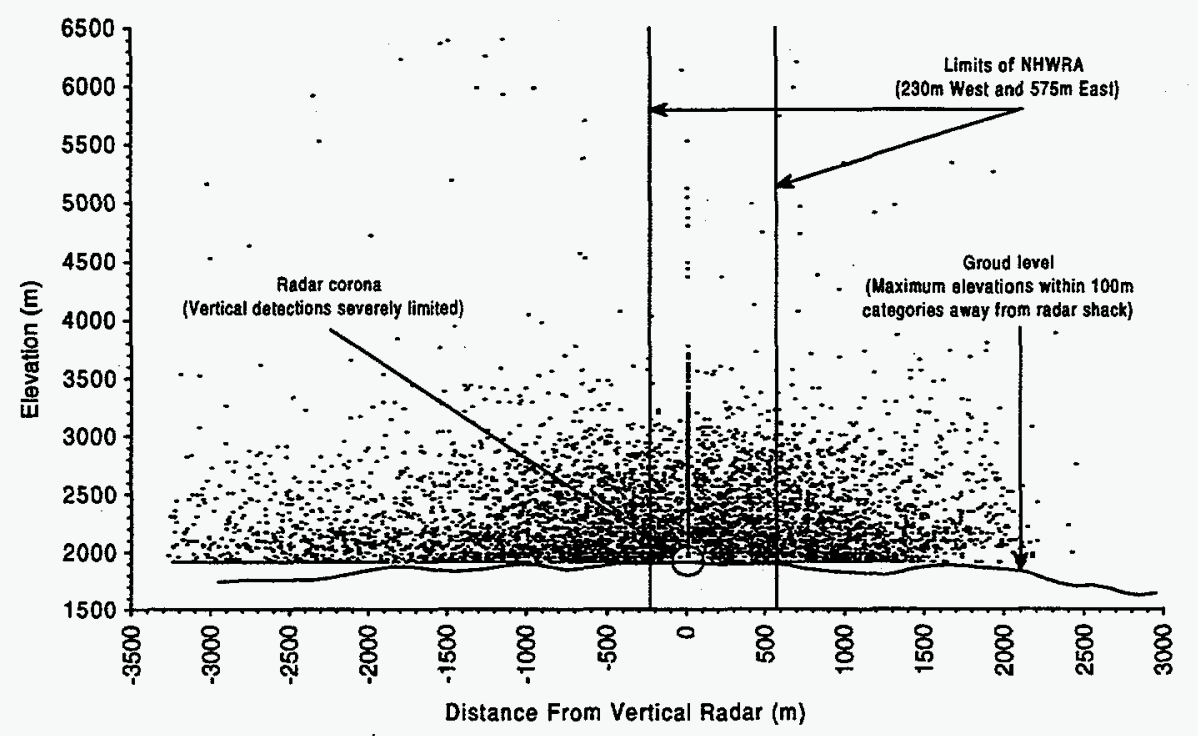

Figure 37. Elevational distribution (above sea level) of all events detected by vertical radar, NHWRA, spring 1996.

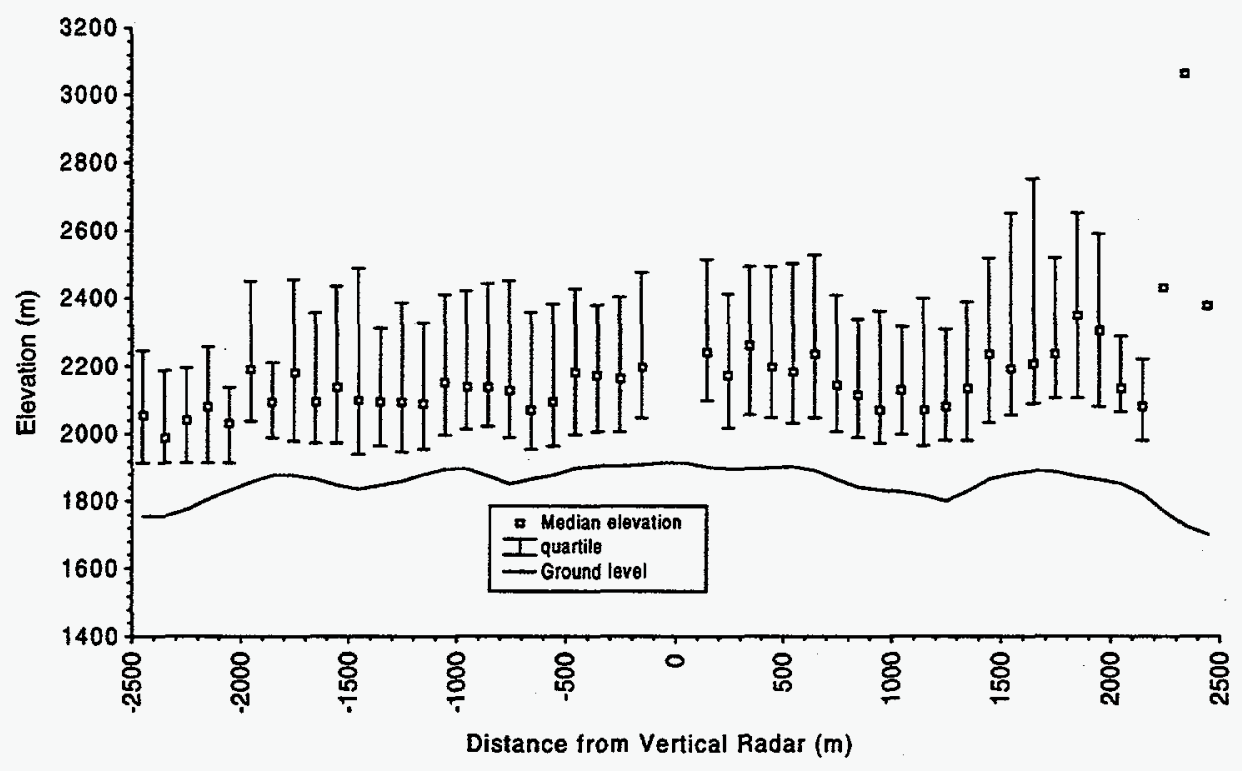

Figure 38. Median elevation (above sea level) of events within each $100 \mathrm{~m}$ horizontal distance category, east and west of vertical radar, NHWRA, spring 1996.

\section{Temporal Profile of Migration}

Autumn 1995. Duration of autumn migration was $\sim 3$ months, from early September to late November, peaking in late October (see Figs. 39 and 40). Passage rates ranged from 0 to 462 events per hour $(\square=41.15$, $\mathrm{SD}=55.85$ ) over 687 sample blocks (full hours or portions of hours) monitored with scanning radar. Highest passage rates occurred within 4 hrs of sunset (see Fig. 41). Lowest rates were recorded between 0100-0700 and 1300-1800 hrs. However, hourly passage rates were most likely not representative of the true pattern of passage. Periods between $0100-0700 \mathrm{hrs}$ were not adequately sampled and vertical radar was inoperable from 18-29 October (peak migration). 


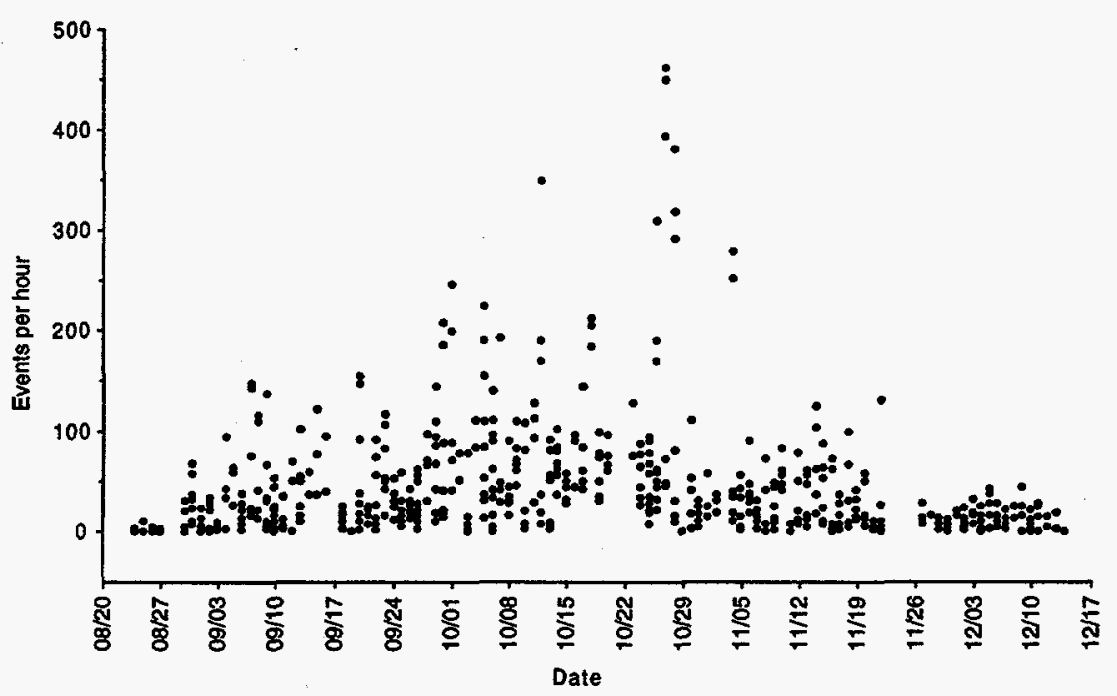

Figure 39. Daily passage rate of events detected by scanning radar between 20 August and 14 December 1995, NHWRA.

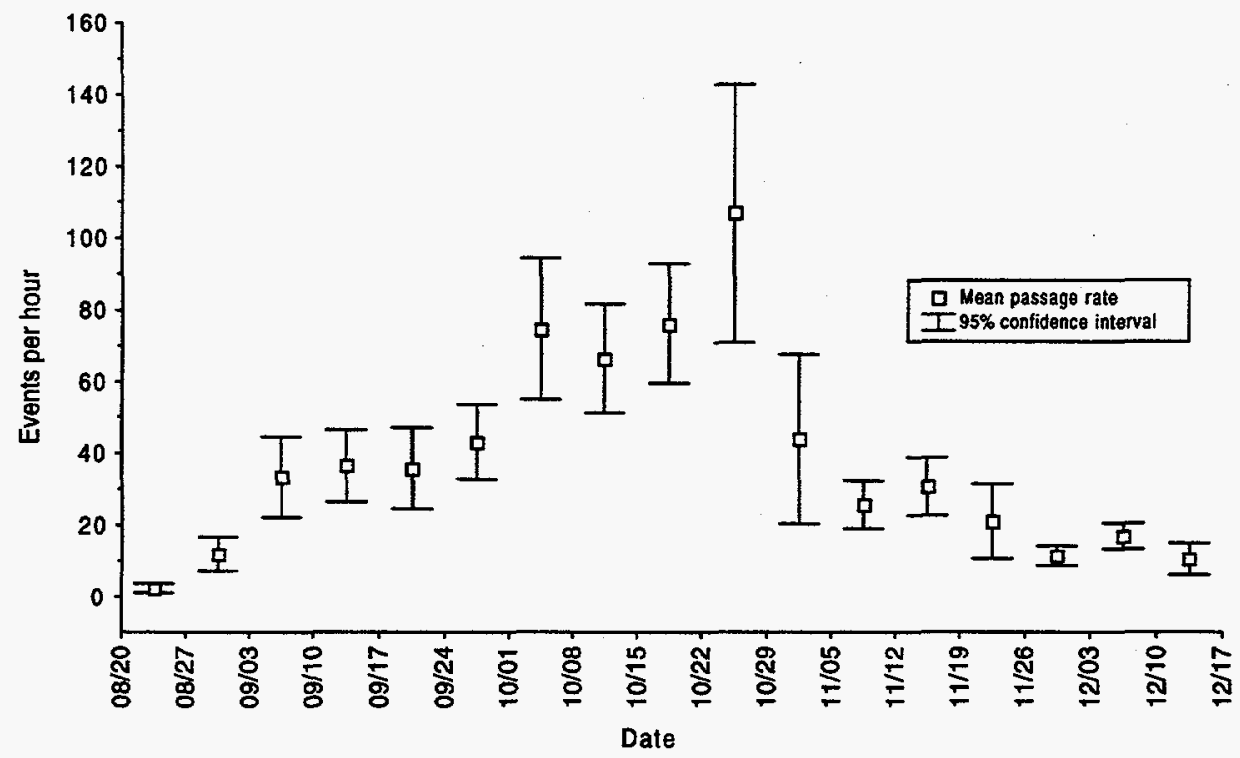

Figure 40. Weekly passage rate of events detected by scanning radar between 20 August and 14 December 1995, NHWRA. 


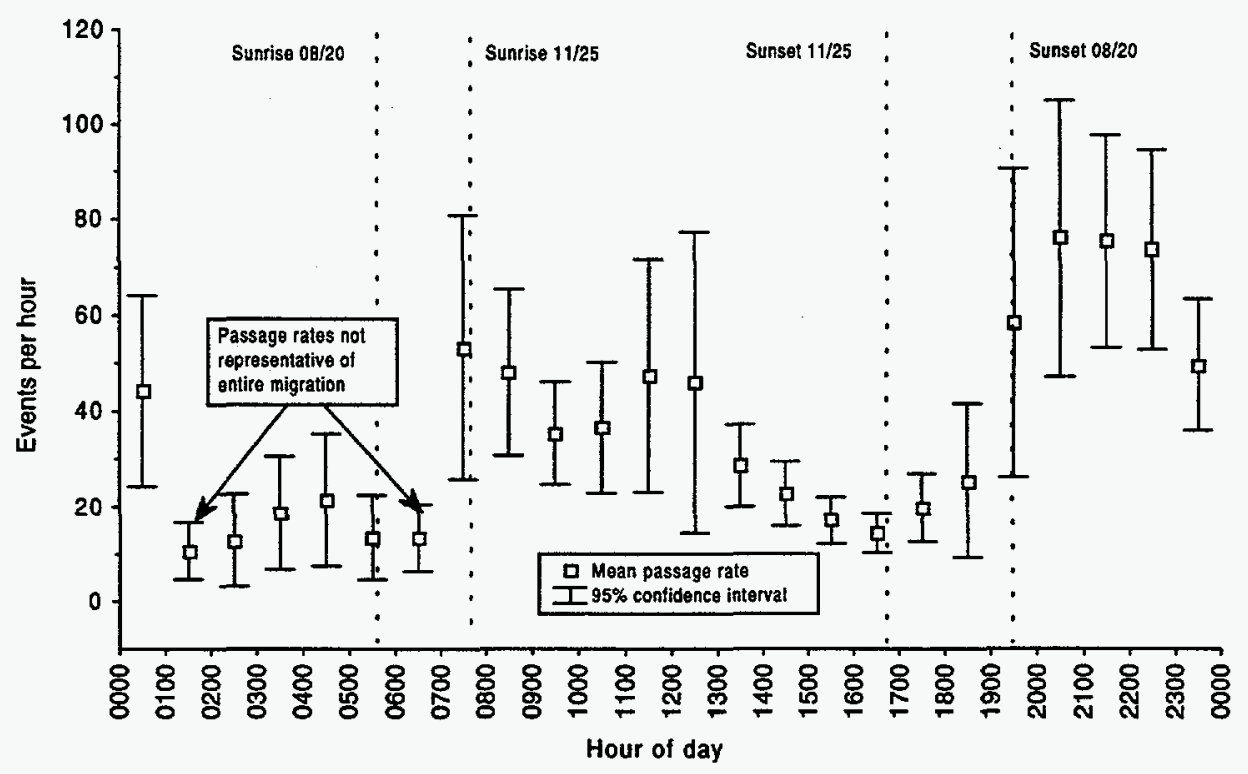

Figure 41. Hourly passage rate of events detected by scanning radar between 20 August and 14 December 1995, NHWRA.

Spring 1996. Duration of vernal migration was $\sim 3$ months, from March to mid-June, possibly peaking in early May (see Figs. 42 and 43). Passage rates ranged from 0 to 3,004 events/hr $(\square=282.82$, SD $=453.12$ ) over 251 sample blocks (full hours or portions of hours) monitored with scanning radar. Weekly mean passage rates did not exhibit a defined peak (as in autumn 1995) but may have been obscured by insect movements after 15 May. If so, spring migration was only $\sim 2$ months long. Rates increased from late April to early June but may have declined subsequently (see Fig. 43). Monitoring ceased in the second week of June so the decline was not confirmed. Passage rates were highest 2 hrs prior to midnight and lowest during daylight hours (see Fig. 44).

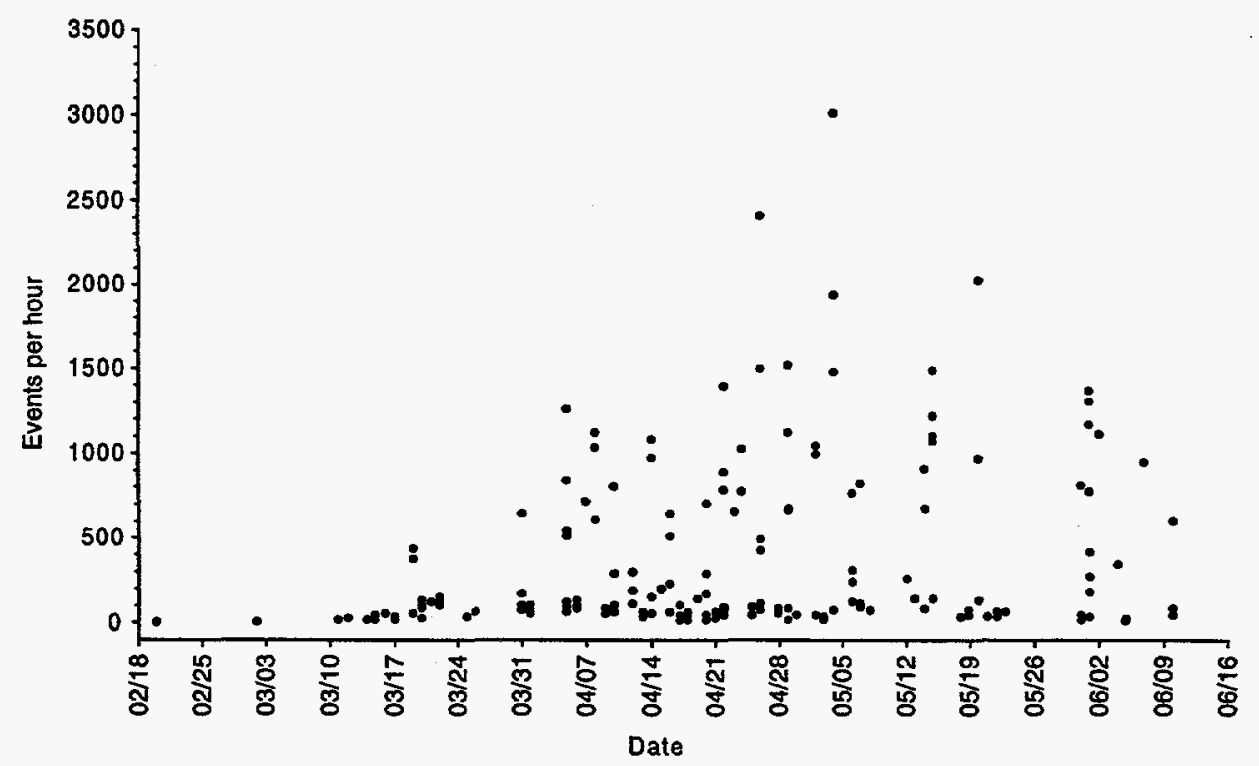

Figure 42. Daily passage rate of events detected by scanning radar between 20 February to 10 June 1996, NHWRA. 


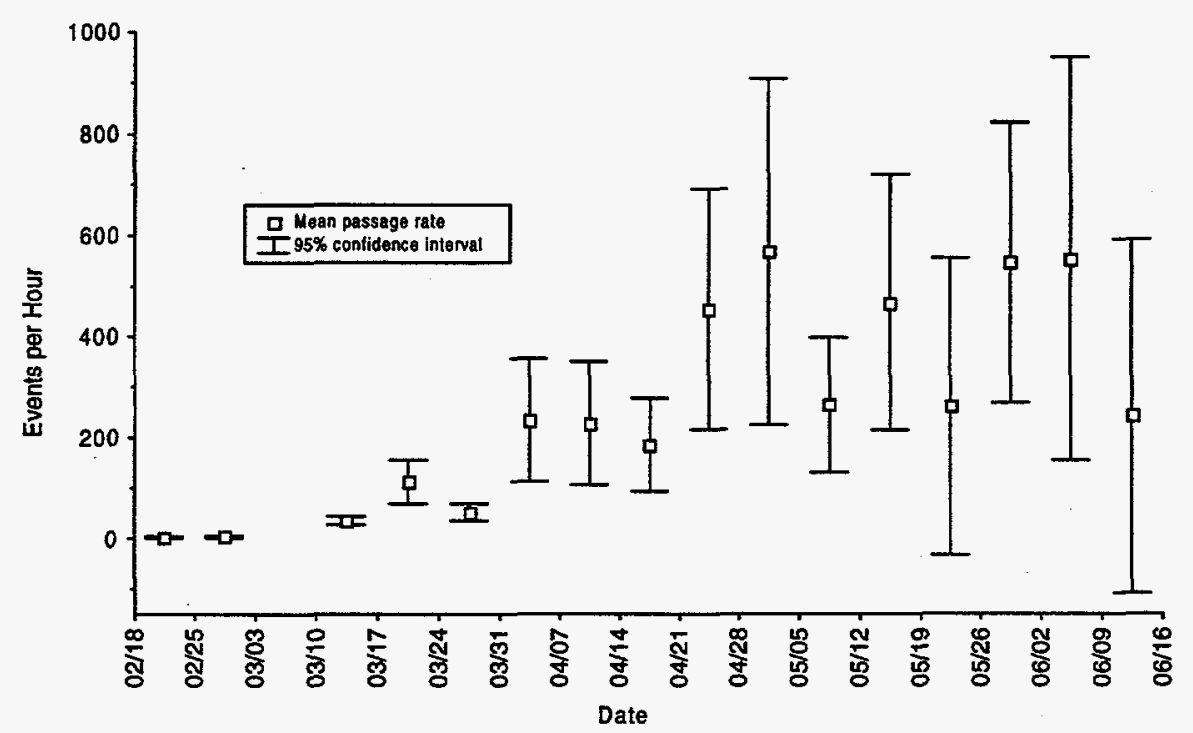

Figure 43. Weekly passage rate of events detected by scanning radar between 20 February and 10 June 1996, NHWRA.

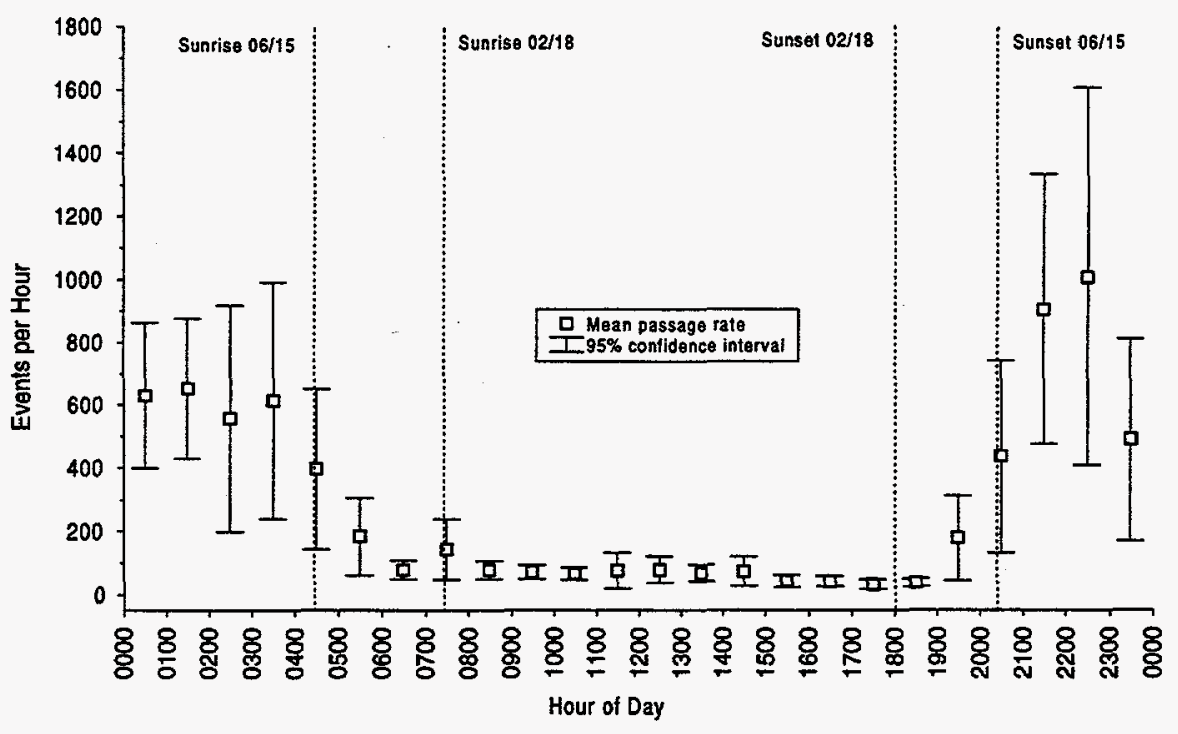

Figure 44. Hourly passage rate of events detected by scanning radar between 20 February and 10 June 1996, NHWRA.

Passage rates determined from vertical radar detections ranged from 0 to 1,091 events per hour $(\square=83.56$, $\mathrm{SD}=162.11$ ) over 233 sample blocks (full hours or portions of hours) in spring 1996 (see Fig. 45); highest mean weekly rate occurred in mid-April (see Fig. 46). Mean weekly rates declined through late April, increased dramatically in early May, and remained relatively constant through early June. A decline in rate similar to that detected by scanning radar was detected in the second week of June. Highest passage rates occurred within $\pm 1 \mathrm{hr}$ of midnight and lowest rates were recorded during daylight hours (see Fig. 47). 


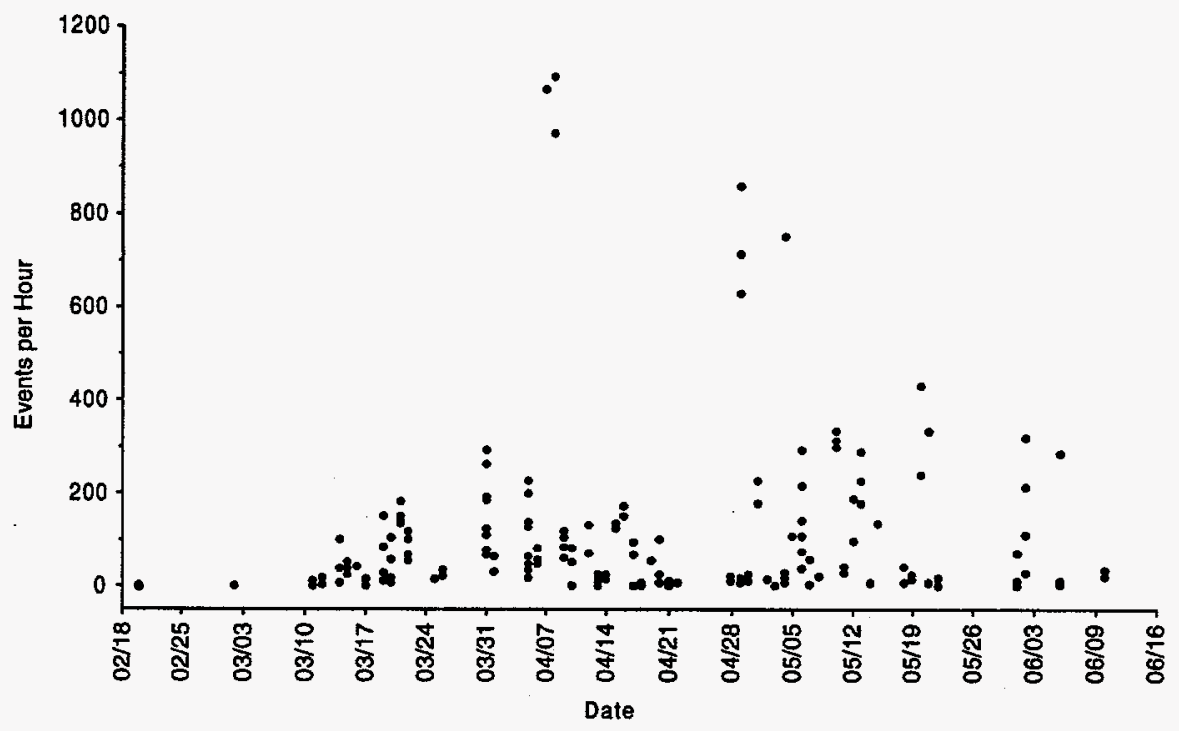

Figure 45. Daily passage rate of events detected by vertical radar between 20 February to 10 June 1996, NHWRA.

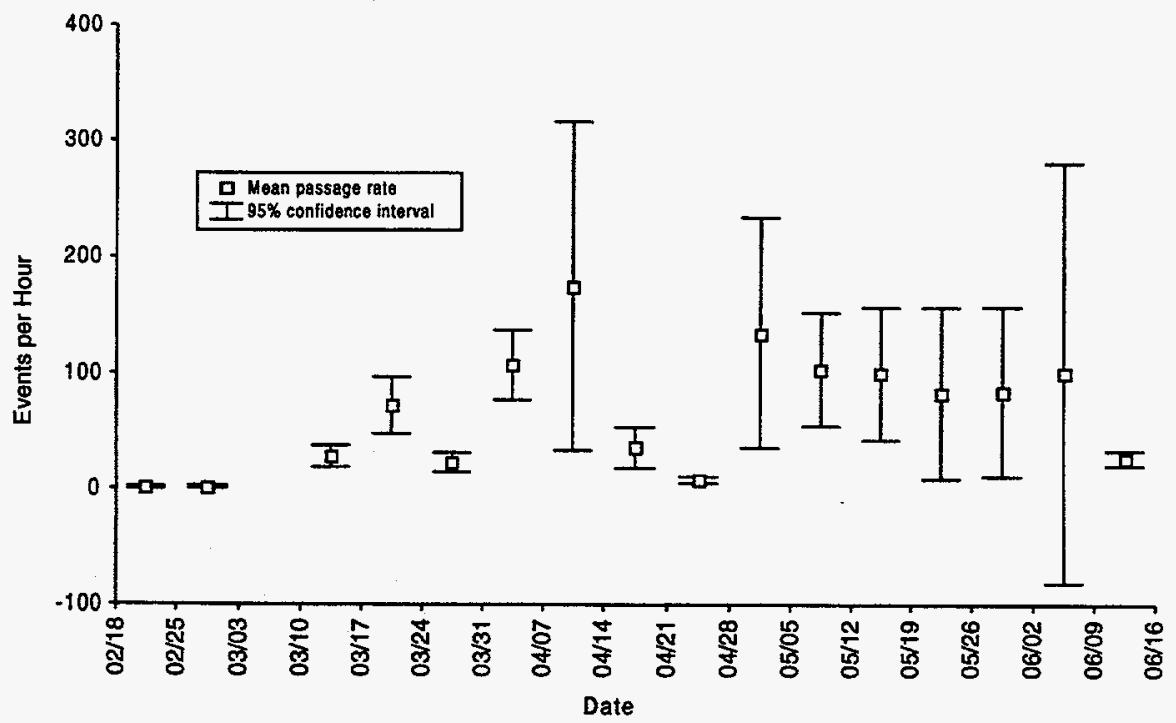

Figure 46. Weekly passage rate of events detected by vertical radar between 20 February and 10 June 1996, NHWRA. 


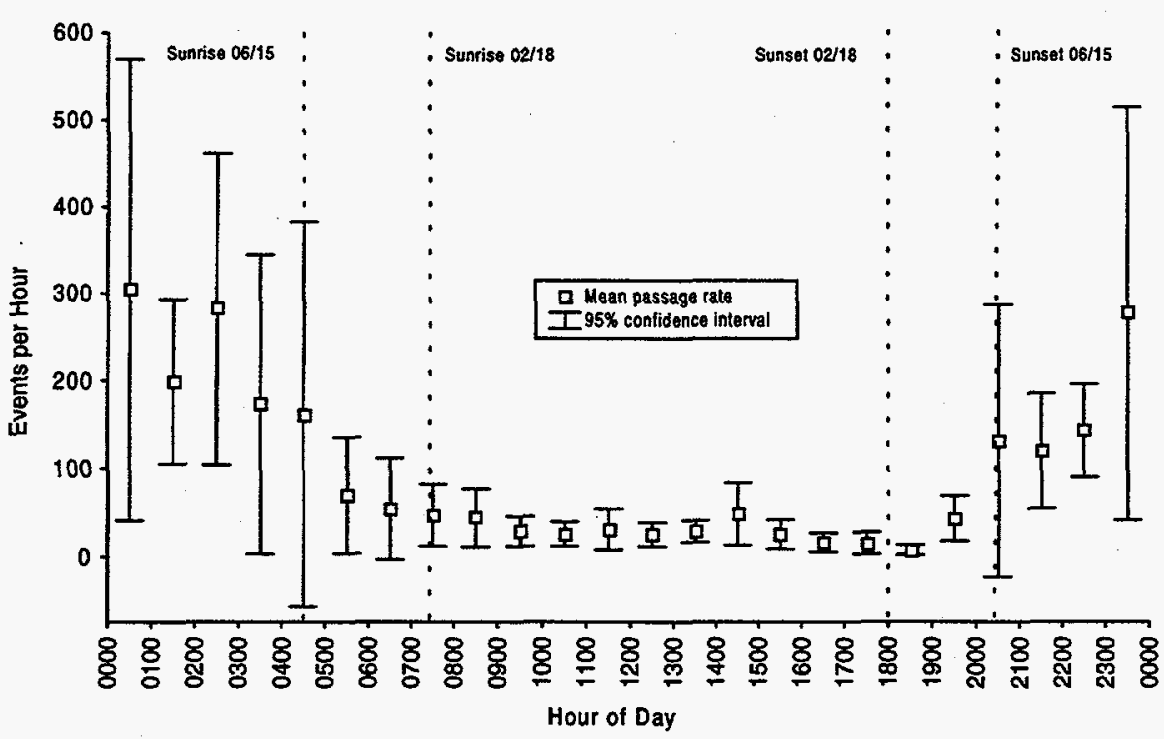

Figure 47. Hourly passage rate of events detected by vertical radar between 20 February and 10 June 1996, NHWRA.

Effect of Weather on Passage Rate. Passage rates detected by scanning radar changed with barometric trends in autumn 1995 (ANOVA, $F=4.551,2,482 \mathrm{df}, \mathrm{P}=0.011$ ) but not in spring 1996 (ANOVA, $\mathrm{F}=1.005$, $2,247 \mathrm{df}, \mathrm{P}=0.3677$ ) (see Table 15). However, passage rates detected by vertical radar did change with barometric trends in spring 1996 (ANOVA, $F=7.914,2,229 \mathrm{df}, \mathrm{P}=0.0005$ ). The Tukey-Kramer multiplecomparison test $(\mathrm{P}<0.05)$ indicated that passage rate (detected by scanning radar) decreased with declining barometric trends in autumn 1995. Conversely, passage rates detected by vertical radar increased with declining barometric trends in spring 1996.

Table 15. Barometric Trends Associated with Mean Passage Rates of Events Detected by Scanning and Vertical Radars, NHWRA, Autumn 1995 and Spring 1996.

\begin{tabular}{lcccccccccc}
\hline & \multicolumn{1}{c}{ Barometric Trend } \\
\cline { 2 - 12 } $\begin{array}{l}\text { Season/Radar Array } \\
\text { (Radar Range nm) }\end{array}$ & \multicolumn{4}{c}{ Steady } & \multicolumn{1}{c}{ Increasing } & \multicolumn{3}{c}{ Decreasing } \\
\cline { 2 - 12 } & $\mathbf{n}$ & $\bar{x}$ & SD & n & $\bar{x}$ & SD & n & $\bar{x}$ & SD \\
\hline $\begin{array}{l}\text { Autumn/Scanning } \\
(1.5)\end{array}$ & 323 & 50.00 & 61.01 & 76 & 51.12 & 63.40 & 86 & 29.62 & 33.07 \\
Spring/Scanning (3.0) & 107 & 252.66 & 439.92 & 80 & 271.10 & 494.92 & 63 & 352.47 & 421.23 \\
Spring/Vertical (1.5) & 91 & 56.76 & 74.45 & 94 & 69.77 & 116.44 & 47 & 164.84 & 292.53 \\
\hline
\end{tabular}




\section{Estimated Magnitude and Altitude of Avian Migration in and near NHWRA}

Number of birds passing within a $2.8-\mathrm{km}(1.7-\mathrm{mi})$ radius of the radar during autumn migration in 1995 was estimated at over 7.4 million (see Table 16). Less than $6 \%$ may have flown over NHWRA, of which $26.9 \%$ (1.5\% of total) may have passed low. An estimated 3.4 million birds passed within a 5.6-km (3.5-mi) radius of the radar site during spring 1996 migration, of which $6.2 \%$ may have passed over NHWRA. Less than 6\% of those that passed over NHWRA ( $<0.4 \%$ of total) may have been in the low-height category.

Table 16. Estimated Magnitude and Altitude of Seasonal Avian Migrations Through NHWRA and Vicinity. Estimate Derived from Adjusted Number of Events Detected by Scanning and Vertical Radars, 1995 and 1996. Low Altitude Was $\leq 61 \mathrm{~m}$ (200 ft).

\begin{tabular}{|c|c|c|c|c|c|c|c|}
\hline \multirow[b]{2}{*}{$\begin{array}{c}\text { Season } \\
\text { (hrs available) }\end{array}$} & \multirow{2}{*}{$\begin{array}{c}\bar{x} \text { Birds } \\
\text { per } \\
\text { Event }\end{array}$} & \multirow[b]{2}{*}{$\begin{array}{l}\text { Radar } \\
\text { Array }\end{array}$} & \multirow{2}{*}{$\begin{array}{c}\mathbf{k m}^{\mathbf{2}} \\
\text { Surveillance } \\
\text { Area }\left(\mathbf{m i}^{\mathbf{2}}\right)\end{array}$} & \multirow[b]{2}{*}{$\begin{array}{c}\text { Hours } \\
\text { Monitored }\end{array}$} & \multicolumn{3}{|c|}{ Estimated Number of Birds (actual) } \\
\hline & & & & & $\begin{array}{l}\text { Within } \\
\text { Radar } \\
\text { Range }\end{array}$ & $\underset{\text { NHWRA }}{\text { In }}$ & $\begin{array}{c}\text { Low } \\
\text { in } \\
\text { NHWRA }\end{array}$ \\
\hline \multirow{2}{*}{$\begin{array}{c}\text { Autumn } 1995 \\
(2,712)\end{array}$} & \multirow[t]{2}{*}{6.12} & Scanning & $18.3(7.1)$ & 658.45 & $\begin{array}{l}\mathbf{7 , 4 6 2 , 5 2 3} \\
(295,911)\end{array}$ & $\begin{array}{l}407,210 \\
(16,147)\end{array}$ & 109,627 \\
\hline & & Vertical & $12.9(8)$ & 599.07 & $\begin{array}{c}265,654^{1} \\
(9,584)\end{array}$ & $\begin{array}{l}41,299 \\
(1,490)\end{array}$ & 11,118 \\
\hline \multirow{2}{*}{$\begin{array}{c}\text { Spring } 1996 \\
(2,664)\end{array}$} & \multirow[t]{2}{*}{4.17} & Scanning & $12.9(5)$ & 137.77 & $\begin{array}{c}\mathbf{3 , 4 2 1 , 4 6 2 ^ { 2 }} \\
(29,979)\end{array}$ & $\begin{array}{c}211,511 \\
(2,620)\end{array}$ & 12,517 \\
\hline & & Vertical & (3.1) & 154.38 & $\begin{array}{l}894,164^{3} \\
(12,412)\end{array}$ & $\begin{array}{l}115,623 \\
(1,605)\end{array}$ & 6,843 \\
\hline
\end{tabular}

${ }^{1}$ Vertical radar was inoperable for 2 weeks during peak migration, so the estimate is not representative.

${ }^{2}$ Corrected for comparability with autumn (scanning area size was 0.707 of autumn)

${ }^{3}$ Monitoring scanning radar was priority during peak periods, so the estimate is not representative. 


\section{Ennis Lake Counts}

A total of 33,926 waterfowls, shorebirds, and raptors was counted on surveys of Ennis Lake in autumn 1995 (Table 17). Waterfowls and shorebirds counted on Ennis Lake correlated with daily mean passage rates detected by scanning radar in or near NHWRA on the same day $(r=0.44, P=0.024)$ (see Fig. 48), but specific groups or species did not correlate (see Appendix Figs. 53-56).

Table 17. Waterfowl, Shorebirds, and Raptors Counted on Ennis Lake between 21 Oct.-16 Dec. (Autumn) 1995 and 9 Mar.-10 June (Spring) 1996.

\begin{tabular}{|c|c|c|c|c|c|c|c|}
\hline \multirow{2}{*}{ Group or Species } & \multicolumn{3}{|c|}{ Autumn $1995(n=31)$} & \multicolumn{4}{|c|}{ Spring 1996} \\
\hline & $\bar{x}$ & SD & $\sum$ & $\mathbf{n}$ & $\bar{x}$ & SD & $\sum$ \\
\hline All Waterfowl and Shorebirds & $1,092.32$ & 597.47 & 33,862 & 25 & 890.56 & $1,497.19$ & 22,264 \\
\hline American White Pelicans & 0.39 & 0.99 & 12 & 17 & 58.12 & 77.09 & 988 \\
\hline Swans (Trumpeter and Tundra) & 71.35 & 103.72 & 2,212 & 25 & 157.84 & 286.21 & 3,946 \\
\hline Canada Geese & 462.68 & 392.00 & 14,343 & 16 & 91.69 & 115.14 & 1,467 \\
\hline Snow Geese & 25.29 & 95.29 & 784 & 16 & - & - & - \\
\hline Ducks & 388.19 & 385.60 & 12,034 & 16 & 708.81 & $1,561.94$ & 11,341 \\
\hline Unknown Waterfowl & 29.00 & 93.72 & 899 & 16 & 12.50 & 39.81 & 200 \\
\hline Others $^{1}$ & 115.42 & 285.55 & 3,578 & 16 & 270.13 & 342.67 & 4,322 \\
\hline Bald Eagles & 1.87 & 2.49 & 58 & 19 & 7.05 & 9.96 & 134 \\
\hline Other Raptors & 0.19 & 0.60 & 6 & 19 & 2.58 & 2.57 & 49 \\
\hline
\end{tabular}




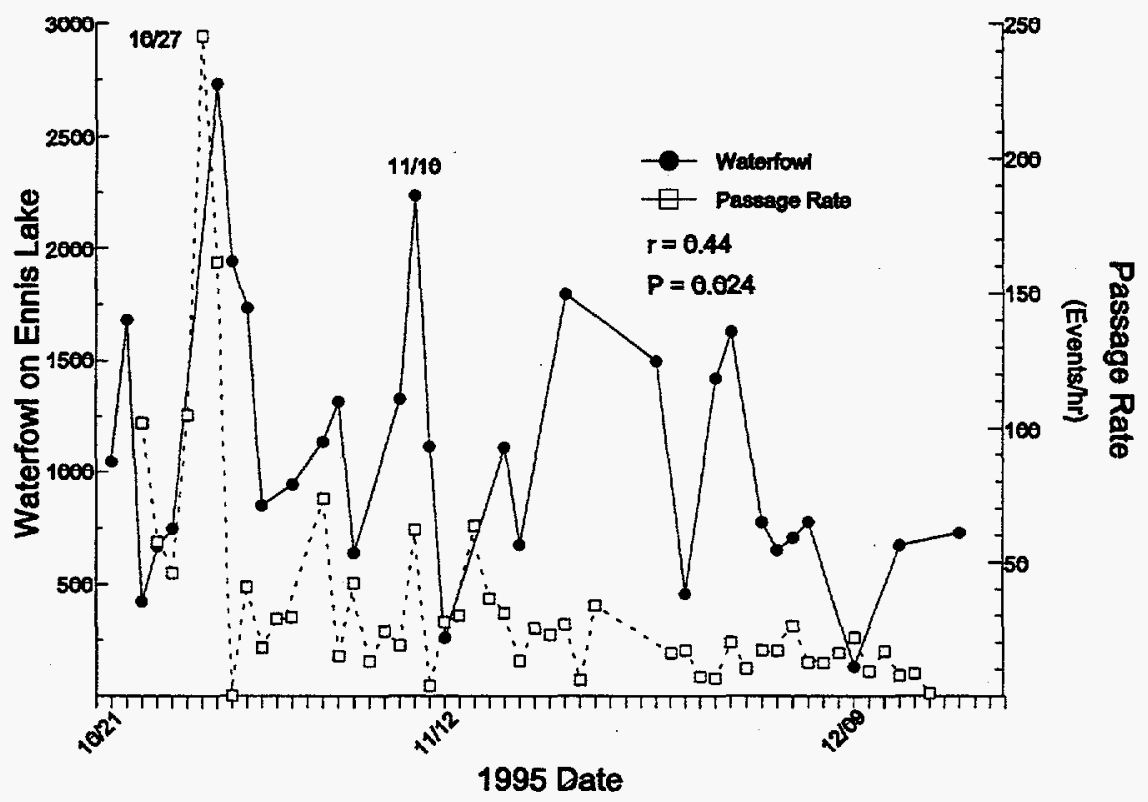

Figure 48. Relationship of numbers of waterfowl counted on Ennis Lake with mean passage rate of events detected by scanning radar located in NHWRA, autumn 1995.

A total of 22,446 waterfowls, shorebirds, and raptors were counted on Ennis Lake during spring 1996 (see Table 17). No correlation was found between numbers of any species or groups counted of Ennis Lake and daily mean passage rates of events detected by scanning radar in or near NHWRA, including all data collected through 10 June (see Fig. 49) (see Appendix Figs. 57-61). However, insect-like signatures began appearing on the screen in mid-May. Restricting analysis of data collected only to $15 \mathrm{May}$ (thereby eliminating insect events), a strong correlation $\left(r^{2}=0.68, P=0.003\right)$ existed between numbers of waterfowls and shorebirds on Ennis Lake and passage rates (see Fig. 49).

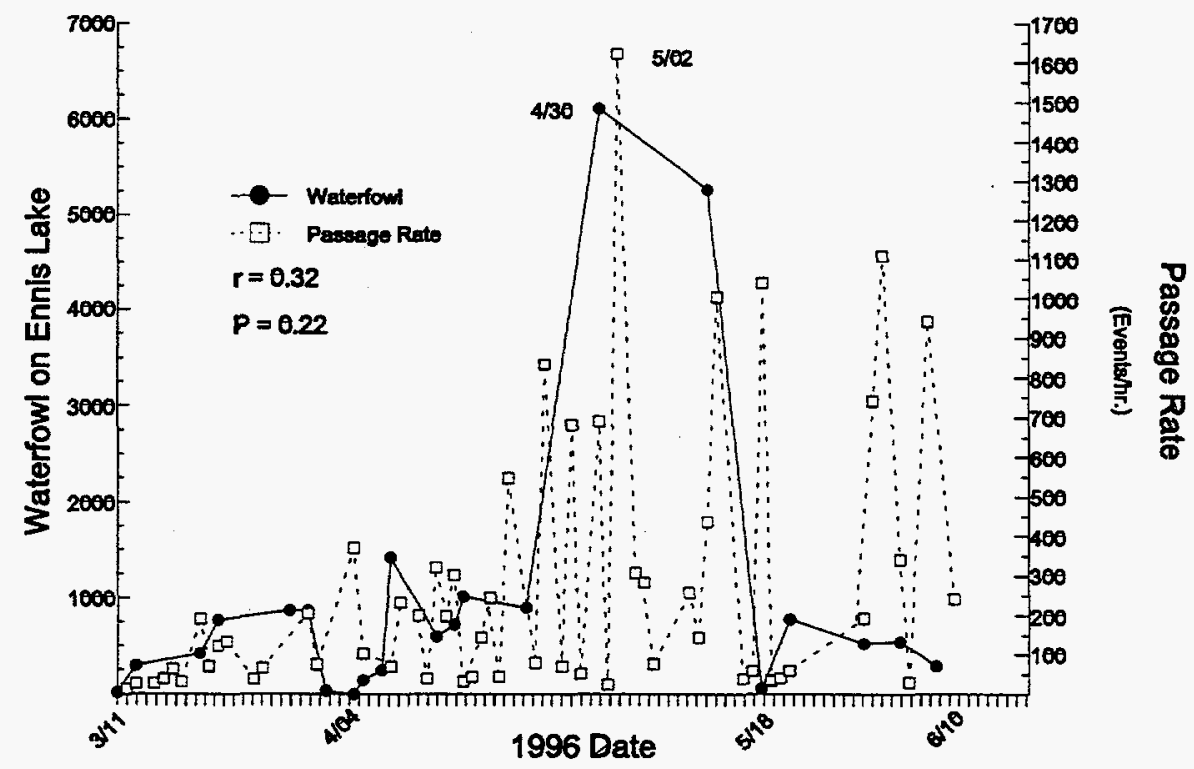

Figure 49. Relationship of numbers of waterfowl counted on Ennis Lake with mean passage rate of events detected by scanning radar located in NHWRA, spring 1996. 


\section{Estimated Minimum Sampling Effort for Future Radar Monitoring}

Bootstrapping analysis of vertical radar data indicated minimum sampling effort for future radar study at NHWRA and vicinity should be in the neighborhood of $65 \%$ to $70 \%$ of the spring 1996 effort (see Fig. 50). Accordingly, the most efficient monitoring effort in any future study of avian migrations during spring in and near NHWRA may be about $112.5 \mathrm{hrs}$ (between 103.6-120.9). Accurate detection of the passage rate would be contingent upon sampling of each hour period as equally as possible.

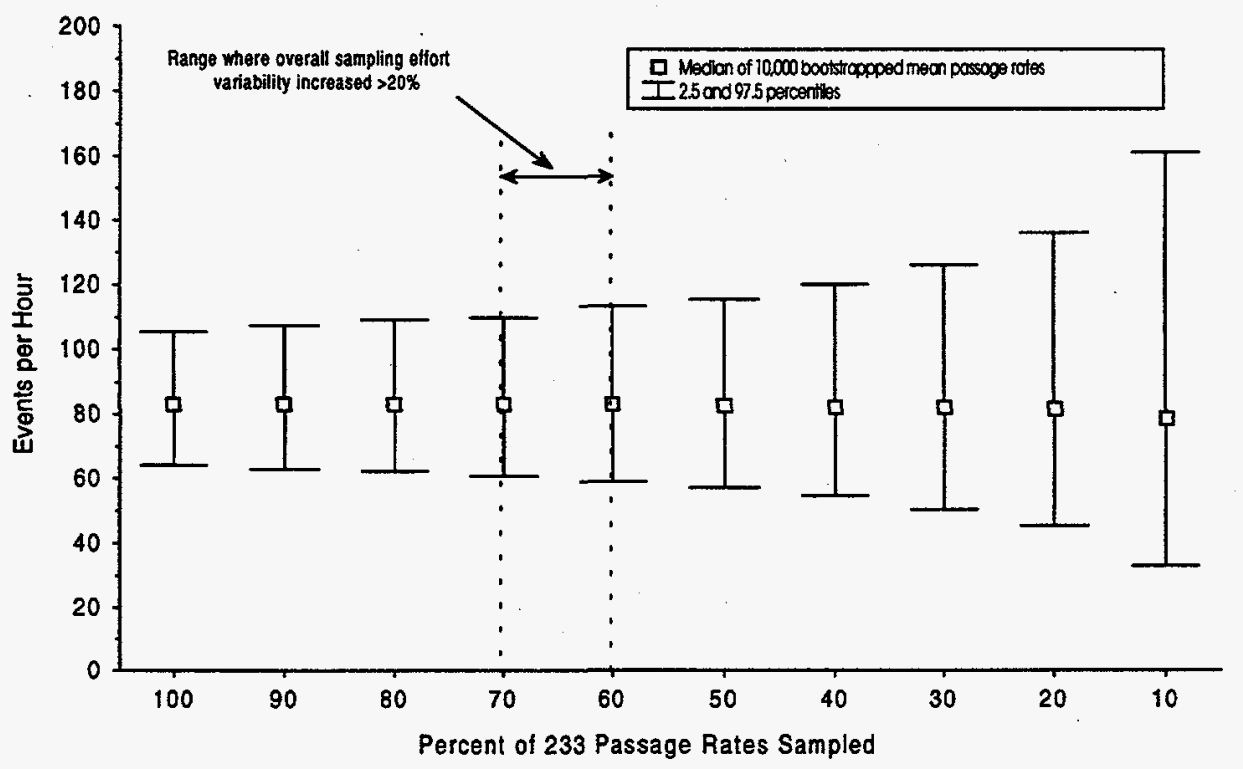

Figure 50. Median and percentile ranges of $10^{4}$ bootstrapped samples of 233 mean passage rates sampled at decreasing percentages. Passage rates were determined during of 172.7 hrs of vertical radar monitoring, NHWRA, spring 1996.

\section{Breeding and Local Nonraptorial Birds}

A total of 57 species was identified during point counts in the NHWRA and vicinity. Ten species comprised $79 \%$ of 1,805 birds representing 57 species detected during point counts (see Table 18). Mean number of birds detected per count was 12.28. Analysis of avian/cover type associations with point count data included only detections within $150 \mathrm{~m}(492 \mathrm{ft}$ ) of each point to ensure that detections occurred in the same vegetative association as the observer. Excluding flyovers, 1,161 birds representing 43 species were used for analysis of relative abundance and species diversity in five cover types (see Table 19). Cumulative species richness and ecological diversity were highest in DRAINAGE cover type and lowest in NHWRA (a GRASSLAND cover type). Relative abundance (the mean number of bird detections per point) differed among cover types (ANOVA, $\mathrm{F}=6.75,4,44 \mathrm{df}, \mathrm{P}<0.0025$ ). Relative abundance was greater in DRAINAGE than in all other cover types (LSD multiple comparison test). Relative abundance was greater in BLUFF BASE than in UPLAND cover type but did not differ among BLUFF BASE, WESTERN, and NHWRA nor among WESTERN, NHWRA, and UPLAND.

Significance of differences in relative abundance among cover types increased when detections in NHWRA and UPLAND were combined into a single GRASSLAND cover type (ANOVA, $F=9.20, \mathrm{df}=3,45$, $P<0.0008)$. A multiple comparison test (LSD) indicated relative abundance was greater in DRAINAGE than in all other cover types; was the same in BLUFF BASE and WESTERN, and WESTERN and GRASSLAND cover types; and higher in BLUFF BASE than in GRASSLAND cover types. Relative avian abundance did not differ within cover types with respect to slope (areas $<30 \%$ vs. $>30 \%$ slope, $\mathrm{P}>0.10$ ). 
Table 18. Abundance of 10 Most Common Avian Species, Including Flyovers, Detected During Point Counts, NHWRA, 1996.

\begin{tabular}{cccc}
\hline $\begin{array}{c}\text { Species } \\
\text { Alpha Code }\end{array}$ & $\begin{array}{c}\text { Percent of } \\
\text { Points Detected }\end{array}$ & $\begin{array}{c}\text { Total } \\
\text { Detected }\end{array}$ & $\begin{array}{c}\text { Percent of Total } \\
\text { Detected }\end{array}$ \\
\hline VESP & 95 & 482 & 26.7 \\
WEME & 89 & 316 & 17.5 \\
BRSP & 48 & 237 & 13.1 \\
SAVS & 50 & 170 & 9.4 \\
CAGO & 3 & 51 & 2.8 \\
BARS & 22 & 49 & 2.7 \\
BHCO & 17 & 44 & 2.4 \\
ROWR & 23 & 43 & 2.4 \\
AMRO & 16 & 43 & 2.4 \\
BRBL & 14 & 36 & 2.0 \\
\hline
\end{tabular}

${ }^{1}$ See Appendix E for definition (species) of alpha code.

Table 19. Number of Species of Birds (Excluding Flyovers) and Abundance within $150 \mathrm{~m}$ (492 ft), Observed During Point Counts and Associated Vegetative Cover Types in and near NHWRA, 1996.

\begin{tabular}{|c|c|c|c|c|c|}
\hline \multirow[b]{2}{*}{ Cover Type $^{1}$} & \multicolumn{3}{|c|}{ Number } & \multirow{2}{*}{$\begin{array}{c}\text { Detections/Point } \\
\bar{x}(\mathbf{S D})\end{array}$} & \multirow{2}{*}{$\begin{array}{l}\text { Species } \\
\text { Diversity }^{2}\end{array}$} \\
\hline & Species & Detections & Points & & \\
\hline NHWRA (grasses) & 4 & 120 & 6 & $20.0(3.8)$ & 1.7 \\
\hline UPLAND (grasses) & 14 & 280 & 14 & $20.0(4.3)$ & 2.3 \\
\hline GRASSLAND $^{3}$ & 14 & 400 & 20 & $20.0(4.1)$ & 2.2 \\
\hline $\begin{array}{l}\text { DRAINAGES (grasses, } \\
\text { forbs, shrubs, trees) }\end{array}$ & 32 & 334 & 11 & $30.4(6.5)$ & 4.2 \\
\hline $\begin{array}{l}\text { BLUFF BASE (grasses, } \\
\text { forbs, shrubs, trees) }\end{array}$ & 18 & 272 & 11 & $24.7(5.6)$ & 2.5 \\
\hline WESTERN (shrub) & 18 & 155 & 7 & $22.1(6.4)$ & 2.9 \\
\hline
\end{tabular}

${ }^{1}$ Dominant species for each group (i.e., grasses, shrubs) listed in Appendix E.

${ }^{2}$ Calculated by Shannon Index.

${ }^{3}$ NHWRA + UPLAND

\section{Breeding and Local Raptors}

\section{Raptor Nest Surveys}

Distribution of raptor breeding areas located within $25 \mathrm{~km}(16 \mathrm{mi})$ of the NHWRA is shown in Figure 51. No raptor nests were located "In" NHWRA in 1996. The nearest breeding area to the NHWRA boundary was within $1 \mathrm{~km}(0.6 \mathrm{mi})$ east and was occupied by red-tailed hawks (Buteo jamaicensis) (see Table 20). Nest sites of northern harriers (Circus cyaneus) and American kestrels (Falco sparverius) were not located, although both species were commonly observed "In" and adjacent to NHWRA. The number of raptor breeding areas increased by $7 \%$ over 1994 (see Table 20), but was most likely a function of increased search effort in 1996. 
Table 20. Raptor Breeding Areas Located During Aerial Surveys within 25 km (16 mi) of NHWRA, 1994 and 1996.

\begin{tabular}{|c|c|c|c|c|c|c|}
\hline \multirow{3}{*}{ Species } & \multicolumn{3}{|c|}{1994 (Harmata 1995) } & \multicolumn{3}{|c|}{1996} \\
\hline & \multirow{2}{*}{$\begin{array}{c}\text { No. of } \\
\text { Breeding } \\
\text { Areas }\end{array}$} & \multicolumn{2}{|c|}{$\begin{array}{c}\text { To Nearest Breeding } \\
\text { Area } \\
\end{array}$} & \multirow{2}{*}{$\begin{array}{l}\text { No. of } \\
\text { Breeding } \\
\text { Areas }\end{array}$} & \multicolumn{2}{|c|}{$\begin{array}{c}\text { To Nearest } \\
\text { Breeding Area }\end{array}$} \\
\hline & & $\mathbf{k m}(\mathbf{m i})$ & Direction & & $\mathbf{k m}(\mathbf{m i})$ & Direction \\
\hline Red-tailed Hawk & 27 & $0.9(0.56)$ & $\mathrm{E}$ & 34 & $0.9(0.56)$ & $\mathbf{E}$ \\
\hline Golden Eagle & 8 & $3.5(2.17)$ & SE & 3 & $6.5(4.04)$ & SE \\
\hline Bald Eagle & 5 & $3.3(2.05)$ & E & 4 & $3.3(2.05)$ & $\mathrm{E}$ \\
\hline Prairie Falcon & 5 & $8.6(5.34)$ & W & 4 & $2.2(1.37)$ & $\mathrm{E}$ \\
\hline Ferruginous Hawk & 4 & $5.3(3.29)$ & $\mathrm{NNW}$ & 1 & $6.0(3.73)$ & SW \\
\hline Swainson's Hawk & 4 & $8.0(5.0)$ & $\mathbf{N}$ & 3 & $10.3(6.40)$ & sw \\
\hline Great-horned Owl & 1 & $1.5(0.93)$ & NNE & 8 & $1.5(0.93)$ & NNE \\
\hline Osprey & & & & 1 & $16.8(10.44)$ & SSW \\
\hline Total & 54 & & & 58 & & \\
\hline
\end{tabular}

\section{Resident Bald Eagles}

Radio-tracking of juvenile bald eagles produced in the Bear Trap Canyon nest (see Fig. 51) between fledging on 19 July 1995 and leaving southwestern Montana on 19 August consumed 94 hrs over 21 days. Neither fledgling eagle was detected within $1 \mathrm{~km}(0.6 \mathrm{mi})$ of the NHWRA. Virtually all their activity was near the nest site and along the shores of the Madison River, upstream to Ennis Lake. Occasionally, they would soar above the Canyon within sight of NHWRA but were never detected in or over it. Although bald eagles were observed over NHWRA in 1995 and 1996 (Appendix Tables 32 \& 33), all was above $200 \mathrm{~m}$ (656 ft) AGL and none displayed wing notching of the fledgling from the Bear Trap Canyon Nest produced in 1995.

Resident adult bald eagles breeding at the Bear Trap Canyon site (see Fig. 51) spent virtually all their time closely associated with aquatic environments. When traveling between the nest site and distant foraging areas, they often soared but seldom ascended above the Canyon Rim. Most foraging areas were within $1.9 \mathrm{~km}(1.2 \mathrm{mi})$ up or downstream of the nest site. One was seen on the southeast shore of Ennis Lake twice. One adult, thought to be the male from the Bear Trap Canyon breeding pair, was observed flying west-to-east across NHWRA at an altitude of approximately $5 \mathrm{~m}$ (16 ft) AGL, within $30 \mathrm{~m}$ ( $98 \mathrm{ft}$ ) of the radar site in early March 1996. Use of the NHWRA by other bald eagles was detected during autumn 1995 and spring 1996 radar monitoring (see Appendix Tables 32 \& 33) and may have represented local birds.

\section{Resident Golden Eagles}

Radio-tagged adult male golden eagles captured near the NHWRA were members of pair's resident at the Bear Trap Canyon and Powerhouse breeding areas (see Fig. 51). Both were located flying over NHWRA during tracking but always at high altitudes (>200 m [656 ft] AGL). Neither was observed taking prey or foraging in the NHWRA or within $200 \mathrm{~m}$ (656 ft) of the boundary. Most flights involved 


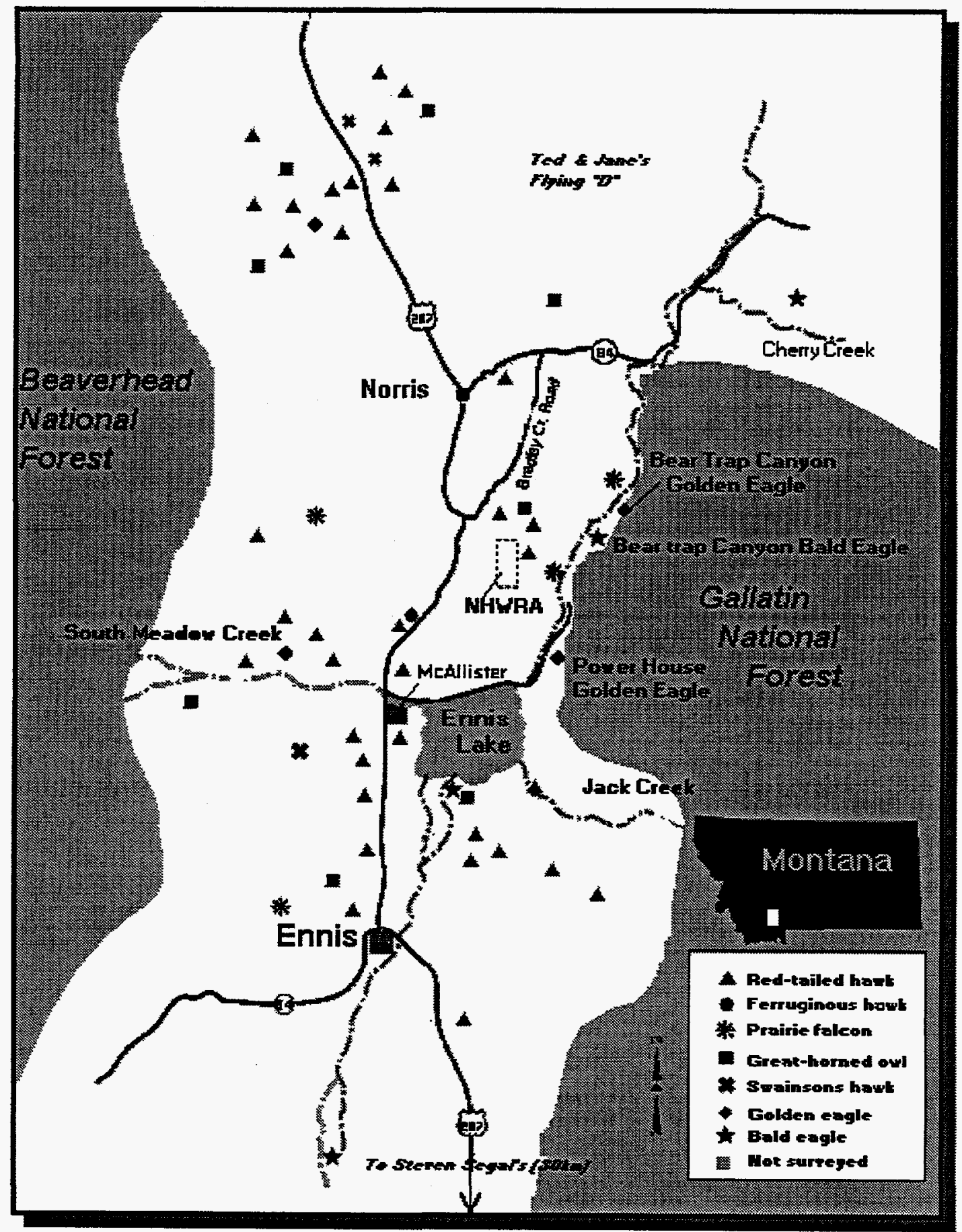

Figure 51. Raptor breeding areas located during aerial and ground surveys, 1996. 
at least one other eagle and appeared to be stimulated by impending territorial encroachments by other adult eagles or the presence of subadult eagles within a territory. The fledgling golden eagles were not radio-tagged in 1995 and neither pair produced young in 1996, so movements of the fledgling golden eagles in relation to NHWRA could not be determined.

Visual and radio-telemetry locations indicated that home ranges of both the Bear Trap Canyon and Power House pair of golden eagles were adjacent. Territorial displays of radio-tagged eagles and their mates indicated the boundary between their territories bisected NHWRA on an east-west line, i.e., $1 / 2$ of the NHWRA was included in each territory and home range. Previous study (Harmata 1995) and supplemental locations of the Power House male indicated home range size (minimum convex polygon) of nearly $30 \mathrm{~km}^{2}\left(\approx 11 \mathrm{mi}^{2}\right.$ ). Home range of the Bear Trap Canyon male was not determined but was conservatively estimated at $16 \mathrm{~km}^{2}\left(6.2 \mathrm{mi}^{2}\right)$, the smallest average home range size reported for the species in the literature (e.g., Phillips et al. 1991). Number of locations "In" the NHWRA represented $2.2 \%$ and $4.1 \%$ of total for the Power House male and Bear Trap Canyon male, respectively, and 2.8\% for both eagles combined. Radio locations "In" and "Out" of the NHWRA indicated that the use of the NHWRA was in proportion to their availabilities for both resident males (see Table 21). Had home ranges been larger than those estimated, use of the NHWRA probably would have been considerably less than expected. Regardless, the entire NHWRA was included in home ranges of resident golden eagles.

Table 21. Use of NHWRA by Radio-tagged Adult Male Golden Eagles Relative to Home Ranges, 1995-1996.

\begin{tabular}{|c|c|c|c|c|c|c|c|c|}
\hline \multirow{3}{*}{$\begin{array}{c}\text { Male Golden } \\
\text { Eagle }\end{array}$} & \multirow{3}{*}{$\begin{array}{c}\text { Home Range } \\
\mathbf{k m}^{2}\left(\mathbf{m i}^{2}\right)\end{array}$} & \multirow{2}{*}{\multicolumn{2}{|c|}{$\begin{array}{c}\text { NHWRA in Home } \\
\text { Range }\end{array}$}} & \multicolumn{4}{|c|}{ Locations } & \multirow{3}{*}{$\begin{array}{c}X^{2} \\
\text { (P value) }\end{array}$} \\
\hline & & & & \multicolumn{2}{|c|}{ Observed } & \multicolumn{2}{|c|}{ \# Expected } & \\
\hline & & $\mathbf{k m}^{2}\left(\mathbf{m i}^{2}\right)$ & $\%^{a}$ & $\mathbf{I n}^{\mathbf{b}}$ & Out ${ }^{\mathbf{b}}$ & In & Out & \\
\hline Power House & $29.67(11.46)$ & $0.65(1 / 4)$ & 2.2 & 3 & 140 & 3.15 & 139.85 & $0.007(0.9319)$ \\
\hline Bear Trap & $16^{c}(6.18)$ & $0.65(1 / 4)$ & 4.1 & 2 & 25 & 1.11 & 25.89 & $0.744(0.3883)$ \\
\hline Both & $45.67(17.63)$ & $1.295(1 / 2)$ & 2.8 & 5 & 165 & 4.82 & 165.18 & $0.007(0.9337)$ \\
\hline
\end{tabular}

${ }^{2}$ Of total home range.

'Of NHWRA.

${ }^{\mathrm{N}}$ Not recorded, conservatively estimated from literature.

\section{Raptor Use of NHWRA}

Red-tailed hawks, northern harriers, common ravens, and prairie falcons (Falco mexicanus) were the most commonly observed species using the NHWRA in spring and summer 1996 (see Table 22). At least one raptor was present $25 \%$ of monitoring time. More raptors were observed in the NHWRA than expected in afternoon and fewer than expected in morning and evening, $\left(X^{2}=44.10,3 \mathrm{df}, \mathrm{P}<0.0001\right)$.

Number of raptor observations/hr varied, depending on time of day, for each of the observation periods (ANOVA, $\mathrm{F}=6.231,3.75 \mathrm{df}, \mathrm{P}<0.01$, see Table 23 ). Observations $/ \mathrm{hr}$ were greater during afternoon than during morning and evening (Tukey-Kramer test, $\mathrm{P}<0.01$ ). Total number of minutes in NHWRA (for any raptor) was greater than expected in the morning and afternoon, and less than expected during midday $\left(X^{2}=52.24,3 \mathrm{df}, \mathrm{P}<0.0001\right.$, Bonferroni test $\left.\mathrm{P}<0.05\right)$. However, there were no differences among time-of-day categories in minutes/hr or minutes in NHWRA/observation (ANOVA, F <1.40, 3 , $75 \mathrm{df}, \mathrm{P}>0.05$ ). 
Visual altitude estimates were obtained for $92.2 \%$ of raptors observed in the NHWRA. Estimated altitudes were lower during morning and evening than during midday and afternoon (see Table 24).

Table 22. Raptor Use of NHWRA During 79.32 Hours of Observation in 30 Periods, 2 July-16 August 1996.

\begin{tabular}{|c|c|c|c|c|c|c|c|c|}
\hline \multirow[b]{3}{*}{ Species } & \multicolumn{3}{|c|}{ No. Observations } & \multicolumn{5}{|c|}{ Time in NHWRA (Min) } \\
\hline & \multirow{2}{*}{ Total } & \multicolumn{2}{|c|}{ per Hour } & \multirow{2}{*}{ Total } & \multicolumn{2}{|c|}{ per Hour } & \multicolumn{2}{|c|}{ per Obser. } \\
\hline & & $\bar{x}$ & SD & & $\bar{x}$ & SD & $\bar{x}$ & SD \\
\hline Red-tailed Hawk & 109 & 1.33 & 1.36 & 856.0 & 10.68 & 16.13 & 7.85 & 19.39 \\
\hline Northern Harrier & 30 & 0.38 & 0.44 & 171.0 & 2.16 & 3.62 & 5.70 & 5.43 \\
\hline Prairie Falcon & 16 & 0.20 & 0.23 & 43.0 & 0.54 & 1.11 & 2.69 & 4.32 \\
\hline American Kestrel & 8 & 0.10 & 0.27 & 54.5 & 0.69 & 2.12 & 6.81 & 7.57 \\
\hline Golden Eagle & 7 & 0.09 & 0.21 & 11.5 & 0.14 & 0.35 & 1.64 & 1.03 \\
\hline Ferruginous Hawk & 7 & 0.09 & 0.20 & 15.2 & 0.19 & 0.54 & 2.17 & 1.53 \\
\hline Osprey & 1 & 0.01 & 0.61 & 2.0 & 0.03 & 0.12 & 2.00 & - \\
\hline Common Raven & 17 & 0.21 & 0.35 & 2.5 & 0.32 & 0.61 & 1.47 & 0.89 \\
\hline Turkey Vulture & 6 & 0.08 & 0.20 & 12.0 & 0.15 & 0.43 & 2.00 & 0.89 \\
\hline Unknown Raptor & 18 & 0.23 & 0.33 & 22.0 & 0.28 & 0.45 & 1.22 & 0.67 \\
\hline All Species & 219 & 2.90 & 2.21 & 1212.2 & 15.16 & 17.00 & 5.54 & 14.18 \\
\hline
\end{tabular}

Table 23. Raptor Use of NHWRA Between 2 July-16 August 1996, as Determined by Radar and Visual Monitoring.

\begin{tabular}{|c|c|c|c|c|c|c|}
\hline \multirow{3}{*}{$\begin{array}{c}\text { Time of Day } \\
\text { (Hours) }\end{array}$} & \multirow{3}{*}{$\begin{array}{c}\text { Hours } \\
\text { Monitored }\end{array}$} & \multirow{3}{*}{$\begin{array}{c}\text { Raptors } \\
\text { Observed } \\
(+ \text { or }-)^{1}\end{array}$} & \multirow{3}{*}{$\begin{array}{c}\text { Observations } \\
\text { per Hour } \\
\bar{x}(\mathbf{S D})\end{array}$} & \multicolumn{3}{|c|}{ Minutes $^{2}$ In NHWRA } \\
\hline & & & & \multirow{2}{*}{$\begin{array}{l}\text { Total } \\
(\text { (+or }-)^{1}\end{array}$} & Per Hour & Per Obs. \\
\hline & & & & & $\bar{x}(\mathbf{S D})$ & $\bar{x}(\mathbf{S D})$ \\
\hline $\begin{array}{l}\text { Morning } \\
(0600-0959)\end{array}$ & 24.3 & $38(-)$ & $1.67(1.67)$ & $415.5(+)$ & $15.01(21.87)$ & $10.93(25.81)$ \\
\hline $\begin{array}{l}\text { Mid-day } \\
(1000-1359)\end{array}$ & 15.6 & 54 & $3.85(2.80)$ & $153.0(-)$ & $8.10(9.98)$ & $2.83(2.88)$ \\
\hline $\begin{array}{l}\text { Afternoon } \\
(1400-1759)\end{array}$ & 21.3 & $95(t)$ & $4.46(3.74)$ & $393.7(+)$ & $21.61(25.37)$ & $4.14(7.02)$ \\
\hline $\begin{array}{l}\text { Evening } \\
(1800-2100)\end{array}$ & 18.1 & $32(-)$ & $1.67(1.81)$ & 250.0 & $13.44(17.59)$ & $7.81(19.87)$ \\
\hline All Times & 79.3 & 219 & $2.90(2.86)$ & $1,212.2$ & $15.16(20.10)$ & $5.54(14.18)$ \\
\hline
\end{tabular}

${ }^{1}(+)$ or $(-)=$ difference from expected.

${ }^{2}$ Minutes any raptor species inside NHWRA. 
Table 24. Visually Estimated Altitudes of Raptors in NHWRA by Time of Day, 2 July-16 August 1996.

\begin{tabular}{|c|c|c|c|c|c|c|}
\hline \multirow{2}{*}{$\begin{array}{l}\text { Time of Day } \\
\text { (Hours) }\end{array}$} & \multirow{2}{*}{$\begin{array}{c}\text { No. } \\
\text { Observations }\end{array}$} & \multicolumn{3}{|c|}{ Altitude (m) } & \multirow{2}{*}{$\begin{array}{c}\text { Mean of } \\
\text { Ranks }\end{array}$} & \multirow[b]{2}{*}{ Difference $^{1}$} \\
\hline & & Mean & SD & Median & & \\
\hline $\begin{array}{c}\text { Morning } \\
(0600-0959)\end{array}$ & 36 & 16.5 & 23.7 & 2.0 & 63.5 & A \\
\hline $\begin{array}{c}\text { Mid-day. } \\
(1000-1359)\end{array}$ & 48 & 48.3 & 43.3 & 35.0 & 124.6 & B \\
\hline $\begin{array}{l}\text { Afternoon } \\
(1400-1759)\end{array}$ & 90 & 51.7 & 61.5 & 30.0 & 111.9 & B \\
\hline $\begin{array}{c}\text { Evening } \\
(1800-2100)\end{array}$ & 28 & 42.0 & 140.1 & 11.0 & 77.3 & $\mathbf{A}$ \\
\hline All Times & 202 & 43.3 & 70.8 & 20.0 & - & - \\
\hline
\end{tabular}

\section{Efficacy of Radar and Visual Monitoring}

\section{Autumn 1995}

Scanning radar detected more events/hr than did visual observers during Paired Silent $(\mathrm{t}=-4.75, \mathrm{P}<0.0001)$ and Paired Verified monitoring $(\mathrm{t}=-9.18, \mathrm{P}<0.0001)$ in autumn 1995 (see Table 25).

Table 25. Detection Rates of Scanning Radar and Visual Monitoring During Paired Observations, Autumn 1995.

\begin{tabular}{cccccc}
\hline \multicolumn{2}{c}{ Observation } & & & & \\
\hline Method & Hours & Blocks $^{1}$ & $\begin{array}{c}\text { Monitoring } \\
\text { Technique }\end{array}$ & $\begin{array}{c}\text { Events } \\
\text { Detected }\end{array}$ & $\begin{array}{c}\bar{x} \text { Events/hr } \\
\text { Detected (SD) }\end{array}$ \\
\hline Paired Silent $^{2}$ & 41.75 & 42 & Visual & 93 & $2.25(2.44)$ \\
& 41.75 & 42 & Radar & 714 & $17.01(20)$ \\
Paired Verified $^{3}$ & 51.5 & 55 & Visual & 104 & $2.06(2.3)$ \\
& 51.5 & 55 & Radar & 1814 & $34.62(26.2)$ \\
\hline
\end{tabular}

${ }^{3}$ Calculated per hour or discrete portion thereof.

${ }^{2}$ Visual and radar monitors at least $1 / 2 \mathrm{~km}$ apart, do not communicate.

${ }^{3}$ Visual and radar monitors at least $1 / 2 \mathrm{~km}$ apart, alert each other to presence of a target.

\section{Spring 1996}

Scanning radar detected more events per hour than did visual observers during Paired Silent $(\mathrm{t}=-10.60$, $\mathrm{P}<0.0001)$ and Paired Verified $(\mathrm{t}=-8.87, \mathrm{P}<0.009$ ) monitoring in spring 1996 (see Table 26). Visual observers acquired less than $1 / 2$ of avian targets detected by scanning and vertical radars during Solo and Paired monitoring sessions in 1996 (see Table 27). Conversely, both radars acquired over $60 \%$ of targets first 
detected visually. Proportion of targets initially acquired by scanning radar that were subsequently detected by visual observers during observations of raptor use of the NHWRA during summer (see Table 28) was similar to Solo and Paired observations during spring migration monitoring. However, scanning radar acquired only $18.1 \%$ of targets first detected visually in summer.

Table 26. Detection Rates of Scanning Radar and Visual Monitoring During Paired Observations, Spring 1996.

\begin{tabular}{|c|c|c|c|c|c|}
\hline \multicolumn{3}{|c|}{ Observation } & \multirow{2}{*}{$\begin{array}{l}\text { Monitoring } \\
\text { Technique }\end{array}$} & \multirow{2}{*}{$\begin{array}{c}\text { Events } \\
\text { Detected }\end{array}$} & \multirow{2}{*}{$\begin{array}{c}\bar{x} \text { Events/hr } \\
\text { Detected (SD) }\end{array}$} \\
\hline Method & Hours & $\begin{array}{l}\text { Sample } \\
\text { Blocks }\end{array}$ & & & \\
\hline \multirow[t]{2}{*}{ Paired Silent ${ }^{1}$} & 14.92 & 21 & Visual & 81 & $4.92(4.92)$ \\
\hline & 13.33 & 20 & Radar & 984 & $72.65(28.17)$ \\
\hline \multirow[t]{2}{*}{ Paired Verified ${ }^{2}$} & 2.15 & 3 & Visual & 4 & $1.33(1.53)$ \\
\hline & 2.15 & 3 & Radar & 34 & $17(2.65)$ \\
\hline
\end{tabular}

${ }^{1}$ Visual and radar monitors at least $1 / 2 \mathrm{~km}$ apart, do not communicate.

${ }^{2}$ Visual and radar monitors at least $1 / 2 \mathrm{~km}$ apart, alert each other to presence of a target.

Table 27. Success of Visual Target Acquisition Attempts by Scanning and Vertical Radar Operators During Solo and Paired Radar Observation Sessions', Spring 1996.

\begin{tabular}{lccc}
\hline $\begin{array}{c}\text { Radar Array } \\
\text { in Use }\end{array}$ & First Observed by: & $\begin{array}{c}\text { Acquisitions } \\
\text { Attempted }\end{array}$ & $\begin{array}{c}\text { Acquisitions } \\
\text { Successful (\%) }\end{array}$ \\
\hline Scanning & Radar & 124 & $59(47.6)$ \\
& Visual & 21 & $14(66.7)$ \\
Vertical & Radar & 83 & $36(43.4)$ \\
& Visual & 21 & $14(66.7)$ \\
\hline
\end{tabular}

One or 2 observers resident at radar station.

Table 28. Success of Target Acquisition Attempts by Coincident Monitoring Method on or Near NHWRA During Raptor Observation Sessions, Summer 1996 (Scanning Radar Only).

\begin{tabular}{lccc}
\hline \multirow{2}{*}{ Seen 1st by: } & \multicolumn{2}{c}{ Acquisition Attempted by: } & $\begin{array}{c}\text { Acquisition } \\
\text { Successful (\%) }\end{array}$ \\
\cline { 2 - 3 } & Method & No. & \\
\hline Scanning Radar & Visual Observer & 455 & $189(41.5)$ \\
Visual & Scanning Radar & 199 & $36(18.1)$ \\
Observer & & & \\
\hline
\end{tabular}


Low proportion of scanning radar acquisitions (see Table 28) were related to altitude of raptors using the NHWRA during summer. Visually estimated altitudes of raptors detected in NHWRA by scanning radar were higher than those of birds not detected by radar (Mann-Whitney U-test, $Z=-5.52, P<0.0001$, Table 29). Most flights not detected by scanning radar were $\leq 15 \mathrm{~m}$ ( $\sim 50 \mathrm{ft}) \mathrm{AGL}$. Low altitude most likely accounted for a low radar detection rate of events first detected visually. Visual observers were more likely to detect events 0 to $15 \mathrm{~m}(50 \mathrm{ft})$ high, while radar was more likely to detect events $>15 \mathrm{~m}(50 \mathrm{ft})$ high.

Table 29. Visually Estimated Altitudes of Raptors Detected or Undetected by Scanning Radar in NHWRA, Summer 1996.

\begin{tabular}{ccccccc}
\hline & \multicolumn{5}{c}{ Estimated Altitude (m [ft]AGL) } \\
\cline { 2 - 7 } Detection Mode & $\mathbf{N}$ & $\bar{x}$ & SD & $95 \%$ CI & Median & Range \\
\hline Detected by Radar & 71 & $61.2(200.8)$ & $45.96(150.8)$ & $\begin{array}{c}50-72.1 \\
(164-236.6)\end{array}$ & $50(164)$ & $2-200(6.6-656.2)$ \\
& & & & & \\
Undetected by Radar & 97 & $40.4(132.6)$ & $91.14(299)$ & $\begin{array}{c}22.1-58.8 \\
(72.5-192.9)\end{array}$ & $12(39.4)$ & $0-750(1 / 2 \mathrm{mi})$ \\
& & & & & \\
All Visually Detected & 168 & $49.2(161.4)$ & $75.93(249.1)$ & $37.6-60.8$ & $30(98.4)$ & $0-750(1 / 2 \mathrm{mi})$ \\
\hline
\end{tabular}

\section{Model Aircraft Flights}

Flights of radio-controlled model aircraft at 14 sites in and around the NHWRA resulted in 209 locations at which scanning radar detections were attempted. A detection rate of the radar decreased with increasing

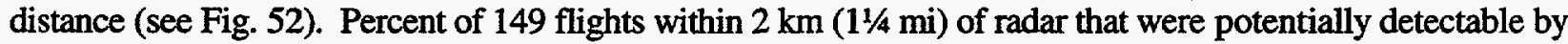
radar (not in topographical shadow) increased with increasing altitude (see Table 30). No flights were detected over $2 \mathrm{~km}\left(1 \frac{1}{4} \mathrm{mi}\right)$, most likely due to ceiling limitations of the model aircraft and visual acuity of the operator. At $>2 \mathrm{~km}(11 / 4 \mathrm{mi})$, topography dropped several hundred meters and flying the plane from ground level to a detectable altitude was often beyond the visual range of the operator. Combining low-and medium-altitude categories, $52 \%$ of flights below $60 \mathrm{~m}(197 \mathrm{ft})$ were detected within $2 \mathrm{~km}\left(1 \frac{1}{4} \mathrm{mi}\right)$ (see Table 30).

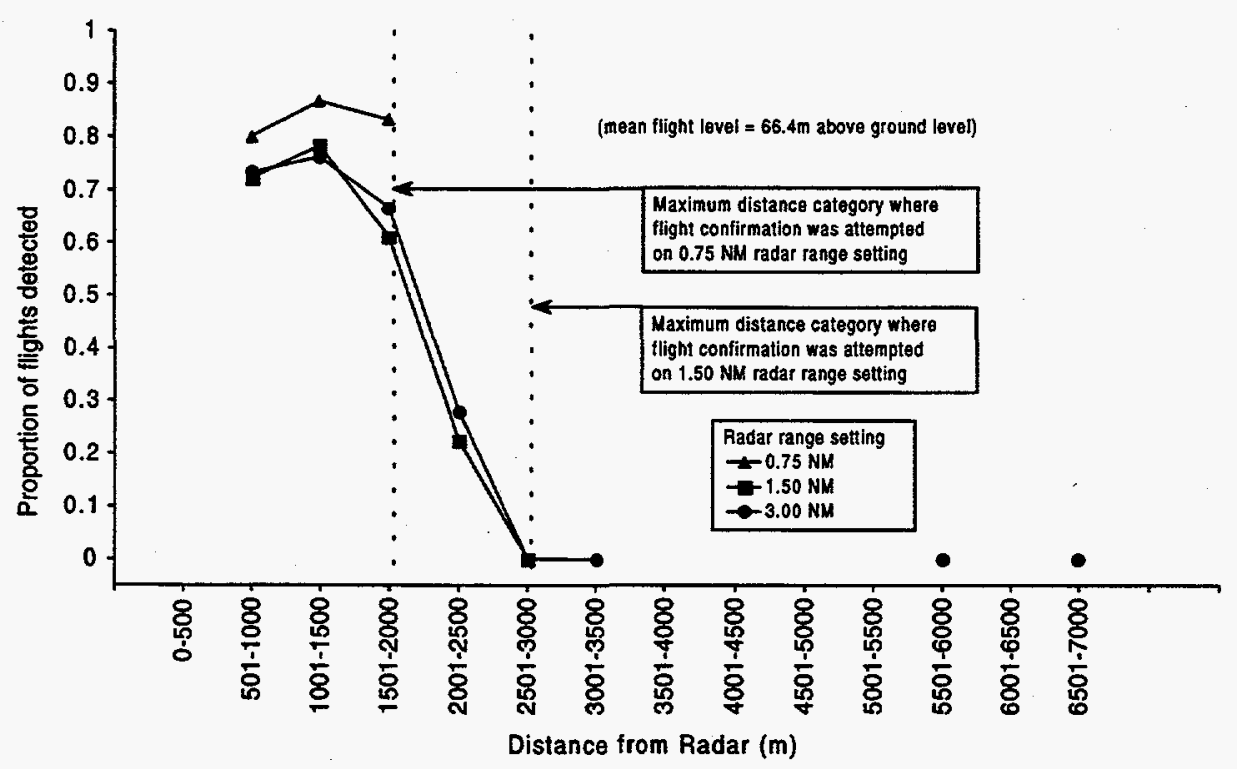

Figure 52. Detectability of radio-controlled model aircraft at three radar ranges when flown in NHWRA and vicinity, June 1996. 
Table 30. Detection Success of All Model Airplane Flights within $2 \mathrm{~km}$ (11/4 mi) of Scanning Radar, NHWRA, Summer 1996.

\begin{tabular}{|c|c|c|c|c|c|c|}
\hline \multirow[b]{3}{*}{$\begin{array}{c}\text { Range } \\
\text { Setting (nm) }\end{array}$} & \multicolumn{6}{|c|}{ Flight Altitude Above Ground Level } \\
\hline & \multicolumn{2}{|c|}{$\begin{array}{c}\text { Low }(<15 \mathrm{~m} \\
[49 \mathrm{ft}]) \\
\end{array}$} & \multicolumn{2}{|c|}{$\begin{array}{c}\text { Medium }(15-60 \mathrm{~m} \\
[49-197 \mathrm{ft}])\end{array}$} & \multicolumn{2}{|c|}{$\begin{array}{c}\text { High }(>60 \mathrm{~m} \\
[197 \mathrm{ft}])\end{array}$} \\
\hline & $\begin{array}{c}\text { Proportion } \\
\text { Detected }\end{array}$ & $\mathbf{n}$ & $\begin{array}{c}\text { Proportion } \\
\text { Detected }\end{array}$ & $\mathbf{n}$ & $\begin{array}{c}\text { Proportion } \\
\text { Detected }\end{array}$ & $\mathbf{n}$ \\
\hline 0.75 & 0.20 & 5 & 0.89 & 9 & 0.95 & 22 \\
\hline 1.50 & 0.25 & 12 & 0.67 & 18 & 0.93 & 29 \\
\hline 3.00 & 0.18 & 11 & 0.69 & 16 & 0.96 & 27 \\
\hline
\end{tabular}




\section{Discussion}

\section{Utility of Marine Surveillance Radars}

Marine surveillance radars were valuable tools for detecting avian movements in and near the NHWRA. Previous diurnal visual observations detected only $\approx 25 \mathrm{birds} / \mathrm{hr}$ in spring of 1994 (Harmata 1995). Scanning radar detected nearly three times as many events as 1994 visual monitoring, with an average of four birds per event. Even without detectability corrections, radar detected at least 12 times as many birds $(\bar{x} \approx 109$ events/hr or $453 \mathrm{birds} / \mathrm{hr}$ ) as strict visual monitoring of spring migration. In addition to detecting far more events than visual observers, radar permitted equally representative sampling at night, a time of more intense migration. Passage rates were up to five times higher at night than during daylight hours during both seasons. Although species may not be identified without visual confirmation, groups were identified with an acceptable degree of confidence. The Mini Automatic Radar Plotting Aid (MARPA) utility of scanning radar permitted accurate recording of bearing to targets, and the VRM capability allowed precise measurement of distances and altitudes relative to radars. The ACQ/CNL (Aquire/Cancel) mode of MARPA also permitted precise determination of target speeds, a guess at best for visual observers. Vertical radar objectively determined altitudes of events during both night and day while altitude estimates of visual observers varied with observer, weather, ambient light, species, and flock size.

Interference between scanning and vertical arrays was problematic but manageable without complicated and expensive mounting structures. As operators became familiar with the systems, interference was merely annoying and did not result in substantial loss of data.

Although ground clutter obliterated up to $35 \%$ of the screen, it did not affect detection (by the operator) of targets during seasonal migration periods. Most events of interest were clearly moving south in autumn and north in spring, and could be tracked entering and exiting clutter. Detecting movements within NHWRA proper by resident birds was more difficult. Residents often did not exit clutter predictably and were occasionally lost. If not supported by visual observations, radar data may have underrepresented use of NHWRA by resident birds. The ground clutter reduction shield reduced clutter but also reduced the sensitivity of the scanning radar to targets at or below eyelevel of the antenna. More events probably would have been detected at greater range, specifically on or over Ennis Lake in spring 1996, had the shield not been used.

A major problem was the "corona effect," or the phenomenon of a blind spot within proximate distance of the radar. Targets within $\approx 50-80 \mathrm{~m}(164-262 \mathrm{ft})$ of the antenna were obliterated by a bright-green circular corona, not unlike that around the sun. The diameter of the corona varied with range setting and precipitation.

Paired visual and radar observations indicated that some birds that flew close to the radar were not visible on screen, especially passerines and occasionally resident raptors. Had the radar not been within the NHWRA these birds probably would have been detected. However, topography and land ownership prevented suitable, alternative siting externally. Inability to detect close events may have resulted in an underestimation of avian use of the NHWRA, but $<1 \%$ of events were undetected because of corona effect.

Vertical radar arrays malfunctioned during both seasons, while no problems were encountered with scanning radar arrays. The motor in the vertical pedestal burned out in autumn, resulting in downtime during the peak of migration. The motor unit was not designed for use in the vertical plane and may not be capable of sustained operation in that position. Moisture inside the plastic antenna housing resulted in reduced sensitivity and increased interference signatures on screen during spring. Simply removing the end caps and drying the unit solved the problem. 
Data logging was tedious and intense during periods of high activity. Data were cumbersome and complicated by virtue of sheer volume. Data management difficulties were due partially to failure to realize and exploit the potential of the radar systems in autumn 1995. Raytheon 1210XX radars have several capabilities that facilitate quick and accurate recording of data; however, most were not used. Capabilities include: tracking up to six targets simultaneously and displaying range, bearing, speed, course, closest point of approach (CPA) and time of CPA; construction of a guard zone on screen such that if a target enters, an alarm will sound (has application to "In" vs. "Out" data recording)and; a window option on screen that permits quick scanning of larger or smaller areas of interest at variable ranges for better resolution of target signatures. Monitoring in spring 1996 exploited most of these capabilities, but establishing comparability of data between seasons was difficult.

Personnel problems were more severe and had more lasting effects than any logistical, weather, or equipment problem. However, intelligent, honest people with no radar experience quickly became efficient and effective in operating both systems in a short period of time. Also, operators with a background in avian biology or natural history were better able to accurately identify and interpret radar signatures. Those with back country, mechanical, electrical (not necessarily electronic), driving, and interpersonal communication savvy promoted efficiency of the project through their abilities to maintain and repair vehicles, generators, electrical systems (wiring, lighting), and solve access problems.

A major question in data analysis was how representative the raw data of spatial relationships were. Little direction was gained from the literature. No other radar ornithology studies reviewed addressed the concept of detectability of different size birds at increasing distance and the effect on interpretation of results, except in a most superficial way. Smaller targets (passerines) were not being detected as far away from the radar as pelicans, swans, or eagles. Controlled flights of a radio-controlled model airplane provided a curve of probability of detection at increasing distance that further illustrated the problem, but results were probably representative only for model airplanes or at best, birds of similar size and profile. Reflective capability of metal was also probably greater than that of feathers; however, determining the extent or effect of this difference was well beyond the scope of this study.

Detectability had to be addressed in detail and resolved objectively if data were to accurately represent passage of migrant birds through the study area. Valid comparisons among distance classes, geographical areas, and most important, "In" vs. "Out" avian use of the NHWRA, also were dependent on resolution of the detectability/distance relationship. The problem was eventually managed by employing detectability techniques used in the analysis of visual avian sampling (Buckland et al. 1993). Application to radar data was apparently appropriate because visual observation of locality and intensity of migration activity were compatible with analysis results.

More precise evaluation of detectability might be accomplished by using multiple radar stations, which might provide more accurate detectability perspective by scanning common areas visible to each station. The number of events detected by each radar in specified areas could be compared and adjusted accordingly. Model airplane flights were useful in this study for gaining insight on declining detectability with increasing distance; however, applicability to birds is tenuous. Utility of model aircraft flights would be prior to monitoring, to determine areas not visible to radar because of vegetative or topographical screening.

\section{Radar Monitoring Effort}

Radar monitoring was much more difficult and logistically demanding during spring than autumn. In addition to monitoring periods characterized by as many as 3,000 events/hr, weather-induced equipment failures were much more common in spring. Frequent storms produced "green-outs," obliterating the radar screen for long periods after arduous travel to the site. Deep snow impeded access to the site, which could not be gained without using two, four-wheel-drive vehicles chained on all four wheels, pulling and winching each other out 
of drifts and mud holes, while taking care to inflict minimal damage to private land. This was time consuming and exhausting. Additionally, vernal migration intensity was such that two radar observers were needed to adequately record number of events and associated data, effectively reducing by half the number of hours monitored. One observer adequately covered autumn monitoring. Despite fewer monitoring hours in 1996, a more representative sample of early morning hours was obtained than in 1995.

Bootstrapping analysis of vernal migration data indicates fewer monitoring hours may have sufficed while still limiting variances to less than $20 \%$ of recorded mean passage rates. Application of this effort to other studies may not be appropriate because numbers and rates of birds passing through compared to other migratory corridors in southwestern Montana may be very different. Duration of seasonal migrations, number of birds, and passage rate all may affect monitoring effort required to adequately describe profiles of migration.

Signature characteristics indicated that radar data may have been confounded by the presence of insects after mid-May, but BACI and spatio-temporal profiles of vernal migration results included data collected through 10 June. Data collected after 15 May, may not have been representative of true avian passage and inclusion in analysis or may not have been appropriate. However, because flight speeds could not be acquired for any suspected insect target and their radar signature did not appear to differ from that of small passerines, there was no way to tease these events from the radar databases other than by date. If this problem is encountered in future studies, more visual observations may be necessary to determine end dates for radar monitoring. For example, after 15 May field personnel commented on several occasions during daylight radar sampling periods, that many small, passerine-like targets were detected within $1 \mathrm{~km}(0.6 \mathrm{mi})$ of radar, but could not be verified visually. Increasing frequency of these types of events may indicate when insects are present and begin to contaminate avian-use data. Similar phenomena encountered during nocturnal monitoring also may indicate increasing insect movement.

\section{Use "In " and "Out" of NHWRA by Migratory Birds}

Both scanning and vertical radars detected more events "In" NHWRA than expected during both autumn 1995 and spring 1996 monitoring. Although adequate as an index for BACI comparisons with "After" data, number "Out" was most likely underrepresentative of actual magnitude due to a decline in detectability of targets by both radars at increasing distances. Hence, detectability was incorporated into estimates of magnitude and spatio-temporal profiles of migration over the entire study area.

The accuracy of detection-probability curves generated by the DISTANCE program is unknown and may require verification. Regardless, the resultant profile of migration based on adjusted numbers of events supported empirical evidence indicating that more migrating birds flew over the pass west of the NHWRA and fewer flew over the canyon to the east. Without adjustments based on detection-probability curves, raw data suggested that the number of migrants that flew over the pass was lower than that over the NHWRA (c.f. Figs. 32 and 34). Further, data adjusted for detectability and related to topography revealed trends not evident in raw data (e.g., the affinity of migrants to fly over passes and swales and to avoid topographic high points [see Fig. 35]). In future studies it may be possible to verify the accuracy of detection-probability curves by employing multiple radar stations at several locations and monitoring simultaneously.

Altitudes of migrating birds appeared more a function of underlying terrain than location "In" or "Out" of the NHWRA during both seasons. Terrain within $805 \mathrm{~m} \mathrm{(1/2} \mathrm{mi)} \mathrm{of} \mathrm{radar} \mathrm{locations} \mathrm{during} \mathrm{both} \mathrm{seasons} \mathrm{was} \mathrm{similar}$ in elevation throughout, but beyond $805 \mathrm{~m} \mathrm{(1/2} \mathrm{mi)} \mathrm{topography} \mathrm{included} \mathrm{more} \mathrm{valleys} \mathrm{and} \mathrm{swales.} \mathrm{There} \mathrm{was}$ no difference in proportional distribution of events by altitude category (High, Medium, Low) "In" the

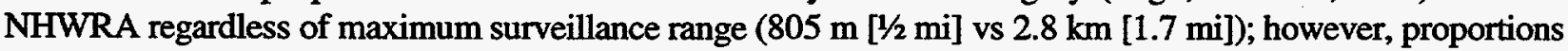
within altitude categories "Out" changed as surveillance range increased from $805 \mathrm{~m}$ to $2.8 \mathrm{~km}$ (1/2 to $1.7 \mathrm{mi})$. Proportionally more events were detected in the Low altitude category at the greater surveillance range. This may be attributable to altitude data not being adjusted for detectability; i.e., higher events at $2.8 \mathrm{~km}(1.7 \mathrm{mi})$ 
horizontal distance from radar would have less probability of detection than low events at the same horizontal distance because they would be farther line-of-sight from radar (see Fig. 53). However, failure to correct for detectability would have no effect on BACI comparisons.

Mean altitude of events relative to radar "In" the NHWRA was higher than that "Out," but relative to ground level, there was no difference. Birds tended to fly at constant altitude AGL (see Fig. 38). Accordingly, more events were detected low relative to radar at greater range because topography generally dropped off in all directions from the radar location.

Vertical radar data indicated that migrating birds flew, on average, $150-250 \mathrm{~m}(492-820 \mathrm{ft})$ lower over the NHWRA and vicinity in autumn 1995 than in spring 1996. A greater proportion of migrant birds, preparing for landing on Ennis Lake, may have actually been descending when detected in autumn. In spring, most birds detected may have been ascending when detected, resuming their migration after a stopover on Ennis Lake.

When compared, vertical and scanning radar data from autumn 1995, adjusted for detectabilty, revealed different results relative to proportions of events detected "In" and "Out" of the NHWRA. The vertical radar unit was inoperable during the peak of migration and no doubt explains the discrepancy. Although scanning data is more representative of the entire period, the difference may indicate that the distribution of flight paths changes over the migratory period. Perhaps, proportionally more birds flew through the NHWRA than "Out" early and late in migration, while proportionally fewer flew through NHWRA during the peak.

Analysis of scanning radar data from spring 1996 also indicated fewer adjusted events than expected were "In" and more than expected were "Out" of the NHWRA; however, vertical radar data showed no difference from expected "In" or "Out." Both radars indicated that fewer events than expected occurred to the east of NHWRA and more than expected occurred to the west. This is probably an indication of the high number of birds that migrated over the pass to the west of the NHWRA and a lower number that migrated along the Madison River in Bear Trap Canyon to the east. Although birds that migrated low over the river would not have been detected by either radar or visual observers, it is unlikely high numbers used the Canyon. Canyon walls are steep and the Canyon circuitous; conditions are not likely to facilitate movement of large flocks of birds, especially at night.

\section{Use "In " and "Out" of NHWRA by Breeding and Local Birds}

Point count results indicated that avian diversity was greater "Out" of the NHWRA than "In," most likely due to greater diversity of vegetation and topography the outside of the NHWRA. Avian abundance, however, did not differ between the two areas. Bird density in the grassland of the NHWRA was equal to that outside, but fewer species were represented.

Resident bald eagles did not use the NHWRA (other than possibly one brief sighting) but golden eagles did. Bald eagles are associated with aquatic resources and related prey. The Madison River seldom freezes in the Bear Trap Canyon so food may be available within the riparian areas year round. There would be no reason for resident bald eagles to visit the NHWRA or its upland environs. Golden eagles were located within the NHWRA with some regularity. Golden eagle prey consists of terrestrial species commonly associated with upland areas. Ground squirrel (Spermophilus spp.) colonies exist within $200 \mathrm{~m}$ (656 ft) of both the north and south boundaries of the NHWRA. Updrafts created by south winds striking the bluffs immediately south of the NHWRA, power poles and fence posts within and near the NHWRA provided energetically inexpensive foraging sites for exploiting these concentrations of prey.

During intensive visual and radar monitoring, seven species of raptors were observed to soar, hunt, or perch in the NHWRA. The greatest use of the NHWRA by raptors occurred during afternoon hours, and visually estimated altitudes of raptors in the NHWRA were higher during midday and afternoon than during morning 
and evening observation hours. Higher use in the afternoon and evening probably reflected availability of thermals for soaring. Other species including accipiters, ravens, swans, and pelicans were detected within the boundaries of the NHWRA, but swans and pelicans did not perch in the NHWRA.

\section{Avian Mortality}

No differences were found in the number of dead birds discovered "In" and "Out" of the NHWRA. This probably reflects the true distribution of mortality in and near the NHWRA. However, the statistical power to detect differences in mortality due to wind power development in the NHWRA, if they occur, is likely to be poor. Thus, measurements of avian use of the NHWRA by radar, telemetry, and visual observations are likely to be more important in assessing impacts than mortality because tests using these data will be based on larger sample sizes and will therefore have higher power (Pollock, 1997).

\section{Profile of Migration in and near NHWRA}

Use of scanning and vertical radar in the NHWRA resulted in detection and recording of over 26,000 events during autumn 1995 and over 20,000 during spring 1996. Detectability analysis and mean event-size adjustments based on visually verified events indicate as many as 7.4 million birds may have passed within the 5.6-km (3.5-mi) radius of the radar site during autumn 1995. Possibly as many as 407,000 of those passed over the NHWRA. In 1996, as many as 3.4 million birds may have passed within the NHWRA and Reference areas, with up to 211,000 passing directly over the NHWRA.

Estimates of the overall magnitude of migration over the NHWRA and the surrounding area may potentially be biased high or low. Estimates were based on unverified detection-probability curves. However, model aircraft flights and visual observations indicated that detectability decreased with target size and distance from radar and, in terms of estimating total migration, needed to be addressed. Because the radar was located inside NHWRA boundaries both years, it is unlikely that detectability adjustments seriously biased estimates within the resource area. Further, estimates were based on mean flock sizes derived from visually verified events observed during daylight. These flock size estimates may have been biased high or low. Visual observers tended to detect large flocks, resulting in high bias. However, flock size estimates actually may have been low because many species of waterfowls and passerines migrate primarily at night and in larger than diumal flocks. Accordingly, overall estimates based on daylight visual observations were low.

Although estimates of total numbers of birds are probably realistic, methods employed to derive these estimates were often tenuous and subjectively based. Estimated numbers of birds, although corrected for surveillance area size differences, may not be comparable between years because of differences in range setting used with scanning radar. Estimated numbers that passed over the NHWRA are more comparable. Much lower numbers estimated to have passed over the NHWRA in the spring may reflect real differences in populations of migrants. Many of the migrants were suspected to be waterfowls and shorebirds, both of which are thought to have high first-year mortality rates (Bellrose 1978). Composition of autumn migration includes recently fledged juveniles in addition to older age classes. By spring, effects of mortality may have been manifest, with a large proportion of first-year birds not available for return to breeding areas. The number of events per hectare per hour detected by scanning radar was similar in autumn $1995(0.22)$ and spring $1996(0.17)$. However, the number of events per meter hour detected by vertical radar was lower in the autumn $(0.0025)$ than in the spring (0.0167). This difference may be a result of the vertical radar being inoperable during the peak of the migration during autumn, or that autumn migration was in fact more protracted than spring migration.

Higher adjusted numbers of events detected coincided with low points in topography, specifically the route of Highway 287 to the west of the NHWRA or deeper valleys east and west. Migrant birds seemed to avoid passing over higher points of topography, especially during strong head winds. Although more birds flew over 
low points in topography, they appeared to be migrating over the entire surveillance area at a relatively constant height AGL, relative to topographical relief. Additionally, higher numbers of events tended to be concentrated over the west aspect of slopes. This may indicate that birds exploited updrafts created by south-southwest winds assaulting the west-facing slopes.

The peak of autumn migration occurred in late October 1995 but no clear peak was evident during vernal migration, although intensity increased in early to mid-April and remained high until early June. The relatively high, constant passage rate after mid-May was probably a result of recording flights of insects, especially swarms of Russian wheat aphids, known to be early spring migrants (Blodgett, 1997b). However, several species of passerines are also late-spring migrants and their passage may have been obscured by insects.

The mean passage rate (events/hr) in autumn was much lower than the spring rate; however, the number of events and estimated number of migrants were higher. This difference may have been affected by three factors: a larger area monitored with scanning radar in spring compared to autumn, inadequate sampling of early morning hours in autumn (early morning hours were sampled more representatively in spring and migration intensity was often high at that time), and a more protracted migration in autumn than spring. Migrant adult birds are presumably not as goal-oriented in autumn as in spring, responding more to proximate ecological factors (such as food availability and open water) than photoperiod to stimulate movement. An innate stimulus for birds of the year to migrate in autumn may be mitigated by inexperience, also resulting in a more protracted migration. The stimulus to breed may be strong in spring, inducing a shorter, more intense migration, as indicated by spring passage rates almost seven times greater than autumn.

Passage rates decreased with the decreasing barometric pressure trend in autumn. Passage rates increased as barometric trend decreased in spring. Low barometric pressure often was associated with storm systems accompanied by strong southerly winds in the Norris Hill area. Storm systems would provide a headwind for migrants moving south in autumn, but a tailwind to vernal migrants flying north. In fact, waterfowls were observed terrain-hugging in autumn during high headwinds, traveling up valleys and utilizing the wind shadow provided by higher ground on the south end of the NHWRA, cresting the hilltops at low altitudes and descending abruptly toward Ennis Lake.

There was a significant positive relationship between counts of waterfowls and shorebirds on Ennis Lake and passage rates of migration detected by radar in autumn 1995. Although the correlation was low in spring, a positive relationship was evident from February through May, beyond which rates may have been confounded by insects. In both years trends in lake counts and passage rates followed similar patterns. Accordingly, counts of waterfowls and shorebirds on Ennis Lake may be an accurate predictor of migration intensity over the NHWRA.

\section{Efficacy of Radar and Visual Monitoring}

Clearly, radar monitoring of avian movements was far superior to visual monitoring. Target detection rates of scanning radar during daylight were between 7 to 17 times those of visual observers. Less than $19 \%$ of targets detected by scanning radar were subsequently detected visually during summer observations of resident raptors, even when the visual observer was alerted to target presence and location.

Visual detection rates did not exceed $51 / 2$ events/hr, even when observers were alerted to the presence of targets. Scanning radar detection rates exceeded 72 events/hr. Number of events/hr detected by radar increased nearly $80 \%$ during Paired Verified observations. These data suggest that if radar operators were alerted to the presence of targets they hadn't detected, a subsequent detection rate (of the operator) increased. However, sampling periods may have occurred during different passage rates of migrant birds and data may not be comparable. When Paired Verified observations were restricted to close ranges (within $1 \mathrm{~km}$ [0.6 mi]), 
a detection rate of radar dropped dramatically. Most birds undetected by radar were less than $50 \mathrm{~m}$ (164 ft) and/or obscured in clutter, while most birds detected visually were not higher than $50 \mathrm{~m}$ (164 ft).

Paired radar and visual observations during daylight confirmed that radar was able to detect many more events than visual monitoring for several reasons. First, scanning radar continuously scanned in all directions from the antenna, whereas visual observers could only concentrate efforts in one direction at a time. Second, scanning and vertical radars were able to detect events at distances and altitudes at which birds could not be detected by visual observers even with the use of binoculars. Third, visual detections were limited by dark background (forest), bright blue sky, sun, and the visual acuity of the observer. Model aircraft flights confirmed that radars could not detect low-altitude flights in addition to decreasing detectability as distance from the antenna increased. 


\section{Recommendations for Future Radar Study of Avian Migration}

\section{Equipment and Array}

Raytheon 1210XX marine surveillance radars performed well and the systems described here (see Methods: Equipment) can be used with confidence in other studies of avian movements. Technical support and turnaround time on repair parts from Raytheon were exemplary. Type and number of radar arrays utilized should be determined by the focus and objectives of a study, as well as by budget, size, and topography of the study area. Studies involving migratory birds may be conducted with just one vertical array because birds will tend to be flying in one direction. Studies of local or nonmigratory populations may require a scanning array or two vertical arrays because local movements are seldom predictable or directional. If scanning arrays are required to meet objectives, systems that provide tracking over ground clutter would be preferable, especially for recording irregular movements of birds within specified areas. However, objectives of most studies similar to this may be met by using vertical array(s).

\section{Siting, Positioning, and Operating Radar}

Dead zones around radar created by corona and donut effects indicate optimal results will be obtained if radars are sited off the area being investigated, especially if they are small $(<800 \mathrm{~m}(1 / 2 \mathrm{mi})$ wide), well outside the influence of both effects. In fact, siting of radar will be a compromise among logistical access realities that minimize detectability loss (the closer the better) and obtain as much of an unobstructed view of a study area as possible (mitigated by topography, clutter, corona, and area size). However, pursuit of the primary objective of study should be paramount in siting considerations. A hypothetical case study illustrates some siting concepts:

Primary objective is to determine responses of birds (primarily waterfowls) to presence of a $230-\mathrm{kV}$ power line across a major river corridor. Time is available for preconstruction and post construction monitoring. The line will be $30 \mathrm{~m}(98 \mathrm{ft})$ above the river surface. Response will be defined as changes in proportional distribution of altitudes of birds flying along the river corridor within $15 \mathrm{~m}$ of the power line, before and after installation. Determination of altitude is critical and budget dictates only one radar may be used. Vertical array is necessary. The most logistically optimal site for the radar is $400 \mathrm{~m}(1,312 \mathrm{ft})$ from the river bank where the proposed line will cross. This site provides complete coverage of the river width including the power line corridor plus a few hundred meters either side and up to $926 \mathrm{~m}$ $(>3,000 \mathrm{ft}$ ) above the river. However, other power lines, vegetation, and traffic hide all birds flying below $30 \mathrm{~m}$ ( $98 \mathrm{ft}$ ) in shadow and clutter. At an alternate site, $50 \mathrm{~m}$ (164 ft) from the river bank, corona obliterates $1 / 2$ of the river corridor but birds flying within inches above the water up to $460 \mathrm{~m}(1,500 \mathrm{ft})$ is detectable in the other $1 / 2$ of the river width. Clearly, objectives will not be met if monitoring is conducted from the former site while they will be from the closer site.

Two vertical radars may have been used to determine altitudinal use of the NHWRA by migrant and local and breeding birds. Siting one radar on the northern or southern boundary surveilling east-west and the other on the eastern or westem boundary surveilling north-south could have provided adequate coverage in and out of the area. This system may have been superior to a scanning radar even for determining number of events because much of the NHWRA was obliterated by ground clutter. Space between two radar arrays used simultaneously will dictate the amount of support equipment needed (i.e., trailers/campers, power sources, etc.). Siting radar arrays well away from each other $(>1 / 2 \mathrm{~km}[1,640 \mathrm{ft}])$ would require two of all support devices. If multiple migration seasons are to be monitored, the same radar site should be used so that results are most comparable. Additionally, use of a video recorder during high-intensity migration and subsequent 
playback and data recording would be preferable to having technicians estimate data capture percentages. However, playback and analysis of videotape would add considerable time to project duration. Finally, detection-probability curves should be verified. This could be accomplished by using two mobile radar stations monitoring the same area simultaneously from different locations and at several distances between the radars.

Interference between two radar arrays at the same site may be minimized by positioning radar arrays as far as possible from each other. A $30-\mathrm{m}$ (98-ft) pedestal-to-monitor cable is available from Raytheon that would facilitate maximum spacing.

A ground clutter reduction shield should not be used on either type of array. Clutter may be managed on scanning arrays by use of SEA CLUTTER and RAIN CLUTTER modes on 1210XX systems. SEA CLUTTER and RAIN CLUTTER modes effectively eliminate some ground and rain clutter but should be used judiciously because they also reduce sensitivity of the radar to close targets, as they also interact with GAIN.

End caps on vertical array antennas should be left off except in inclement weather. Absence of caps will minimize moisture accumulation on the wave guide and facilitate drying. All radar-monitoring personnel should read the radar manual and be thoroughly familiar with all the capabilities and functions of the radar system, prior to the initiation of monitoring.

\section{Data Logging and Recording}

Avian activity and numbers during migration in the vicinity of the NHWRA were prodigious and likely will be similar in the vicinity of any proposed wind resource area development with similar topography and geography; where the wind bloweth, the birds goeth. During periods of intense activity, accuracy of data capture was dependent on the amount of data that needed to be recorded. Accordingly, data needs should be kept to an absolute minimum required to meet objectives, and data sheets should reflect those minimal needs (e.g., Appendix C3).

Designation of Reference areas was helpful in minimizing recording effort, comparing event magnitudes or distributions "In" and "Out" of NHWRA, estimating numbers, and displaying spatial relationships of bird flights to topography. Such area delineations, if comparable over seasons, would also facilitate more direct comparisons between seasons and among years, if needed. Recording number and altitudes of events by impact and Reference area was quicker and more accurate than plotting flight paths and compiling relative locations later. For studies similar to this, Reference areas should be at least the same size as impact area, located directly perpendicular to the migratory pathway of birds, and adjacent to the impact area. In this position, Reference areas may be used by scanning and/or vertical radar and magnitudes more easily adjusted for detectability for a spatial profile of use. Prior to formal monitoring, precise distances to and locations (on screen) of impact and Reference area boundaries, identifiable landmarks, and clutter should be determined. Plotting/recording location of events is much more accurate with a correct spatial perception of the relationship of topographical features to screen display. Acetate screen overlays can dramatically improve efficiency of data collection and recording. Grids placed over the radar screen, with lines drawn based on VRM measurements, can aid in assigning altitude or distance categories to detected events. 


\section{Literature Cited}

Bellrose, F.C. (1964)."Radar Studies of Waterfowl Migration." Transcript of 29th North American Wildlife \& Natural Resources Conference; pp. 128-142.

Bellrose, F.C. (1978). Ducks. Geese \& Swans of North America. Harrisburg PA. Stackpole Books; 540 pp.

Blodgett, S. (1997a). Personal Communication. Department of Entomology, Montana State University.

Blodgett, S. (1997b). Personal Communication. Department of Entomology, Montana State University.

Buckland, S.T., D.R. Anderson, K.P. Burnham, and J.L. Laake. (1993). Distance sampling Estimating Abundance of Biological Populations. 2-6 Boundary Row, London SE1 8HN. Chapman \& Hall; 446 pp.

Burnham, K.P., D.R. Anderson, and J.L. Laake. (1980). "Estimation of Density from Line Transect Sampling of Biological Populations." Wildlife Monograms 72; 202 pp.

Cooper, B.A., R.H. Day, R.J. Ritchie, and C.L. Cranor. (1991). "An Improved Marine Radar System for Studies of Bird Migration.” Joumal of Field Omithology 62; 367-377.

Eastwood, E. (1967). Radar Omithology. London, UK: Methuen; 278 pp.

Fuller, M.R., and J.A. Mosher. (1987).” Raptor Survey Techniques.” pp. 37-65 In B.A. Giron Pendleton, B.A. Millsap, K.W. Cline, and D.M. Bird, eds. Raptor management techniques manual. Washington, D.C.: National Wildlife Federation; $420 \mathrm{pp}$.

Gauthreaux, S.A., Jr. (1984). "The Use of Small Mobile Radars to Detect, Monitor, and Quantify Bird Movements." pp. 121-1313 in M.J. Harrison, S.A. Gauthreaux, Jr., and L.A. Abron-Robinson, eds. Proceedings, conference, and training workshop on wildlife hazards to aircraft.

Gauthreaux, S.A., Jr. (1985a). Radar, Electro-optical, and Visual Methods of Studying Bird Flight Near Transmission Lines. Final Report to Electric Power Research Institute, RP 1636, Palo Alto, CA.

Gauthreaux, S.A., Jr. (1985b). "An avian mobile research laboratory: hawk migration studies." pp. 339-346 in M. Harwood, ed. Proceedings of Hawk Migration Conference IV. Rochester, NY: Hawk Migration Association of North America.

Gauthreaux, S.A. (1995). Minimum standards for avian studies during the siting, pre-, and post-construction phases of wind farm development. Palo Alto, CA: Electric Power Research Institute.

Green, R.H. (1979). Sampling design and statistical methods for environmental biologists. New York: John Wiley \& Sons; 257 pp.

Harmata, A. R. (1985). "Capture of wintering and nesting bald eagles." pp. 139-159 in J.M. Gerrard and T.N. Ingram, eds. The Bald Eagle in Canada. Proceeds of Bald Eagle Days 1983. Apple River, IL: White Horse Plains Publishing, Headingly, Manitoba and The Eagle Foundation.

Harmata, A. and B. Oakleaf. (1992). Bald eagles of the Greater Yellowstone Ecosystem: An Ecological Study with Emphasis on the Snake River. Wyoming. Cheyenne, WY: Wyoming Game \& Fish Department; 2 volumes, $368 \mathrm{pp}$. 
Harmata, A.R. (1995). "Avian Use of Norris Hill Wind Resource Area." Year one of a pre-development investigation. Montana State University, Bozeman. 79 pp.

Hintze, J.L. (1989). Solo. BMDP Statistical Software. Los Angeles, CA. 85 pp.

Holm, S. 1979. "A Simple Sequentially Rejective Multiple Test Procedure." Scandinavian Joumal of Statistics 6:65-60.

Jackman, R.E., W.G. Hunt, D.E. Driscoll, and F.J. Lapsansky. (1994). "Refinements to Selective Trapping Techniques: A Radio-Controlled Bow Net and Power Snare for Bald and Golden Eagles." 28:268273.

Kerlinger, P. (1989). Elight Strategies of Migrating Hawks. Chicago, IL: University of Chicago Press; 375 pp.

Kerlinger, P., and S.A. Gauthreaux, Jr. (1984). "Flight Behavior of Sharp-Shinned Hawks during Migration-I: Over Land." Animal Behavior; Volume 32, pp. 1021-1028.

Laake, J.L., S.T. Buckland, D.R. Anderson, and K.P. Burnham. (1993). DISTANCE User's Guide V2.0. Fort Collins, Colorado: Cooperative Fish and Wildlife Resources Colorado Unit; Colorado State University; $72 \mathrm{pp}$.

Orloff, S. and A. Flannery. (1992). Wind Turbine Effects on Avian Activity, Habitat Use and Mortality in the Altamont Pass and Solano County Wind Resource Areas 1989-1991. Santa Cruz, CA: BioSystems Analysis, Inc.

Phillips, R.L. A.H. Wheeler, J.M. Lockhart, T.P. McEneaney, and N.C. Forrester. (1990). Distribution and Abundance of Golden Eagles and other Raptors in Campell and Converse Counties. Wyoming. USDI, Fish and Wildlife Service, Fish and Wildlife Technical Report. 27; $31 \mathrm{pp.}$

Pollock, K. (1997). Personal communication. North Carolina State University.

Ralph, C.J., G.R. Geupel, P. Pyle, T.E. Martin, and D.F. DeSante. (1993). Handbook of Field Methods for Monitoring Land Birds. USDA, Forest Service General Technical Report PSW-GTR-144. Pacific SW Field Station, Berkeley, CA. 41 pp.

Shannon, D.E. (1948). A Mathematical Theory of Communications. Bell System Technology Journal. 27:379-423, 623-656.

Statsoft. (1995). Statistica (Release 5): Quick reference. Tulsa, OK: Statsoft Inc. 198pp.

Tyus, H.M. and J.M. Lockhart. (1979). "Mitigation and Research Needs for Wildlife on Western Surface Mined Lands. G. A., Swanson, ed. The Mitigation Symposium. USDA: pp 252-255. 


\section{Appendix A - Data Sheets}




\section{Autumn 1995 Data Sheet}

Date: Observer Comments

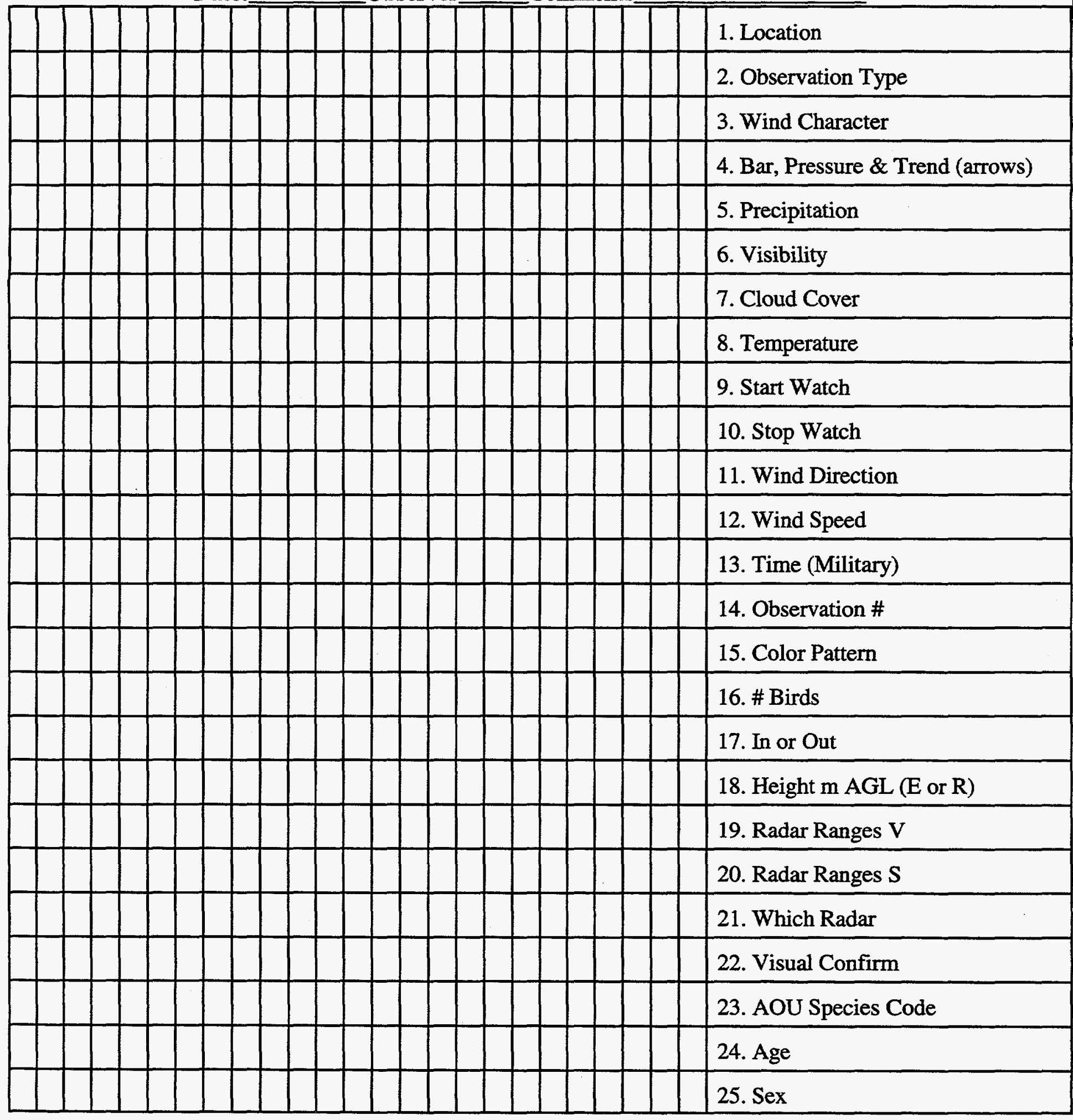


Spring 1996 Data Sheet

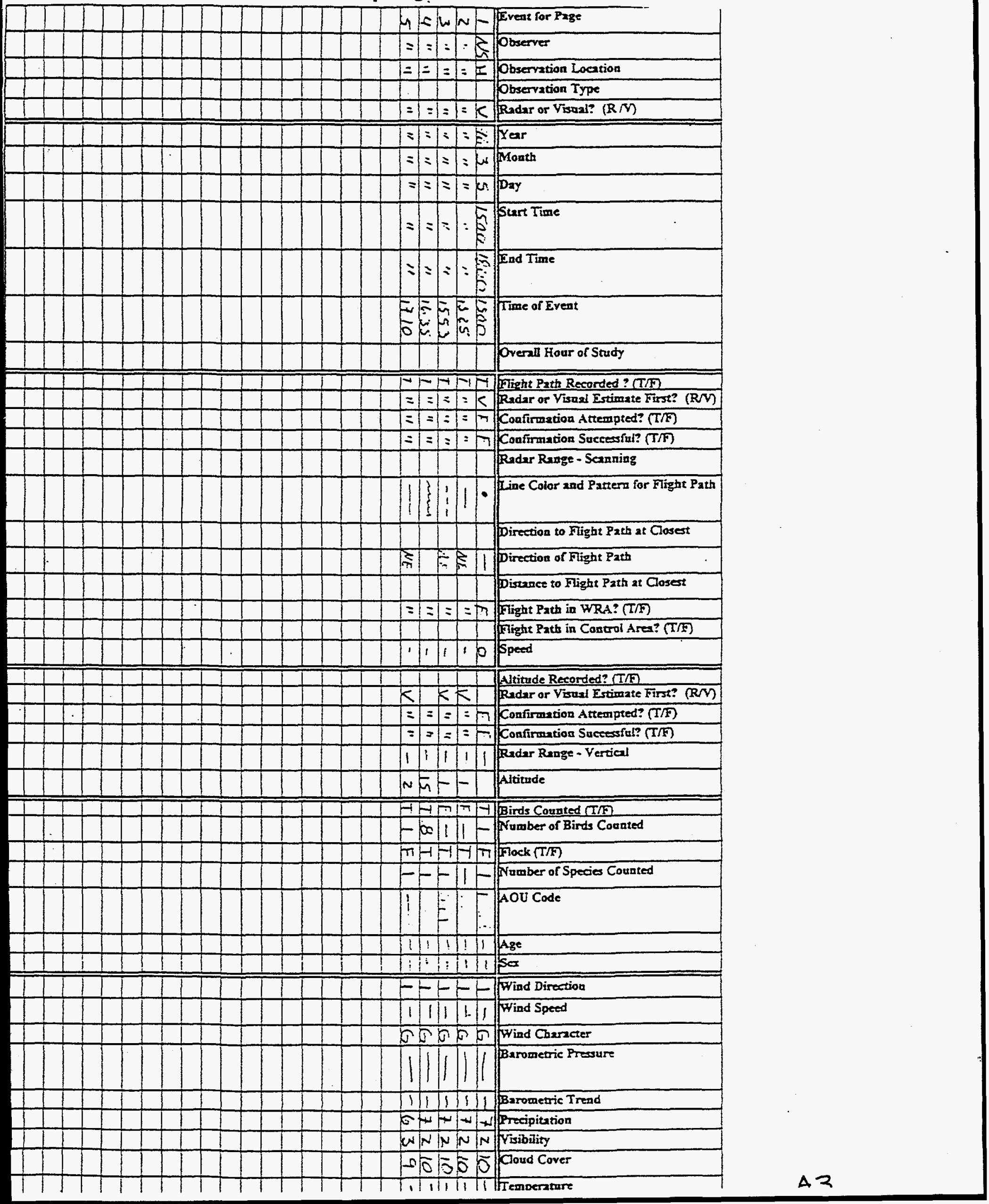


Tally Sheet

Migration Event Tally Form

$$
4 / 22 / 46
$$

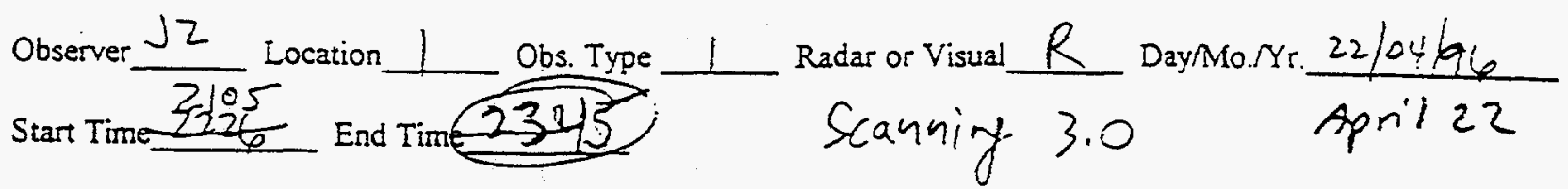

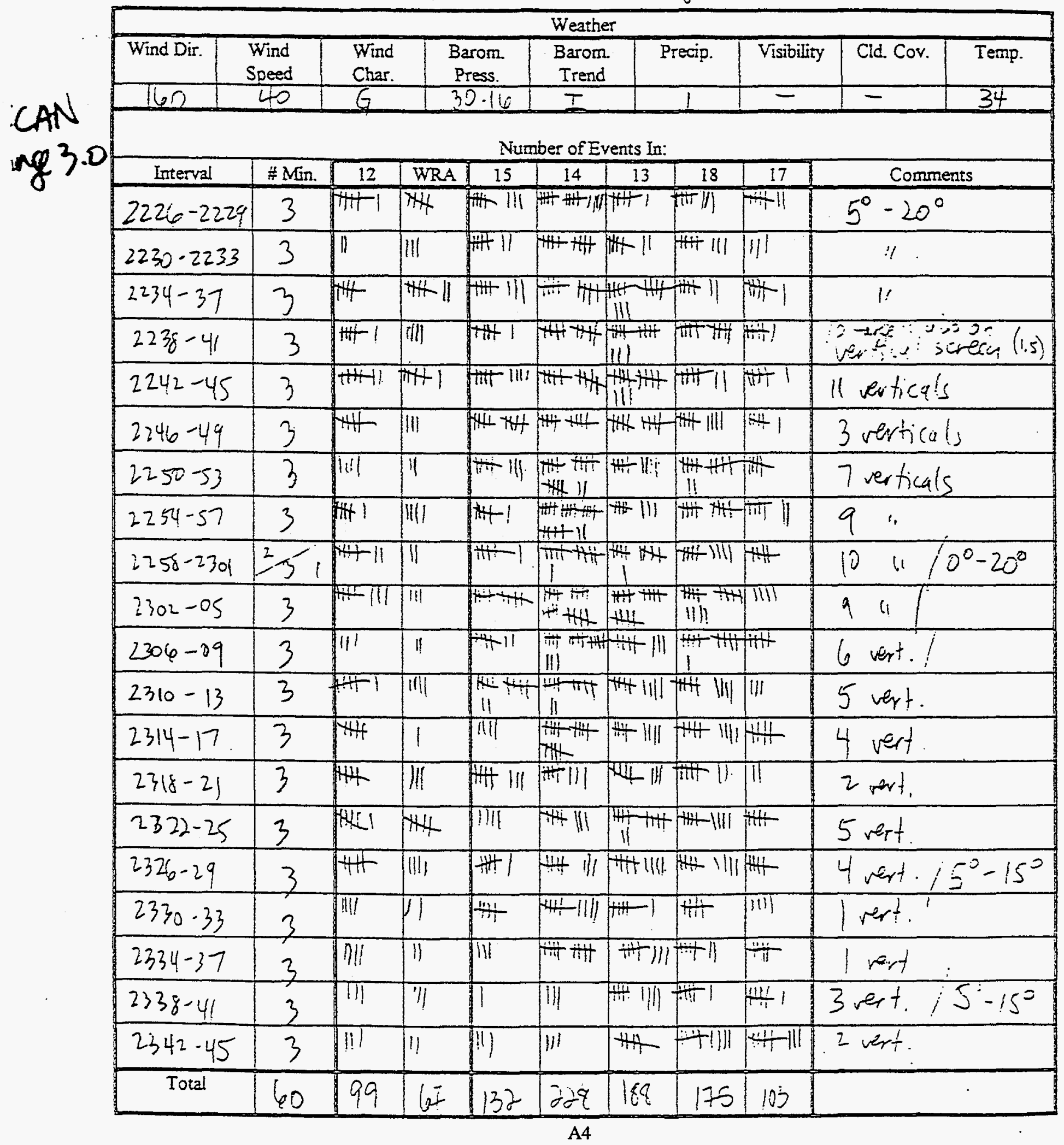




\section{Point Count Data Sheet}

Norris Hill Wind Resource Area- Jreeding Bird Jurvey - Foint Count Lata

Date

Observer

\begin{tabular}{|c|c|c|c|c|c|c|c|c|c|c|c|c|}
\hline \multirow[t]{2}{*}{ species } & \multicolumn{4}{|c|}{$0-3 \mathrm{~min}}$. & \multicolumn{4}{|c|}{$3-5 \mathrm{~min}}$. & \multicolumn{3}{|c|}{ 5-10 min. } & Tot \\
\hline & $50 \mathrm{~m}$ & $50-150$ & $>150$ & $f / 0$ & $<50 \pi$ & $50-150$ & $>150$ & $1 / 0$ & $<50 \pi$ & $50-150 \mid>150$ & $\$ 10$ & \\
\hline
\end{tabular}

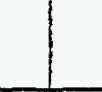

|


Appendix B - Data Base Formats 


\section{Autumn 1995 Database Format}

\begin{tabular}{|c|c|c|}
\hline Number & Name & Description \\
\hline 1 & PAGE & Data sheet page \\
\hline 2 & EVENT & Event number for page \\
\hline 3 & DATE & Date of collection \\
\hline 4 & WEEK & Week of data collection \\
\hline 5 & STARTOBS & Observation session start time \\
\hline 6 & ENDOBS & Observation session end time \\
\hline 7 & MTSDTIME & Time of event (Mountain Standard Time) \\
\hline 8 & HOUR & Hour of event \\
\hline 9 & MINS & Minutes monitored in hour sample block \\
\hline 10 & EVTS & Events recorded in hour sample block \\
\hline 11 & EV_H & Events per hour for sample block \\
\hline 12 & EV_SCAN & Events recorded in hour sample block from scanning radar \\
\hline 13 & EPH_SCAN & Events per hour for sample block from scanning radar \\
\hline 14 & VERTDOWN & Vertical radar inoperable. T/F \\
\hline 15 & LOCATION & Location of observer \\
\hline 16 & OBSTYPE & Observation type \\
\hline 17 & WINDIR & Wind direction, category \\
\hline 18 & WINDSPEE & Wind speed, category \\
\hline 19 & WINDCHAR & Wind character, category \\
\hline 20 & BAROPRES & Barometric pressure \\
\hline 21 & BAROTREN & Barometric trend, category \\
\hline 22 & PRECIP & Precipitation, category \\
\hline 23 & VISIBILI & Visibility, category \\
\hline 24 & CLOUDCOV & Cloud cover, category \\
\hline 25 & TEMP & Temperature, $\mathrm{F}$ \\
\hline 26 & VIS & Visually observed event only, T/F \\
\hline 27 & EVENTCOL & Map label, event color and line pattern \\
\hline 28 & BIRDSCOU & Birds counted, T/F \\
\hline 29 & NUMBIRDS & Number of birds counted \\
\hline 30 & FLOCK & Flock, T/F \\
\hline 31 & NUMSPECI & Number of species \\
\hline 32 & INWRA & Flight path in NHWRA, T/F \\
\hline 33 & CLOSERAN & Distance category of event at closest point \\
\hline 34 & ALTRECOR & Altitude recorded, $T / F$ \\
\hline 35 & ALTITUDE & Altitude above radar, $\mathrm{m}$ \\
\hline 36 & FLT_ELEV & Flight elevation relative to sea level \\
\hline 37 & RADEST & Radar or visual estimate of altitude \\
\hline 38 & RADARANG & Radar range setting \\
\hline 39 & VISUAL & Visual confirmation of event, $\mathrm{T} / \mathrm{F}$ \\
\hline 40 & AOU & Alpha code for species \\
\hline 41 & AGE & Age of bird \\
\hline 42 & SEX & Sex of bird \\
\hline 43 & OBSERVER & Observer initials \\
\hline 44 & RECORDER & Recorder initials \\
\hline
\end{tabular}




\section{Scanning Radar Database-1996}

\begin{tabular}{|c|c|c|}
\hline Number & Name & Description \\
\hline 1 & PAGE & Data sheet page \\
\hline 2 & EVENT & Event number for page \\
\hline 3 & OBSERVER & Observer initials \\
\hline 4 & LOCATION & Location of observer \\
\hline 5 & OBS_TYPE & Observation type \\
\hline 6 & RAD_OR_V & Radar or visual observation session \\
\hline 7 & DATE & Date of collection \\
\hline 8 & WEEK & Week of data collection \\
\hline 9 & START_TI & Observation session start time \\
\hline 10 & END_TIME & Observation session end time \\
\hline 11 & MTSDTIME & Time of event (Mountain Standard Time) \\
\hline 12 & HOUR & Hour of event \\
\hline 13 & MINS & Minutes monitored in hour sample block \\
\hline 14 & EVT & Events recorded in hour sample block \\
\hline 15 & MIN@RNG & Minutes monitored in hour sample block at given range setting \\
\hline 16 & EV@RNG & Events recorded in hour sample block at given range setting \\
\hline 17 & PCAP@RNG & Estimated percent of events recorded (capture rate) at given range setting \\
\hline 18 & AJEV@RG & Events recorded in hour sample block at given range setting, adjusted for capture rate \\
\hline 19 & AEPH@RG & Events per hour for sample block at given range setting, adjusted for capture rate \\
\hline 20 & PTH_RCR & Flight path recorded, T/F \\
\hline 21 & R_V_1ST & Radar or visual estimate first \\
\hline 22 & CONF_ATT & Confirmation attempted, T/F \\
\hline 23 & CONF_SCC & Confirmation successful, T/F \\
\hline 24 & RAD_RNG & Radar range setting \\
\hline 25 & LINE_COL & Map label, event color and line pattern \\
\hline 26 & DIR_TO_P & Direction to flight path at closest, degrees \\
\hline 27 & DIR_OF_P & Direction of flight path at closest, degrees \\
\hline 28 & DIS_TO_P & Distance to flight path at closest, meters \\
\hline 29 & IN_WRA & Flight path in NHWRA, T/F \\
\hline 30 & IN_CONTR & Flight path in reference area, T/F \\
\hline 31 & MĀJ_IN_C & Majority of flight path in which control area \\
\hline 32 & SPEED & Speed of event , knots \\
\hline 33 & BIRDS_CN & Birds counted, $\mathrm{T} / \mathrm{F}$ \\
\hline 34 & NUM_BIRD & Number of birds counted \\
\hline 35 & FLOCK & Flock, T/F \\
\hline 36 & NUM_SPP & Number of species \\
\hline 37 & AOU_CODE & Alpha code for species \\
\hline 38 & AGE & Age of bird \\
\hline 39 & SEX & Sex of bird \\
\hline 40 & WIN_DIR & Wind direction, degrees \\
\hline 41 & WIND_SPE & Wind speed, $\mathrm{km} / \mathrm{hr}$ \\
\hline 42 & WIND_CHA & Wind character, category \\
\hline 43 & BAROM_PR & Barometric pressure \\
\hline 44 & BAROM_TR & Barometric trend, category \\
\hline 45 & PRECIP & Precipitation, category \\
\hline 46 & VISIBILI & Visibility, category \\
\hline 47 & CLOUD_CO & Cloud cover, category \\
\hline 48 & TEMP & Temperature, $\mathrm{C}$ \\
\hline
\end{tabular}




\section{Vertical Database Format-1996}

\begin{tabular}{|c|c|c|}
\hline Number & Name & Description \\
\hline 1 & PAGE & Data sheet page \\
\hline 2 & EVENT & Event number for page \\
\hline 3 & OBSERVER & Observer initials \\
\hline 4 & LOCATION & Location of observer \\
\hline 5 & OBS_TYPE & Observation type \\
\hline 6 & RAD_OR_V & Radar or visual observation session \\
\hline 7 & DATE & Date of collection \\
\hline 8 & WEEK & Week of data collection \\
\hline 9 & START_TI & Observation session start time \\
\hline 10 & END_TIME & Observation session end time \\
\hline 11 & MTSDTIME & Time of event (Mountain Standard Time) \\
\hline 12 & HOUR & Hour of event \\
\hline 13 & MINS & Minutes monitored in hour sample block \\
\hline 14 & EVT & Events recorded in hour sample block \\
\hline 15 & MIN@RNG & Minutes monitored in hour sample block at given range setting \\
\hline 16 & EV@RNG & Events recorded in hour sample block at given range setting \\
\hline 17 & PCAP@RNG & Estimated percent of events recorded (capture rate) at given range setting \\
\hline 18 & AJEV@RG & $\begin{array}{l}\text { Events recorded in hour sample block at given range setting, adjusted for capture } \\
\text { rate }\end{array}$ \\
\hline 19 & AEPH@RG & Events per hour for sample block at given range setting, adjusted for capture rate \\
\hline 20 & ALT_RCR & Altitude recorded, T/F \\
\hline 21 & R_V_1ST & Radar or visual estimate first \\
\hline 22 & CONF_ATT & Confirmation attempted, T/F \\
\hline 23 & CONF_SCC & Confirmation successful, T/F \\
\hline 24 & RAD_RNG & Radar range setting \\
\hline 25 & ALTTTUDE & Altitude above radar, $\mathrm{m}$ \\
\hline 26 & FLT_ELEV & Flight elevation relative to sea level, $\mathrm{m}$ \\
\hline 27 & FLT_AGL & Flight altitude above ground level, m \\
\hline 28 & DIR_TO_P & Direction to flight path at closest, degrees \\
\hline 29 & E_OR W & Direction to flight path at closest East or West \\
\hline 30 & DIR_OF_P & Direction of flight path at closest, degrees \\
\hline 31 & DIS_TO_P & Distance to flight path at closest, meters \\
\hline 32 & IN_WRA & Flight path in NHWRA, T/F \\
\hline 33 & IN_CONTR & Flight path in reference area, $T / F$ \\
\hline 34 & MAJ_IN_C & Majority of flight path in which control area \\
\hline 35 & BIRDS_CN & Birds counted, $\mathrm{T} / \mathrm{F}$ \\
\hline 36 & NUM_BIRD & Number of birds counted \\
\hline 37 & FLOCK & Flock, T/F \\
\hline 38 & NUM_SPP & Number of species \\
\hline 39 & AOU_CODE & Alpha code for species \\
\hline 40 & AGE & Age of bird \\
\hline 41 & SEX & Sex of bird \\
\hline 42 & WIN_DIR & Wind direction, degrees \\
\hline 43 & WIND_SPE & Wind speed, $\mathrm{km} / \mathrm{hr}$ \\
\hline 44 & WIND_CHA & Wind character, category \\
\hline 45 & BAROM_PR & Barometric pressure \\
\hline 46 & BAROM_TR & Barometric trend, category \\
\hline 47 & PRECIP & Precipitation, category \\
\hline 48 & VISIBILI & Visibility, category \\
\hline 49 & CLOUD_CO & Cloud cover, category \\
\hline 50 & TEMP & Temperature, $\mathrm{C}$ \\
\hline
\end{tabular}


Appendix C - Tables 
Appendix Table 31. Transects Completed for Assessment of Preimpact Avian Mortality in and near NHWRA, August 1995 - August 1996.

\begin{tabular}{|c|c|c|c|c|c|c|c|c|c|}
\hline \multirow{2}{*}{\multicolumn{2}{|c|}{$\begin{array}{c}\text { Year } \\
\text { Transect No. }\end{array}$}} & \multicolumn{2}{|c|}{$\begin{array}{c}\text { Transect Length } \\
(\mathbf{k m})\end{array}$} & \multicolumn{4}{|c|}{ Total Completed } & \multicolumn{2}{|c|}{$\begin{array}{l}\text { Dead Birds } \\
\text { Found } \\
\end{array}$} \\
\hline & & In WRA & Total & No. & Length (km) & km In WRA & Out & In & Out \\
\hline \multirow[t]{9}{*}{1995} & 1 & - & 8.2 & 1 & 8.2 & - & 8.2 & - & - \\
\hline & 2 & 0.73 & 6.16 & 9 & 55.46 & 6.30 & 48.93 & - & - \\
\hline & 3 & - & 1.61 & 3 & 4.87 & - & 4.87 & - & - \\
\hline & 4 & - & 1.92 & 4 & 9.48 & - & 7.66 & - & - \\
\hline & 5 & - & 2.37 & 4 & 2.37 & - & 9.48 & - & 1 \\
\hline & 6 & - & 4.5 & 5 & 22.52 & - & 22.52 & - & - \\
\hline & 7 & 0.72 & 2.11 & 7 & 14.77 & 5.05 & 9.71 & - & - \\
\hline & 8 & - & 3.23 & 5 & 16.13 & - & 16.13 & - & - \\
\hline & 9 & 0.85 & 1.41 & 7 & 9.87 & 5.96 & 3.91 & - & - \\
\hline \multicolumn{2}{|c|}{1995 Total } & 2.30 & 31.51 & 45 & 148.9 & 17.54 & 131.37 & 0 & 1 \\
\hline \multirow[t]{5}{*}{1996} & 2 & 0.73 & 6.16 & 8 & 49.3 & 5.84 & 43.5 & - & - \\
\hline & 6 & - & 3.88 & 8 & 31.12 & - & 31.12 & - & 2 \\
\hline & 7 & 1.56 & 2.93 & 8 & 23.46 & 12.48 & 10.98 & 1 & - \\
\hline & 8 & - & 3.23 & 8 & 25.84 & - & 25.84 & - & - \\
\hline & 9 & 0.85 & 1.41 & 8 & 11.28 & 6.82 & 4.46 & - & - \\
\hline \multicolumn{2}{|c|}{1996 Total } & 3.14 & 17.61. & 40 & 140.91 & 25.1 & 115.82 & 1 & 2 \\
\hline \multicolumn{2}{|c|}{ Both Years } & 5.44 & 49.12 & 85 & 289.81 & 42.64 & 247.19 & 1 & 3 \\
\hline
\end{tabular}


Appendix Table 32. Raptors, Swans, and Pelicans Visually Detected During Radar Monitoring, NHWRA, Autumn 1995.

\begin{tabular}{|c|c|c|c|c|c|}
\hline \multirow{2}{*}{ Group } & \multirow{2}{*}{$\begin{array}{c}\text { Species } \\
\text { Alpha Code }^{1}\end{array}$} & \multicolumn{2}{|c|}{ No. Observed } & \multicolumn{2}{|c|}{ No. In WRA (\% of Total) } \\
\hline & & Events & Individuals & Events & Individuals \\
\hline \multirow[t]{3}{*}{ Eagles } & BAEA & 21 & 22 & $2(9.5)$ & $2(9.1)$ \\
\hline & GOEA & 37 & 50 & $7(18.9)$ & $10(20)$ \\
\hline & UNEA & 15 & 16 & $1(6.7)$ & $1(6.3)$ \\
\hline \multirow[t]{2}{*}{ Falcons } & AMKE & 4 & 4 & $2(50)$ & $2(50)$ \\
\hline & PRFA & 2 & 2 & $2(100)$ & $2(100)$ \\
\hline \multirow[t]{4}{*}{ Buteos } & RLHA & 20 & 21 & $7(35)$ & $7(33.3)$ \\
\hline & RTHA & 27 & 30 & $13(48.1)$ & $14(46.7)$ \\
\hline & SWHA & 2 & 3 & $1(50)$ & $2(33.3)$ \\
\hline & UNHA & 15 & 15 & - & - \\
\hline \multirow[t]{3}{*}{ Accipiters } & COHA & 2 & 2 & $1(50)$ & $1(50)$ \\
\hline & NOGO & 1 & 1 & $1(100)$ & $1(100)$ \\
\hline & UNAC & 1 & 1 & - & - \\
\hline Harriers & NOHA & 9 & 9 & $5(55.6)$ & $5(55.6)$ \\
\hline Raptors & UNRA $^{2}$ & 41 & 49 & $5(12.2)$ & $5(10.2)$ \\
\hline Swans & UNSW & 3 & 103 & - & - \\
\hline Pelicans & AWPE & 8 & 153 & $2(25)$ & $53(34.6)$ \\
\hline
\end{tabular}

${ }^{1}$ See Appendix $\mathrm{E}$ for definition of alpha code. UN prefix indicates unidentified species.

${ }^{2}$ Unidentified raptors. 
Appendix Table 33. Raptors, Swans, and Pelicans Visually Detected During Radar Monitoring, NHWRA, Spring 1996.

\begin{tabular}{|c|c|c|c|c|c|}
\hline \multirow[t]{2}{*}{ Group } & \multirow{2}{*}{$\begin{array}{c}\text { Species } \\
\text { Alpha Code }\end{array}$} & \multicolumn{2}{|c|}{ No. Observed } & \multicolumn{2}{|c|}{$\begin{array}{c}\text { No. In WRA (\% of } \\
\text { Total) }\end{array}$} \\
\hline & & Events & Individuals & Events & Individuals \\
\hline \multirow[t]{3}{*}{ Eagles } & BAEA & 11 & 11 & $6(54.5)$ & $6(54.5)$ \\
\hline & GOEA & 42 & 74 & $15(35.7)$ & $27(36.5)$ \\
\hline & UNEA & 5 & 5 & $1(20)$ & $1(20)$ \\
\hline \multirow[t]{3}{*}{ Falcons } & AMKE & 12 & 12 & $7(58.3)$ & $7(58.3)$ \\
\hline & PRFA & 1 & 1 & - & - \\
\hline & UNFA & 1 & 1 & - & - \\
\hline \multirow[t]{3}{*}{ Buteos } & RLHA & 2 & 3 & $2(100)$ & $3(100)$ \\
\hline & RTHA & 26 & 34 & $11(42.3)$ & $15(44.1)$ \\
\hline & UNHA & 7 & 8 & $1(14.3)$ & $1(12.5)$ \\
\hline \multirow[t]{2}{*}{ Accipiters } & $\mathrm{COHA}$ & 1 & 1 & - & - \\
\hline & SSHA & 1 & 1 & $1(100)$ & $1(100)$ \\
\hline Harriers & NOHA & 4 & 4 & $3(75)$ & $3(75)$ \\
\hline Raptors $^{2}$ & UNRA & 9 & 13 & $1(11.1)$ & $1(7.7)$ \\
\hline Osprey & OSPR & 1 & 1 & $1(100)$ & $1(100)$ \\
\hline Pelicans & AWPE & 16 & 284 & $1(6.3)$ & $1(0.4)$ \\
\hline
\end{tabular}

${ }^{1}$ Appendix $\mathrm{E}$ for definition of alpha code. UN prefix indicates unidentified species.

${ }^{2}$ Unidentified raptors. 
Appendix Table 34. Other Species and Respective Altitude Ranges Detected in NHWRA, Summer 1996.

\begin{tabular}{lcc}
\multicolumn{1}{c}{ Species } & $\begin{array}{c}\text { No. } \\
\text { Observed }\end{array}$ & $\begin{array}{c}\text { Range of Visually Estimated } \\
\text { Altitudes (m) }\end{array}$ \\
\hline Clark's Nutcracker (Nucifraga columbiana) & 171 & $15-65$ \\
$\begin{array}{l}\text { American White Pelican (Pelecanus } \\
\text { erythrorhynchos) }\end{array}$ & 46 & $25-700$ \\
Mountain Bluebird (Sialia currucoides) & 42 & $5-10$ \\
American Robin (Turdus migratorius) & 15 & 20 \\
Rock Dove (Columba livia) & 8 & $15-30$ \\
Cliff Swallow (Hirundo pyrrhonota) & 8 & 40 \\
Tree Swallow (Tachycineta bicolor) & 3 & 15 \\
Great Blue Heron (Ardea herodias) & 2 & 40 \\
Sandhill Crane (Grus canadensis) & 2 & 20 \\
\hline
\end{tabular}


Appendix D - Figures 


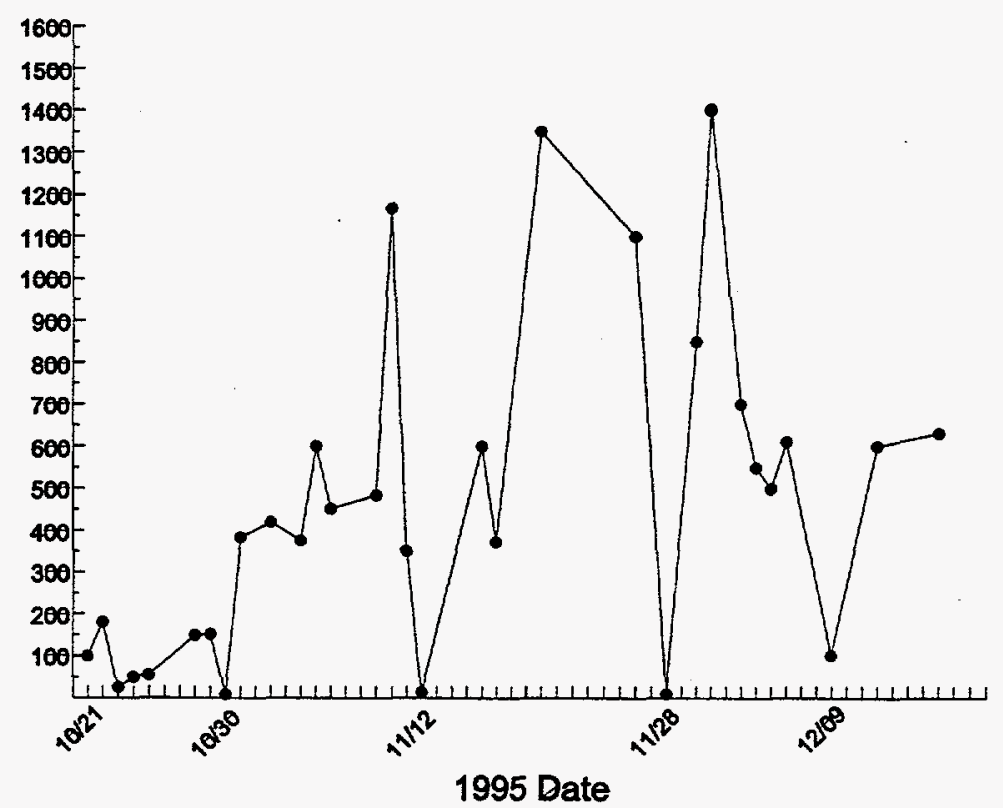

Appendix Figure 53. Canada geese counted on Ennis Lake, autumn 1995.

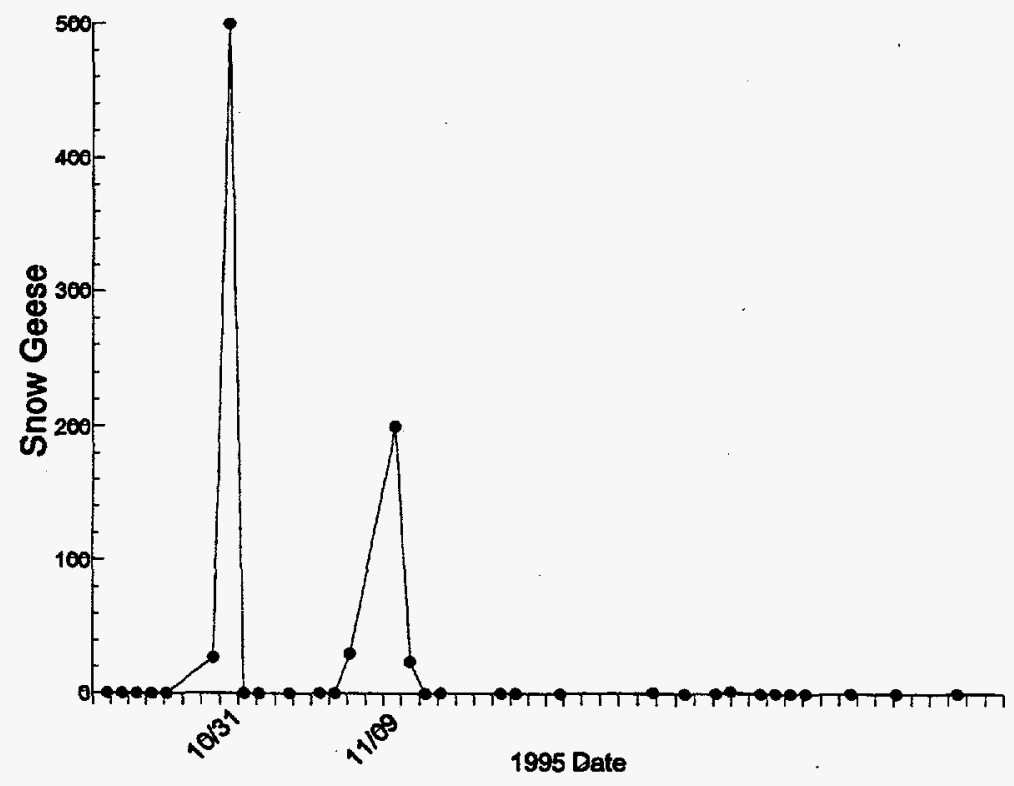

Appendix Figure 54. Snow geese counted on Ennis Lake, autumn 1995. 


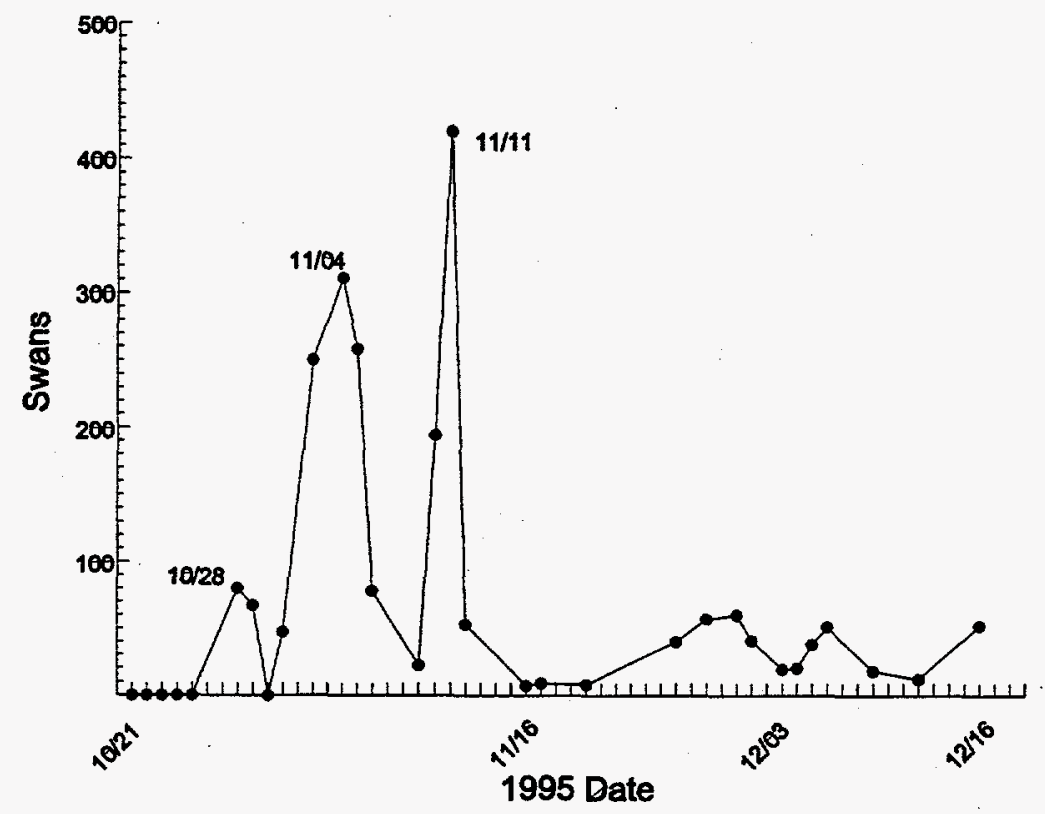

Appendix Figure 55. Swans (trumpeter and tundra) counted on Ennis Lake, autumn 1995.

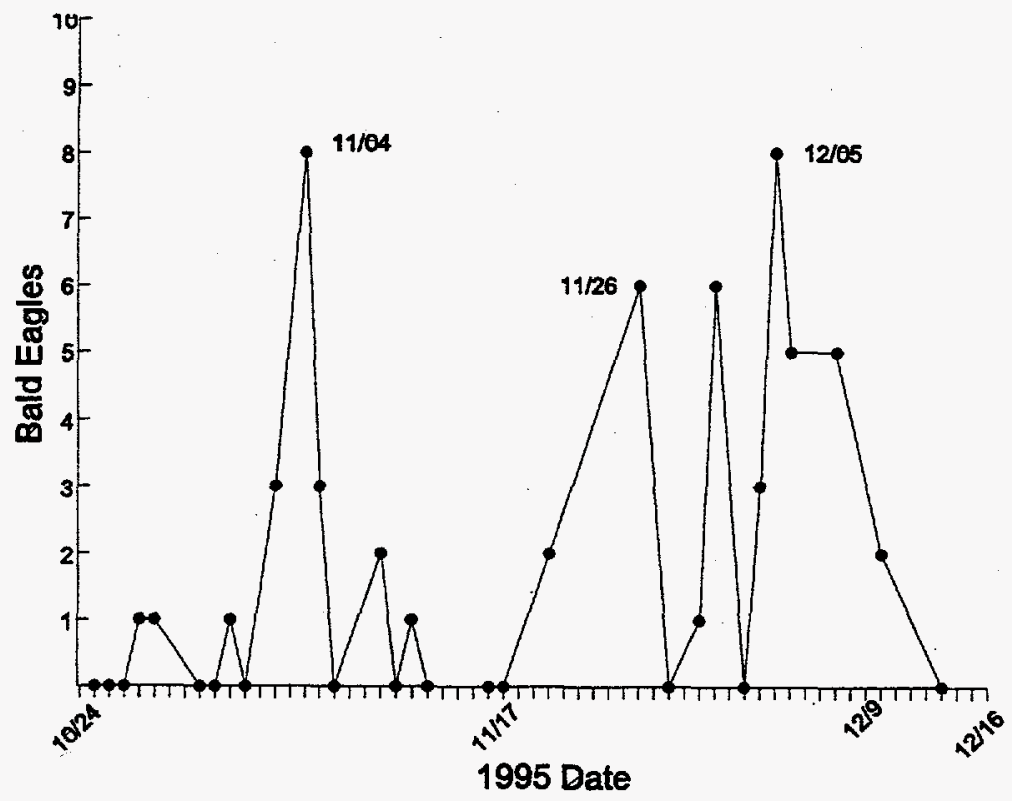

Appendix Figure 56. Bald eagles counted on Ennis Lake, autumn 1995. 


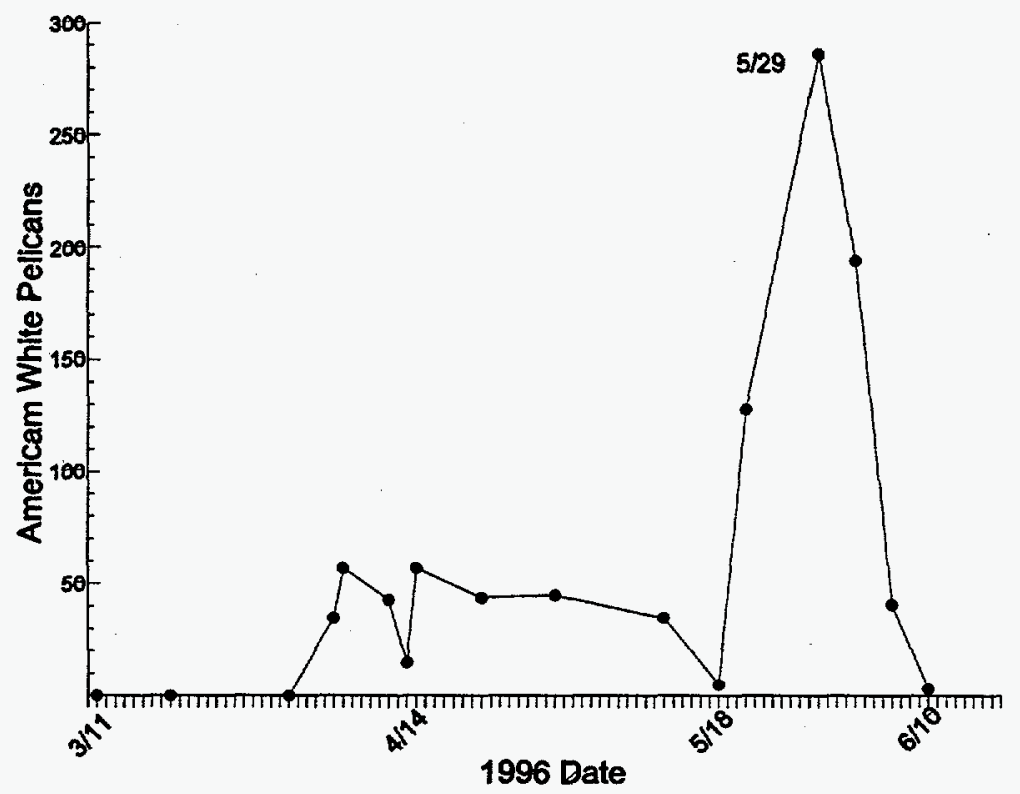

Appendix Figure 57. American white pelicans counted on Ennis Lake, spring 1996.

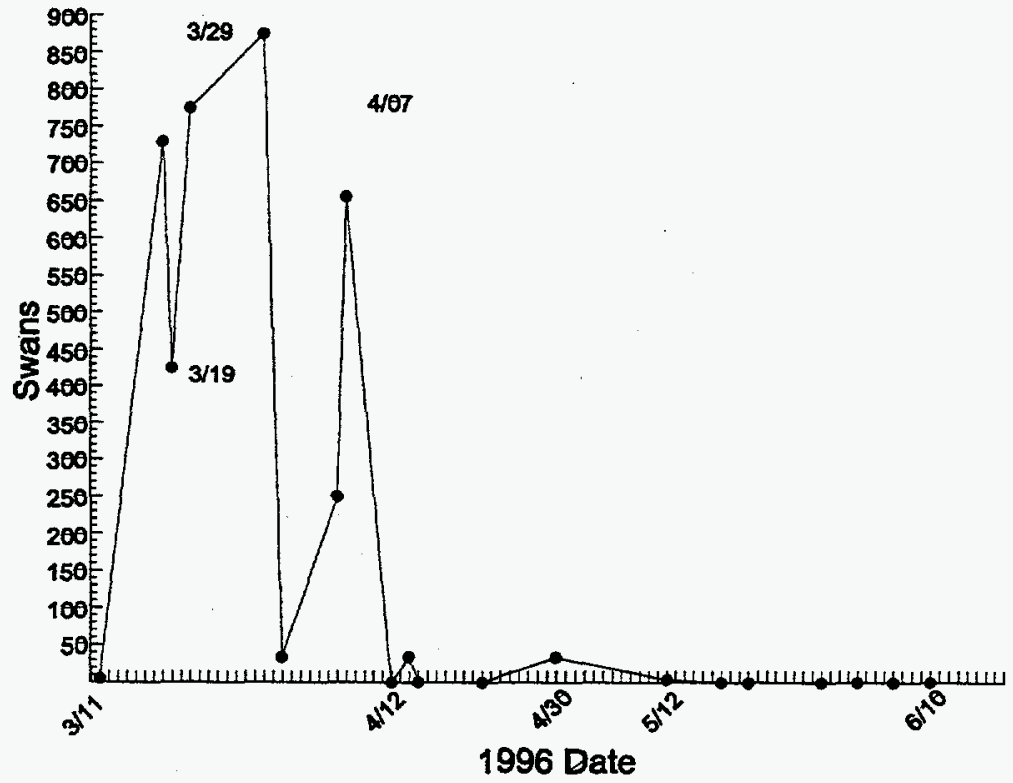

Appendix Figure 58. Swans (trumpeter and tundra) counted on Ennis Lake, spring 1996. 


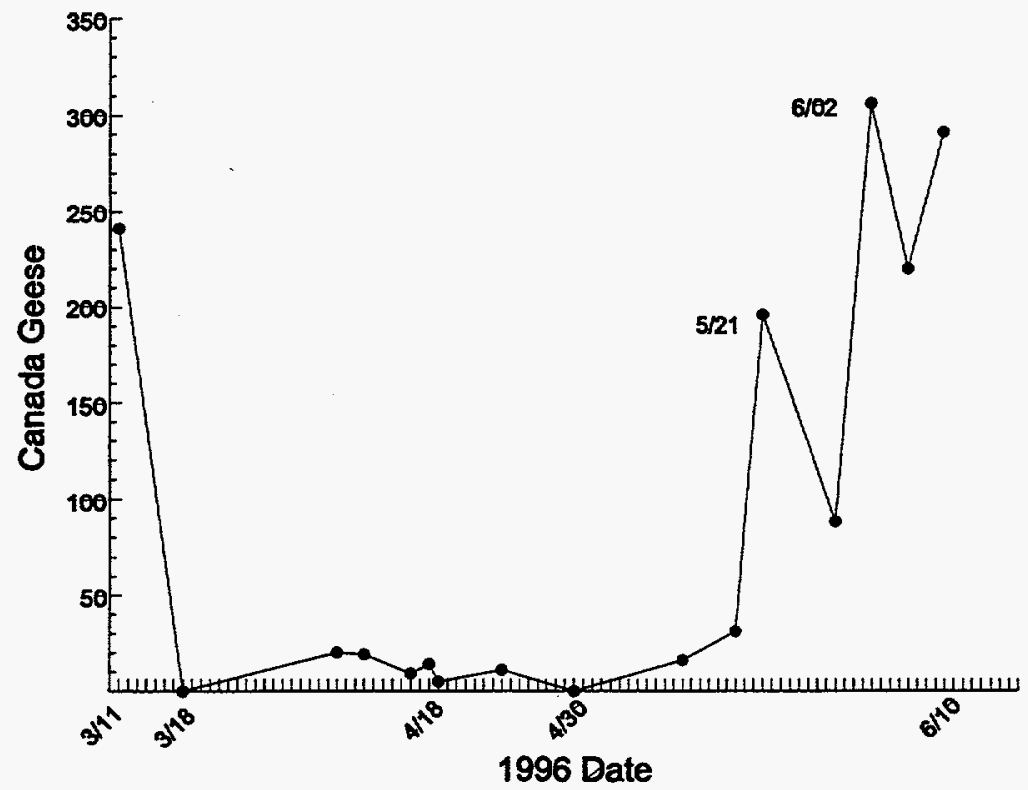

Appendix Figure 59. Canada geese counted on Ennis Lake, spring 1996.

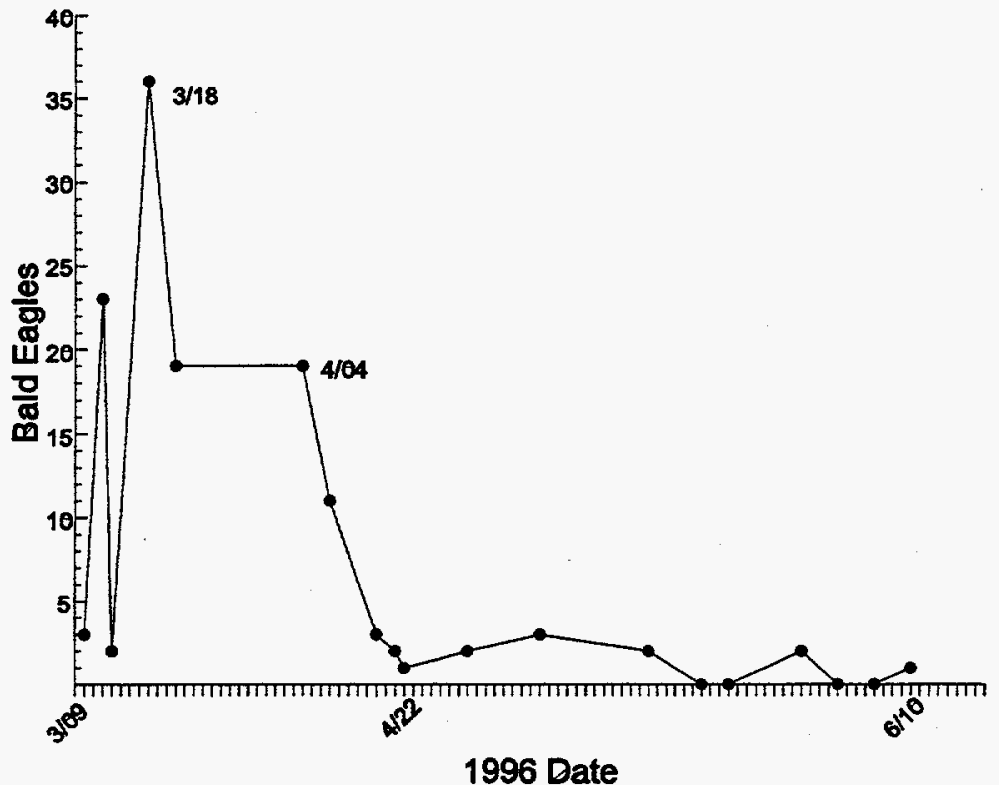

Appendix Figure 60. Bald eagles counted on Ennis Lake, spring 1996. 


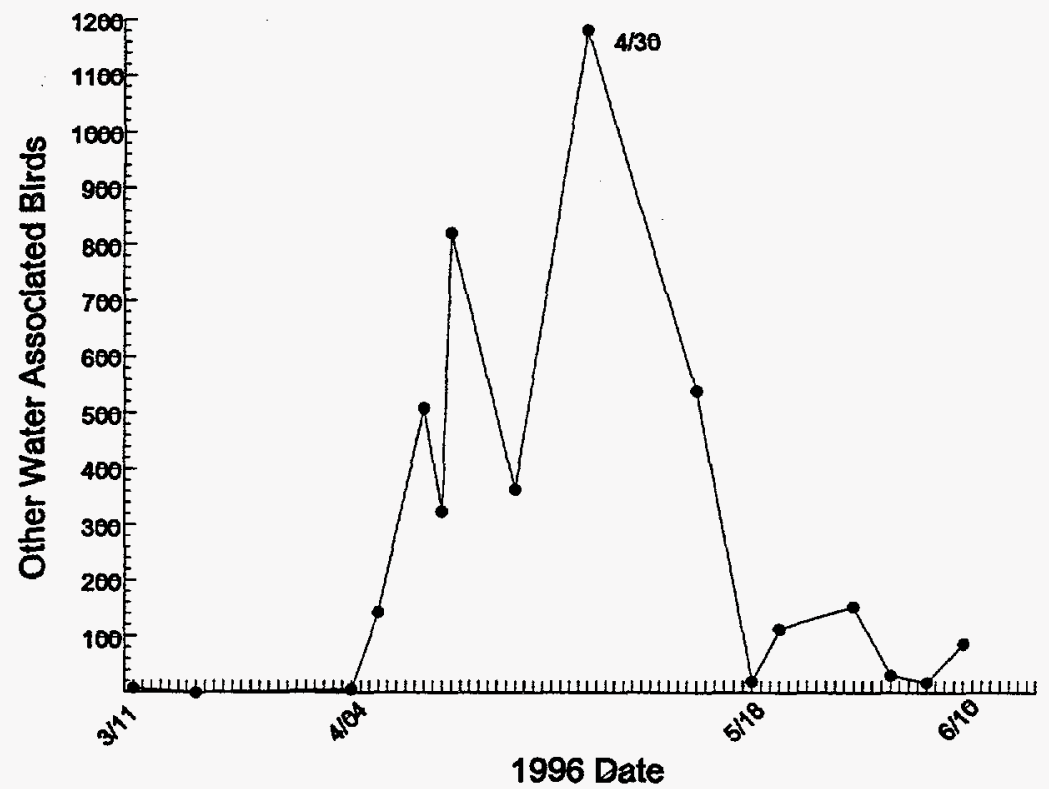

Appendix Figure 61. Other water-associated birds (e.g., grebes, loons, gulls, cranes, coots, herons, shorebirds) counted on Ennis Lake, spring 1996. 
Appendix E - Alpha Codes for North American Bird Species and Vegetative Groups Associated with Cover Types 
ALPHA SPECIES COOES FOR BIRDS IX THE MORTH AMERICAK BIRD BAMDING MAXUAL JULY. 1988

ALPHABETICAL SORT

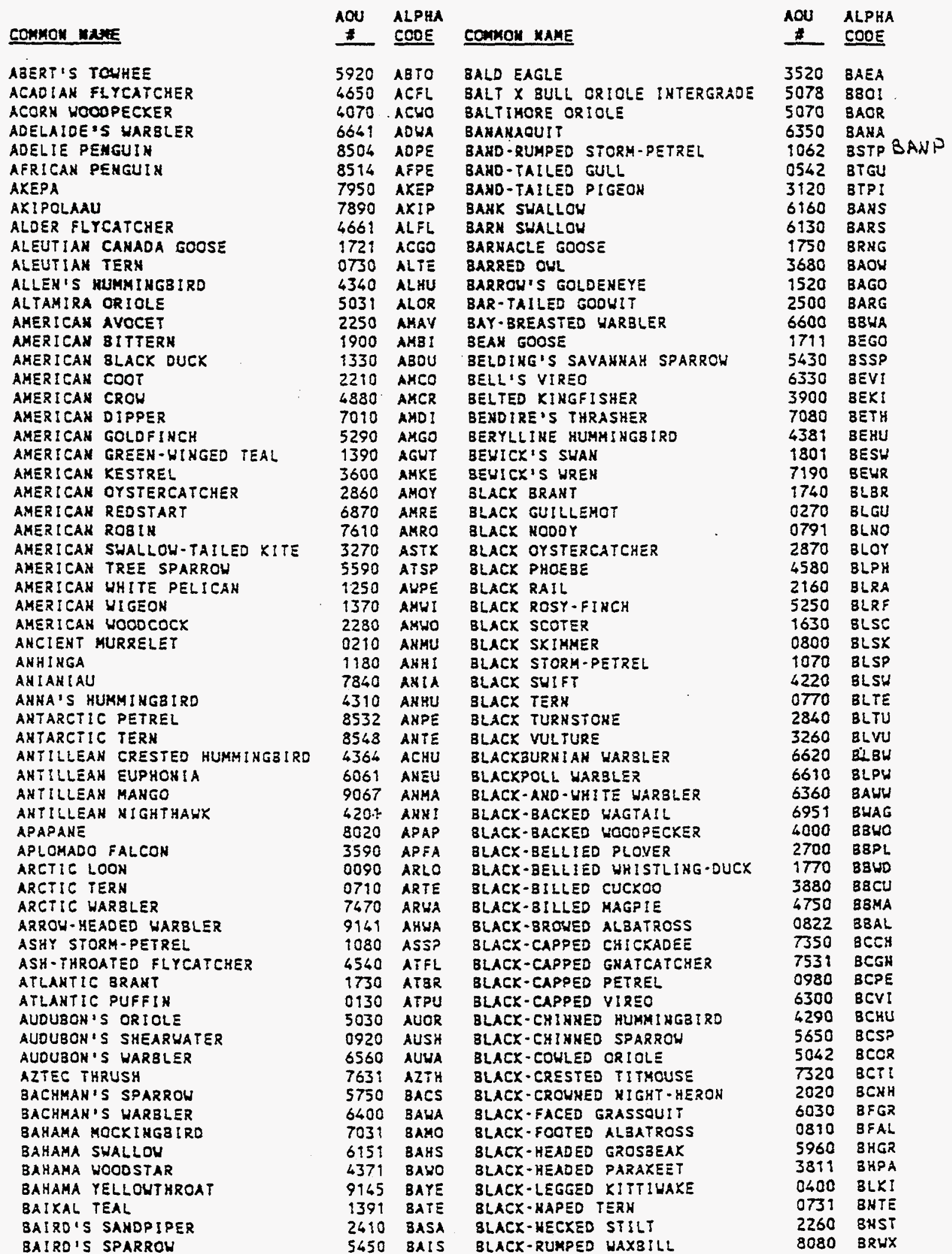




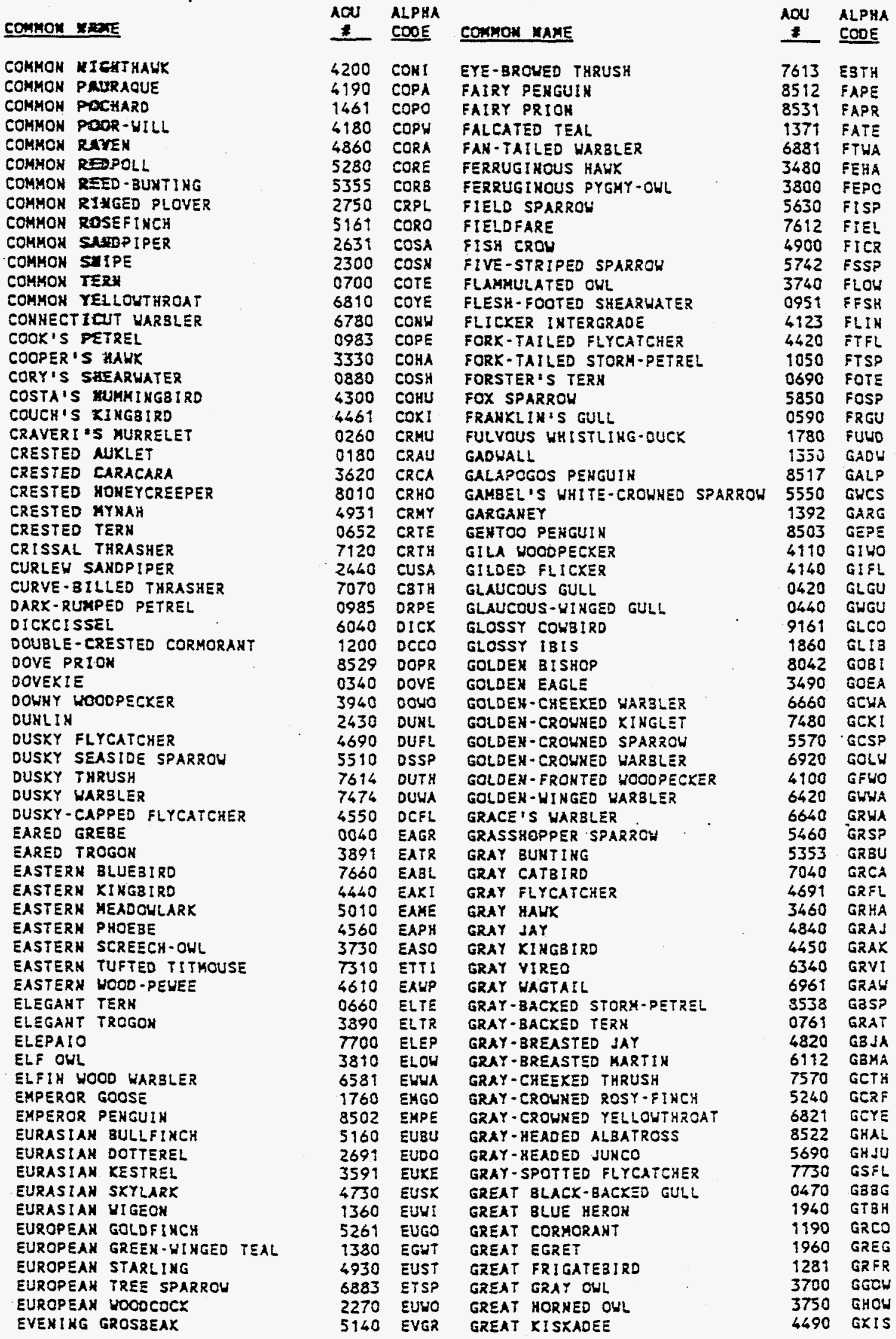




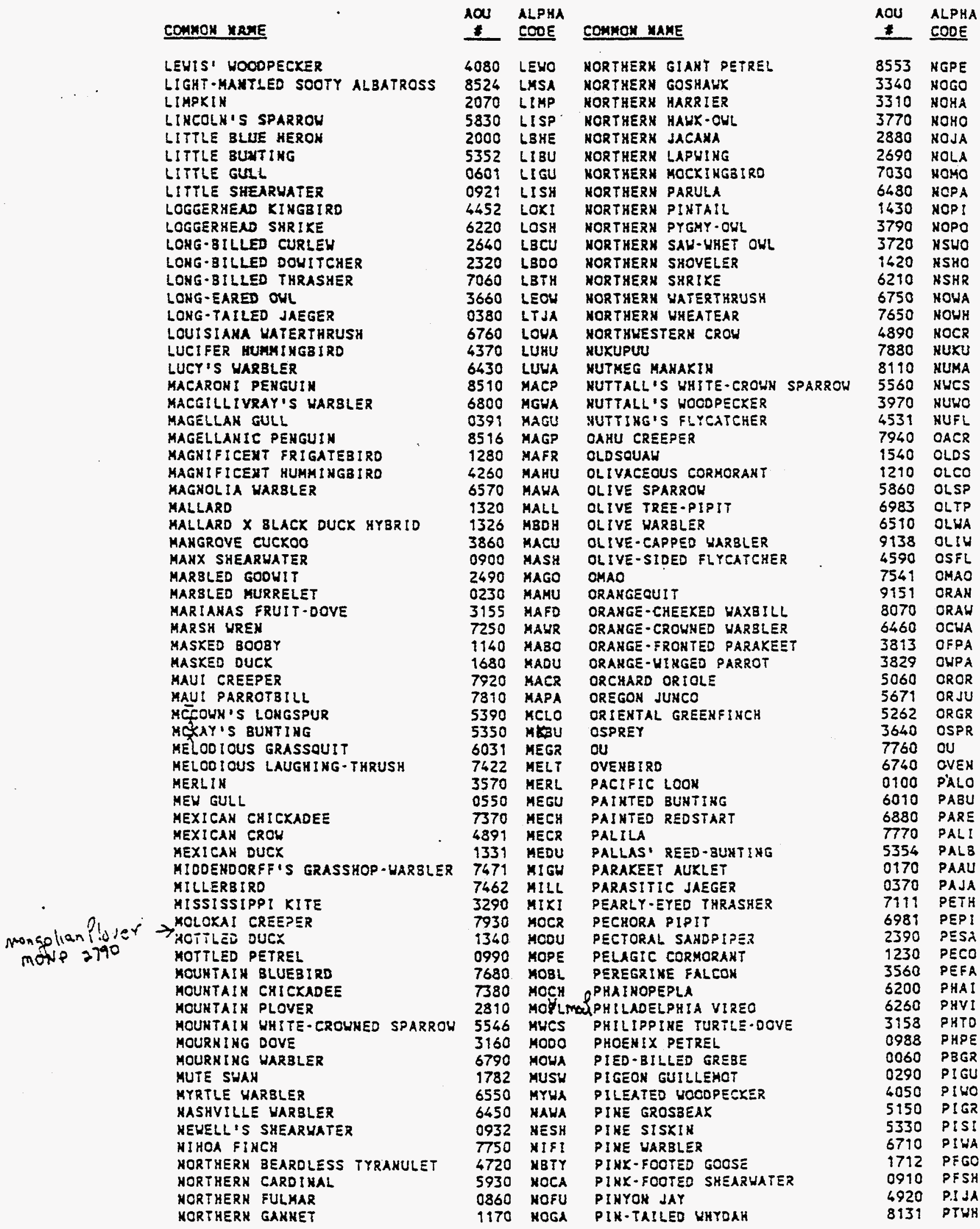




\begin{tabular}{|c|c|c|c|c|c|}
\hline СOMHON NAME & 10U & $\begin{array}{l}\text { ALPHA } \\
\text { COOE }\end{array}$ & CONHON YAME & $\begin{array}{c}\text { AOU } \\
+ \\
\end{array}$ & $\begin{array}{l}\text { ALPHA } \\
\text { CODE }\end{array}$ \\
\hline $\begin{array}{l}\text { SHORT-TAILED SHEARWATER } \\
\text { SHORT-TAILED SWIFT }\end{array}$ & $\begin{array}{l}0960 \\
4231\end{array}$ & $\begin{array}{l}\text { SHOS } \\
\text { STSW }\end{array}$ & $\begin{array}{l}\text { THIM-BILLEO PRION } \\
\text { THREE-TOED WOOOPECXER }\end{array}$ & $\begin{array}{l}8530 \\
6010\end{array}$ & $\begin{array}{l}\text { TEPR } \\
\text { TTUC }\end{array}$ \\
\hline SHY ALBATROSS & 0823 & SHAL & TOUMSENO'S SHEARWATER & 0931 & TOSH \\
\hline $\begin{array}{l}\text { SIBERIAH ACCEHTOR } \\
\text { SIBERIAK FLYCATCHER }\end{array}$ & $\begin{array}{l}7491 \\
7720\end{array}$ & $\begin{array}{l}\text { SIAC } \\
\text { SIFL }\end{array}$ & $\begin{array}{l}\text { TOWNSEND'S SOLITAIRE } \\
\text { TOWHSENO'S WARBLER }\end{array}$ & $\begin{array}{l}7540 \\
6680\end{array}$ & $\begin{array}{l}\text { TOSO } \\
\text { TOWA }\end{array}$ \\
\hline & 7649 & SIRU & TRAILL'S FLYCATCHER & 4669 & $\begin{array}{l}\text { TRFL } \\
\text { TRES }\end{array}$ \\
\hline $\begin{array}{l}\text { SIBERIAN TIT } \\
\text { SLATE-COLORED JUHCO }\end{array}$ & $\begin{array}{l}7390 \\
5670\end{array}$ & $\begin{array}{l}\text { SIT! } \\
\text { SCJU }\end{array}$ & $\begin{array}{l}\text { TREE SWALLOW } \\
\text { TREMBLER }\end{array}$ & $\begin{array}{l}6140 \\
9116\end{array}$ & $\begin{array}{l}\text { TRES } \\
\text { TREM }\end{array}$ \\
\hline $\begin{array}{l}\text { SLATE-COLORED JUNCO } \\
\text { SLATE-THROATED REDSTART }\end{array}$ & 6890 & $\begin{array}{l}\text { SCJU } \\
\text { SLAR }\end{array}$ & TRICOLORED BLACXEIRO & 5000 & TRBL \\
\hline SLATY-BACKED GULL & 0480 & SBGU & TRICOLORED HEROH & 1990 & TRHE \\
\hline SMALL CAMADA GOOSE & 1729 & scGo & TROPICAL KIKGSIRO & 4660 & $\operatorname{TR} \times I$ \\
\hline SMITH'S LOKGSPUR & 5370 & SHLO & TROPICAL MOCXIYGBIRO & 7032 & TRMO \\
\hline SMDOTH-SILLED ANI & 3830 & S8AN & TROPICAL PARULA & 6490 & TRPA \\
\hline SNAIL KITE & 3300 & SHXI & TROUPIAL & 9166 & TROU \\
\hline SNOW BUNTIYG & 5340 & SN8U & TRUMPETER SWAH & 1810 & TRUS \\
\hline SNOU PETREL & 8537 & SHPE & TUFTED DUCX & 1491 & TUOU \\
\hline SNOW $\times$ BLUE GOOSE IMTERGRADE & 1695 & 5861 & TUFTED PUFFIN & 0120 & TUPU \\
\hline SNOUY EGRET & 1970 & SHEG & TURKEY VULTURE & 3250 & TUVu \\
\hline SNOWY OWL & 3760 & SHOW & UNIOENTIFIED OARK-EYED JUNCO & 5677 & UDEJ \\
\hline SHOWY PLOVER & 2780 & SHPL & UHIOENTIFIEO GULL & 0534 & UNCU \\
\hline SHOWY SHEATHBILL & 8543 & SNSH & UNIOENTIFIED HLIAHINGSIRO & 6409 & UNHU \\
\hline SOLITARY SANDPIPER & 2560 & Sosh & UNIDENTIEIED TEAL & 1601 & UNTE \\
\hline SOLITARY YIREC & 6290 & Sovl & UPLAND SANDPIPER & 2610 & UPSA \\
\hline SONG SPARROW & 5810 & sosp & VARIED BUNTIKG & 6000 & VABU \\
\hline SOOTY ALBATROSS & 8523 & SOAL & YARIED THRUSH & 7630 & VATH \\
\hline SOOTY SHEARWATER & 0950 & $505 \mathrm{H}$ & VARIED. TAT & 7341 & VAT! \\
\hline SOOTY STORM-PETREL & 1071 & SOCP & VAUX'S SUIFT & 4260 & VASW \\
\hline $\begin{array}{l}\text { SOOTY TERN } \\
\text { SORA }\end{array}$ & $\begin{array}{l}0750 \\
2140\end{array}$ & $\begin{array}{l}\text { SOTE } \\
\text { SORA }\end{array}$ & $\begin{array}{l}\text { VEERY } \\
\text { VEROIN }\end{array}$ & $\begin{array}{l}7560 \\
7460\end{array}$ & $\begin{array}{l}\text { YEER } \\
\text { VERO }\end{array}$ \\
\hline SOUTH POLAR SXUA & 0352 & SPSK & VERHILION FLYCATCHER & 4710 & VEFL \\
\hline SOUTHERM BLACK-BACKED GULL & 8546 & $588 G$ & VESPER SPARROU & 5400 & VESP \\
\hline SOUTKERM FULMAR & 8526 & sofu & VICTORIA PENGUIN & 8506 & VIPE \\
\hline SOUTHERN GIANT PETREL & 8525 & SGPE & VIOLET-CROWNED KUMMINGEIRO & 4391 & VCHU \\
\hline SOUTHERN HOUSE WREN & 9109 & SHWR & VIOLET-GREEN SWALLOU & 6150 & VGSW \\
\hline SPECTACLED EIDER & $1580^{\circ}$ & SPE! & VIRGINIA RAIL & 2120 & VIRA \\
\hline $\begin{array}{l}\text { SPOONBILL SANDPIPER } \\
\text { SPOTTEO DOVE }\end{array}$ & $\begin{array}{l}2450 \\
3151\end{array}$ & $\begin{array}{l}\text { SPOS } \\
\text { SPDO }\end{array}$ & $\begin{array}{l}\text { VIRGINIA'S WARBLER } \\
\text { WANDERING RLBATROSS }\end{array}$ & $\begin{array}{l}6440 \\
0811\end{array}$ & $\begin{array}{l}\text { VIWA } \\
\text { WAAL }\end{array}$ \\
\hline SPOTTED OWL & 3690 & SPOH & WAMOERING TATTLER & 2590 & WATA \\
\hline SPOTTED SANOPIPER & 2630 & SPSA & WARBLING SILVERBILL & 8100 & HAS! \\
\hline SPOTTEO TOWHEE & 5880 & SPTO & WARSLING VIREO & 6270 & WAV! \\
\hline SPOTTED-BREASTED ORIOLE & 5032 & $5 P 00$ & WATER PIPIT & 6970 & WAP! \\
\hline $\begin{array}{l}\text { SPRAGUE'S PIPIT } \\
\text { STELLER'S EIDER }\end{array}$ & $\begin{array}{l}7000 \\
1570\end{array}$ & $\begin{array}{l}\text { SPPI } \\
\text { SIEI }\end{array}$ & $\begin{array}{l}\text { WEDGE-RUMPED STORH-PETREL } \\
\text { WEDGE-TAILED SHEARWATER }\end{array}$ & $\begin{array}{l}1063 \\
0961\end{array}$ & $\begin{array}{l}\text { WRSP } \\
\text { UTSH }\end{array}$ \\
\hline STELLER'S SAY & 4780 & STIA & WEST IHOIAN WHISTLIKC-DUCK & $177 i$ & UI जO \\
\hline STILT SANDPIPER & 2330 & STSA & WESTERN BLUESIRO & 7670 & WESL \\
\hline $\begin{array}{l}\text { STOLID FLYCATCHER } \\
\text { STREAKED SHEARWATER }\end{array}$ & $\begin{array}{l}4553 \\
0881\end{array}$ & $\begin{array}{l}\text { STOF } \\
\text { STRS }\end{array}$ & $\begin{array}{l}\text { WESTERH FLYCATCHER } \\
\text { WESTERM GRESE }\end{array}$ & $\begin{array}{l}4640 \\
0010\end{array}$ & $\begin{array}{l}\text { WEFL } \\
\text { WEGR }\end{array}$ \\
\hline $\begin{array}{l}\text { STREAK-BACXED ORIOLE } \\
\text { STREAMERTAIL }\end{array}$ & $\begin{array}{l}5051 \\
9071\end{array}$ & $\begin{array}{l}\text { STRO } \\
\text { STTL }\end{array}$ & $\begin{array}{l}\text { WESTERN GULL } \\
\text { WESTERH KIHGBIRO }\end{array}$ & $\begin{array}{l}0490 \\
4470\end{array}$ & $\begin{array}{l}\text { WEGU } \\
\text { WEXI }\end{array}$ \\
\hline $\begin{array}{l}\text { STRICXLANO'S WOODPELAEA } \\
\text { STRIPE-HEAOED TAHAGER }\end{array}$ & $\begin{array}{l}3>0 \\
6101\end{array}$ & $\begin{array}{l}\text { STHO } \\
\text { SHA }\end{array}$ & $\begin{array}{l}\text { WESTERK MEADOWLARX } \\
\text { WESTERK PALH WARBLER }\end{array}$ & $\begin{array}{l}5011 \\
6720\end{array}$ & $\begin{array}{l}\text { WEME } \\
\text { WPWA }\end{array}$ \\
\hline SULPHUR-BELLIEO FLYCATCHER & 4510 & SBFL & WESTERK SAKDPIPER & 2470 & UESA \\
\hline SUMMER TANAGER & 6100 & SUTA & MESTERK SCREECH-OWL & 3732 & WESO \\
\hline $\begin{array}{l}\text { SURF SCOTER } \\
\text { SURFB IRO }\end{array}$ & $\begin{array}{l}1660 \\
2820\end{array}$ & $\begin{array}{l}\text { SUSC } \\
\text { SURF }\end{array}$ & $\begin{array}{l}\text { WESTERK TANAGER } \\
\text { WESTERN WOOO-PEWEE }\end{array}$ & $\begin{array}{l}6070 \\
4620\end{array}$ & $\begin{array}{l}\text { WETA } \\
\text { WEWP }\end{array}$ \\
\hline SUTTON'S WAR3LER & 6634 & SUWA & WHIMBREL & 2650 & WHIS \\
\hline SWAINSON'S HAUK & 3420 & SUHA & HHIP-POOR-YILL & 4170 & WPW: \\
\hline SHAINSON'S THRUSH & 7580 & SWTH & HH!SKERED AUKLET & 0190 & WHAU \\
\hline SWAINSON'S WARBLER & 6380 & SWHA & WHISKERED SCREECH.OHL & 3731 & Whso \\
\hline SHAMP SPARROH & 5840 & SWSP & WHISTLIKG SWAN & 1800 & WHS:- \\
\hline TAHNY-SHCULDERED SLACXBIRD & 5001 & TSaL & WH!TE 1815 & 1840 & WH! 3 \\
\hline TENNESSEE WARSLER & 6470 & TEWA & WHITE TERK & 0793 & WHTE \\
\hline THAYER'S GULL & 0431 & THGU & WH:TE WAGTATL & 6940 & WHWA \\
\hline $\begin{array}{l}\text { THICX-BILLED XIKGBIRD } \\
\text { THICX-BILLED MURRE }\end{array}$ & $\begin{array}{l}4451 \\
0310\end{array}$ & $\begin{array}{l}\text { TBXI } \\
\text { TBMU }\end{array}$ & $\begin{array}{l}\text { WHITE-BELLIEO DOVE } \\
\text { WHITE-BREASTEO HUTHATCY }\end{array}$ & $\begin{array}{l}3181 \\
7270\end{array}$ & $\begin{array}{l}\text { W800 } \\
\text { WBNU }\end{array}$ \\
\hline $\begin{array}{l}\text { THICK-BILLED PARROT } \\
\text { THICK-BILLED VIREO }\end{array}$ & $\begin{array}{l}3821 \\
9130\end{array}$ & $\begin{array}{l}\text { TBPA } \\
\text { T8V! }\end{array}$ & $\begin{array}{l}\text { WHITE-CHEEXED PINTA!L } \\
\text { WHITE-CHIXHED PETRE! }\end{array}$ & $\begin{array}{l}1431 \\
8533\end{array}$ & $\begin{array}{l}\text { WHi? } \\
\text { WCPE }\end{array}$ \\
\hline & & & & & \\
\hline
\end{tabular}


Dominant Species in Groups Associated with Major Vegetative Cover Types in and Near Norris Hill Wind Resource Area, Montana

\begin{tabular}{|c|c|c|c|}
\hline No. & Scientific Name & Common Name & Comments \\
\hline & Grasses & & \\
\hline 1 & Agropyron spicatum & Bluebunch wheatgrass & Montana State Grass \\
\hline 2 & Bromus carinatus & Mountain Brome & \\
\hline 3 & Bromus tectorum & Cheatgrass & Exotic species \\
\hline 4 & Festuca idahoensis & Idaho fescue & \\
\hline 5 & Phleum pratense & Timothy & Exotic species \\
\hline 6 & Poa pratensis & Kentucky bluegrass. & Exotic species \\
\hline 7 & Spike spicatum & Spike trisetum & \\
\hline 8 & Stipa viridula & Green needlegrass & \\
\hline 9 & Stipa comata & Needle \& thread grass & \\
\hline & Forbs & & \\
\hline 1 & Antennaria microphylla & Pussy toes & \\
\hline 2 & Astragalus spp. & Purple clover looking thing & \\
\hline 3 & Delphinium spo. & Delphinium & \\
\hline 4 & Geranium viscosissimum & Sticky geranium & \\
\hline 5 & Haplopappus spo. & Yellow thing & \\
\hline 6 & Lupine spo. & Lupine SPR. & \\
\hline 7 & Lupinus sericeus & Silky lupine & \\
\hline 8 & Melilotus officinalis & Yellow sweet-clover & Exotic species \\
\hline 9 & Mentha spo. & Mint & \\
\hline 10 & Solidage spo. & Goldenrod & \\
\hline 11 & Artemesia nova & Sage spp. & \\
\hline 12 & Heracleum lantum & Cow parsnip & \\
\hline & Shrubs & & \\
\hline 1 & Amelanchier alnifolia & Serviceberny & \\
\hline 2 & Artemisia ludoviciana & Sage spo. & \\
\hline 3 & Artemisia tridentata & Mountain sagebrush & \\
\hline 4 & Grindellia squareosa & Gum weed & \\
\hline 5 & Physocarpus malvacaulus & Ninebark & \\
\hline 6 & Prunus virainiana & Chokecherry & \\
\hline 7 & Salix bebbiana & Bebb's willow & \\
\hline 8 & Symohoracarous occidentalis & Snowberny & \\
\hline 9 & Chysothamnus nauseusum & Rubber rabbit brush & \\
\hline 10 & Gutteriezia sop. & Snake weed & \\
\hline & Trees & & \\
\hline 1 & Juniperus scopulorum & Rocky Mountain iuniper & \\
\hline 2 & Pinus flexilis & Limber pine & \\
\hline 3 & Pseudotsuga menziesii & Douglas fir & \\
\hline
\end{tabular}




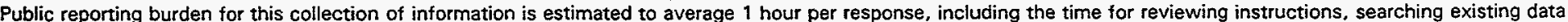

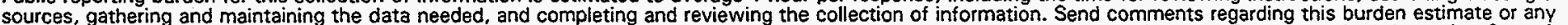

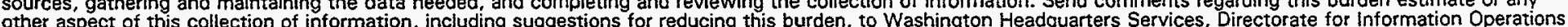

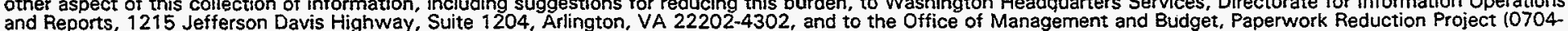
and Reports, 1215 Jefferson Davis
01881 . Washington. DC 20503.

1.

2. REPORT DATE July 1998

4. TITLE AND SUBTITLE

Avian Use of Norris Hill Wind Resource Area, Montana

6. AUTHOR(S)

A. Harmata, K. Podruzny, J. Zelenak

7. PERFORMING ORGANIZATION NAME(S) AND ADDRESS(ES)

Fish and Wildife Program

Biology Department

Montana State University

Bozeman, Montana 59717-0346

9. SPONSORING/MONITORING AGENCY NAME(S) AND ADDRESS(ES

National Renewable Energy Laboratory

1617 Cole Blvd.

3. REPORT TYPE AND DATES COVERED Subcontractor Report

Golden, CO 80401-3393

8. PERFORMING ORGANIZATION REPORT NUMBER
5. FUNDING NUMBERS

C: XAN-5-15126-01

TA: WE801410

10. SPONSORING/MONITORING AGENCY REPORT NUMBER

SR-500-23822

\section{SUPPLEMENTARY NOTES}

12a. DISTRIBUTION/AVAILABILITY STATEMENT National Technical Information Service

U.S. Department of Commerce

5285 Port Royal Road

Springfield, VA 22161 12b. DISTRIBUTION CODE

\section{ABSTRACT (Maximum 200 words)}

Avian use and mortality in a proposed wind resource area and vicinity in southwestern Montana were investigated. The primary objective was to collect pre-impact information on various parameters of avian use in and around Norris Hill Wind Resource Area for comparison with similar data collected post-impact, should NHWRA be developed. Secondary objectives included a description of the spatio-temporal profile of seasonal use in and near NHWRA and an evaluation of the efficacy of monitoring techniques for describing avian movements. A Before-After Control-Impact study design was used to initiate impact analysis, with results of this study serving as Before-lmpact and Before-Control data. During monitoring of seasonal migrations, parameters of avian use were recorded "In" and "Out" of NHWRA. The primary technique for detecting avian movements was employment of two marine surveillance radars. Visual observations and radar were used throughout the study, testing the detection capability of each. Radar excelled at detecting birds but species or number could not be identified, except subjectively. Detailed data are provided in the report. Equipment, operation, data needs, and monitoring efforts for future study are addressed.

\begin{tabular}{|c|c|c|c|c|c|c|c|}
\hline 14. & SUBJECT TERMS & & & & & 15. & NUMBER OF PAGES \\
\hline & renewable ener & nerg & vian; radar; mar & eilla & radar & 16. & PRICE CODE \\
\hline 17. & $\begin{array}{l}\text { SECURITY } \\
\text { CLASSIFICATION } \\
\text { OF REPORT } \\
\text { Unclassified }\end{array}$ & 18. & $\begin{array}{l}\text { SECURITY } \\
\text { CLASSIFICATION } \\
\text { OF THIS PAGE } \\
\text { Unclassified }\end{array}$ & 19. & $\begin{array}{l}\text { SECURITY } \\
\text { CLASSIFICATION } \\
\text { OF ABSTRACT } \\
\text { Unclassified }\end{array}$ & 20. & $\begin{array}{l}\text { LIMITATION OF ABSTRACT } \\
\text { UL }\end{array}$ \\
\hline
\end{tabular}

